\title{
A STUDY OF GRAIN REFINEMENT OF AZ91E AND Mg-9 wt.\% Al ALLOYS USING ZINC OXIDE
}

\author{
by \\ Subrata Kumar Saha \\ Bachelor of Technology (Honours) \\ Indian Institute of Technology (IIT)-Kharagpur, India, 1996
}

\begin{abstract}
A thesis
presented to Ryerson University

in partial fulfillment of the

requirements for the degree of
\end{abstract}

Master of Applied Science

in the Program of

Mechanical and Industrial Engineering

Toronto, Ontario, Canada, 2014

(C) Subrata Kumar Saha 2014 


\section{Author's Declaration}

I hereby declare that I am the sole author of this thesis. This is a true copy of the thesis, including any required final revisions, as accepted by my examiners.

I authorize Ryerson University to lend this thesis to other institutions or individuals for the purpose of scholarly research.

I further authorize Ryerson University to reproduce this thesis by photocopying or by other means, in total or in part, at the request of other institutions or individuals for the purpose of scholarly research.

I understand that my thesis may be made electronically available to the public. 


\title{
Abstract \\ A STUDY OF GRAIN REFINEMENT OF AZ91E AND Mg-9 wt.\% Al ALLOYS USING ZINC OXIDE
}

\author{
Master of Applied Science, 2014 \\ Subrata Kumar Saha \\ Mechanical and Industrial Engineering \\ Ryerson University
}

Grain refinement is a proven method to improve mechanical properties of $\mathrm{Mg}$ alloys. In this research, the influence of $\mathrm{ZnO}$ on the microstructure of selected magnesium alloys was investigated. For graphite mold casting with an addition of $0.75 \mathrm{wt} . \% \mathrm{ZnO}$, the grain size of the AZ91E alloy decreased from $217 \mu \mathrm{m}$ to $108 \mu \mathrm{m}$. For the binary alloy (Mg-9 wt.\% Al), the grain size reduced from $288 \mu \mathrm{m}$ to $93 \mu \mathrm{m}$ with an addition of $3 \mathrm{wt} \% \mathrm{ZnO}$. No significant fading of $\mathrm{ZnO}$ grain refiner was observed for both the alloys.

In permanent mold casting process, with an addition of $0.5 \mathrm{wt} . \% \mathrm{ZnO}$, the grain size of the AZ91E alloy decreased from $133 \mu \mathrm{m}$ to $79 \mu \mathrm{m}$ with significant improvements in mechanical properties. Cleavage type fracture was dominant in the base alloy while alloys refined with 0.5 wt.\% $\mathrm{ZnO}$ showed more quasi-cleavage type fracture. 


\section{Acknowledgements}

First and foremost, I would like to express my deepest gratitude to my supervisor, mentor Professor C. Ravindran, for his constant guidance, advice and encouragement. I am thankful for his support and kindness extended to me. It is my privilege to have had the opportunity to work with him. He is and will always be a source of inspiration in my life.

I would also like to thank all the members of the Centre for Near-net-shape Processing of Materials for their help with the experimental trials and stimulating discussions; in particular, Dr. Sophie Lun Sin, Francesco D’Elia, Abdallah Elsayed and Anthony Lombardi.

I have sincere appreciation for Mr. Alan Machin for his continuous technical support and useful discussions. My thanks also goes to Mr. Joseph Amankrah and Mr. Qiang Li for their help in sample preparation and SEM analysis. I appreciate Prof. B. S. Murty (IIT-Madras) for his valuable comments.

In a special way, I would like to thank my wife Subhra and my two wonderful daughters-Sulagna and Sucheta for their undying love and support extended to me which is always my greatest strength. Thanks to my parents and all family members. 


\section{Dedication}

To Sufhra, Sulagna and Sucheta

-my fove, my dream 


\section{Table of Contents}

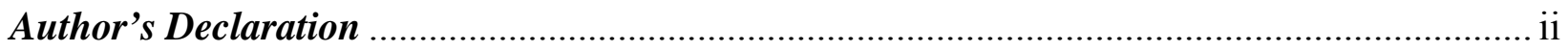

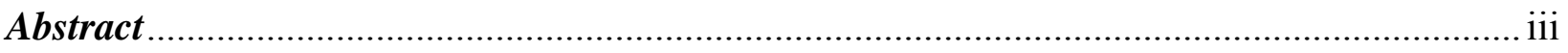

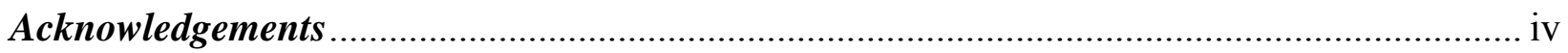

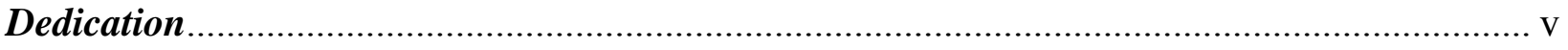

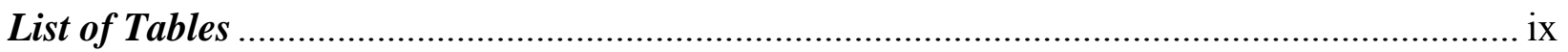

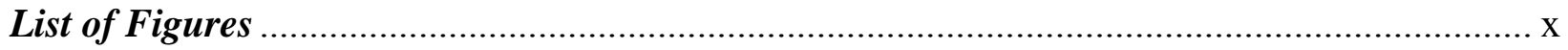

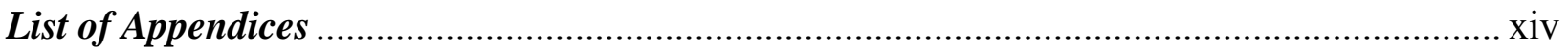

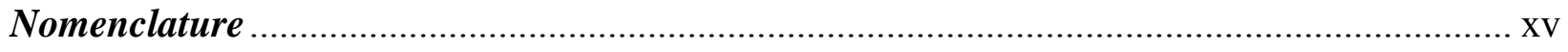

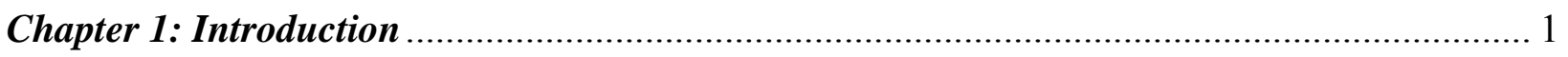

Chapter 2: Theoretical Background and Literature Review .................................................... 3

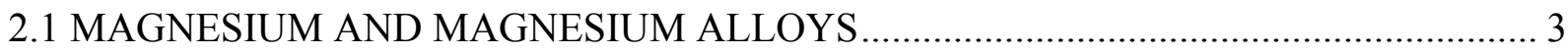

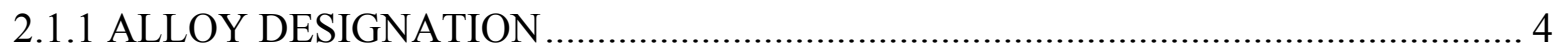

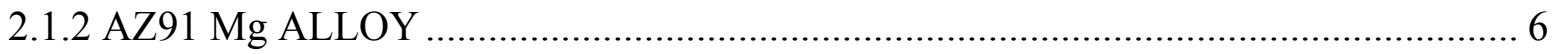

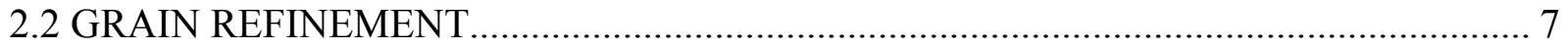

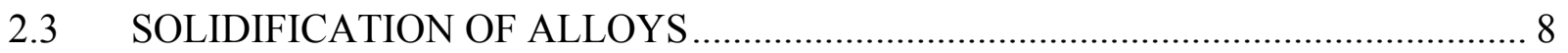

2.3.1 NUCLEATION

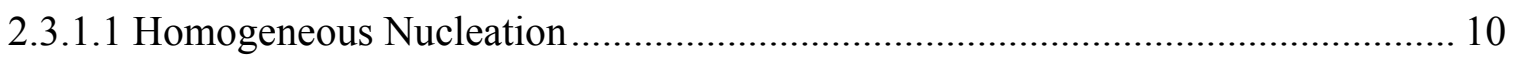

2.3.1.2 Heterogeneous Nucleation ............................................................................. 10

2.3.2 EFFECT OF CRYSTAL STRUCTURE ON GRAIN REFINEMENT _................... 13

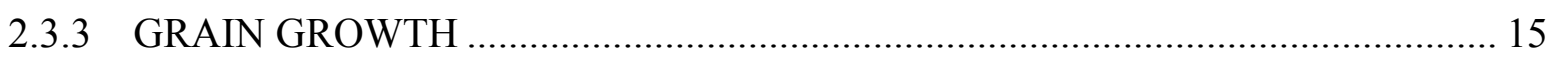

2.4 CONSTITUTIONAL UNDERCOOLING …………........................................... 17

2.5 EFFECT OF SOLUTE ON GRAIN GROWTH..................................................... 18

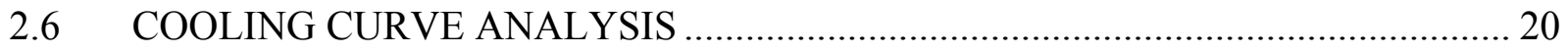

2.7 ROUTES FOR Mg-Al ALLOY GRAIN REFINEMENT ………………….............. 22

2.7.1 MECHANICAL GRAIN REFINEMENT TECHNIQUES ..................................... 22

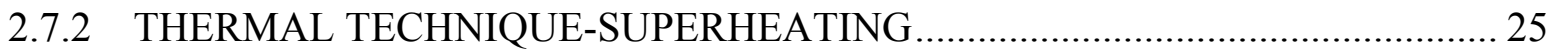

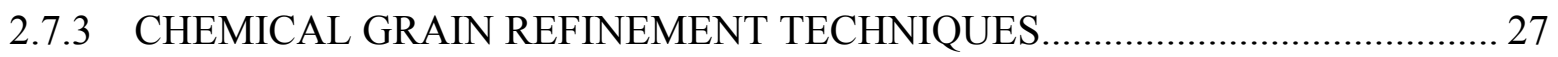

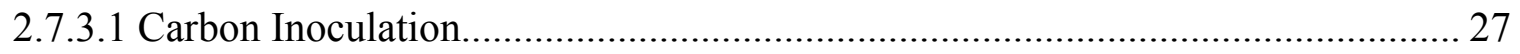

2.7.3.2 The Elfinal Process ........................................................................................ 32

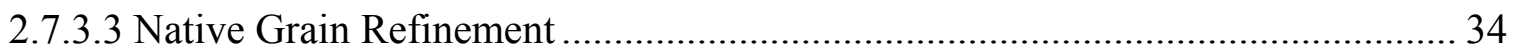

2.7.3.4 Grain Refinement by Adding Other Additives ................................................... 36

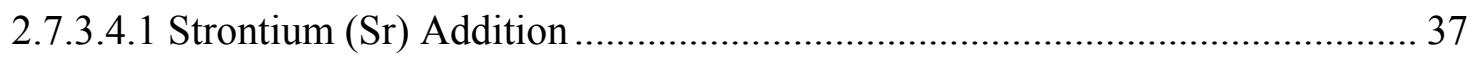

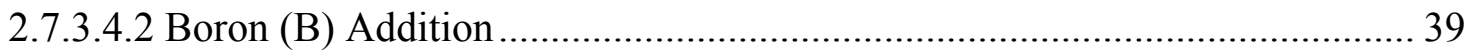




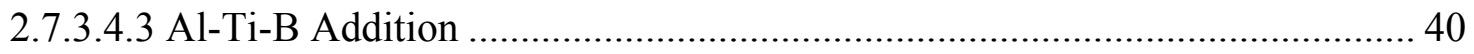

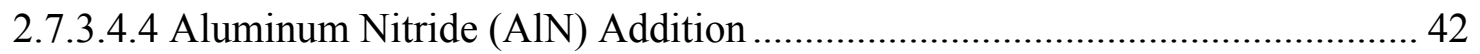

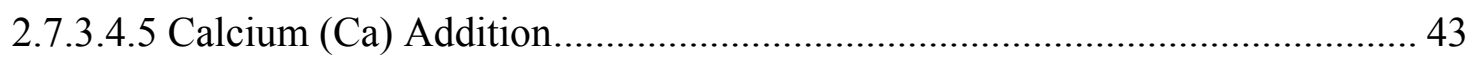

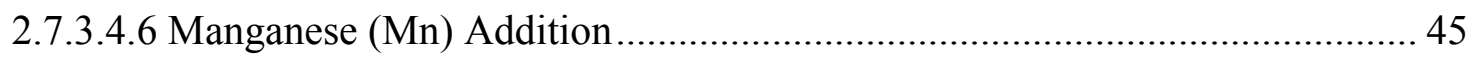

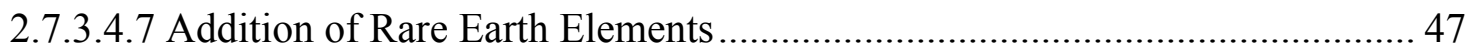

2.7.3.4.8 ZnO-A Potential Grain Refiner................................................................. 48

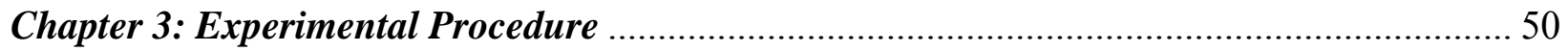

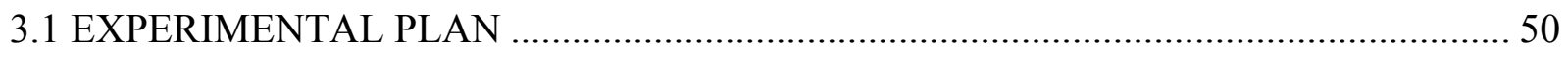

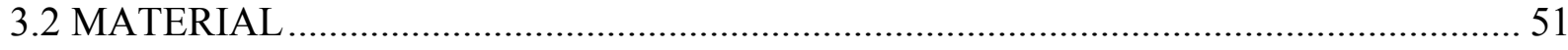

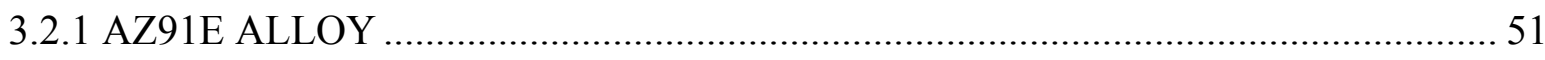

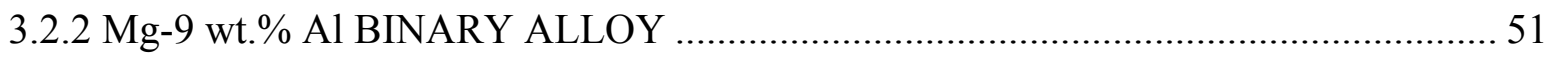

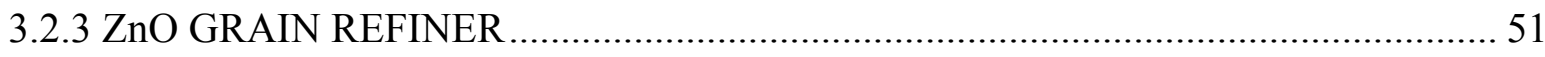

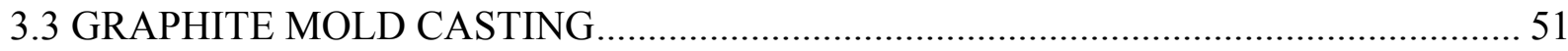

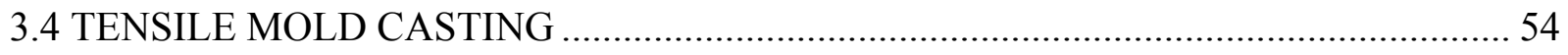

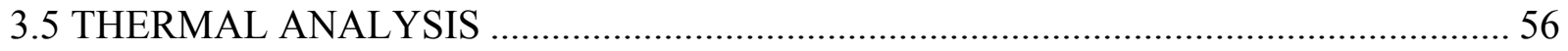

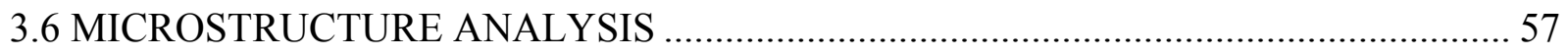

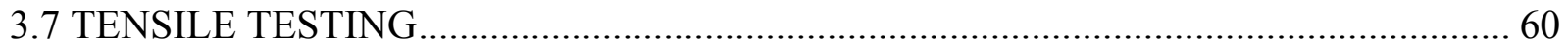

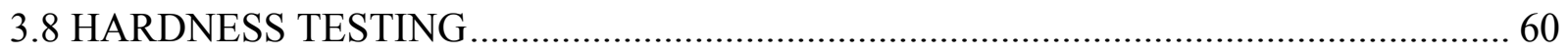

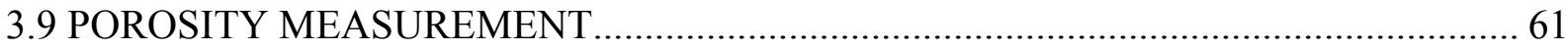

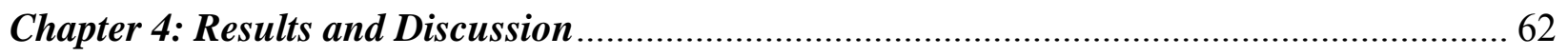

4.1 GRAIN REFINEMENT OF AZ91E ALLOY (GRAPHITE MOLD) ................................. 62

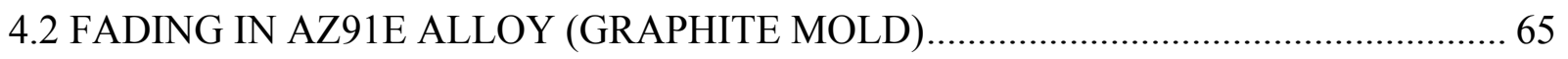

4.3 MECHANISM OF GRAIN REFINEMENT IN AZ91E ALLOY (GRAPHITE MOLD) . 66

4.4 THERMAL ANALYSIS OF AZ91E ALLOY (GRAPHITE MOLD) ………………......... 67

4.5 GRAIN REFINEMENT IN Mg-9 wt.\% Al ALLOY(GRAPHITE MOLD) ……….......... 70

4.6 FADING IN Mg-9 wt.\% Al ALLOY (GRAPHITE MOLD) ………………………....... 72

4.7 MECHANISM OF GRAIN REFINEMENT IN Mg-9 wt.\% Al ALLOY (GRAPHITE

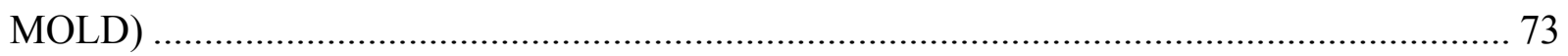

4.8 THERMAL ANALYSIS OF Mg-9 wt.\% Al ALLOY (GRAPHITE MOLD) ................... 76

4.9 GRAIN REFINEMENT OF AZ91E ALLOY (PERMANENT TENSILE MOLD) ........... 77

4.10 MECHANISM OF GRAIN REFINEMENT IN AZ91E ALLOY (PERMANENT

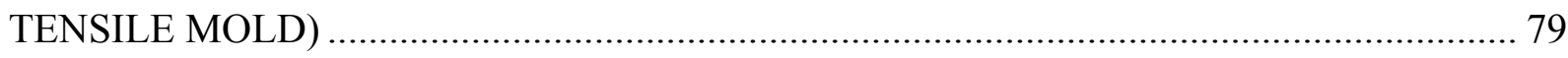


4.11 EFFECTS OF ZnO CONTENT ON MECHANICAL PROPERTIES OF AZ91E ALLOY

(PERMANENT TENSILE MOLD) …..................................................................... 84

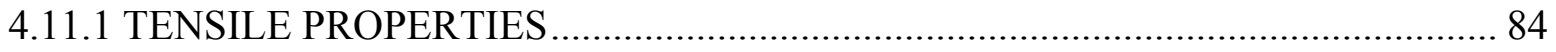

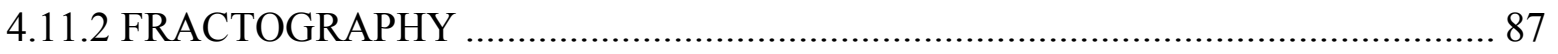

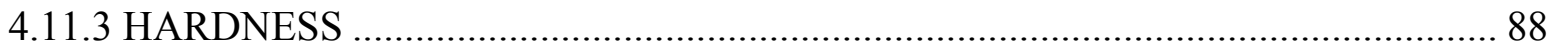

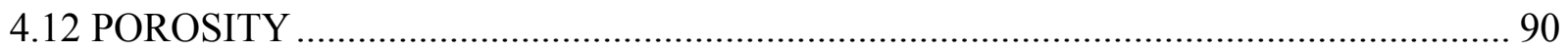

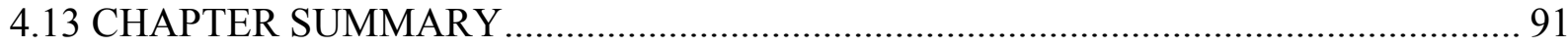

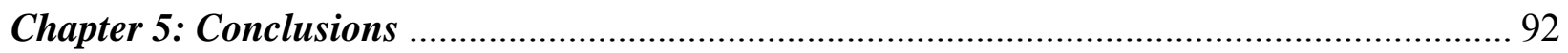

Chapter 6: Recommendations for Future Work ............................................................... 94

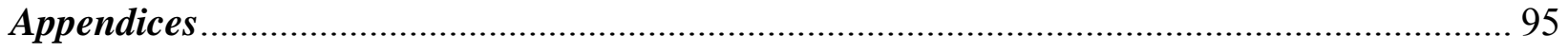

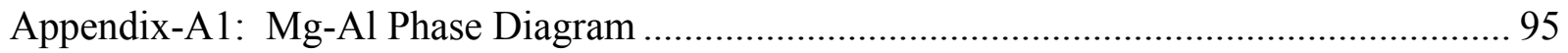

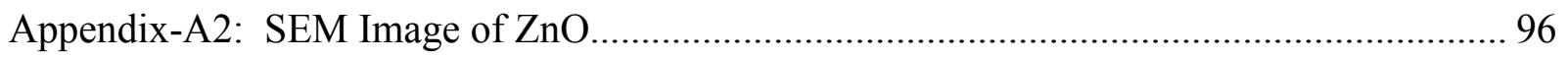

Appendix-A3: Cooling Curves of AZ91E+X wt.\% ZnO ............................................... 97

Appendix-A4: Free Energy Calculations .................................................................... 101

Appendix-A5: Cooling Curves of Mg-9 wt.\% Al+X wt.\% ZnO ..................................... 102

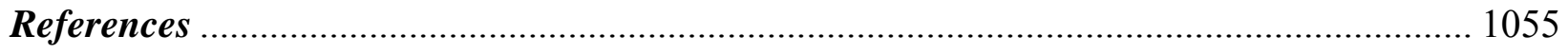




\section{List of Tables}

Table 2.1.1 Standard ASTM System for designation of Mg Alloys [ASM

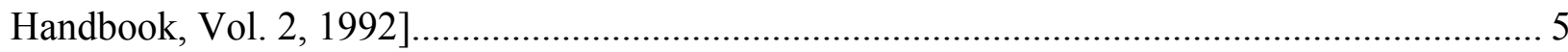

Table 2.5.1 GRF Values of Different Alloying Elements in Mg [Lee et. al., 2000]. .................. 20 Table 2.7.1 Mechanical Properties of As-cast AZ91 Alloy with B Addition [Suresh et. al., 2009].

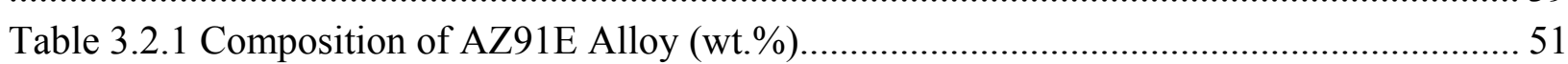

Table 3.3.1 Graphite Mold Casting Parameters........................................................................ 54

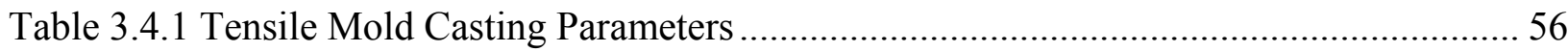

Table 3.6.1 Chemical Composition of Etchant Solution ............................................................... 59

Table 4.1.1. Grain Size of AZ91E Alloy at Different Addition Levels of ZnO (Graphite Mold) 64 Table 4.2.1. Grain Size of AZ91E Alloy at Different Addition Levels of ZnO and Holding Time

Table 4.4.1. Freezing Range of AZ91E Alloy at Different Addition Levels of ZnO ................... 69

Table 4.5.1. Grain Size of Mg-9 wt.\% Al Alloy at Different Addition Levels of ZnO................ 71

Table 4.6.1. Grain Size of AZ91E Alloy at Different Addition Levels of ZnO and Holding Time

Table 4.8.1. Freezing Range of Mg-9 wt.\% Al Alloy at Different Addition Levels of $\mathrm{ZnO}$....... 77

Table 4.9.1. Grain Size of AZ91E Alloy at Different Addition Levels of ZnO (Permanent Tensile

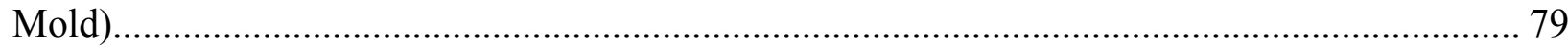

Table 4.10.1. Average Zn Content (wt.\%) of AZ91E Alloy Castings Obtained Through EDX

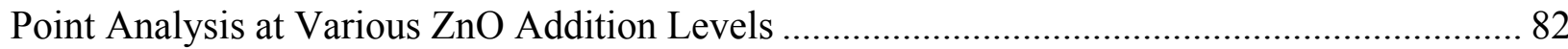

Table 4.11.1Tensile Properties of AZ91E Alloy with ZnO Addition.......................................... 85

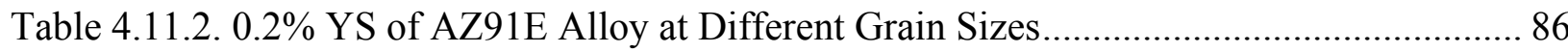

Table 4.11.3. Hardness of AZ91E Alloy with ZnO Addition....................................................... 88

Table 4.12.1. Average Porosity (\%) Levels of AZ91E Alloy at Different Addition Levels of ZnO

Table A3.1. Heats of Formation, Standard Entropies of Different Substances .......................... 101 


\section{List of Figures}

Fig. 2.1.1. Optical micrograph of AZ91 alloy (a) as-cast condition (b) heat treated condition

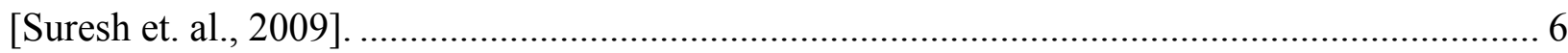

Fig. 2.3.1. Temperature profile of an engineering alloy solidifying unidirecionally [Flemings, 1974]. 8

Fig. 2.3.2. Free energy changes of solid-liquid system as a function of radius of nucleating

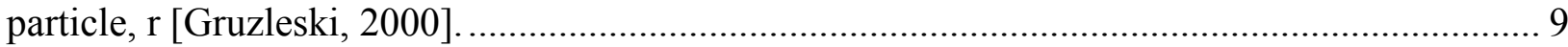

Fig. 2.3.3. Schematic showing formation of a cluster on a substrate [Flemings, 1974]............... 11

Fig. 2.3.4. Schematic representation showing the relationship between radius of curvature of a spherical cap and contact angle, $\theta$ [Gruzleski, 2000]. 12

Fig. 2.3.5. Schematic showing edge-to-edge matching model between two phases [Kelly et. al., 2006]. 14

Fig. 2.3.6. Schematic showing chill zone, columnar zone and equiaxed zone in a casting [Flemings, 1974]. 16

Fig. 2.3.7. (a-d) Schematic showing growth of dendrite in an alloy at various stages of solidification [Flemings, 1974]. 16

Fig. 2.3.8. Equiaxed grains grow almost equally in all directions [Gruzleski, 2000].................. 17

Fig. 2.6.1. Cooling curve of a pure material with undercooling present. ..................................... 21

Fig. 2.6.2. Cooling curve of a pure material without undercooling............................................ 21

Fig. 2.7.1 Measured average grain size as a function of vibration frequency for AZ31 and

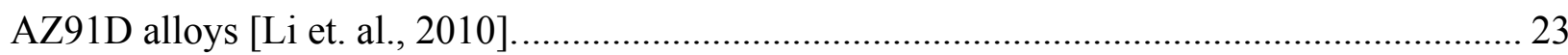

Fig. 2.7.2 Microstructure of AZ91D alloy (a) without UST (b) with UST [Liu et. al., 2008]. .... 24 Fig. 2.7.3. Grain structure of AZ91E alloys at different conditions. (a and b) quenched sample (c and d) cast sample ( $a$ and c) Superheat treated (b and d) non-superheat treated [Motegi, 2005]. 27 Fig. 2.7.4 Optical micrograph of as cast $\mathrm{AZ} 31 \mathrm{Mg}$ alloy (a) without $\mathrm{C}_{2} \mathrm{Cl}_{6}$ addition (b) with 0.6

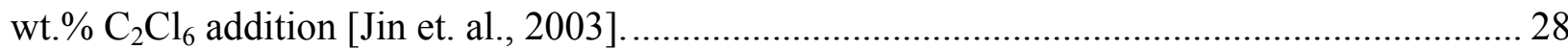

Fig. 2.7.5 Grain refinement efficiency of ground $\mathrm{Al} 4 \mathrm{C} 3$ in $\mathrm{Mg}-3 \mathrm{wt} . \% \mathrm{Al}$ at $735^{\circ} \mathrm{C}$ (a) base alloy (b) 20 min after addition of $\mathrm{Al}_{4} \mathrm{C}_{3}$ [Lu et. al., 2005]. 30

Fig. 2.7.6 Grain refinement efficiency of ground $\mathrm{Al}_{4} \mathrm{C}_{3}$ in $\mathrm{Mg}-3 \mathrm{wt} . \% \mathrm{Al}$ at $785^{\circ} \mathrm{C}$ (a) base alloy (b) 30 min after addition of $\mathrm{Al}_{4} \mathrm{C}_{3}$ [Lu et. al., 2005]. 30

Fig. 2.7.7 Optical micrograph of as-cast alloys: (a) Mg-3 wt.\% Al (b) Mg-3 wt.\% Al-0.3 wt.\% $\mathrm{SiC}$ (c) Mg-3 wt.\% Al- 10 wt.\% SiC [Huang et. al., 2011]. 31

Fig. 2.7.8 Variation of grain size of AM60B alloy with $\mathrm{SiC}$ addition [Chen et. al., 2010].......... 31

Fig. 2.7.9 Grain refinement of $\mathrm{Mg}-3$ wt.\% $\mathrm{Al}$ with $\mathrm{FeCl}_{3}$ at $750^{\circ} \mathrm{C}$ [Cao et. al., 2004]............... 33

Fig. 2.7.10 Grain refinement of $\mathrm{Mg}-9$ wt.\% $\mathrm{Al}$ with $\mathrm{FeCl}_{3}$ at $750^{\circ} \mathrm{C}$ [Cao et. al., 2004]............. 34

Fig. 2.7.11 Effect of source $\mathrm{Mg}$ purity on the grain size of Mg-Al alloys [Cao et. al., 2005]..... 36

Fig. 2.7.12 Grain size vs GRF value of AZ31-Sr alloys [Zeng et. al., 2006] ............................. 38

Fig. 2.7.13 Yield strength as a function of grain size for AZ31-Sr alloys [Zeng et. al., 2006] ... 38

Fig. 2.7.14 SEM micrograph and EDS spectrum of $0.032 \mathrm{wt} . \% \mathrm{~B}$ added to AZ91 alloy [Suresh et. al., 2009]. 
Fig. 2.7.15 Variation of grain size with holding time with Al-5Ti-1B addition to AZ91D [Chen et. al., 2012]

Fig. 2.7.16 Microstructure of Mg-3 wt.\% Al sample held at $765^{\circ} \mathrm{C}$ (a) without AlN (b) with AlN addition [Fu et. al., 2009] 43

Fig. 2.7.17 Hot tearing susceptibility coefficient (HSC) and grain size of AZ91D alloy with various levels of $\mathrm{Ca}$ addition [Li et. al., 2004]. 44 Fig. 2.7.18 Average grain size of AZ91D alloy with various levels of Ca addition [Elsayed et. al., 2009]. 45

Fig. 2.7.19 Effect of Mn on average grain size of (a) high purity binary Mg-Al alloys and (b) AZ31 commercial alloy [Cao et. al., 2006]. 46

Fig. 2.7.20 Microstructure of Mg-3 wt.\% Zn alloy (a) base alloy (b) after 1 wt.\% ZnO addition

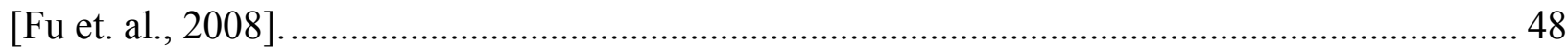

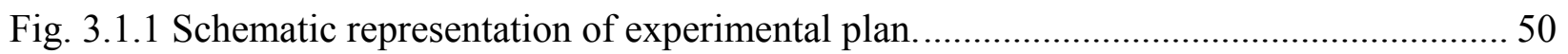

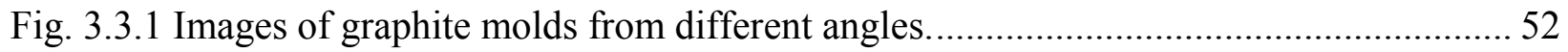

Fig. 3.2.2 Casting set-up in graphite mold (All dimensions are in $\mathrm{mm}$ )................................... 53

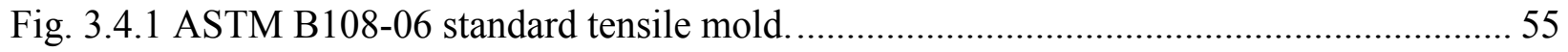

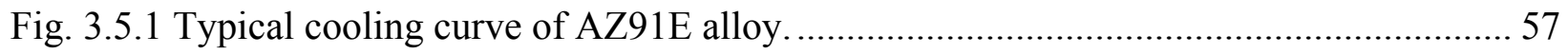

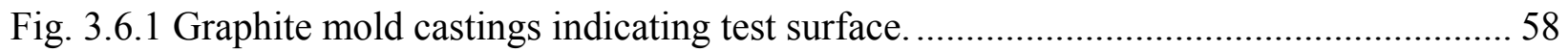

Fig. 3.6.2 Schematic showing the test surface of permanent tensile mold cast sample................ 59

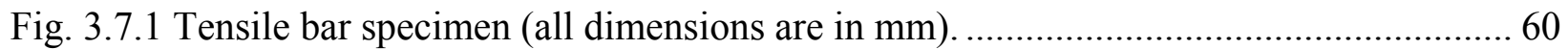

Fig. 4.1.1. Optical micrograph of (a) as cast base AZ91E alloy; after solutionized for 24 hours at $420^{\circ} \mathrm{C} / 788^{\circ} \mathrm{F}$ and etched (b) base alloy (average grain size $217 \mu \mathrm{m}$ ) (c) AZ91E $+0.5 \mathrm{wt} . \% \mathrm{ZnO}$ (average grain size $126 \mu \mathrm{m})(\mathrm{d})$ AZ91E $+0.75 \mathrm{wt} . \% \mathrm{ZnO}$ (average grain size $108 \mu \mathrm{m})$. ............. 63

Fig. 4.1.2. Average grain size of AZ91E alloy with various $\mathrm{ZnO}$ addition levels. ...................... 64

Fig. 4.2.1. Fading effect of $\mathrm{ZnO}$ in AZ91E at different holding times and addition levels.......... 65 Fig. 4.3.1. SEM image of AZ91E with 3 wt.\% of $\mathrm{ZnO}$ (a) at low magnification and (b) at high

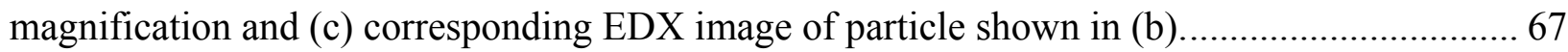
Fig. 4.4.1. Cooling curve of base AZ91E alloy and AZ91E with 0.5 wt.\% ZnO. Enlarged region

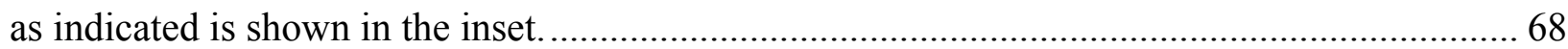

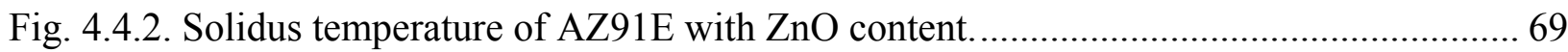
Fig. 4.5.1. Microstructure of Mg-9 wt.\% Al binary alloy after solution heat treatment (a) base alloy (average grain size- $288 \mu \mathrm{m}$ ) (b) with $1 \mathrm{wt} . \% \mathrm{ZnO}$ addition (average grain size-121 $\mu \mathrm{m}$ ). 70 Fig. 4.5.2. Average grain size of Mg-9 wt.\% Al binary alloy with various levels of $\mathrm{ZnO}$ addition.

Fig. 4.6.1. Fading effect of $\mathrm{ZnO}$ in $\mathrm{Mg}-9$ wt.\% Al binary alloy at different holding times and addition levels.

Fig. 4.7.1. (a) SEM image of base Mg-9 wt.\% Al showing $\alpha$-phase and $\beta$-phases (b-c) shows the EDX analysis of point-A and point-B respectively. 73 
Fig. 4.7.2. SEM image and corresponding Zn element map of (x200) of Mg 9 wt.\% Al with (a-b) no addition of $\mathrm{ZnO}$, (c d) 1 wt.\% $\mathrm{ZnO}$ addition, (e f) 2 wt.\% $\mathrm{ZnO}$ addition (g h) 3 wt.\% $\mathrm{ZnO}$ addition. 75

Fig. 4.7.3. Mg-9 wt.\% Al with 2 wt.\% ZnO (a) SEM image and (b) EDX results at location

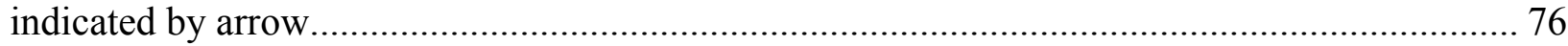

Fig. 4.8.1. Solidus temperature of $\mathrm{Mg}-9$ wt.\% Al with $\mathrm{ZnO}$ content. ..................................... 77 Fig. 4.9.1. Optical micrograph of (a) as cast base AZ91E alloy (b) base alloy after solution heat treatment at $420^{\circ} \mathrm{C}$ for 24 hours and etching (average grain size $133 \mu \mathrm{m}$ ) (c) AZ91E+0.5 wt.\% $\mathrm{ZnO}$ (average grain size $79 \mu \mathrm{m})(\mathrm{d}) \mathrm{AZ91E}+0.75$ wt.\% $\mathrm{ZnO}$ (average grain size $72 \mu \mathrm{m}$ )........ 78 Fig. 4.9.2. Average grain size of AZ91E alloy with increasing levels of $\mathrm{ZnO}$ addition in permanent tensile mold casting. 79

Fig. 4.10.1. (a) SEM image of base AZ91E alloy showing $\alpha$-phase and $\beta$-phase (b-c) shows the EDX analysis of point-A and point-B respectively. 80

Fig. 4.10.2. SEM image of AZ91E alloy with 3 wt.\% $\mathrm{ZnO}$ (a) at low magnification (b) at high magnification and (c) corresponding EDX image of particle shown in (b).

Fig. 4.10.3. SEM image and corresponding EDX map of AZ91E alloy with (a-b) no addition of $\mathrm{ZnO}$ and (c-d) 3 wt. $\% \mathrm{ZnO}$ addition. 82

Fig. 4.10.4. SEM image and corresponding EDX analysis of AZ91E alloy with (a-b) no addition of $\mathrm{ZnO}$ and (c-d) $3 \mathrm{wt} . \% \mathrm{ZnO}$ addition. 83

Fig. 4.10.5. SEM image and corresponding EDX analysis of AZ91E alloy with 3 wt.\% ZnO

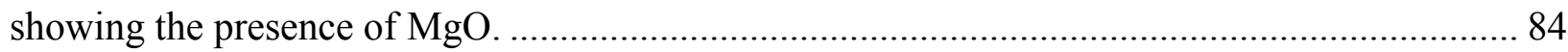

Fig. 4.11.1. Tensile properties of AZ91E alloy with various levels of $\mathrm{ZnO}$ addition. ............... 85

Fig. 4.11.2. Average YS of AZ91E alloy at different grain sizes......................................... 86 Fig. 4.11.3. SEM images of fracture surface of AZ91E alloy with (a) no addition of ZnO and (b) 0.5 wt.\% ZnO addition. (1) Cleavage steps (2) Secondary crack.......................................... 87

Fig. 4.11.4. Average HRE of AZ91E alloy with $\mathrm{ZnO}$ addition............................................... 89

Fig. 4.11.5. Average microhardness of AZ91E alloy with $\mathrm{ZnO}$ addition.................................. 90

Fig. 4.12.1. Average porosity (\%) of AZ91E alloy with $\mathrm{ZnO}$ addition.................................... 91

Fig. A.1 Mg-Al phase diagram [Emely, 1966]............................................................. 95

Fig. A.2 (a) Representative SEM image of $\mathrm{ZnO}$ (b) showing dimensions of individual $\mathrm{ZnO}$

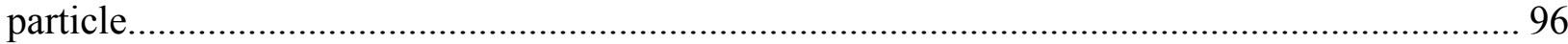

Fig. A.3.1. Cooling curve of base AZ91E alloy. .................................................................. 97

Fig. A.3.2. Cooling curve of base AZ91E +0.25 wt.\% ZnO alloy. ....................................... 97

Fig. A.3.3. Cooling curve of base AZ91E + 0.5 wt.\% ZnO. ................................................... 98

Fig. A.3.4. Cooling curve of base AZ91E + 0.75 wt. \% ZnO. .............................................. 98

Fig. A.3.5. Cooling curve of base AZ91E + 1 wt.\% ZnO. ...................................................... 99

Fig. A.3.6. Cooling curve of base AZ91E + 2 wt.\% ZnO. ................................................... 99

Fig. A.3.7. Cooling curve of base AZ91E + 3 wt.\% ZnO. .................................................. 100

Fig. A.5.1. Cooling curve of base Mg-9 wt.\% Al.............................................................. 102

Fig. A.5.2. Cooling curve of base Mg-9 wt.\% Al + 0.5 wt.\% ZnO ....................................... 102 
Fig. A.5.3. Cooling curve of base Mg-9 wt.\% Al + 1 wt.\% ZnO......................................... 103

Fig. A.5.4. Cooling curve of base Mg-9 wt.\% Al + 2 wt.\% ZnO....................................... 103

Fig. A.5.5. Cooling curve of base Mg-9 wt.\% Al + 3 wt.\% ZnO....................................... 104 


\section{List of Appendices}

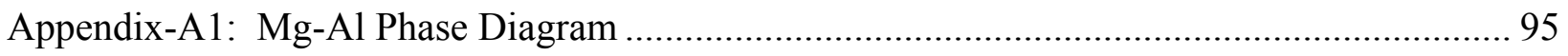

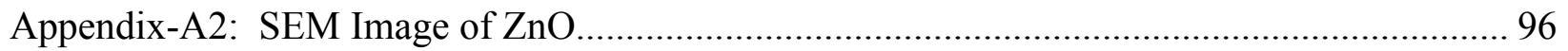

Appendix-A3: Cooling Curves of AZ91E+X wt.\% ZnO ...................................................... 97

Appendix-A4: Free Energy Calculations ................................................................... 101

Appendix-A5: Cooling Curves of Mg-9 wt.\% Al+X wt.\% ZnO ........................................ 102 


\section{Nomenclature}

\section{A. English}

\begin{tabular}{|c|c|c|}
\hline $\mathrm{c}_{0}$ & Initial Concentration of Alloy & wt.\% \\
\hline $\mathrm{c}_{\mathrm{oi}}$ & Initial Concentration of Element $\mathrm{i}$ & wt.\% \\
\hline d & Average Grain Size & $\mu \mathrm{m}$ \\
\hline $\mathrm{D}_{1}$ & Diffusion Coefficient of the Solute in the Liquid & $\mathrm{m}^{2} / \mathrm{sec}$ \\
\hline EMV & Electromagnetic Vibration & \\
\hline$\Delta \mathrm{G}$ & Free Energy of Formation & cal \\
\hline$\Delta \mathrm{G}_{\mathrm{T}}$ & Total Free Energy Change & $\mathrm{J}$ \\
\hline $\mathrm{G}_{1}$ & Temperature Gradient in the Liquid Ahead of & \\
\hline & Solid-Liquid Interface & $\mathrm{K} / \mathrm{m}$ \\
\hline$\Delta \mathrm{G}_{\mathrm{v}}$ & Free Energy Change per Unit Volume & $\mathrm{J} / \mathrm{m}^{3}$ \\
\hline GRF & Growth Restriction Factor & $\mathrm{K}$ \\
\hline$\Delta \mathrm{H}$ & Heat of Formation & cal \\
\hline $\mathrm{H}_{\mathrm{f}}$ & Latent Heat of Fusion per Unit Volume & $\mathrm{J} / \mathrm{m}^{3}$ \\
\hline HRE & Hardness, Rockwell E & \\
\hline HSC & Hot Tearing Susceptibility Coefficient & \\
\hline HV & Vickers Hardness & \\
\hline $\mathrm{k}$ & Distribution Coefficient & wt.\%/wt.\% \\
\hline $\mathrm{k}_{\mathrm{i}}$ & Distribution Coefficient of Element $\mathrm{i}$ & wt.\%/wt.\% \\
\hline $\mathrm{k}_{\mathrm{y}}$ & Stress Concentration Factor & $\mathrm{Nm}^{-5 / 2}$ \\
\hline $\mathrm{m}_{\mathrm{L}}$ & Liquidus Slope in Phase Diagram & K/wt.\% \\
\hline $\mathrm{m}_{\mathrm{li}}$ & Slope of the Liquidus Line of Element $i$ & K/wt.\% \\
\hline $\mathrm{M}_{\mathrm{m}}$ & Mass of the Sample & $\mathrm{g}$ \\
\hline
\end{tabular}




\begin{tabular}{|c|c|c|}
\hline $\mathrm{M}_{\mathrm{m}+\mathrm{w}}$ & Mass of Water with Sample & g \\
\hline OR & Orientation Relationship & \\
\hline $\mathrm{r}$ & Radius of Nucleant & $\mathrm{m}$ \\
\hline$r^{*}$ & Critical Radius of Nucleant & $\mathrm{m}$ \\
\hline $\mathrm{R}$ & Growth Rate of Solid Liquid Interface & $\mathrm{m} / \mathrm{sec}$ \\
\hline$\Delta \mathrm{S}$ & Entropy of Reaction & $\mathrm{cal} / \mathrm{deg}$ \\
\hline $\mathrm{T}$ & Temperature & ${ }^{\circ} \mathrm{C}$ \\
\hline$\Delta \mathrm{T}$ & Undercooling & ${ }^{\circ} \mathrm{C}$ \\
\hline $\mathrm{T}_{\mathrm{E}}$ & Equilibrium Solidification Temperature & ${ }^{\circ} \mathrm{C}$ \\
\hline $\mathrm{T}_{\mathrm{F}}$ & Freezing Temperature & ${ }^{\circ} \mathrm{C}$ \\
\hline $\mathrm{T}_{\mathrm{G}}$ & Growth Temperature & ${ }^{\circ} \mathrm{C}$ \\
\hline $\mathrm{T}_{\mathrm{L}}$ & Liquidus Temperature & ${ }^{\circ} \mathrm{C}$ \\
\hline $\mathrm{T}_{\mathrm{m}}$ & Equilibrium Solidification & $\mathrm{K}$ \\
\hline $\mathrm{T}_{\mathrm{N}}$ & Nucleation Temperature & ${ }^{\circ} \mathrm{C}$ \\
\hline $\mathrm{T}_{\mathrm{o}}$ & Ambient Temperature & ${ }^{\circ} \mathrm{C}$ \\
\hline $\mathrm{T}_{\mathrm{S}}$ & Solidus Temperature & ${ }^{\circ} \mathrm{C}$ \\
\hline UST & Ultrasonic Treatment & \\
\hline
\end{tabular}


B. Greek

\begin{tabular}{lll}
$\sigma_{\mathrm{sl}}$ & \multicolumn{1}{c}{ Surface Free Energy of Solid-Liquid Interface } & $\mathrm{J} / \mathrm{m}^{2}$ \\
$\sigma_{\mathrm{SL}}$ & Surface Free Energy of Substrate-Liquid Interface & $\mathrm{J} / \mathrm{m}^{2}$ \\
$\sigma_{\mathrm{SC}}$ & Surface Free Energy of Substrate-Cluster Interface & $\mathrm{J} / \mathrm{m}^{2}$ \\
$\sigma_{\mathrm{LC}}$ & Surface Free Energy of Liquid-Cluster Interface & $\mathrm{J} / \mathrm{m}^{2}$ \\
$\theta$ & Wetting Angle & \\
$\sigma_{\mathrm{y}}$ & Yield Strength & $\mathrm{MPa}$ \\
$\sigma_{0}$ & Friction Stress (Experimental Constant) & $\mathrm{MPa}$ \\
$\rho_{\mathrm{s}}$ & Theoretical Density of Sample & $\mathrm{g} / \mathrm{cm}^{3}$ \\
$\rho_{\mathrm{w}}$ & Density of Water at Room Temperature & $\mathrm{g} / \mathrm{cm}^{3}$
\end{tabular}




\section{Elements}

\begin{tabular}{|c|c|}
\hline $\mathrm{Mg}$ & Magnesium \\
\hline $\mathrm{Al}$ & Aluminum \\
\hline $\mathrm{Zn}$ & Zinc \\
\hline $\mathrm{RE}$ & Rare earth \\
\hline Mn & Manganese \\
\hline $\mathrm{Zr}$ & Zirconium \\
\hline $\mathrm{Fe}$ & Iron \\
\hline $\mathrm{Ni}$ & Nickel \\
\hline $\mathrm{Si}$ & Silicon \\
\hline $\mathrm{Sn}$ & Tin \\
\hline $\mathrm{Ca}$ & Calcium \\
\hline $\mathrm{Cu}$ & Copper \\
\hline $\mathrm{Ge}$ & Germanium \\
\hline $\mathrm{Sc}$ & Scandium \\
\hline $\mathrm{Sr}$ & Strontium \\
\hline $\mathrm{Ce}$ & Cerium \\
\hline $\mathrm{Yb}$ & Ytterbium \\
\hline $\mathrm{Y}$ & Yttrium \\
\hline $\mathrm{Pb}$ & Lead \\
\hline $\mathrm{Li}$ & Lithium \\
\hline
\end{tabular}




\section{Chapter 1: Introduction}

The demand for reduced carbon emissions and increased fuel economies has necessitated the need for new light weight materials to be used in automotive and aerospace applications. Magnesium (Mg) which is $85 \%$ lighter than iron and 35\% lighter than aluminum (Al) is considered as a potential alternative to $\mathrm{Al}$ in the automotive industry to reduce component weights and reduce emissions. Magnesium also has a high strength-to-weight ratio and a high impact resistance. The AZ91 series of alloys are the most popular and widely used cast $\mathrm{Mg}$ alloys in the industry. However, some of the major drawbacks like their inadequate mechanical properties and poor workability have maintained the use of $\mathrm{Mg}$-Al alloys to a marginal level in comparison to those of $\mathrm{Al}$ alloys. Increasing the mechanical properties of $\mathrm{Mg}-\mathrm{Al}$ alloys will increase their use for more demanding industrial applications.

Improving the mechanical properties of $\mathrm{Mg}$-Al alloys will augment their use for more demanding industrial applications. Grain refinement can significantly improve the mechanical properties of $\mathrm{Mg}$ alloys through fine and uniform grain structure, as well as promoting a more uniform distribution of secondary phases [Vinotha et. al., 2009].

Over the past few years, a significant number of publications related to grain refinement of $\mathrm{Mg}-\mathrm{Al}$ alloys have been produced. Studies suggest that carbon based grain refiners resulted in the most effective of grain refinement of $\mathrm{Mg}-\mathrm{Al}$ alloys. However, environmental concern related to release of green house gases associated with these refiners has limited their use in the industry. Researchers have found some alternative potential environmentally friendly grain refiners for Mg-Al alloys. In spite of some success with these refiners, there is no universally accepted refiner for Mg-Al alloys that is effective as well as environment friendly. This warrants the development of alternative environmentally friendly effective grain refiners for $\mathrm{Mg}$-Al alloys. In this study, grain refining potential of $\mathrm{ZnO}$ in $9 \mathrm{wt} . \% \mathrm{Al}$ bearing $\mathrm{Mg}$ alloys was examined which is an ongoing quest towards improving $\mathrm{Mg}$ grain refinement, with cost effective approach. 


\section{Objective}

The main objective of this study was to specifically examine the effectiveness of $\mathrm{ZnO}$ as a potential grain refiner in $\mathrm{Mg}$ alloys bearing 9 wt.\% $\mathrm{Al}$ (AZ91E commercial alloys and Mg-9 wt.\% Al binary alloys). In this regard, an extensive study of the influence of the effect of $\mathrm{ZnO}$ on the grain size, microstructure, hardness, and tensile properties of the alloys at ambient temperature were carried out. In addition, this study sought to determine the refining mechanism of $\mathrm{ZnO}$ in the $\mathrm{Mg}-\mathrm{Al}$ alloys. 


\section{Chapter 2: Theoretical Background and Literature Review}

This chapter begins with a discussion on magnesium alloys. Thereafter, there is a discussion of literature relevant to the process and mechanism of grain refinement in these alloys.

\subsection{MAGNESIUM AND MAGNESIUM ALLOYS}

Sir Humphrey Davy discovered magnesium $(\mathrm{Mg})$ in 1808 . It comprises $2.7 \%$ of earth's crust and $0.13 \%$ of world's ocean water [Avedesian et. al., 1999]. Magnesium is the lightest structural metal and is $85 \%$ lighter than iron and 35\% lighter than aluminum (Al). Being the lightest structural metal, $\mathrm{Mg}$ and its alloys are potential candidates to replace denser metals such as cast iron, steel, copper base alloys and even aluminum alloys in automotive applications [Mordike et. al., 2001]. Magnesium also has a high strength-to-weight ratio and a high impact resistance [Elsayed et. al., 2014]. Magnesium, in its alloyed form with other metals, has the most use in engineering application.

Magnesium is mainly alloyed with $\mathrm{Al}$, zinc ( $\mathrm{Zn})$, manganese $(\mathrm{Mn})$, rare earths (RE) and zirconium $(\mathrm{Zr})$ to improve strength or corrosion resistance. A summary of the major effects of common alloying elements in $\mathrm{Mg}$ are as follows [Avedesian et. al., 1999]:

(i) Aluminum has the most favourable effect on $\mathrm{Mg}$ of all other alloying elements. It improves strengths and hardness, widens freezing range and improves castability. Commercial $\mathrm{Mg}$ alloys generally contain up to $10 \mathrm{wt} . \%$ of $\mathrm{Al}$.

(ii) Zinc is the second most favourable alloying element next to Al. It helps overcome the corrosive effects of iron and nickel impurities. When combined with $\mathrm{Al}$ it improves room temperature strength.

(iii) Iron ( $\mathrm{Fe})$ is a harmful impurity in $\mathrm{Mg}$ alloys that greatly reduces corrosion resistance even at small concentration. For maximum resistance to corrosion, $0.005 \%$ is specified as the upper limit for the Fe content in Mg alloys.

(iv) Manganese improves the salt water resistance of $\mathrm{Mg}-\mathrm{Al}$ and $\mathrm{Mg}-\mathrm{Al}-\mathrm{Zn}$ alloys by removing Fe. It also slightly increases yield strength.

(v) Nickel (Ni) is another harmful impurity in $\mathrm{Mg}$ alloys which greatly reduces corrosion resistance. 
(vi) Silicon ( $\mathrm{Si}$ ) increases fluidity of molten $\mathrm{Mg}$. However, it decreases corrosion resistance in the presence of Fe.

(vii) Rare earth metals increase the strength of $\mathrm{Mg}$ alloys at elevated temperatures. They also reduce weld cracking and porosity in castings as they narrow the freezing range of the alloys.

(viii) Tin ( $\mathrm{Sn}$ ) increases ductility of $\mathrm{Mg}$ alloys and makes it more suitable for hammer forging.

(ix) $\mathrm{Zr}$ is a powerful grain refiner for $\mathrm{Mg}$ alloys. However, it cannot be used with the alloys containing $\mathrm{Al}$ and $\mathrm{Mn}$ as they form stable compounds with these elements and thus removed from solid solution.

Since $\mathrm{Al}$ is the most preferred and common alloying element for $\mathrm{Mg}, \mathrm{Mg}$ alloys can be generally classified in two groups- (i) Al free such as ZE41 and ZK60 and (ii) Al bearing such as AM50, AM60 and AZ91 [StJohn et. al., 2005]. The nomenclature for Mg alloy designations contains letters to identify the alloying elements and numbers to indicate the alloy concentration and will be discussed further in the next section.

\subsubsection{ALLOY DESIGNATION}

No international system has been developed for $\mathrm{Mg}$ alloy designation, but the naming method adopted by American Society for Testing and Materials (ASTM) in 1948 is being widely used. The standard is explained in Table 2.1.1 [ASM Handbook, Vol. 2, 1992].

For example, for the alloy AZ91E-T6, the first part of the designation, AZ, signifies two principal alloying elements are $\mathrm{Al}$ and $\mathrm{Zn}$. The second part, 91, gives the rounded off weight percentage of $\mathrm{Al}$ and $\mathrm{Zn}$ respectively. The third part, $\mathrm{E}$, indicates that this is the fifth alloy containing 9 wt.\% Al and 1 wt.\% Zn. The fourth part, T6, denotes that alloy is solution treated and artificially aged. 


\section{Table 2.1.1 Standard ASTM System for designation of Mg Alloys \\ [ASM Handbook, Vol. 2, 1992]}

\begin{tabular}{|c|c|c|c|c|}
\hline First Part & Second Part & Third Part & Fourth Part & \\
\hline $\begin{array}{l}\text { Indicates the two } \\
\text { principal alloying } \\
\text { elements }\end{array}$ & $\begin{array}{c}\text { Indicates the } \\
\text { amount of the two } \\
\text { principal alloying } \\
\text { elements }\end{array}$ & $\begin{array}{l}\text { Distinguishes } \\
\text { between different } \\
\text { alloys with the } \\
\text { same percentage of } \\
\text { the two principal } \\
\text { alloying elements. }\end{array}$ & $\begin{array}{l}\text { Indicates } \\
\text { condition } \\
\text { (temper) }\end{array}$ & Description \\
\hline $\begin{array}{l}\text { Consists of two } \\
\text { code letters } \\
\text { representing the } \\
\text { two main alloying } \\
\text { elements arranged } \\
\text { in order of } \\
\text { decreasing } \\
\text { percentage (or } \\
\text { alphabetically if } \\
\text { percentages are } \\
\text { equal) }\end{array}$ & $\begin{array}{l}\text { Consists of two } \\
\text { numbers } \\
\text { corresponding to } \\
\text { rounded-off } \\
\text { percentage of the } \\
\text { two main alloying } \\
\text { elements and } \\
\text { arranged in same } \\
\text { order as alloy } \\
\text { designation in first } \\
\text { part. }\end{array}$ & $\begin{array}{l}\text { Consists of a letter } \\
\text { of the alphabet } \\
\text { assigned in order } \\
\text { as composition } \\
\text { become standard. }\end{array}$ & $\begin{array}{l}\text { Consists of a } \\
\text { letter followed } \\
\text { by a number } \\
\text { (separated from } \\
\text { the third part of } \\
\text { the designation } \\
\text { by a hyphen). }\end{array}$ & Representation \\
\hline $\begin{array}{c}\text { A-aluminum } \\
\text { B-bismuth } \\
\text { C-copper } \\
\text { D-cadmium } \\
\text { E-rare earth } \\
\text { F- iron } \\
\text { G-magnesium } \\
\text { H-thorium } \\
\text { K-zirconium } \\
\text { L-lithium } \\
\text { M-manganese } \\
\text { N-nickel } \\
\text { P-lead } \\
\text { Q-silver } \\
\text { R-chromium } \\
\text { S-silicon } \\
\text { T-tin } \\
\text { W-yttrium } \\
\text { Y-antimony } \\
\text { Z-zinc }\end{array}$ & Whole numbers & $\begin{array}{c}\text { Letters of alphabet } \\
\text { except I and O. }\end{array}$ & $\begin{array}{c}\text { F-fabricated } \\
\text { O-annealed } \\
\text { H10 and H11- } \\
\text { slightly strain } \\
\text { hardened } \\
\text { H23,H24 and } \\
\text { H26- strained } \\
\text { hardened and } \\
\text { partially } \\
\text { annealed } \\
\text { T4-solution heat } \\
\text { treated } \\
\text { T5-artificially } \\
\text { aged only } \\
\text { T6-solution heat } \\
\text { treated and } \\
\text { artificially aged } \\
\text { T8-solution heat } \\
\text { treated, cold } \\
\text { worked and } \\
\text { artificially aged. }\end{array}$ & Values \\
\hline
\end{tabular}

The primary Mg alloy investigated in this thesis is AZ91E and the next section describes its physical properties and microstructure. 


\subsubsection{AZ91 Mg ALLOY}

The AZ91 series of alloys are the most popular and preferred Mg alloys in the industry as they have the best combination of castability, mechanical strength and ductility [Celotto, 2000]. The density of AZ91 is $1.81 \mathrm{~g} / \mathrm{cm}^{3}$ which is slightly higher than that of pure $\mathrm{Mg}\left(1.738 \mathrm{~g} / \mathrm{cm}^{3}\right)$ but much lower than that of pure $\mathrm{Al}\left(2.7 \mathrm{~g} / \mathrm{cm}^{3}\right)$ [ASM Handbook, Vol. 2, 1992]. The liquidus and solidus temperatures of this alloy are $598^{\circ} \mathrm{C}$ and $468^{\circ} \mathrm{C}$ respectively which results in a very wide freezing range of $130^{\circ} \mathrm{C}$ and allows the alloys to be highly castable. The cast microstructure of this alloy consists of primary $\mathrm{Mg}(\alpha-\mathrm{Mg})$ and intermetallic compound, $\beta-\mathrm{Mg}_{17} \mathrm{Al}_{12}$. Optical micrographs of as-cast and heat treated (solution treatment at $400^{\circ} \mathrm{C}$ for 24 hours and ageing at $200^{\circ} \mathrm{C}$ for 30 minutes) AZ91 alloy are shown in Fig. 2.1.1 [Suresh et. al., 2009] with levels identifying each phase. The solidification sequence starts with nucleation of $\alpha-\mathrm{Mg}$ at $650-600^{\circ} \mathrm{C}$ and at the later stage, eutectic phase, $\beta-\mathrm{Mg}_{17} \mathrm{Al}_{12}$ forms at $437^{\circ} \mathrm{C}$ [Dahle et. al., 2001]. A Mg-Al equilibrium phase diagram is presented in Fig. A.1 (in Appendix-A1). During cooling under still ambient air the $\mathrm{Mg}_{17} \mathrm{Al}_{12}$ eutectic takes a completely divorced form [Avedesian et. al., 1999].
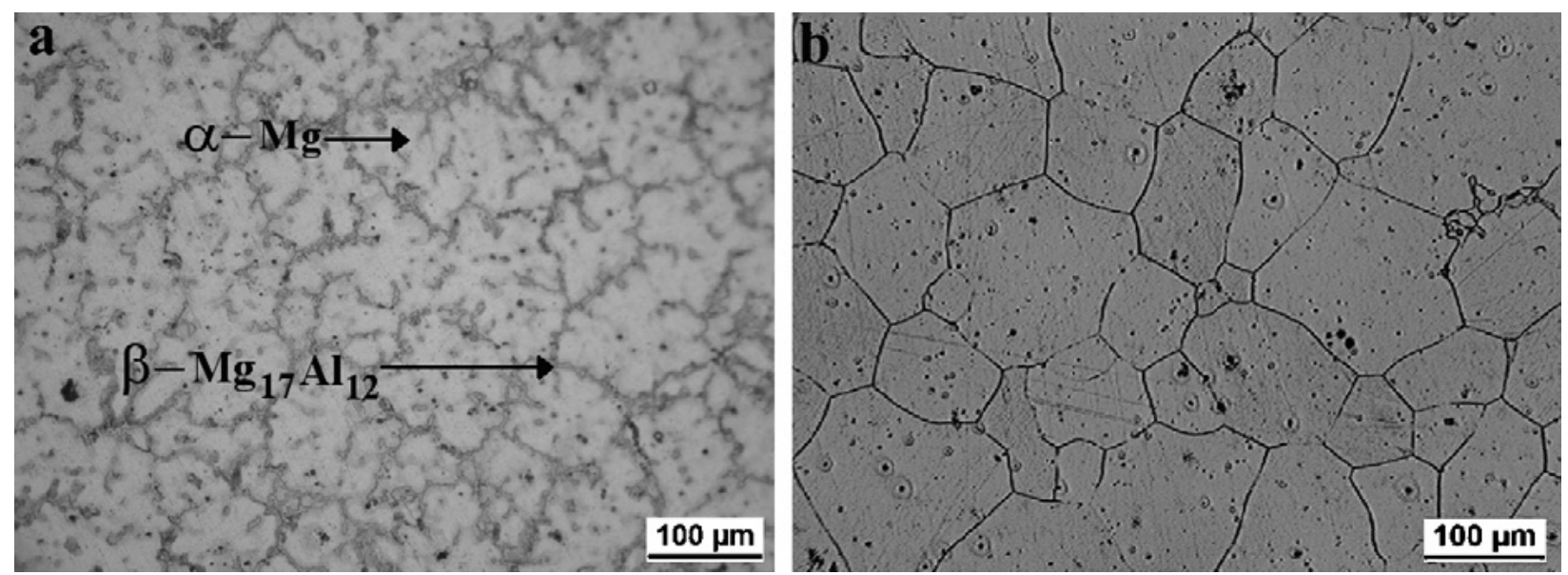

Fig. 2.1.1. Optical micrograph of AZ91 alloy (a) as-cast condition (b) heat treated condition [Suresh et. al., 2009].

However, some of the major drawbacks of Mg alloys (including AZ91E alloy) limiting their use in the automotive industry are their inadequate mechanical properties and poor workability relative to $\mathrm{Al}$ alloys [Liu et. al., 2010]. 
Since the AZ91E alloy series is the most popular among Mg alloys, it is important to develop an understanding regarding how to control its grain size and its effect on properties.

\subsection{GRAIN REFINEMENT}

Grain refinement is one of the best methods to improve the properties of an alloy. Some of the major advantages that can be achieved through grain refinement process are [Robert et. al., 1992]:

(a) good porosity distribution into small non-interconnected holes

(b) improvement in machinability

(c) uniformity in mechanical properties

(d) better distribution of secondary phase

(e) improvement in the surface finish of the castings and in the subsequent machining

The larger grain boundary area associated with a smaller grain size effectively increases the yield strength of a material [Gruzleski, 2000] by impeding dislocation motion. The variation of yield strength with grain size follows the classic Hall-Petch relation (Equation 2.2.1) [Dieter, 1986].

$\sigma_{y}=\sigma_{0}+k_{y} d^{-\frac{1}{2}}$

Equation 2.2.1

Where:

$\sigma_{\mathrm{y}}$ is the yield stress

$\sigma_{0}$ is the friction stress (an experimental constant)

$\mathrm{k}_{\mathrm{y}}$ is the stress concentration factor (an experimental constant)

$\mathrm{d}$ is the average grain size.

Adding alloying elements during solidification process is one of the most effective ways to grain refine cast metals. However, issues related to understanding solidification of alloys, constitutional undercooling, solute effects and analysis of cooling curves are required for development of effective grain refiners for $\mathrm{Mg}-\mathrm{Al}$ alloys and are discussed in the following sections. 


\subsection{SOLIDIFICATION OF ALLOYS}

Solidification of alloys is the phase transformation process where non-crystallographic liquid turns into crystallographic solid. For alloys, solidification occurs over a range of temperatures and the temperature profile of an engineering alloy solidifying unidirectionally is schematically shown in Fig. 2.3.1 [Flemings, 1974]. The rate of solidification depends upon a driving force for nucleation, undercooling and heat removal efficiency from the system. The two basic phenomena associated with alloy solidification are nucleation and grain growth.

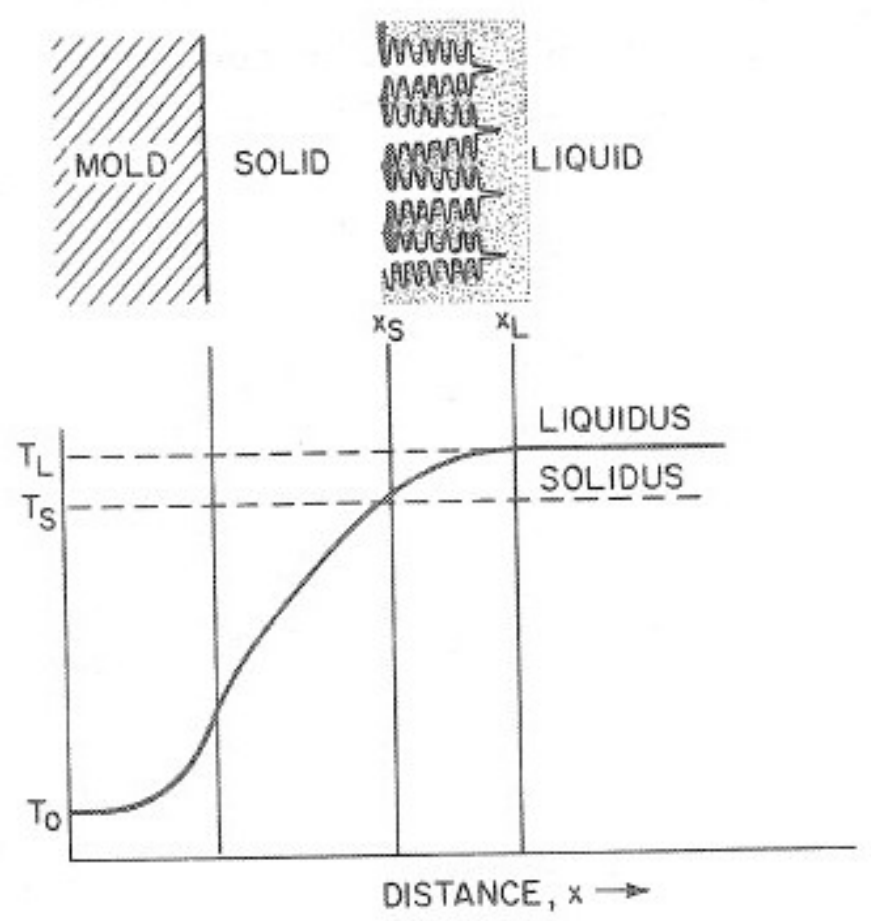

Fig. 2.3.1. Temperature profile of an engineering alloy solidifying unidirecionally [Flemings, 1974].

\subsubsection{NUCLEATION}

Nucleation is the primary process of solidification and can be defined as the formation of first nanocrystallities from molten material [Askeland et. al., 2010]. As the temperature of the liquid alloy goes below its liquidus temperature, a nucleating particle starts to form within the melt. The driving force associated with this change is the difference between the free energy of liquid and solid, $\Delta \mathrm{G}_{\mathrm{T}}$. This energy change is the sum of volume free energy $\left(\Delta \mathrm{G}_{\mathrm{v}}\right)$ and surface free 
energy $\left(\sigma_{s l}\right)$ which for spherical nucleating particle of radius $\mathrm{r}$ can be written as [Askeland et. al., 2010] :

$\Delta \mathrm{G}_{\mathrm{T}}=\frac{4}{3} \pi r^{3} \Delta G_{v}+4 \pi r^{2} \sigma_{s l}$

Equation 2.3.1

Where:

$\frac{4}{3} \pi r^{3}$ is the volume of spherical nucleating particle

$4 \pi r^{2}$ is the surface area of spherical nucleating particle

$\Delta \mathrm{G}_{\mathrm{v}}$ is volume free energy and $\sigma_{s l}$ is the surface free energy of the solid liquid interface

Fig. 2.3.2 shows the changes in volume free energy, surface free energy and resultant total free energy as a function of the radius of a nucleating particle, $r$ [Gruzleski, 2000]. The total free energy reaches a maximum when $r$ is equal to a critical value, $r^{*}$ Nuclei with $r>r^{*}$ are stable and begin to grow while those with $r<r^{*}$ remelt. As the nuclie grow, the total free energy decreases rapidly.

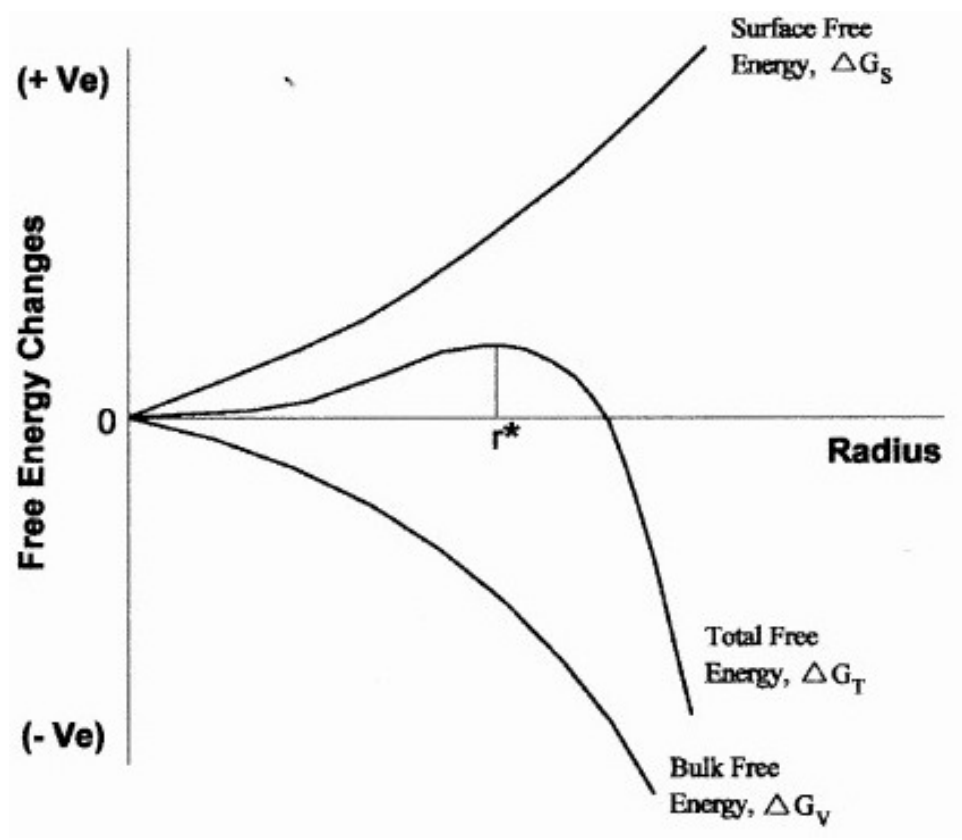

Fig. 2.3.2. Free energy changes of solid-liquid system as a function of radius of nucleating particle, r [Gruzleski, 2000]. 
Nucleation process can be broadly divided in two categories: homogeneous and heterogeneous nucleation.

\subsubsection{Homogeneous Nucleation}

In homogeneous nucleation, solid forms within its own melt without the aid of foreign materials. Nucleation in this way requires a large amount of driving force because of the relatively large contribution of surface energy to total free energy, $\Delta \mathrm{G}_{\mathrm{T}}$, of very small particles [Flemings, 1974].

The critical radius, $r^{*}$ of a spherical particle undergoing homogeneous nucleation due to undercooling $\Delta \mathrm{T}$ is given by [Askeland et. al., 2010]:

$$
r^{*}=\frac{2 \sigma_{s l} T_{m}}{\Delta H_{f} \Delta T}
$$

where $\Delta \mathrm{T}$ is defined as $\Delta \mathrm{T}=\mathrm{T}_{\mathrm{m}}-\mathrm{T}$ with $\mathrm{T}_{\mathrm{m}}$ and $\mathrm{T}$ being the melting point and melt temperature respectively. $\mathrm{H}_{\mathrm{f}}$ is the latent heat of fusion per unit volume.

From Equation 2.3.2 it is evident that with the increase of undercooling the critical radius required for nucleation decreases. However, homogeneous nucleation rarely occurs in practice due to the presence of melt impurities and the mould wall. Nucleation under these effects is termed heterogeneous nucleation.

\subsubsection{Heterogeneous Nucleation}

Heterogeneous nucleation is nucleation on a pre-existing surface. Metals and most other liquids usually undercool by no more than a few degrees before crystallization begins. This crystallization originates on impurity particles such as nucleating agents or mold walls and thus can avoid very large thermodynamic barrier to homogeneous nucleation [Flemings, 1974]. A solid forming on an impurity needs a smaller increase in surface energy to reach the critical radius, $r^{*}$. Heterogeneous nucleation occurs more readily as the amount of undercooling required for $r$ to be equal to $r^{*}$ is lower than that for homogeneous nucleation and relatively fewer atoms are required to cluster together to form a stable nuclei. Heterogeneous nucleation largely depends upon the contact angle or wetting angle $(\theta)$ between the nucleating phase and nucleating surface. Fig. 2.3.3 shows schematic of the formation of a cluster on a substrate [Flemings, 1974]. 


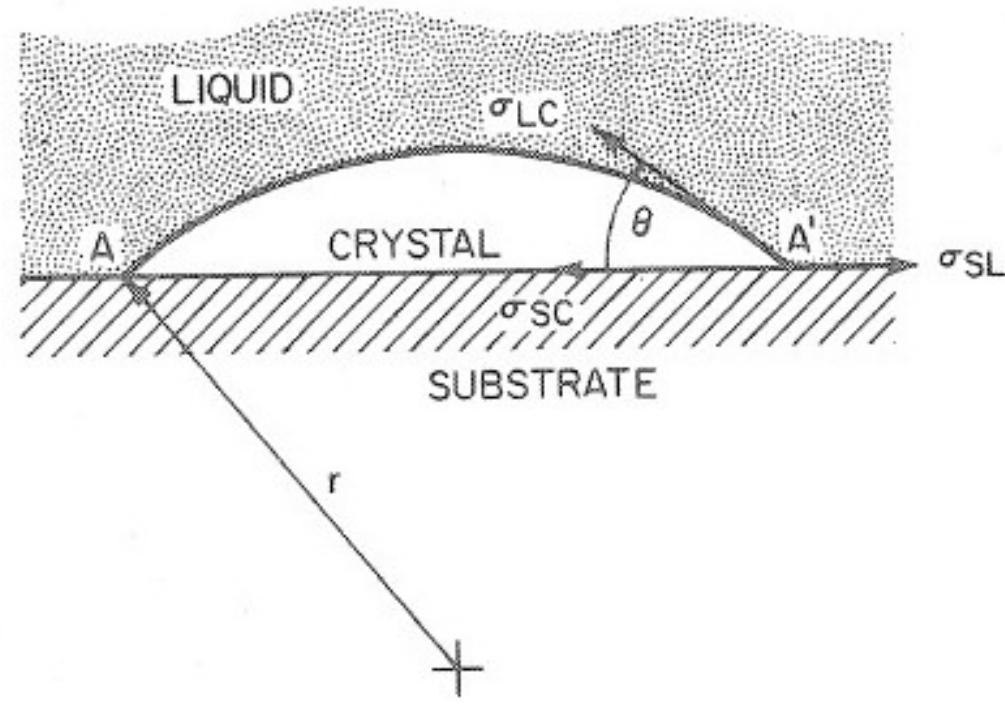

Fig. 2.3.3. Schematic showing formation of a cluster on a substrate [Flemings, 1974].

Where:

$\sigma_{S L}$ is the surface energy of the substrate-liquid interface

$\sigma_{S C}$ is the surface energy of the substrate-cluster interface

$\sigma_{L C}$ is the surface energy of the liquid-cluster interface

$\theta$ is the contact (or wetting) angle.

The equilibrium relationship of heterogeneous nucleation of a cluster shown in Fig. 2.3.3 can be modeled by the following equation [Flemings, 1974]:

$\sigma_{S L}-\sigma_{S C}=\sigma_{L C} \cos \theta$

Equation 2.3.3

Solving equation 2.3.3 for $\cos \theta$ yields:

$\cos \theta=\frac{\sigma_{S L}-\sigma_{S C}}{\sigma_{L C}}$

Equation 2.3.4

The most favourable condition of heterogeneous nucleation is when $\theta \rightarrow 0^{\circ}$ or complete wetting occurs. In this condition the largest radius of curvature is created with the fewest number of 
atoms. Contact angles exceeding $0^{\circ}$ result in decreasing states of partial wetting, until $\theta=180^{\circ}$, when the situation has reverted to that of homogeneous nucleation. The various conditions of $\theta$ and $r$ are illustrated in Fig. 2.3.4 [Gruzleski, 2000].
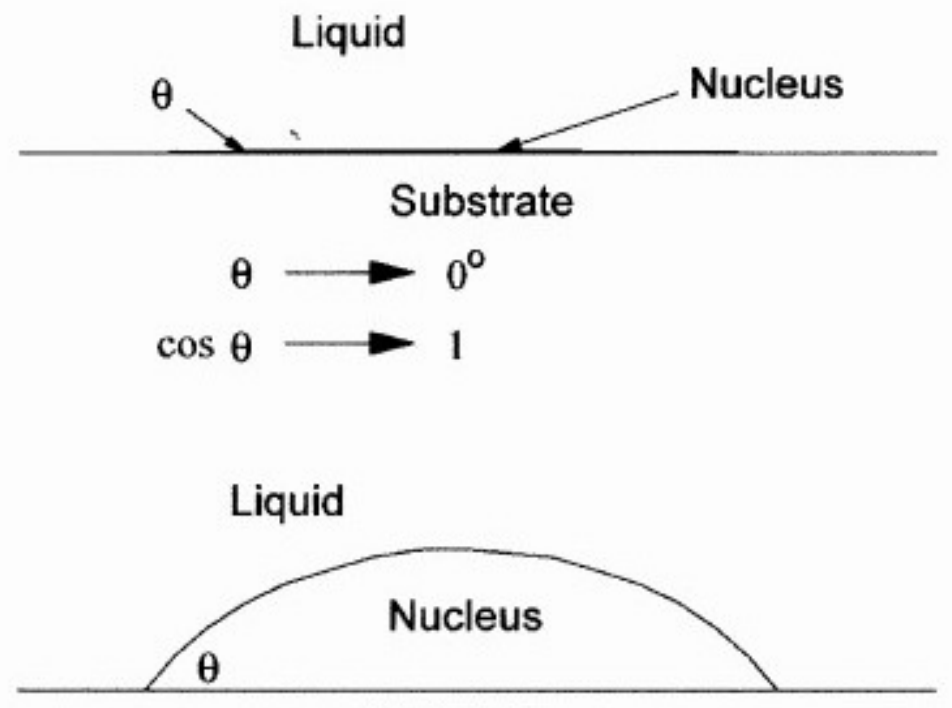

Substrate

$\theta$ increases

$\cos \theta$ decreases

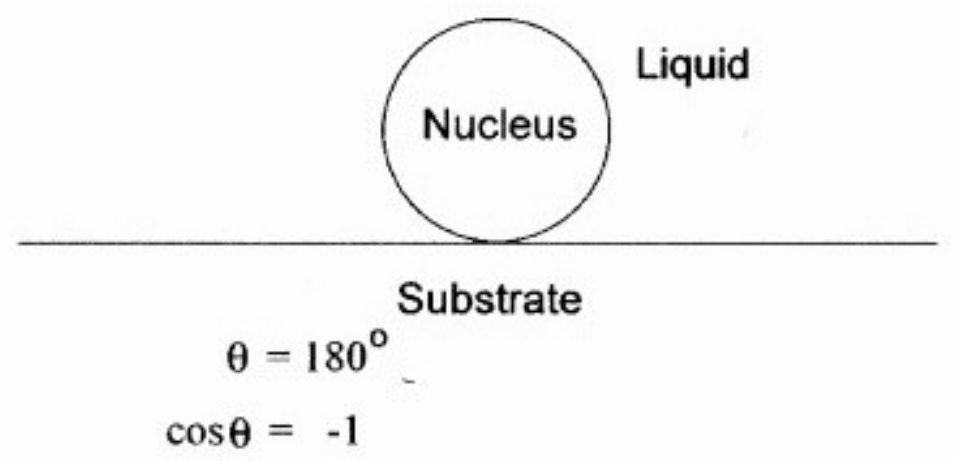

Fig. 2.3.4. Schematic representation showing the relationship between radius of curvature of a spherical cap and contact angle, $\theta$ [Gruzleski, 2000].

In commercial foundry practice, inoculants are added to molten alloys to promote heterogeneous nucleation, and thus to produce fine grained castings. From the above discussion it is evident that a good grain refiner (inoculants) should produce a small contact angle between the nucleating 
substrate and the growing nucleus. Also, the nucleating substrate needs to be stable in the melt and not undergo other reactions that would destroy the active substrate [Gruzleski, 2000]. Some of the other characteristics of a good grain refiner can be summarized as follows [Murty et. al., 2002]:

1. It should have a higher melting point than the alloy being solidified.

2. It should be able to initiate freezing at very small undercooling.

3. A sufficient numbers of nucleating particles should be uniformly distributed.

4. The nucleating particles should be larger than a critical size, which depends on the undercooling of the melt.

Crystallographic similarity between nucleating agents and alloying elements also plays an important role for effective grain refinement and will be discussed in the subsequent section.

\subsubsection{EFFECT OF CRYSTAL STRUCTURE ON GRAIN REFINEMENT}

One of the basic requirements of good grain refiner is its crystal structure similarity to the material to be nucleated [Gruzleski, 2000]. The Edge-to-Edge Matching Model is a computer based program used to examine actual atom matching of two compounds of known crystallography across an interface between any two phases [Zhang et. al., 2005]. With the input data of crystal structures, lattice parameters and atom positions, it can predict an orientation relationship (OR) between any two phases (i.e., substrate and matrix). In this model, first closed packed or nearly closed packed rows of atoms between two phases are identified and then parallelism between one such rows in each phase is established. Next, closed packed planes containing these selected rows are identified in both the phases and a pair of these planes (one from each phase) are arranged to meet edge-to-edge. These matching planes are then rotated relative to one another and a value of rotation angle is established, where there is a maximum matching of atom rows in the interface between two phases. From these crystallographic manipulations the resulting OR and interface plane between the two phases can be identified [Kelly et. al., 2006]. Fig. 2.3.5 shows a schematic of the final edge-to-edge matching process between two phases [Kelly et. al., 2006]. Here, $\left(h_{1} k_{1} l_{1}\right)_{A}$ and $\left(h_{1} k_{1} l_{1}\right)_{B}$ planes of phase A and B are matched. These two planes are rotated by an angle $\varphi$ so that closed packed parallel atom rows $[\mathrm{uvw}]_{\mathrm{A}}$ and $[\mathrm{uvw}]_{\mathrm{B}}$ of phase $\mathrm{A}$ and $\mathrm{B}$, respectively, have a maximum match. 


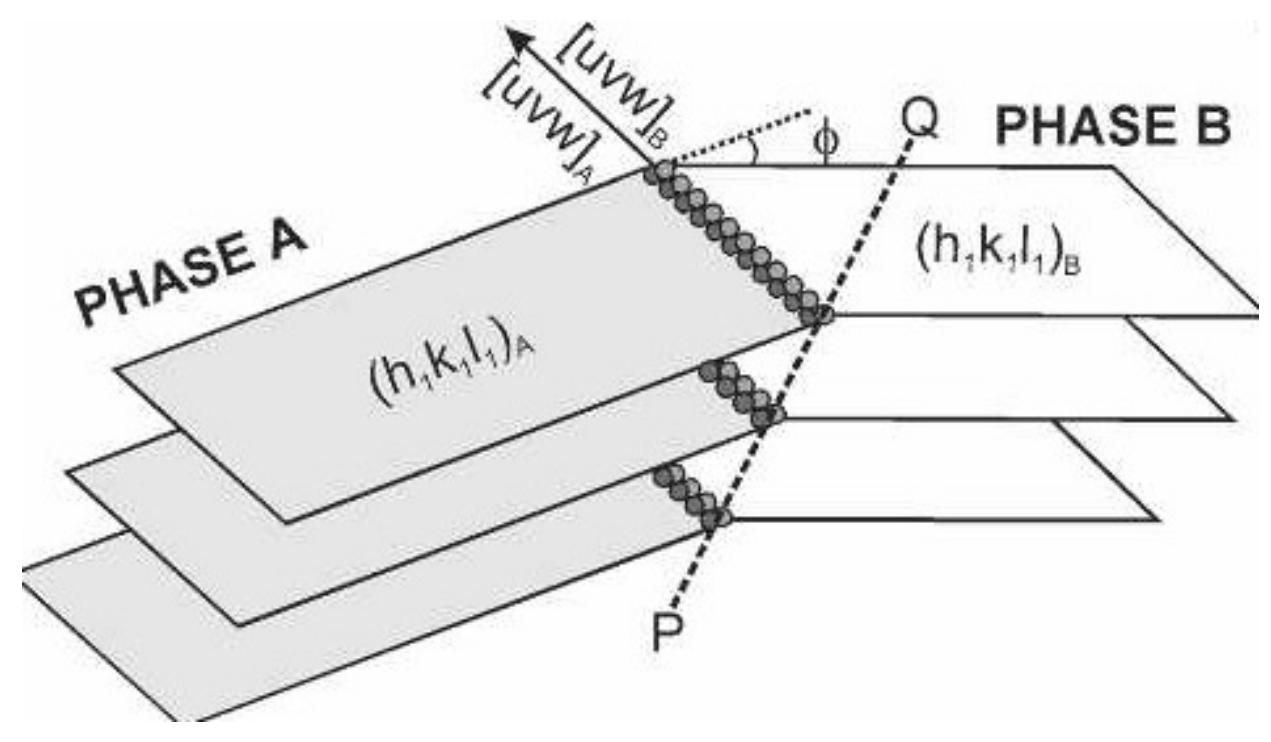

Fig. 2.3.5. Schematic showing edge-to-edge matching model between two phases [Kelly et. al., 2006].

For a substrate to act as an effective nucleant it should have less than $10 \%$ inter-atomic misfits along the matching direction and d-value (inter-planer distance) mismatch between matching planes that contains these directions should be $6 \%$ or less [Zhang et. al., 2005].

It was found that $\mathrm{Al}_{4} \mathrm{C}_{3}$ or $\mathrm{Al}-\mathrm{C}-\mathrm{O}$ is the most reasonable mechanism for the grain refinement of $\mathrm{Mg}$ alloys through carbon inoculation processes [Qian et. al., 2005] using experimental technique and edge-to-edge model [Zhang et. al., 2005]. This is assumed to be due to crystallographic and lattice parameter similarity between $\alpha-\mathrm{Mg}$ and Al-C-O based compounds [Bamberger, 2001]. Also, $\mathrm{ZnO}$ is one of the new potential nucleants which have very similar crystallographic structure with $\alpha-\mathrm{Mg}$. Both $\mathrm{Mg}$ and $\mathrm{ZnO}$ have hexagonal closed packed (HCP) crystal structure. The lattice parameters of $\mathrm{Mg}$ are $\mathrm{a}=3.2029 \AA, \mathrm{c}=5.2000 \AA, \mathrm{c} / \mathrm{a}=1.6235$ and for $\mathrm{ZnO}$ are $\mathrm{a}=3.2495 \AA, \mathrm{c}=5.2069 \AA$ and $\mathrm{c} / \mathrm{a}=1.602$ [Pearson, 1964]. Using edge-to-edge matching model, the interplanar spacing (d-value) mismatch between matching planes and interatomic spacing misfit along matching directions are found to be 1.7 and $0.59 \%$ respectively [Fu et. al., 2008] for $\mathrm{ZnO}$ and $\mathrm{Mg}$. With such crystallographic similarities, it is expected that $\mathrm{ZnO}$ would be an effective nucleant for $\alpha-\mathrm{Mg}$. There is a need to do experimental trials to confirm its performance in Mg alloys. 


\subsubsection{GRAIN GROWTH}

Once nucleation takes place in an alloy, the next phase of solidification is grain growth. Fig. 2.3.6 shows the general grain structure of a casting consisting of an outer chill zone, an intermediate columnar zone and central equiaxed zone [Flemings, 1974]. The chill zone is a narrow brand of randomly oriented grains that occurs at the wall of the molds. As the heat is removed from the casting by the mold material, the grains in the chill zone grow in the direction opposite to that of the heat flow. This thin, elongated column like grains which are perpendicular to the mold wall form columnar zone. An equiaxed zone is frequently formed at the center of the casting. The equiaxed zone contains new, randomly oriented grains that can be promoted by a low pouring temperature, alloying elements or grain refining or inoculating agents [Askeland et. al., 2010]. More often, however, one or another of the zones is absent.

Columnar dendritic growth is the most common form of growth during solidification. In most commercial alloys, a highly branched columnar dendritic morphology can be seen [Flemings, 1974]. A fully developed dendritic structure may have primary, secondary or even higher order branches. Fig. 2.3.7 shows the growth of a dendrite growth in an alloy [Flemings, 1974]. Figures (a) through (d) show a fixed position at various stages of solidification. The growth of arms can be seen during the solidification process. Many smaller arms disappear while larger ones grow. 


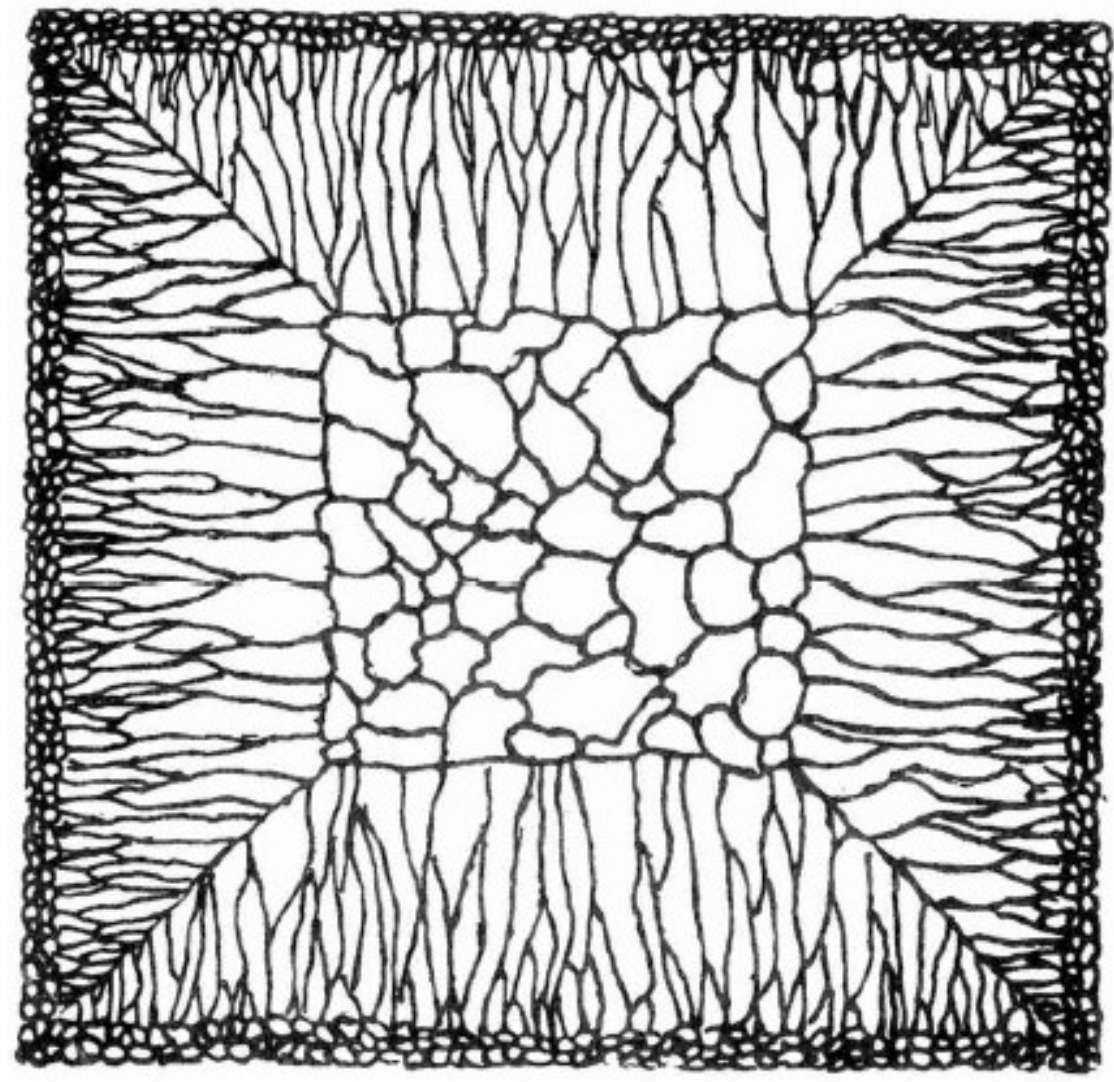

Fig. 2.3.6. Schematic showing chill zone, columnar zone and equiaxed zone in a casting [Flemings, 1974].

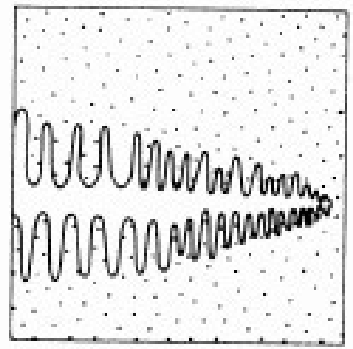

(a)

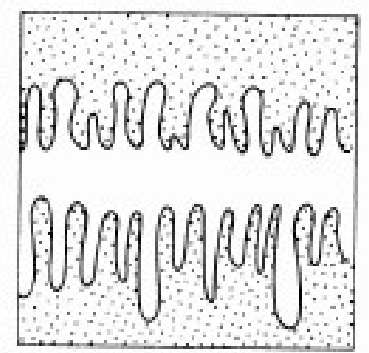

(b)

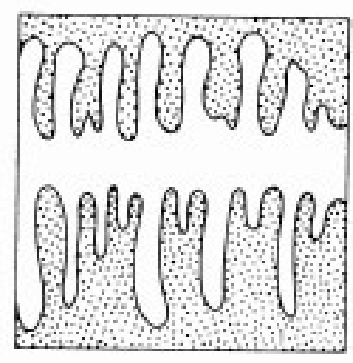

(c)

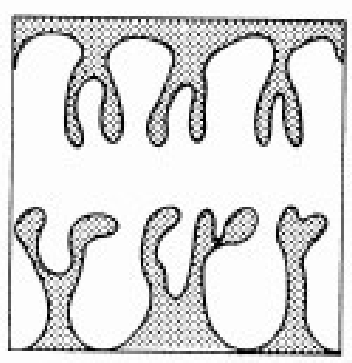

(d)

Fig. 2.3.7. (a-d) Schematic showing growth of dendrite in an alloy at various stages of solidification [Flemings, 1974].

Equiaxed grains grow in the same direction as that of heat flow towards the mold wall. These grains are characterized by having equal dimensions in all directions. Equiaxed grains are the result of copious nucleation throughout the body of the liquid, followed by free growth of the 
individual grains until that growth is halted by grain impingement. Fig. 2.3.8 is a schematic of equiaxed grain growth [Gruzleski, 2000].

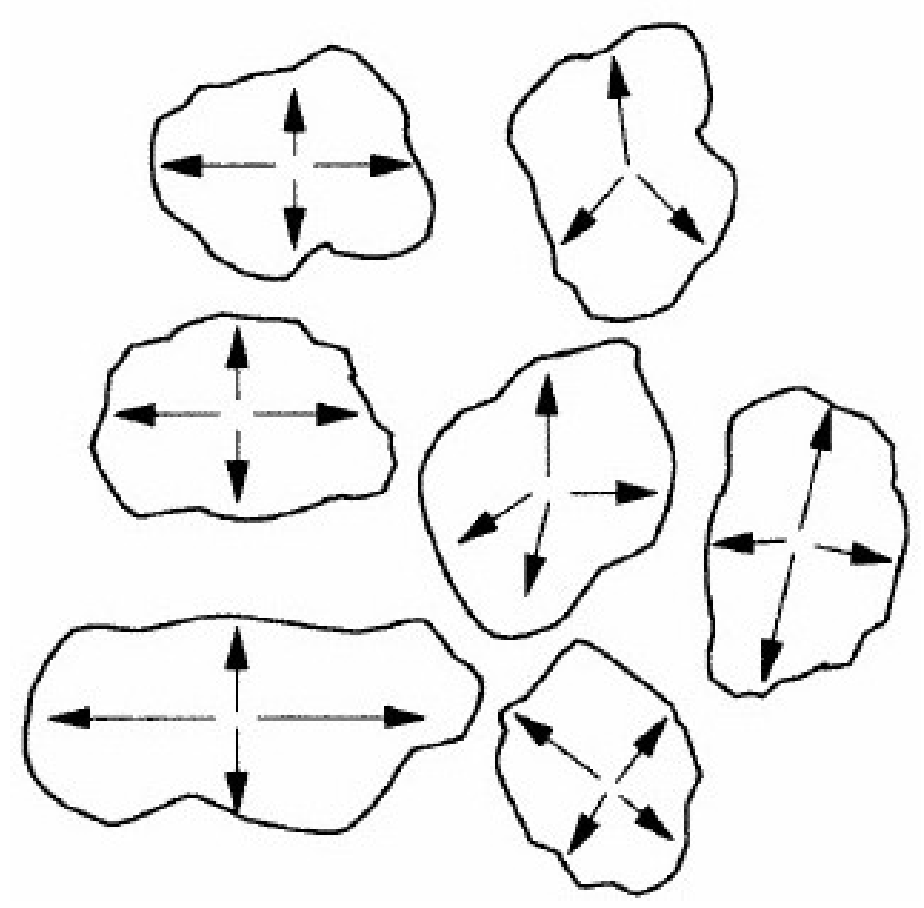

Fig. 2.3.8. Equiaxed grains grow almost equally in all directions [Gruzleski, 2000].

The constitutional undercooling plays a vital role in grain growth stage. Grain growth occurs when large amount of constitutional undercooling is present in the melt. Discussion on constitutional undercooling will be presented in the subsequent section.

\subsection{CONSTITUTIONAL UNDERCOOLING}

Constitutional undercooling is the driving force for crystal growth of alloys. During solidification, a solute-rich layer builds ahead of the solid-liquid interface. The liquid immediately in front of the solid-liquid interface is at a temperature below its equilibrium liquidus temperature. Therefore, it is undercooled. This undercooling arises due to changes in composition, not temperature, and results in instability of the solidification front since any protuberance forming on the interface would find itself in undercooled liquid and therefore would not remelt [Flemings, 1974]. At steady state conditions with no convection, the criterion for constitutional undercooling is given by [Flemings, 1974]: 
$\frac{G_{l}}{R} \geq-\frac{m_{l} c_{0}(1-k)}{k D_{l}}$

Equation 2.4.1

Where:

$\mathrm{G}_{1}$ is the actual temperature gradient in the liquid ahead of solid-liquid interface

$\mathrm{R}$ is the growth rate of solid liquid interface

$\mathrm{m}_{1}$ is the liquidus slope in the phase diagram

$\mathrm{c}_{0}$ is the initial concentration of alloy

$\mathrm{k}$ is the distribution coefficient

$\mathrm{D}_{1}$ is the diffusion coefficient of the solute in the liquid.

Growth in practical alloy solidification conditions generate a large amount of constitutional undercooling far in excess of what can be eliminated by simple cellular solidification. This difficulty is handled by generating a dendritic structure [Gruzleski, 2000].

\subsection{EFFECT OF SOLUTE ON GRAIN GROWTH}

Solute elements play an important role in controlling grain growth and subsequent nucleation [Lee et. al., 2000]. Solute elements build up ahead of solid-liquid interface, providing constitutional undercooling and restricting grain growth. The growth restriction effect of an element can be quantified in terms of a growth restriction factor (GRF). The GRF indicates how susceptible solute elements are in producing a diffusion layer in front of the advancing solid-liquid interface which slows the grain growth. A higher GRF value means the solute has a higher efficiency of restricting grain growth resulting in smaller grain sizes. The common method of calculating GRF is to use the formula based on phase diagram features which is as follows [StJohn et. al., 2007]: 
For a binary system,

$\mathrm{GRF}=\mathrm{m}_{1} \mathrm{c}_{0}(\mathrm{k}-1)$

Equation 2.5.1

For alloys with i elements,

$G R F=\sum_{1}^{i} m_{l i} c_{0 i}\left(k_{i}-1\right)$

Equation 2.5.2

where,

$\mathrm{m}_{\mathrm{li}}$ is the slope of the liquidus line of element $\mathrm{i}$

$c_{o i}$ is the initial concentration of element $i$

$\mathrm{k}_{\mathrm{i}}$ is the distribution coefficient of element $\mathrm{i}$.

The GRF values of various alloying elements in Mg alloys determined through using binary phase diagrams are summarized in Table 2.5.1 [Lee et. al., 2000]. The GRF values of $\mathrm{Zr}$, Ca and $\mathrm{Si}$ are the highest, followed by $\mathrm{Ni}, \mathrm{Zn}$ and $\mathrm{Cu}$. These elements have potentially high grain refining efficiency resulting from their high segregating potential at low addition levels in $\mathrm{Mg}$ alloys.

Along with the GRF values of elements analysis of cooling curve is useful for understanding of the solidification processes which includes nucleation and grain growth. Discussion on cooling curve analysis will be presented in the subsequent section. 
Table 2.5.1 GRF Values of Different Alloying Elements in Mg [Lee et. al., 2000].

\begin{tabular}{|c|c|c|}
\hline Element & System & GRF \\
\hline $\mathrm{Zr}$ & Peritectic & 38.29 \\
\hline $\mathrm{Ca}$ & Eutectic & 11.94 \\
\hline $\mathrm{Si}$ & Eutectic & 9.25 \\
\hline $\mathrm{Ni}$ & Eutectic & 6.13 \\
\hline $\mathrm{Zn}$ & Eutectic & 5.31 \\
\hline $\mathrm{Cu}$ & Eutectic & 5.28 \\
\hline $\mathrm{Ge}$ & Eutectic & 4.41 \\
\hline $\mathrm{Al}$ & Eutectic & 4.32 \\
\hline $\mathrm{Sc}$ & Peritectic & 3.96 \\
\hline $\mathrm{Sr}$ & Eutectic & 3.51 \\
\hline $\mathrm{Ce}$ & Eutectic & 2.74 \\
\hline $\mathrm{Yb}$ & Eutectic & 2.53 \\
\hline $\mathrm{Y}$ & Eutectic & 1.70 \\
\hline $\mathrm{Sn}$ & Eutectic & 1.47 \\
\hline $\mathrm{Pb}$ & Eutectic & 1.03 \\
\hline
\end{tabular}

\subsection{COOLING CURVE ANALYSIS}

Cooling curves are the thermal fingerprint of material as it freezes. Proper interpretation of cooling curves can yield considerable information about solidification processes [Gruzleski, 2000]. Understanding of the cooling of a material is best explained using Fig. 2.6.1. Fig. 2.6.1. shows the changes in temperature of a pure material versus time for a case where undercooling is present. During solidification of an alloy, when no additional inoculants are present in the melt, the alloy does not begin to solidify immediately at the freezing, $T_{F}$ [D' Elia, 2009] which is also called equilibrium solidification temperature. Instead, the liquid undercools to some minimum temperature, $\mathrm{T}_{\mathrm{Min}}$ which is often equal to the nucleation temperature, $\mathrm{T}_{\mathrm{N}}$ where nucleation occurs. With nucleation and crystal growth, latent heat is evolved and temperature starts rising again to the growth temperature, $\mathrm{T}_{\mathrm{G}}$. This reheating to growth temperature is known as recalescence. These temperatures are shown in Fig. 2.6.1.

As shown in Fig. 2.6.2, if sufficient inoculants are present no recalescence will be observed. In this case solidifications begins at the freezing temperature, $T_{F}$ indicating that undercooling of liquid is not required to activate nucleating particles. 


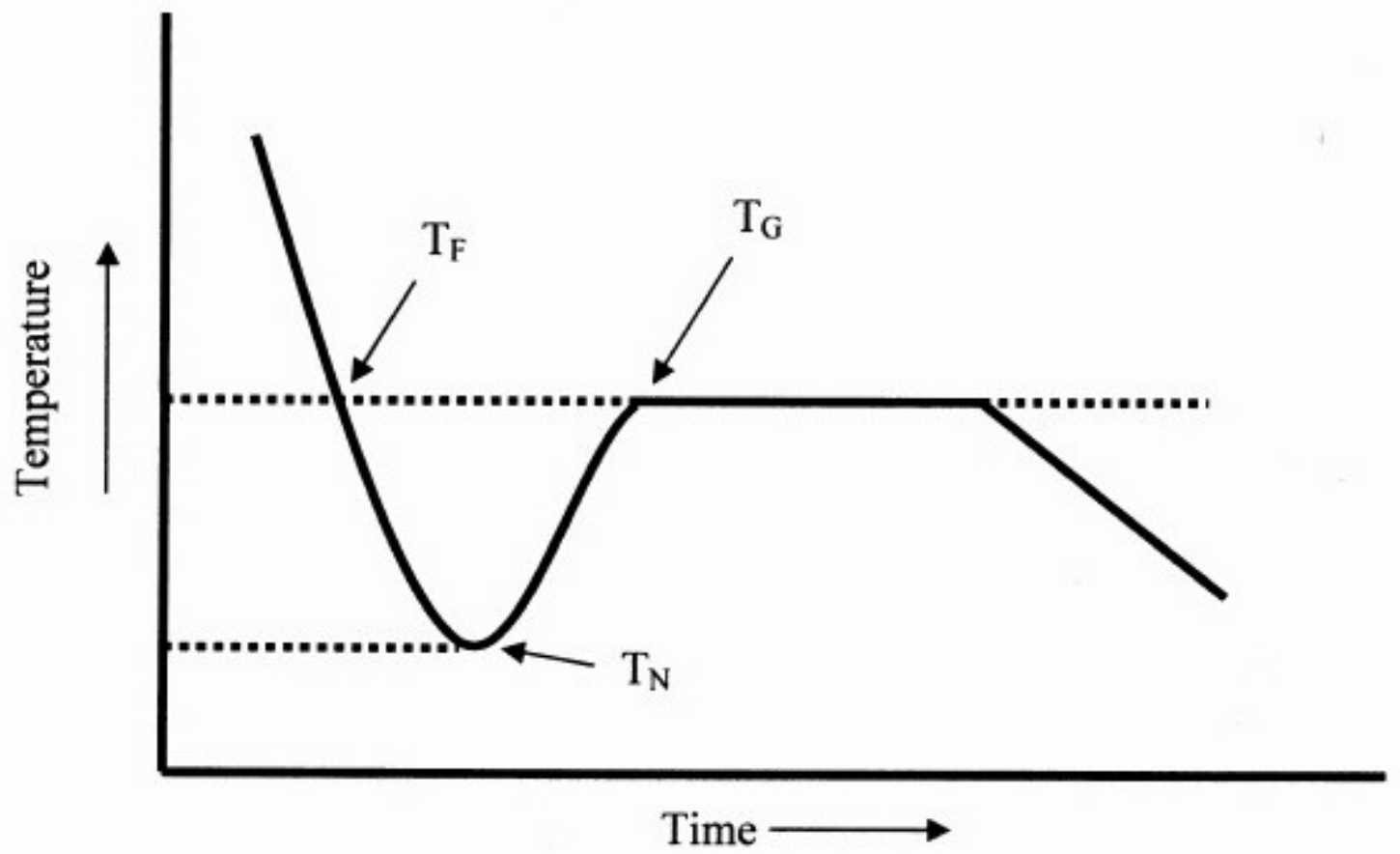

Fig. 2.6.1. Cooling curve of a pure material with undercooling present.

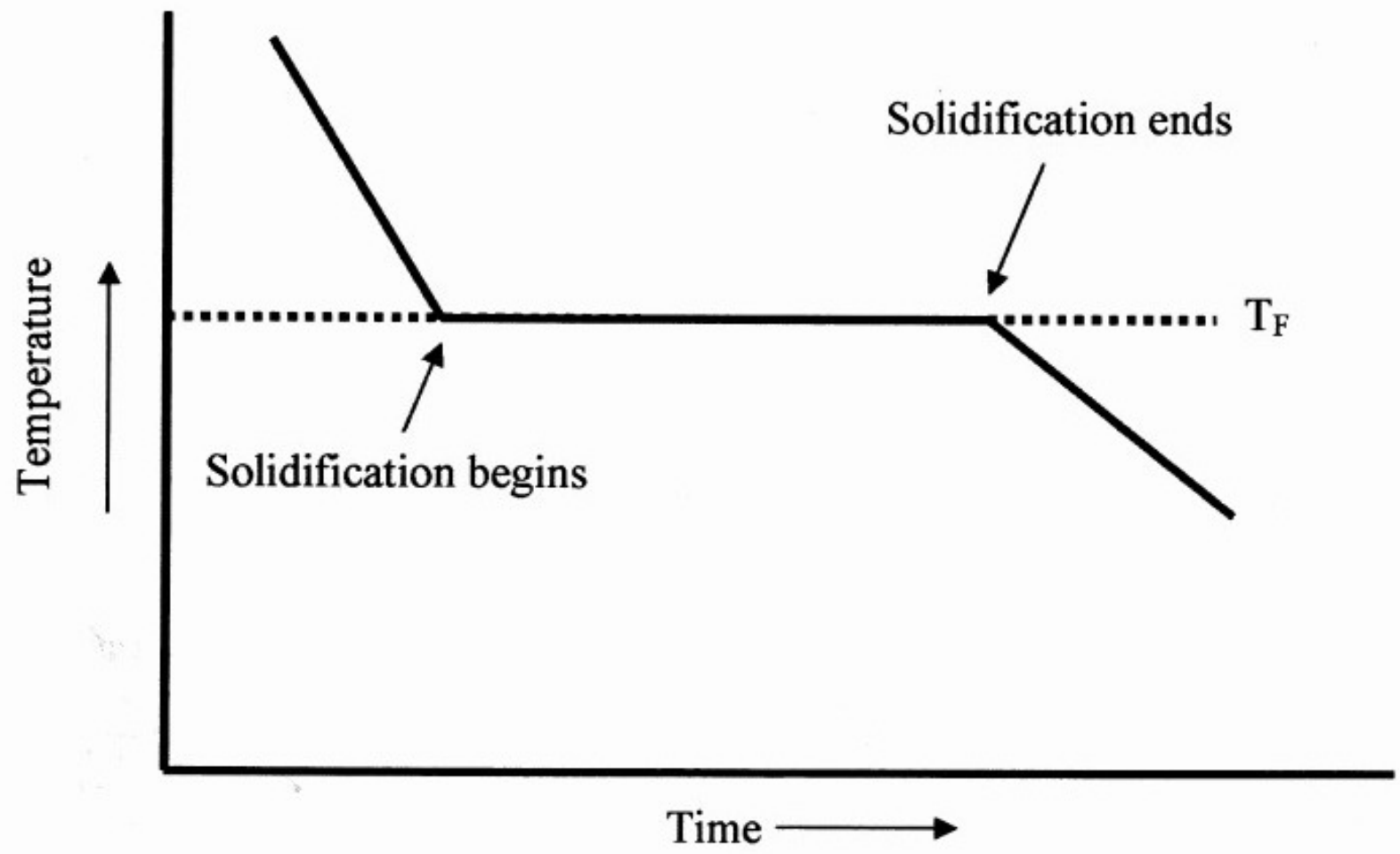

Fig. 2.6.2. Cooling curve of a pure material without undercooling. 
The purpose of grain refinement is to provide suitable inoculants into molten alloys to ease the transition from liquid to solid during solidification. The following section describes some grain refinement techniques for $\mathrm{Mg}-\mathrm{Al}$ alloys.

\subsection{ROUTES FOR Mg-AI ALLOY GRAIN REFINEMENT}

Grain refinement of $\mathrm{Mg}-\mathrm{Al}$ alloys can be achieved through three major techniques:(i) mechanical (ii) thermal and (iii) chemical. Agitation of melt during solidification is a typical example of a mechanical technique. Thermal techniques involve rapid cooling and superheating. On the other hand, addition of alloying elements and nucleating agents is classified as part of the chemical techniques for grain refinement. Due to its process simplicity and efficiency, chemical grain refinement techniques have become the most popular methods of grain refinement of $\mathrm{Mg}$ alloys in the casting industry.

Over the past few years, a significant number of publications related to grain refinement of Mg-Al alloys have been produced. The following discussion presents a summary of current methods (published) of grain refinement for Mg and its alloys. Special emphasis has been given to $\mathrm{Al}$ bearing $\mathrm{Mg}$ alloys, as they are the most commonly used alloys automotive applications.

\subsubsection{MECHANICAL GRAIN REFINEMENT TECHNIQUES}

Grain refinement through mechanical techniques can be achieved by applying mechanical motion (such as vibration or shaking) to the melt during solidification. Electromagnetic vibration (EMV) and ultrasonic treatment (UST) have been successfully applied for grain size reduction and distribution of AZ91 Mg alloy [Aghayani et. al., 2011]. Electromagnetic vibration is generated based on Fleming's left hand rule, which requires a perpendicular relation between the direction of the magnetic field and that of the flowing electric current [Li et. al., 2010]. Ultrasonic treatment uses an ultrasonic system to produce ultrasonic vibration during solidification. These applied vibrations break apart developing dendrites and refine the grain size. 
In a recent study [Li et. al., 2010], EMV was utilized at frequencies from 50 to $5000 \mathrm{~Hz}$ to refine the grain size of AZ31 and AZ91D alloys. A significant reduction in grain size was observed at medium frequencies ( $\mathrm{f}=500$ to $2000 \mathrm{~Hz}$ for $\mathrm{AZ31}$ and $\mathrm{f}=900 \mathrm{~Hz}$ for AZ91D) for both the alloys as can be seen from Fig. 2.7.1 [ $\mathrm{Li}$ et. al., 2010]. The average grain sizes were large at low frequencies and decrease with the increase of frequencies. The average minimum grain sizes were $53 \mu \mathrm{m}$ for AZ31 and $57 \mu \mathrm{m}$ for AZ91D alloys. A further increase of frequency led to the increase of grain size.

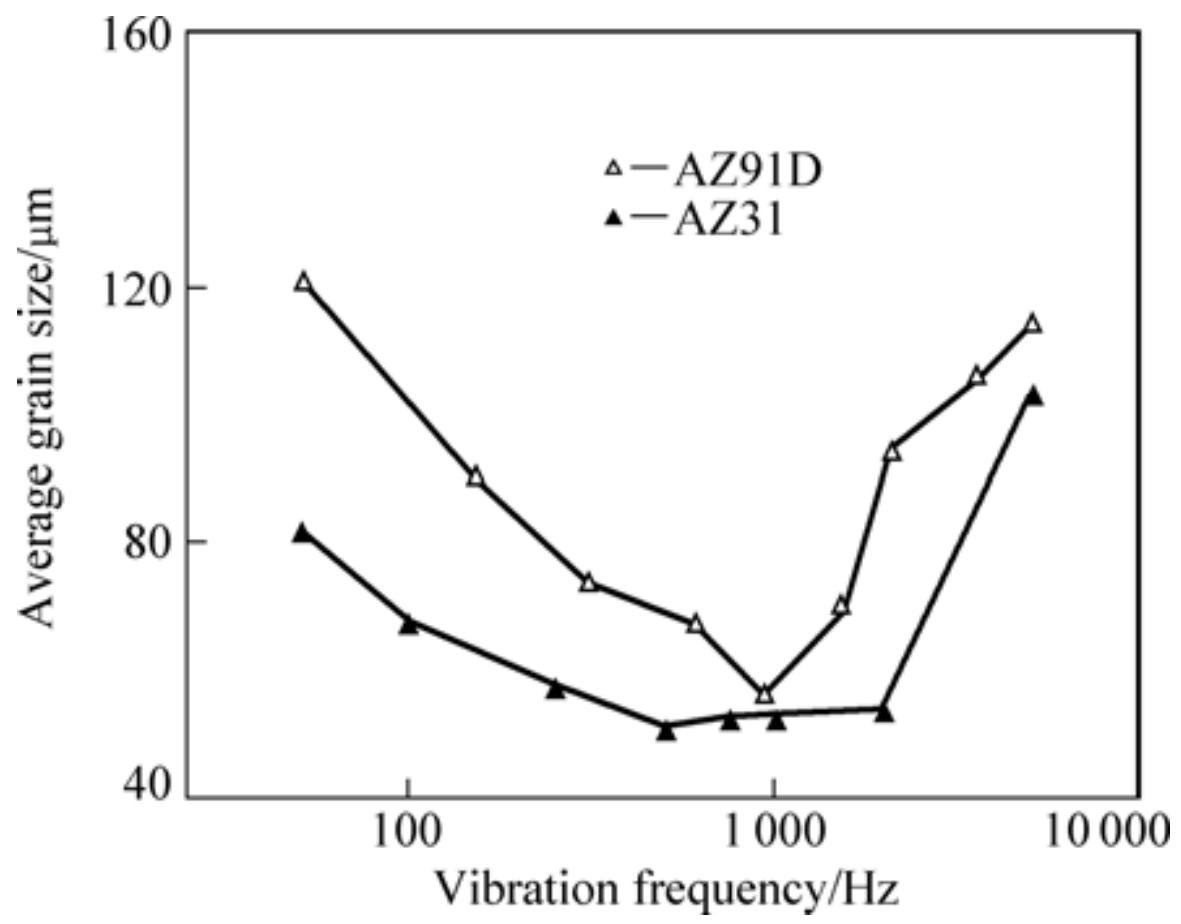

Fig. 2.7.1 Measured average grain size as a function of vibration frequency for AZ31 and AZ91D alloys [Li et. al., 2010].

Use of UST also revealed similar success with AZ91 Mg alloys [Aghayani et. al., 2011, Liu et. al., 2008]. Without UST, the alloy microstructure showed coarse dendrites of $\alpha-\mathrm{Mg}$; while under UST the alloy showed a fine and uniform grain structure. The microstructures of the AZ91D for with and without use of UST are shown in Fig. 2.7.2 [Liu et. al., 2008]. Without any UST applied, the coarse dendrites of the $\alpha-\mathrm{Mg}$ were present; the grain size of which was in the range of few millimetres (Fig. 2.7.2-a). With UST applied during solidification (at temperatures 
from $615^{\circ} \mathrm{C}$ to $580^{\circ} \mathrm{C}$ ) fine and uniform grains of the primary $\alpha$-Mg were produced (Fig. 2.7.2-b) with an average size of $195 \mu \mathrm{m}$.
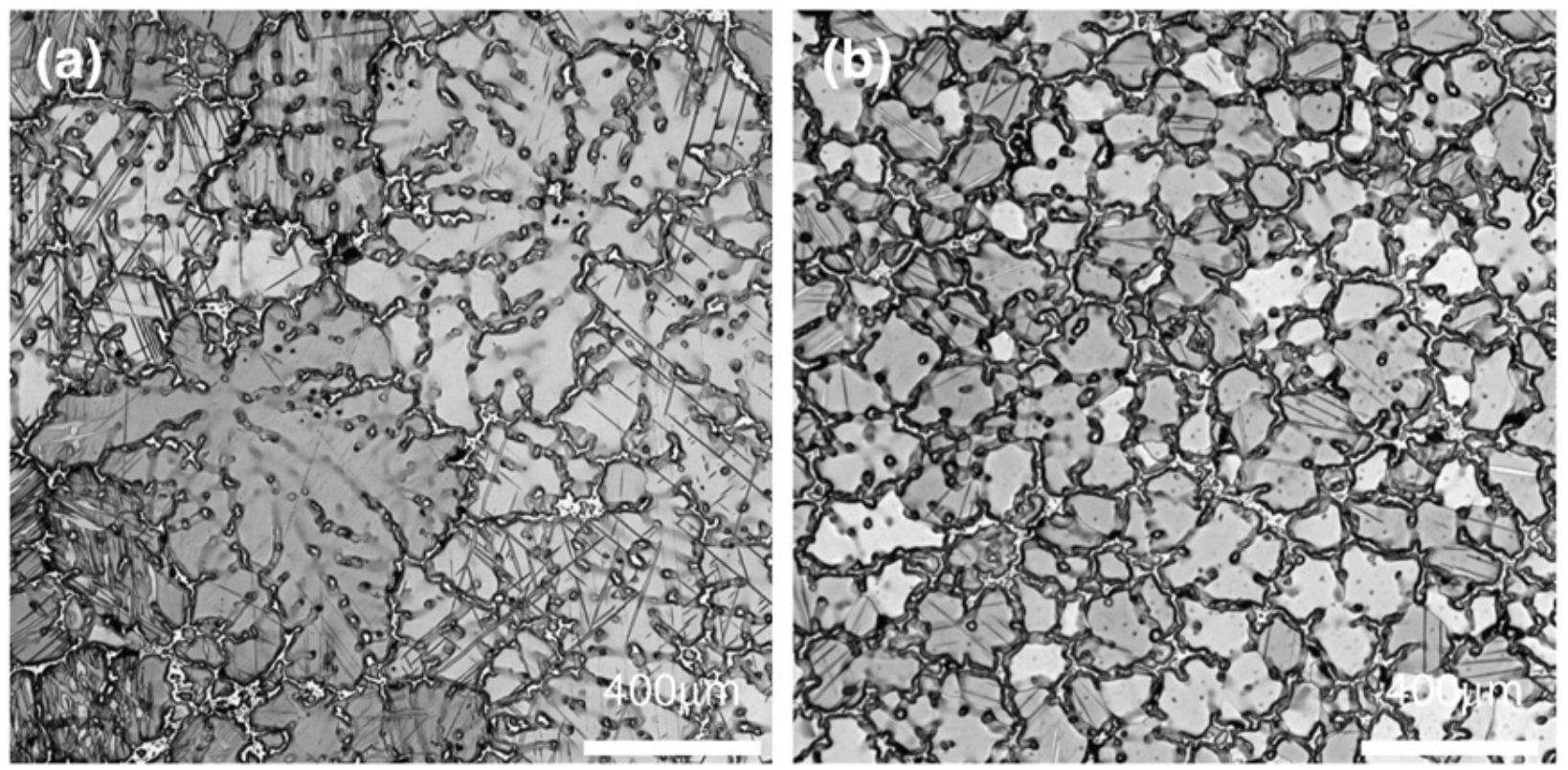

Fig. 2.7.2 Microstructure of AZ91D alloy (a) without UST (b) with UST [Liu et. al., 2008].

Aghayani et. al., 2011 reported that increasing applied ultrasonic power resulted in smaller; more rounded and better distributed grains and intermetallic particles of AZ91 alloy. Ultrasonic treatment also significantly improved tensile strength of the alloy. Tensile strength of the alloy without applying any UST was $94 \pm 2 \mathrm{MPa}$, whereas with $60 \%$ UST the tensile strength increased to $165 \pm 6 \mathrm{MPa}$.

The mechanism of grain refinement through agitation is not clear [Lee et. al., 2000]. Liu et. al., 2008 suggested that grain refinement was mainly attributed to the acoustic cavitation and flows induced by agitation through ultrasonic vibration; this made the most impurity particles active as nucleation centers. Some researchers showed that the grain refinement effect achieved for $\mathrm{Mg}$ alloys through agitation is more or less equivalent to the grain refinement obtained through superheating [Lee et. al., 2000]. At higher temperatures agitation increases the rate of nuclei phase formation resulting in grain refinement [Lee et. al., 2000]. 
Rameriz et. al., 2009 studied the role of solute in high-intensity ultrasonic grain refinement of $\mathrm{Mg}$ alloys. The study showed that the grain refinement exhibited was strongly dependant on the amount of solute present. The high-intensity ultrasonication has not changed the role of solute and the ultrasonic grain refinement arises from the effects of solute as well as ultrasonication.

Despite some success achieved with grain refinement of $\mathrm{Mg}$ alloys through agitation of the melt during solidification, these methods are not very popular in the casting industry owing to the complexity of adding additional equipment to the casting process incurring increased processing time and cost.

\subsubsection{THERMAL TECHNIQUE-SUPERHEATING}

A high temperature grain refinement technique for $\mathrm{Al}$ bearing $\mathrm{Mg}$ alloys is superheating [Vinotha et. al., 2009]. The superheating process involves heating a molten Mg-Al alloy to a temperature in the range of $180-300^{\circ} \mathrm{C}$ above its liquidus, holding it at that temperature for a period of time, and then cooling rapidly to the required pouring temperature [Cao et. al., 2007]. Some of the major features of grain refinement through superheating, identified through a literature review are summarized below:

(i) Superheating effect does not occur to a marked extent with any system other than Mg-Al alloys [Emley, 1966].

(ii) Grain refinement through this process requires the presence of $\mathrm{Fe}$ and $\mathrm{Mn}$ and is significantly influenced by these elements [StJohn et. al., 2005].

(iii) The required holding times decrease with increasing Al content and increasing maximum melt temperature and increases with crucible size and rate of heating [Emley, 1966].

(iv) The refinement effect is suppressed by the presence of $\mathrm{Be}, \mathrm{Zr}$, Ti and excess $\mathrm{Mn}$ [Emley, 1966].

The exact mechanism of grain refinement through superheating is not clear with some conflicting results among researchers. In a research review [StJohn et. al., 2005], several hypotheses were identified for the mechanism of grain refinement through superheating. One of the hypotheses proposed is that $\mathrm{Al}-\mathrm{Fe}$ or Al-Mn-Fe intermetallics precipitate from the melt and 
act as nucleants [Emley, 1966]. This is supported by the observation that $\mathrm{Mg}-\mathrm{Al}$ alloys exhibiting the superheating effect require the presence of Fe or Mn. Another hypothesis is the temperaturesolubility theory [Achenbach et. al., 1939 as in StJohn et. al., 2005]. According to this theory, particles which are too large to act as nucleants at normal melting temperature will dissolve in the melt at high melting temperatures and then re-precipitate in larger number as fine nucleation sites upon cooling. Another hypothesis proposed is nucleation through $\mathrm{Al}_{4} \mathrm{C}_{3}$ particles based on the assumption that there is an uptake of carbon from the steel crucible walls at high superheating temperature [Emley, 1966]. Other researchers proposed nucleation on inclusions that formed (such as combination of particles composed of $\mathrm{Mg}, \mathrm{Al}, \mathrm{O}$ and $\mathrm{C}$ ) during the superheating process [Tamura et. al., 2002].

Regardless of the mechanism, a marked degree of grain refinement is observed through this process for $\mathrm{Mg}-\mathrm{Al}$ alloys. The effect of superheating on AZ91E alloy obtained by quenching from $600^{\circ} \mathrm{C}(873 \mathrm{~K})$ is shown in Fig. 2.7.3 [Motegi, 2005]. In this research, melt was superheated to $850^{\circ} \mathrm{C}(1123 \mathrm{~K})$ for $900 \mathrm{~s}$ and then cooled at $2.5 \mathrm{~K} / \mathrm{s}$ to different temperatures $\left(750^{\circ} \mathrm{C} / 1023 \mathrm{~K}\right.$, $700^{\circ} \mathrm{C} / 973 \mathrm{~K}, 650^{\circ} \mathrm{C} / 923 \mathrm{~K}$ and $600^{\circ} \mathrm{C} / 873 \mathrm{~K}$ ) then immediately poured into two copper blocks. The superheated casting showed finer grain size than the untreated melt.

The major disadvantages associated with superheating are [StJohn et. al., 2005] the requirement of rapid cooling from treatment temperature to the pouring temperature and additional associated time and energy requirements; it is not very practical for large scale commercial melts. Because of the sometimes impractical requirements of superheating, alternative grain refinement techniques have been developed. 


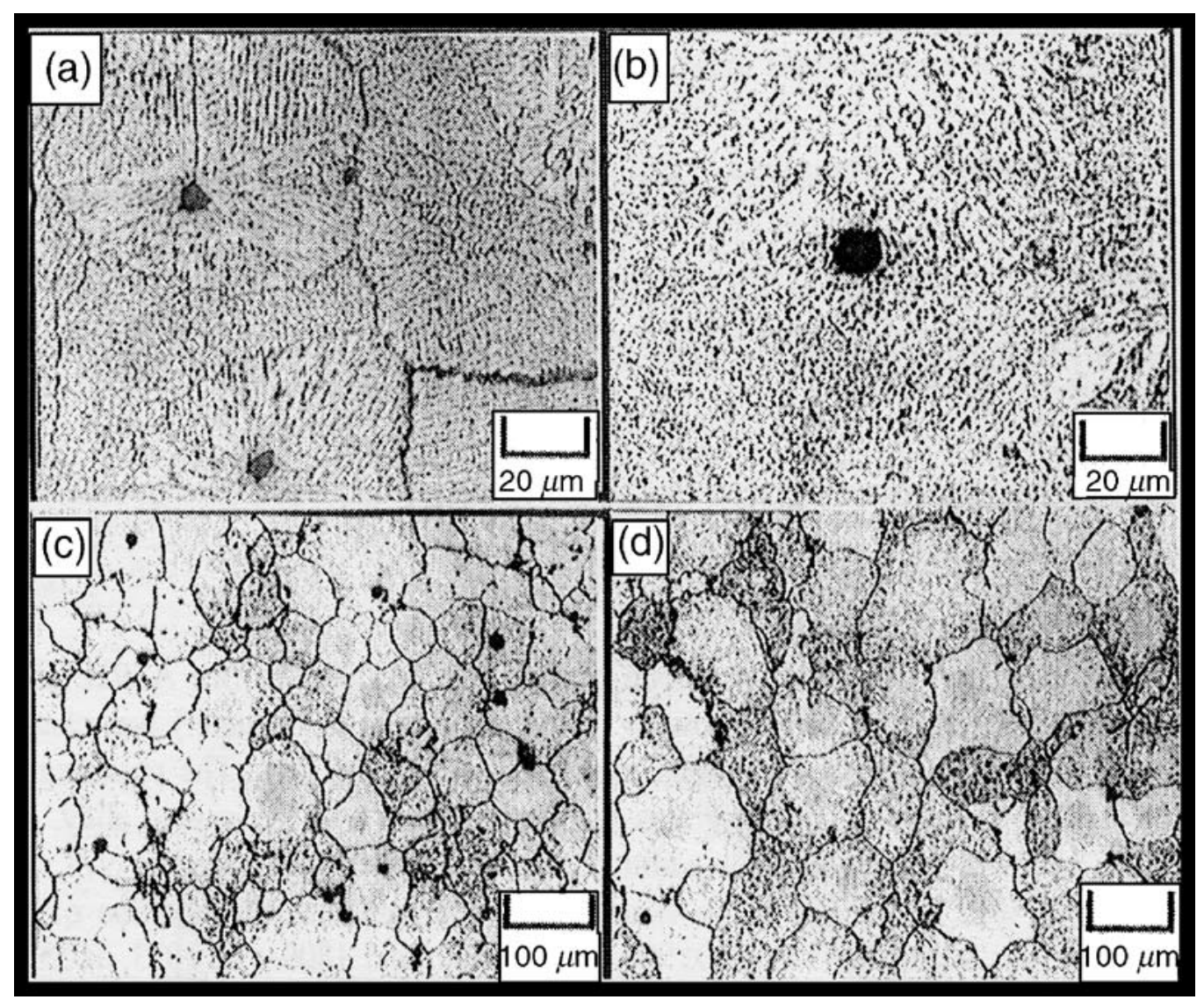

Fig. 2.7.3. Grain structure of AZ91E alloys at different conditions. (a and b) quenched sample ( $c$ and $d$ ) cast sample ( $a$ and $c$ ) Superheat treated (b and d) non-superheat treated [Motegi, 2005].

\subsubsection{CHEMICAL GRAIN REFINEMENT TECHNIQUES}

The addition of alloying elements and nucleating agents is classified as part of the chemical grain refinement techniques. Due to its process simplicity and efficiency, chemical grain refinement techniques have become the most popular methods of grain refinement for cast Mg alloys. Some of the methods that have achieved varying degrees of success in grain refining of $\mathrm{Mg}$ alloys are discussed in the following subsections.

\subsubsection{Carbon Inoculation}

Grain refinement through carbon inoculation is widely used means for grain refinement of $\mathrm{Mg}-\mathrm{Al}$ alloys. Addition of different carbon containing agents (carbon inoculation) offers many 
practical advantages like having lower operating temperature and lower tendency to fading [Dahle et. al., 2001] than many nucleating agents. Carbon can be effectively introduced to Mg-Al alloys in various forms, such as hexachloroethene $\left(\mathrm{C}_{2} \mathrm{Cl}_{6}\right)$, hexachlorobenzene $\left(\mathrm{C}_{6} \mathrm{Cl}_{6}\right)$, paraffin wax, lamp-black, carbonaceous gases, etc [Emley, 1966]. Different carbides like $\mathrm{CaC}_{2}$ [Emley, 1966], $\mathrm{Al}_{4} \mathrm{C}_{3}$ [Nimityongskul et. al., 2010] [Lu et. al., 2005], $\mathrm{SiC}$ [Chen et. al., 2010] [Easton et. al., 2006] and carbonates like $\mathrm{MgCO}_{3}$ [Chen et. al., 2011] [Gao et. al., 2010] have all been successfully used to refine $\mathrm{Mg}-\mathrm{Al}$ alloys with $\mathrm{C}_{2} \mathrm{Cl}_{6}, \mathrm{Al}_{4} \mathrm{C}_{3}$ and $\mathrm{SiC}$ being the most effective.

In a recent study [Jin et. al., 2003] it was found that adding of 0.6 wt. $\% \mathrm{C}_{2} \mathrm{Cl}_{6}$ to $\mathrm{AZ31}$ alloy at $780^{\circ} \mathrm{C}$ significantly decreased the grain size from approximately $400 \mu \mathrm{m}$ (for base, as cast) to $120 \mu \mathrm{m}$ as shown in Fig. 2.7.4 [Jin et. al., 2003]. Along with the grain refinement the use of $\mathrm{C}_{2} \mathrm{Cl}_{6}$ is also advantageous as it can be used for melt degassing $(0.0025-0.1 \%$ of the metal charge at about $750^{\circ} \mathrm{C}$ ) [Emley, 1966]. However, use of $\mathrm{C}_{2} \mathrm{Cl}_{6}$ may cause environmental problems [StJohn et. al., 2005] due to the release of greenhouse gases. Therefore, alternative methods to grain refine without releasing greenhouse gases are necessary.
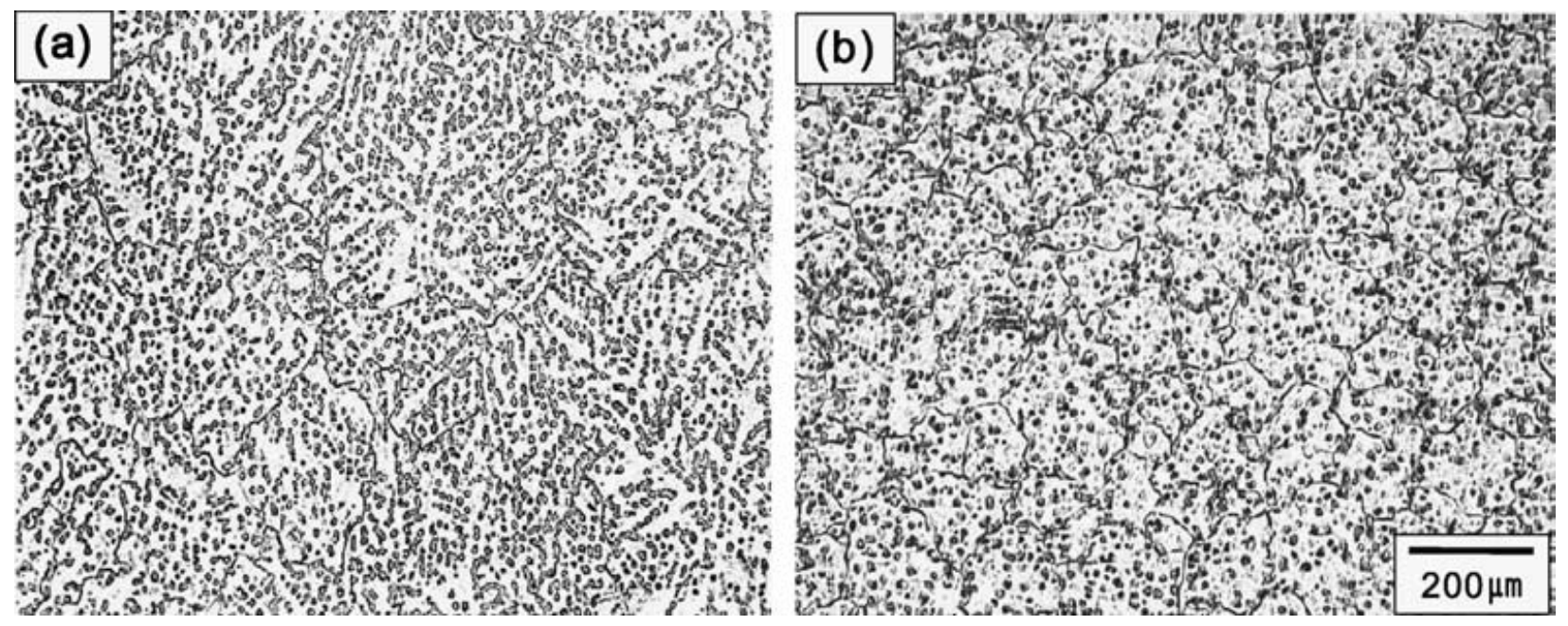

Fig. 2.7.4 Optical micrograph of as cast $A Z 31 \mathrm{Mg}$ alloy (a) without $\mathrm{C}_{2} \mathrm{Cl}_{6}$ addition (b) with 0.6 wt.\% $\mathrm{C}_{2} \mathrm{Cl}_{6}$ addition [Jin et. al., 2003]. 
Use of $\mathrm{Al}_{4} \mathrm{C}_{3}$ as grain refiner is considered as a more ecofriendly means of grain refinement for $\mathrm{Mg}$ - $\mathrm{Al}$ alloys than $\mathrm{C}_{2} \mathrm{Cl}_{6}$. In one study [Lu et. al., 2005], significant grain reduction was observed when freshly ground $1 \mathrm{wt} . \% \mathrm{Al}_{4} \mathrm{C}_{3}$ powder was added to $\mathrm{Mg}-3 \mathrm{wt} . \% \mathrm{Al}$ alloy at $735^{\circ} \mathrm{C}$ and $785^{\circ} \mathrm{C}$. At both addition temperatures, cast samples displayed similar equiaxed dendritic structure as can be seen in Fig. 2.7.5 and Fig. 2.7.6 [Lu et. al., 2005].

A similar grain refinement effect was also observed with the addition of 5 wt. $\% \mathrm{Al}_{4} \mathrm{C}_{3}$ (particle size $<44 \mu \mathrm{m})$ to AM60B in an ultrasonic cavitation based solidification processing setup [Nimityongskul et. al., 2010]. The average grain size for the base AM60B at room temperature was $254 \mu \mathrm{m}$, which was reduced to $60 \mu \mathrm{m}$ after addition of $5 \mathrm{wt} . \% \mathrm{Al}_{4} \mathrm{C}_{3}$. At the same time, the mechanical properties were enhanced by the addition of $\mathrm{Al}_{4} \mathrm{C}_{3}$ to $\mathrm{AM} 60 \mathrm{~B}$ alloy.

Addition of $\mathrm{SiC}$ is another effective means of grain refinement for $\mathrm{Al}$ bearing $\mathrm{Mg}$ alloys. Chen et. al., 2010 added $\mathrm{SiC}$ in three compositions, such as, Al-33.3 wt.\% SiC, Mg-33.3 wt.\% $\mathrm{SiC}$ and (Mg+JDMJ reagent)-33.3 wt.\% $\mathrm{SiC}$ in AZ91D alloy at different temperatures from $710^{\circ} \mathrm{C}$ to $770^{\circ} \mathrm{C}$. JDMJ is a commercial degassing reagent for Mg alloys and it contains 43-45 wt.\% $\mathrm{MgCl}_{2}, \quad 20-30$ wt.\% $\mathrm{KCl}, 20-30$ wt.\% $\mathrm{NaCl}, 3-5$ wt.\% $\mathrm{CaCl}_{2}$, 3-4.5 wt.\% $\mathrm{BaCl}_{2}$ and 1 wt.\% foaming agent. $\mathrm{Mg}$ and JDMJ were added in equal amount in wt.\%. The average grain size reduced from $311 \mu \mathrm{m}$ for the base alloy to $71 \mu \mathrm{m}$ with $0.2 \mathrm{wt} . \%$ addition of $\mathrm{SiC}$ added into the melt in the form of $\mathrm{Mg}-33.3 \mathrm{wt} . \% \mathrm{SiC} 770^{\circ} \mathrm{C}$. The melt was held for $10 \mathrm{~min}$ and rapidly cooled to $705^{\circ} \mathrm{C}$ then immediately poured. Huang et. al., 2011 investigated the effect of $\mathrm{SiC}$ in $\mathrm{Mg}-3$ wt.\% $\mathrm{Al}$ alloy. Silicon carbide with an average particle size of $2 \mu \mathrm{m}$ was added to the melt in the form of an Al-SiC master alloy. After inoculation by $\mathrm{SiC}$ particles, the grain size of the Mg-3 wt.\% $\mathrm{Al}$ decreased significantly and the grain size distribution was more homogeneous (Fig. 2.7.7). The grain size decreased from $417 \mu \mathrm{m}$ for base alloy to $128 \mu \mathrm{m}$ and $120 \mu \mathrm{m}$ after adding $0.3 \mathrm{wt} . \%$ and $10 \mathrm{wt} . \%$ of $\mathrm{SiC}$ respectively. It is noticeable that $\mathrm{SiC}$ addition more than $0.3 \mathrm{wt} . \%$ has little influence on the grain size of Mg-Al alloys. 

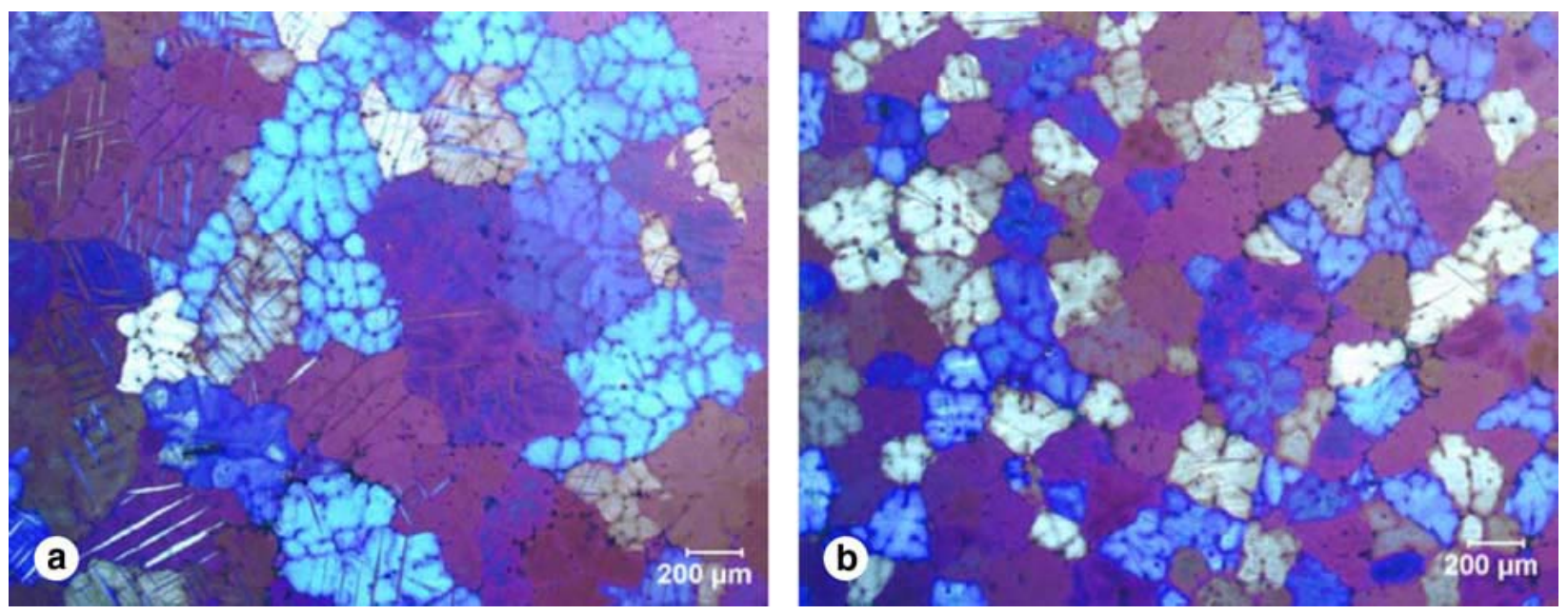

Fig. 2.7.5 Grain refinement efficiency of ground Al4C3 in $\mathrm{Mg}-3 \mathrm{wt} \% \mathrm{Al}$ at $735^{\circ} \mathrm{C}$ (a) base alloy (b) 20 min after addition of $\mathrm{Al}_{4} \mathrm{C}_{3}$ [Lu et. al., 2005].
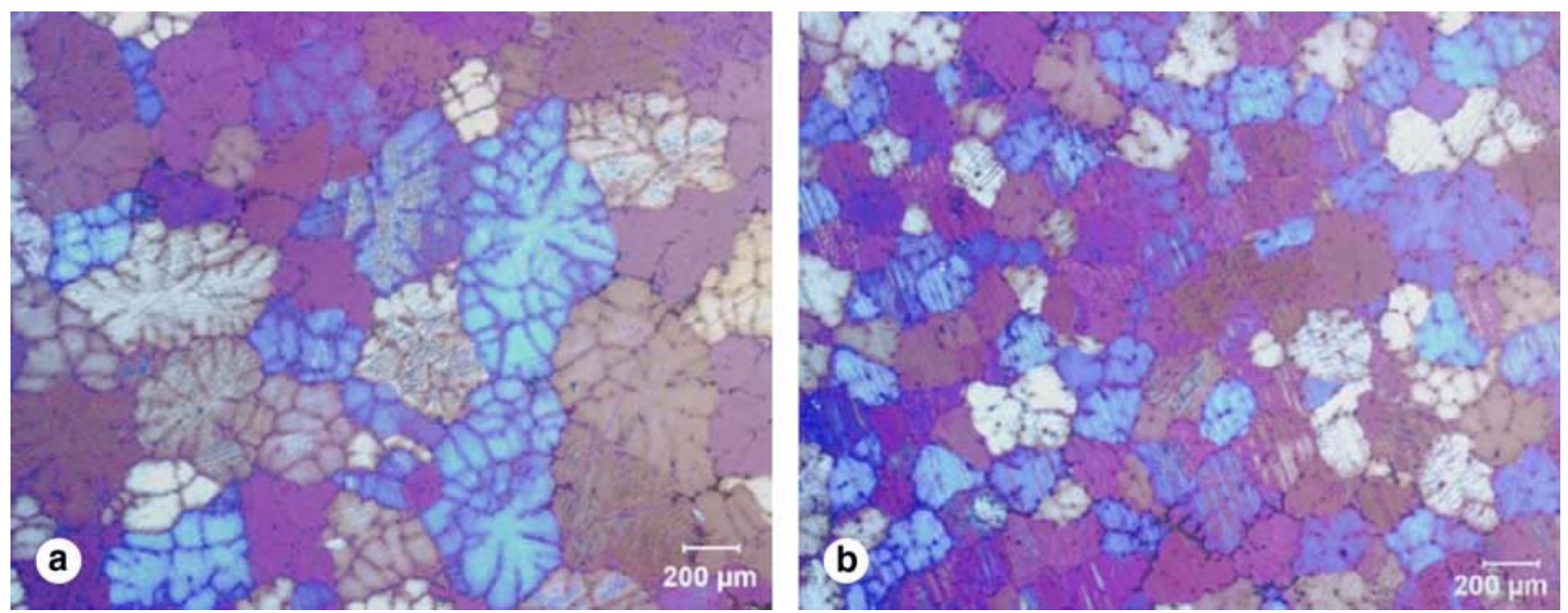

Fig. 2.7.6 Grain refinement efficiency of ground $A I_{4} C_{3}$ in $M g-3$ wt. $\% A l$ at $785^{\circ} \mathrm{C}$ (a) base alloy (b) 30 min after addition of $\mathrm{Al}_{4} \mathrm{C}_{3}$ [Lu et. al., 2005]. 

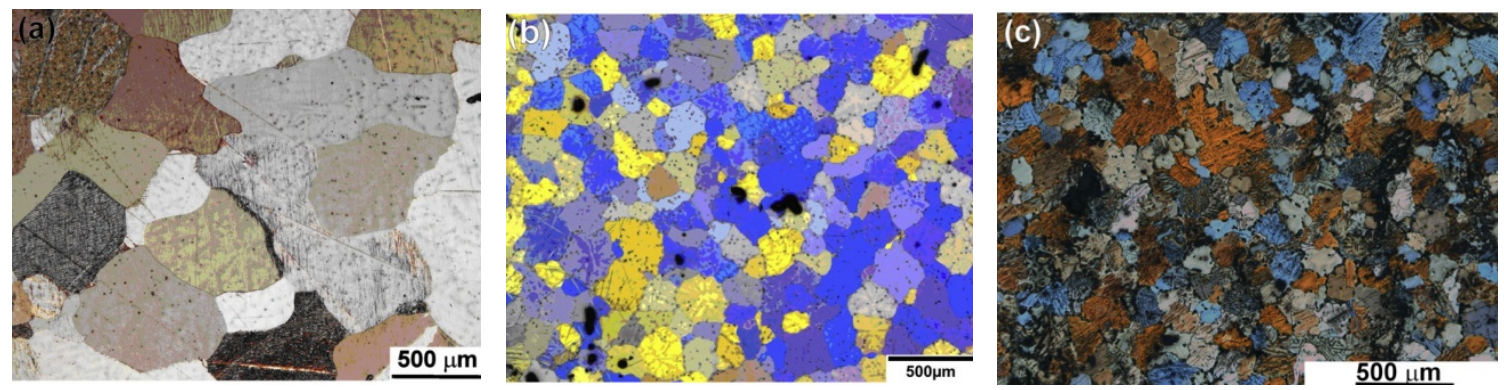

Fig. 2.7.7 Optical micrograph of as-cast alloys: (a) Mg-3 wt.\% Al (b) Mg-3 wt.\% Al-0.3 wt.\% SiC (c) Mg-3 wt.\% Al- 10 wt.\% SiC [Huang et. al., 2011].

Chen et. al., 2010 found similar results with the addition of SiC to AM60B alloy. With 0.1 and 0.2 wt.\% SiC additions significant refinement in primary $\mathrm{Mg}$ with fine equiaxed dendrites were found. When the addition level exceeded 0.2 wt.\%, grain coarsening was observed. The quantitative change in grain size with $\mathrm{SiC}$ addition amount can be seen from Fig. 2.7.8 [Chen et. al., 2010].

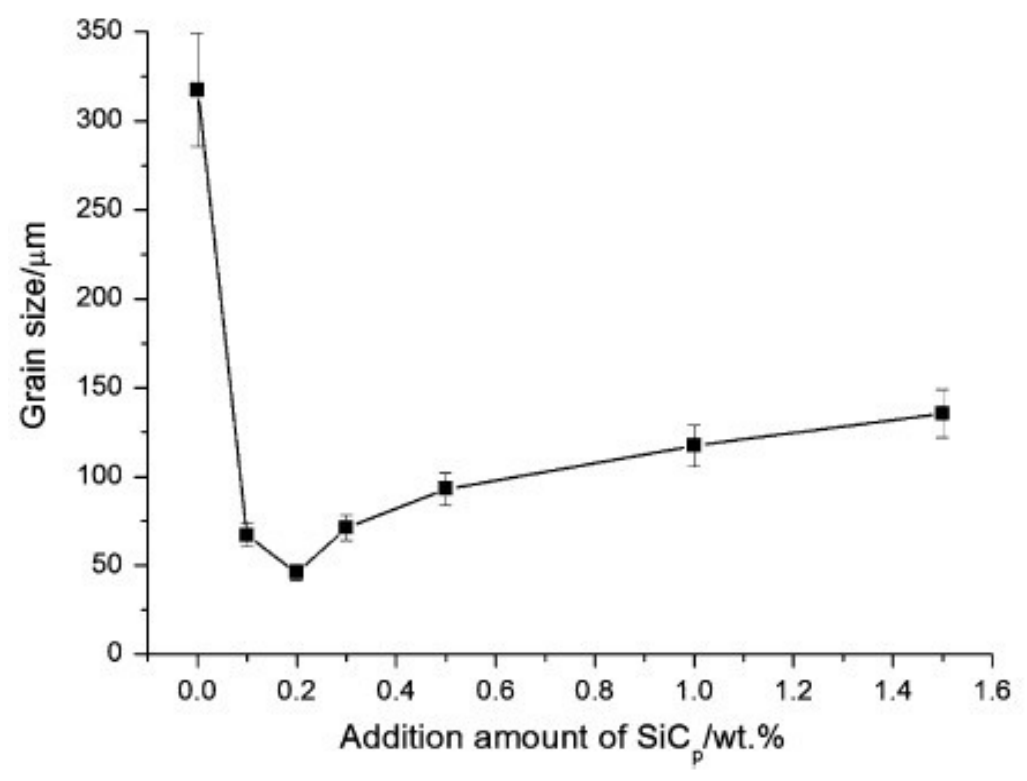

Fig. 2.7.8 Variation of grain size of AM60B alloy with SiC addition [Chen et. al., 2010]. 
Easton et. al., 2006 studied the potential of $\mathrm{SiC}$ particles as grain refiner to $\mathrm{Mg}$-Al alloys with $\mathrm{Al}$ content range from $1 \mathrm{wt} . \%$ to $9 \mathrm{wt} . \%$. Silicon carbide was introduced to the alloys in the form of $\mathrm{Mg}-\mathrm{SiC}$ master alloy. The results suggested effective grain refinement of $\mathrm{SiC}$ in the range of $\mathrm{Mg}-\mathrm{Al}$ alloys investigated. The greatest reductions in grain size were observed for the alloys with lower Al content. At higher Al content, such as 9 wt.\% Al, grain refinement using SiC was relatively small. In the study, it was also observed that the addition of Mn poisoned the grain refining effect of $\mathrm{SiC}$ probably by forming less potent carbides containing $\mathrm{Al}, \mathrm{Mn}$ and $\mathrm{C}$.

There are number of hypothesizes that exist regarding the mechanism of grain refinement through carbon inoculation. The main hypothesis is nucleation through the formation of $\mathrm{Al}_{4} \mathrm{C}_{3}$

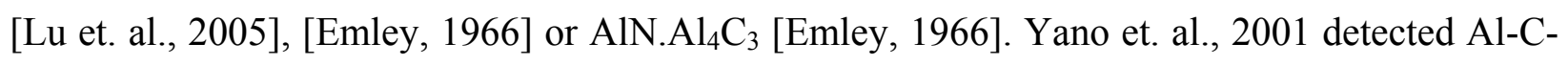
$\mathrm{O}$ based particles in $\mathrm{Mg}$ grains after carbon inoculation and proposed that Al-C-O particles are responsible for grain refinement. Although, Qian et. al., 2005 regarded the Al-C-O hypothesis as a modified version of the $\mathrm{Al}_{4} \mathrm{C}_{3}$ hypothesis. The strong segregation power of carbon is also believed to be responsible for grain refinement through carbon inoculation [Jin et. al., 2003]. According to this hypothesis, the segregation tendency of carbon element could greatly affect the constitutional undercooling and restrict the grain growth during the solidification process.

In spite of the contradictions over the grain refinement mechanism through carbon inoculation, it is an effective approach for grain refinement of $\mathrm{Mg}$-Al alloys. However, these carbon based refiners may cause environmental problems due to harmful chlorine emissions [Zeng et. al., 2006]. Another major challenge with carbon inoculation is the existence of excess carbon left in the melt from a corrosion point of view [StJohn et. al., 2005].

\subsubsection{The Elfinal Process}

Grain refinement through the Elfinal process requires introduction of anhydrous $\mathrm{FeCl}_{3}$ into the melt. This process was invented by a German company based on the hypothesis that iron particles could act as nucleation sites for Mg grains [StJohn et. al., 2005]. This process was observed to work fairly well with $\mathrm{Mg}-\mathrm{Al}$ alloys at $750^{\circ} \mathrm{C}$ but this is not the case if $\mathrm{Mn}$ is absent in the alloy [Nelson, as in Emley, 1966]. Cao et. al., 2004 studied the grain refinement effect of $\mathrm{FeCl}_{3}$ in high purity Mg-3 wt.\% $\mathrm{Al}$ and $\mathrm{Mg}-9$ wt.\% $\mathrm{Al}$ alloys. The alloys were melted in a carbon 
free aluminum titanite $\left(\mathrm{AlTi}_{2} \mathrm{O}_{5}\right)$ crucible. The anhydrous $\mathrm{FeCl}_{3}$ was introduced into the melt at $750^{\circ} \mathrm{C}$. The results of the experiment are shown in Fig. 2.7.9 and Fig. 2.7.10 [Cao et. al., 2004]. The results indicate that anhydrous $\mathrm{FeCl}_{3}$ has a significant grain refinement effect on Mg-3 wt.\% Al and Mg-9 wt.\% Al alloys respectively. The results also suggest that the Elfinal process is capable of grain refining high purity $\mathrm{Mg}-\mathrm{Al}$ alloys that contain very low concentrations of $\mathrm{Mn}(<10 \mathrm{ppm})$, contrary to the observations by Nelson, as in Emley, 1966.

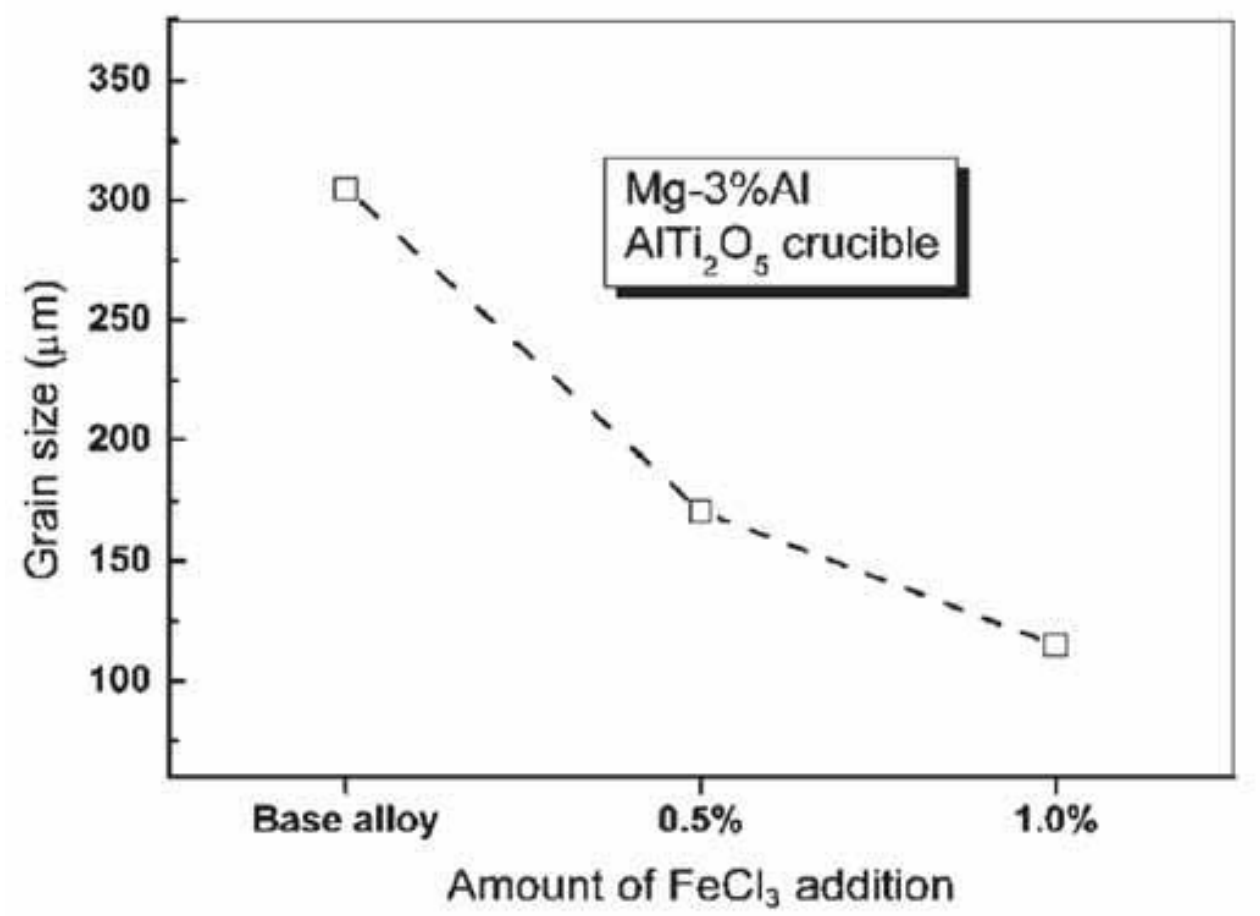

Fig. 2.7.9 Grain refinement of $\mathrm{Mg}-3$ wt.\% Al with $\mathrm{FeCl}_{3}$ at $750^{\circ} \mathrm{C}$ [Cao et. al., 2004]. 


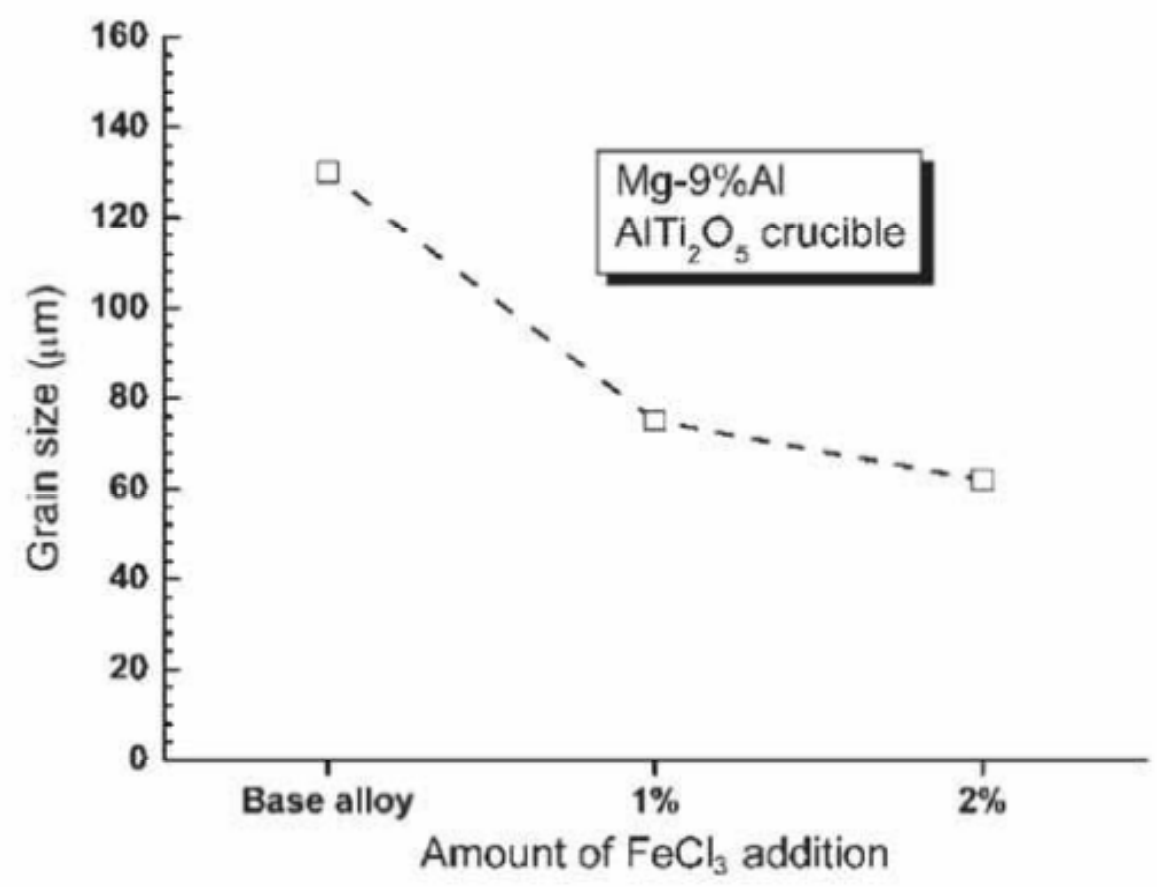

Fig. 2.7.10 Grain refinement of $\mathrm{Mg}-9$ wt.\% Al with $\mathrm{FeCl}_{3}$ at $750^{\circ} \mathrm{C}$ [Cao et. al., 2004].

Cao et. al., 2004 observed the formation of many Fe- and Al-rich particles within Mg grains. With these observations they concluded that $\mathrm{Fe}$ - and Al-rich particles acted as nucleants for $\mathrm{Mg}$ grains and were responsible for grain refinement of $\mathrm{Mg}$ - $\mathrm{Al}$ alloys through the Elfinal process.

Although, the Elfinal process is an efficient grain refiner for $\mathrm{Mg}$ - $\mathrm{Al}$ alloys, it introduces $\mathrm{Fe}$ into the melt which is detrimental to the corrosion resistance of $\mathrm{Mg}$ - $\mathrm{Al}$ alloys. In addition, the release of $\mathrm{Cl}$ or $\mathrm{HCl}$ associated with use of $\mathrm{FeCl}_{3}$ is another concern [StJohn et. al., 2005].

\subsubsection{Native Grain Refinement}

The native grain refinement of $\mathrm{Mg}-\mathrm{Al}$ alloys is the process of grain refinement through control of impurity levels of Mg. Native grain size is the grain size that results in the alloy when high purity alloying elements are used. Accordingly, native grain refinement is the phenomenon where the native grain size is finer than that of the corresponding commercial purity alloy [Cao et. al., 2005]. Tamura et. al., 2002 investigated the effect of purity level on Mg-9 wt.\% Al alloy prepared from commercial high-purity Al (99.99\%) and distilled high-purity 
$\mathrm{Mg}(<99.99 \%)$. A small amount of $\mathrm{Fe}$ and $\mathrm{Mn}$ were added to the alloy to see the influence of these impurities on grain sizes. It was observed that the grain sizes of the high-purity Mg-9 wt.\% Al alloy refined naturally without using the grain refiner or superheat treatment were $40 \mu \mathrm{m}$ and the grain size increased with increasing the Fe and Mn concentrations. The grain sizes of the alloy containing $0.01 \mathrm{wt} . \%$ Fe or $0.47 \mathrm{wt} . \%$ Mn were about $160 \mu \mathrm{m}$.

The native grain refinement phenomenon was further confirmed through the work done by Cao et. al., 2005. They identified that this approach of grain refinement is a unique characteristic of Mg-Al alloys. Other Mg alloy systems do not show the native grain refinement effect. Cao et. al., 2005 used high purity Al (Fe: 0.0001 wt.\%, Si: 0.001 wt.\%, Cu: 0.0015-0.003 wt.\%, Zn: 0.001 wt. $\%$ and Ti: 0.001 wt.\%) and $\mathrm{Mg}$ at two different purity levels- sublimed high purity $\mathrm{Mg}$ (99.98 wt.\%) and commercial purity $\mathrm{Mg}$ (99.7 wt.\%). One group of Mg-Al alloys were prepared by using high purity $\mathrm{Mg}$ and other group by using commercial purity Mg. For both the alloy groups, the $\mathrm{Al}$ content was varied in the range of $0.5-9 \mathrm{wt} . \%$. It was found that at all levels of $\mathrm{Al}$ content; the high purity alloy consistently demonstrated finer grain size than commercial purity as can be seen from Fig. 2.7.11 [Cao et. al., 2005].

Tamura et. al., 2002 suggested that native grain refinement could be attributed to the heterogeneous nucleation of $\mathrm{Mg}$ on some combination of $\mathrm{Al}, \mathrm{O}$, and $\mathrm{C}$ particles. Cao et. al., 2005 assumed that probably $\mathrm{Al}_{4} \mathrm{C}_{3}$ nucleant particles were responsible for native grain refinement of $\mathrm{Mg}-\mathrm{Al}$ alloys rather than $\mathrm{Al}-\mathrm{O}-\mathrm{C}$ particles. It was also identified that the presence of $\mathrm{Fe}$ and $\mathrm{Mn}$ in the alloy forms less potent nucleants through binding with effective nucleation substances and degrade the potency of $\mathrm{Al}_{4} \mathrm{C}_{3}$ [Tamura et. al., 2002]. 


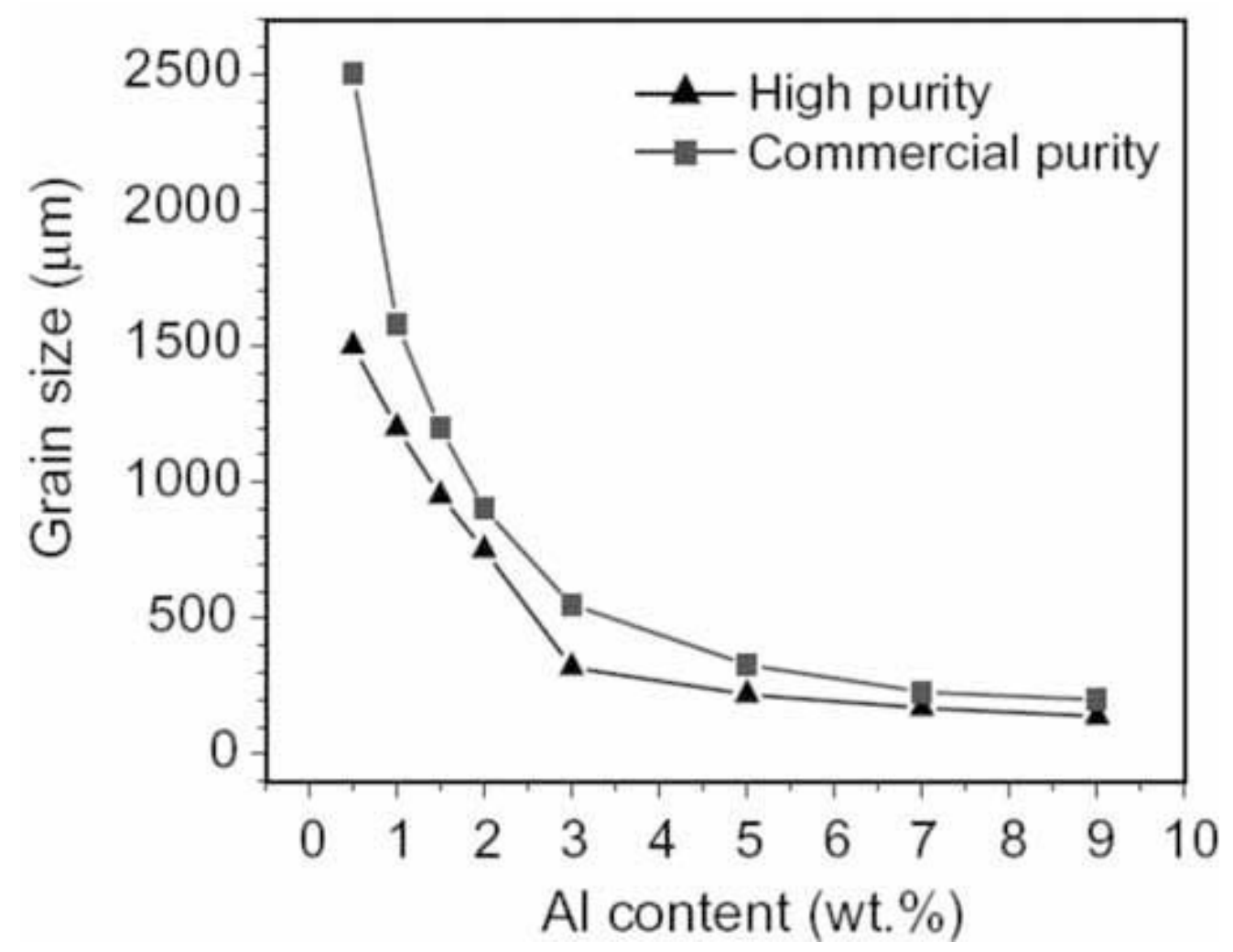

Fig. 2.7.11 Effect of source $M g$ purity on the grain size of $M g-A l$ alloys [Cao et. al., 2005].

\subsubsection{Grain Refinement by Adding Other Additives}

Environmental concerns and corrosion related issues arising from carbon inoculation and the Elfinal process warrant the development of alternative grain refiners for $\mathrm{Mg}-\mathrm{Al}$ alloys. Over the past few years, a significant number of publications related to grain refinement of $\mathrm{Mg}-\mathrm{Al}$ alloys have been produced. Some of the potential and effective Mg-Al grain refiners that have resulted from the research are strontium, Sr [Zeng et. al., 2006], [Liu et. al., 2008], boron, B [Suresh et. al., 2009], Al-Ti-B [Chen et. al., 2012], AlN [Fu et. al., 2009], calcium, Ca [Lee et. al., 2000], [Li et. al., 2005], [Elsayed et. al., 2009], manganese, Mn [Elsayed et. al., 2009], [Cao et. al., 2006], rare-earth elements like cerium, Ce [Liu et. al., 2009] and yttrium, Y [ Qiu et. al., 2009]. Grain refinement effect due to addition of these alloying elements to $\mathrm{Mg}-\mathrm{Al}$ alloys are discussed in the subsequent sub-sections. 


\subsection{Strontium (Sr) Addition}

Grain refinement of $\mathrm{Mg}$-Al alloys using $\mathrm{Sr}$ has been extensively studied. Recent studies indicated that $\mathrm{Sr}$ is an effective grain refiner for $\mathrm{Mg}-\mathrm{Al}$ alloys. It also acts as a good modifier for Si-containing Mg-Al alloys [Srinivasan et. al., 2006]. Strontium can be introduced in the Mg-Al melt in multiple forms, such as an Al-Sr master alloy, $\mathrm{Mg}$-Sr master alloy or as pure $\mathrm{Sr}$. Zeng et. al., 2006 added pure Sr to commercial AZ31B ingots while Yang et. al., 2007 introduced $\mathrm{Sr}$ as $\mathrm{Al}-10 \mathrm{Sr}$ and $\mathrm{Mg}-10 \mathrm{Sr}$ master alloys to AZ31. In all the cases referred here, it was found that a small addition $(\sim 0.1$ wt.\%) of Sr can effectively decrease the grain size of alloys. Yang et. al., 2007 found that the refinement efficiency of Mg-10Sr master alloy is higher than that of the Al-10Sr master alloy.

The refinement mechanism of $\mathrm{Sr}$ in $\mathrm{Mg}$-Al alloys is attributed to solute enrichment in the liquid ahead of the growing interface restricting grain growth during solidification. Zeng et. al., 2006 established a relationship between grain size and GRF value of the AZ31 alloy at different addition levels of Sr. The relationship is shown in Fig. 2.7.12 [Zeng et. al., 2006]. From this relationship, it can be seen that the grain size decreased with increasing GRF values with $\mathrm{Sr}$ addition upto $0.1 \mathrm{wt} . \%$ which is the solid solubility limit of $\mathrm{Sr}$ in $\mathrm{Mg}$. Decrease in grain growth of the alloy below the solid solubility limit of $\mathrm{Sr}$ in $\mathrm{Mg}$ is due to the constitutional undercooling generated by $\mathrm{Al}, \mathrm{Zn}$ and $\mathrm{Sr}$. The excess $\mathrm{Sr}$ atoms above the solubility limit formed $\mathrm{Mg}_{16}(\mathrm{Al}, \mathrm{Zn})_{2} \mathrm{Sr}$ intermetallic particles which reduces the grain growth restriction effect of $\mathrm{Sr}$. Zeng et. al., 2006 observed that increases in yield strength were consistent with the reductions in grain size of the AZ31 alloys with Sr addition as shown in Fig. 2.7.13 [Zeng et. al., 2006]. The yield strength increases followed the Hall-Petch relationship. 


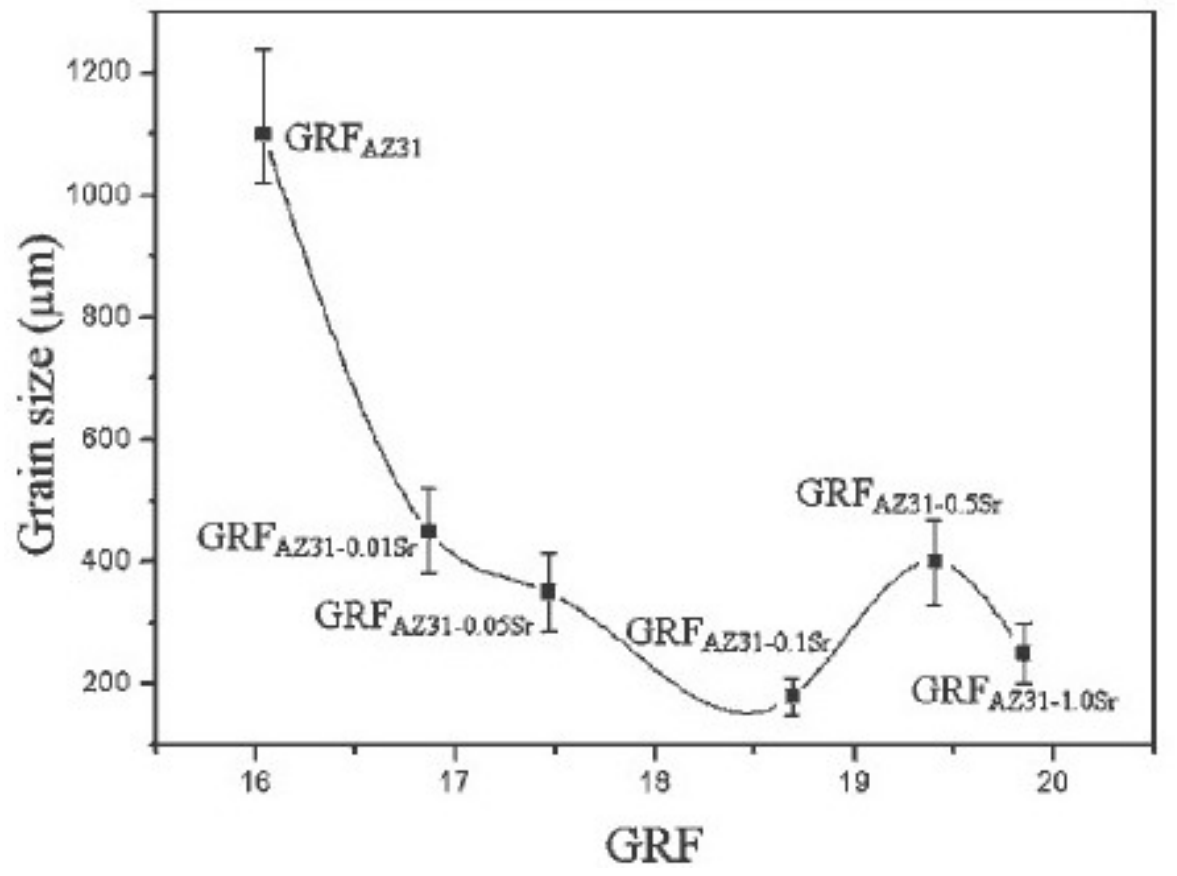

Fig. 2.7.12 Grain size vs GRF value of AZ31-Sr alloys [Zeng et. al., 2006].

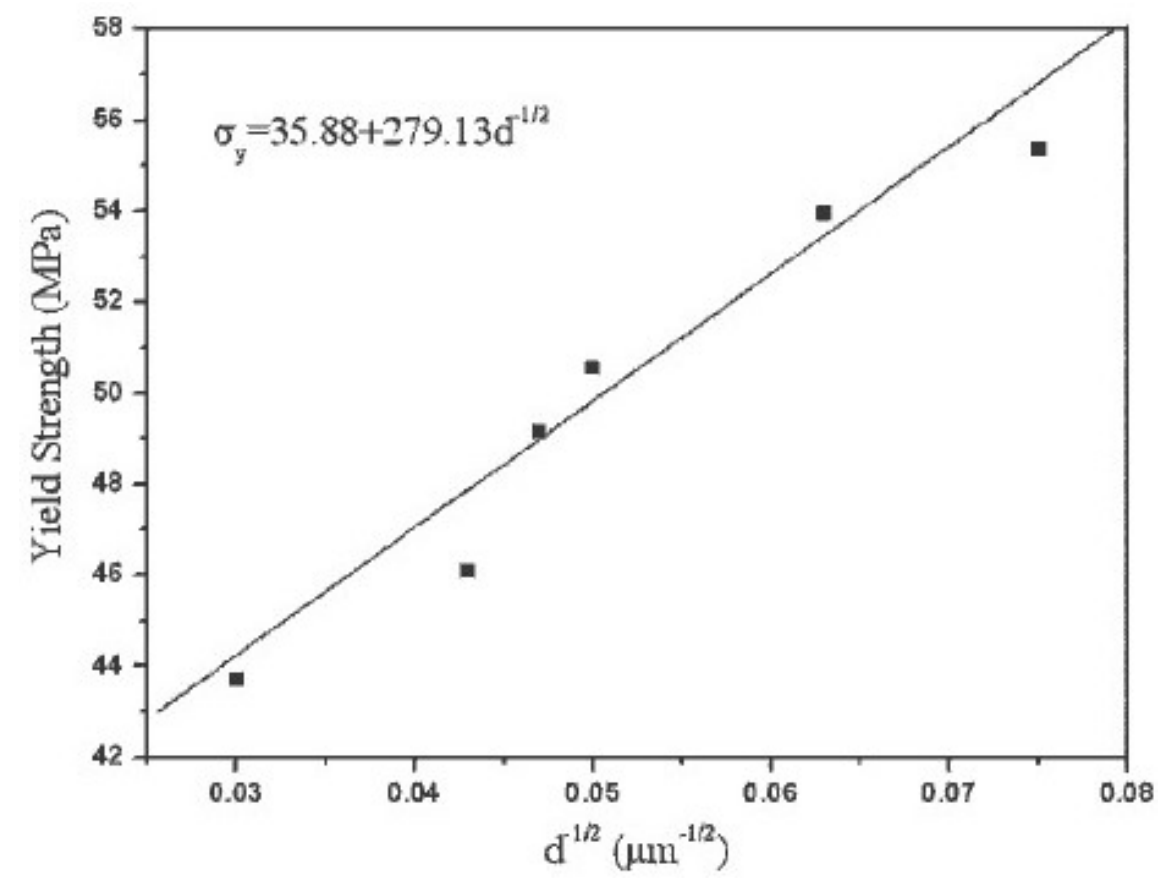

Fig. 2.7.13 Yield strength as a function of grain size for AZ31-Sr alloys [Zeng et. al., 2006]. 
Lee et. al. 2005 pointed out one of the major demerits of $\mathrm{Sr}$ in $\mathrm{Mg}$-Al alloys with high Al content. The study, conducted to see the effect of Sr addition in low (3 wt.\%) and high (9 wt.\%) Al-containing binary $\mathrm{Mg}$ alloys, revealed significant grain refinement effect of $\mathrm{Sr}$ in low $\mathrm{Al}$ content alloy but the addition of $\mathrm{Sr}$ to high $\mathrm{Al}$ content alloy produced no significant grain refinement. It was suspected that $\mathrm{Sr}$ was poisoned at high concentration of Al. As the concentration of $\mathrm{Al}$ increased, the formation of $\mathrm{Al}_{4} \mathrm{Sr}$ poisoned the grain refining effect of $\mathrm{Sr}$.

\subsection{Boron (B) Addition}

Suresh et. al., 2009 studied the effect of B addition in the form of an Al-4B at $740^{\circ} \mathrm{C}$ on the grain size and mechanical properties of AZ91E alloy. The unrefined alloy had a grain size of $100 \mu \mathrm{m}$ and with an addition of 0.008 wt.\%, 0.02 wt.\% and 0.032 wt.\% B, the grain size of the alloy reduced to $70 \mu \mathrm{m}, 45 \mu \mathrm{m}$ and $30 \mu \mathrm{m}$, respectively. Further increased additions of B produced no significant changes in grain size. Along with the reduction in grain size, improved mechanical properties of the AZ91E alloy were also observed with the addition of B. Table 2.7.1 presents the mechanical properties of the as-cast AZ91 alloy with and without B addition.

Table 2.7.1 Mechanical Properties of As-cast AZ91 Alloy with B Addition

[Suresh et. al., 2009]

\begin{tabular}{|c|c|c|c|c|}
\hline Alloy & BHN & $\mathbf{0 . 2 \%}$ YS (MPa) & UTS (MPa) & Elong. (\%) \\
\hline AZ91 & 61 & 95 & 180 & 3.3 \\
\hline AZ91+0.008 wt.\%B & 67 & 102 & 197 & 3.9 \\
\hline AZ91+0.02 wt.\%B & 72 & 107 & 211 & 4.4 \\
\hline AZ91+0.032 wt.\%B & 77 & 110 & 226 & 4.8 \\
\hline AZ91+0.04 wt.\%B & 79 & 113 & 229 & 4.9 \\
\hline
\end{tabular}

Combined SEM and EDS analyses revealed $\mathrm{AlB}_{2}$ particles at the centre portions of grains as shown in Fig. 2.7.14 [Suresh et. al., 2009]. These $\mathrm{AlB}_{2}$ particles are thought to be attributed to the grain refinement of the alloy acting as heterogeneous nucleation site for Mg grains. This assumption of grain refinement mechanism was further supported by the fact that both $\mathrm{AlB}_{2}$ particles and $\alpha-\mathrm{Mg}$ have similarity in crystallographic structure. Both of them have hexagonal crystal structure and their lattice parameters are also very close to each other $(\mathrm{Mg}: \mathrm{a}=0.3202 \mathrm{~nm}$, $\mathrm{c}=0.521 \mathrm{~nm}$ and $\mathrm{AlB}_{2}: \mathrm{a}=0.30054 \mathrm{~nm}, \mathrm{c}=0.32528 \mathrm{~nm}$ [Suresh et. al., 2009]). Despite reported significant success in reducing the grain size and increasing the mechanical properties of AZ91E 
with $\mathrm{B}$ addition, the fading behaviour of $\mathrm{B}$, which is a very important parameter in the industry, has not been studied.

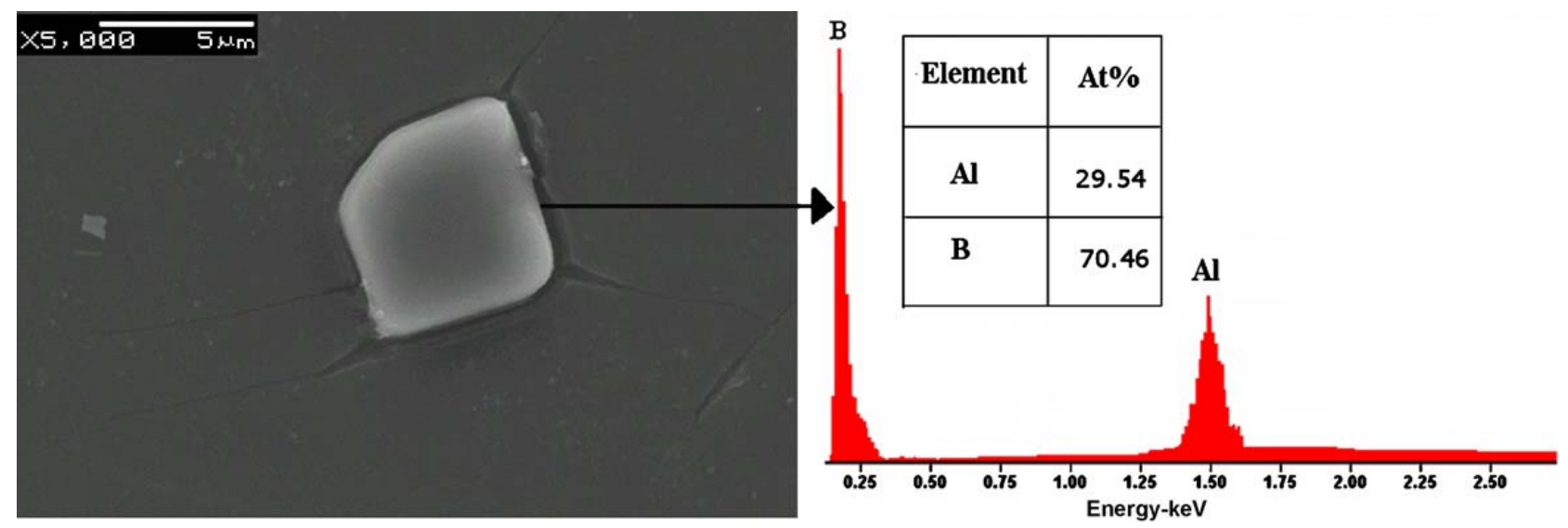

Fig. 2.7.14 SEM micrograph and EDS spectrum of 0.032 wt.\% B added to AZ91 alloy [Suresh et. al., 2009].

\subsection{Al-Ti-B Addition}

Al-Ti-B master alloys are known to be the most effective type of grain refiner for Al alloys and it is also commercially available commonly in the form of Al-5Ti-1B (TiBor). Keeping this in mind, many researchers have tried this type of refiner for Mg-Al alloys. Xu-liang et. al., 2010 studied the efficiency of Al-5Ti-1B master alloy in AZ61 alloy. The master alloy was added to the melt at $730^{\circ} \mathrm{C}$ and held for different times before pouring. The average grain size of the unrefined alloy was $400 \mu \mathrm{m}$ which was reduced to $50 \mu \mathrm{m}$ with an optimum addition level of 0.5 wt.\% Al-5Ti-1B and for 30 minutes holding time. However, the grain size showed an increasing trend beyond $0.5 \mathrm{wt} \% \%$ addition level and for holding times longer than 30 minutes. Along with the grain refinement effect, the addition of Al-5Ti-1B resulted in an increase in the mechanical properties of the AZ61 alloy. The average microhardness of the AZ61 alloy refined with the addition of 1 wt.\% Al-5Ti-1B was 8\% higher compared to the non-refined AZ61 alloy. A similar grain refinement effect of Al-5Ti-1B master alloy was observed for AZ91D alloy [Chen et. al., 2012]. In this case, the grain size of the unrefined AZ91D alloy was reduced from $422 \mu \mathrm{m}$ (base alloy) to $79 \mu \mathrm{m}$ with addition of $0.3 \mathrm{wt} . \% \mathrm{Al}-5 \mathrm{Ti}-1 \mathrm{~B}$ master alloy at $750^{\circ} \mathrm{C}$ and holding the melt for 30 minutes. The grain size of the alloy tended to increase with increasing 
addition levels exceeding $0.3 \mathrm{wt} . \%$. An improvement in the mechanical properties of AZ91D alloys was also observed with addition of Al-5Ti-1B. Elsayed, 2010 added Al-5Ti-1B to AZ91E alloy and observed the similar grain refinement behaviour.

Similar to an Al-Ti-B master alloy, Liu et. al., 2009 used a Mg-50 wt.\%TiB 2 master alloy as a grain refiner in AZ91D Mg alloys. The $\mathrm{Mg}-50 \% \mathrm{TiB}_{2}$ master alloy was added to the melt at $720^{\circ} \mathrm{C}$ and held for 10 minutes before pouring. The average grain size continually decreased with increasing $\mathrm{Mg}-50 \% \mathrm{TiB}_{2}$. The base AZ91D alloy had an average grain size of $240 \mu \mathrm{m}$ and reduced to $124 \mu \mathrm{m}, 64 \mu \mathrm{m}$ and $50 \mu \mathrm{m}$ with addition of 0.6 wt.\%, 1.2 wt.\% and 1.8 wt. $\% \mathrm{Mg}-50$ wt. $\% \mathrm{TiB}_{2}$, respectively. This established that $\mathrm{TiB}_{2}$ particles had significant grain refinement in AZ91D alloy.

The grain refinement mechanism of Al-Ti-B master alloys in $\mathrm{Mg}-\mathrm{Al}$ has been attributed to $\mathrm{TiB}_{2}$ being an effective nucleant for $\mathrm{Mg}$. In addition to the nucleation potency of $\mathrm{TiB}_{2}$, some researchers [Chen et. al., 2012] assumed that grain growth restriction by Ti also contributes in reducing the grain size of $\mathrm{Mg}$. The tendency of increasing grain size after exceeding certain addition level of Al-Ti-B to Mg-Al alloys was attributed to a saturation of $\mathrm{TiB}_{2}$ particles within the melt and the $\mathrm{TiB}_{2}$ agglomerating and settling resulting in a decrease in the effective substrate number under this condition [Chen et. al., 2012].

From all these studies it was established that Al-Ti-B refiners can effectively reduce the grain size of Mg-Al alloys with the main disadvantage being its poor fading behaviour. Fig. 2.7.15 shows the fading behaviour of Al-5Ti-1B in AZ91D +0.3 wt. $\%$ Al-5Ti-1B at $750^{\circ} \mathrm{C}$ [Chen et. al., 2012]. The grain size decreased with holding up to 30 minutes; beyond which, increasing holding time increased the grain size. It has been assumed that similar to excess addition of $\mathrm{Al}-\mathrm{Ti}-\mathrm{B}$ refiner, $\mathrm{TiB}_{2}$ particles agglomerate and settle down after certain time period. This results in the decrease of nucleate substrate number and thus the increase of grain size. 


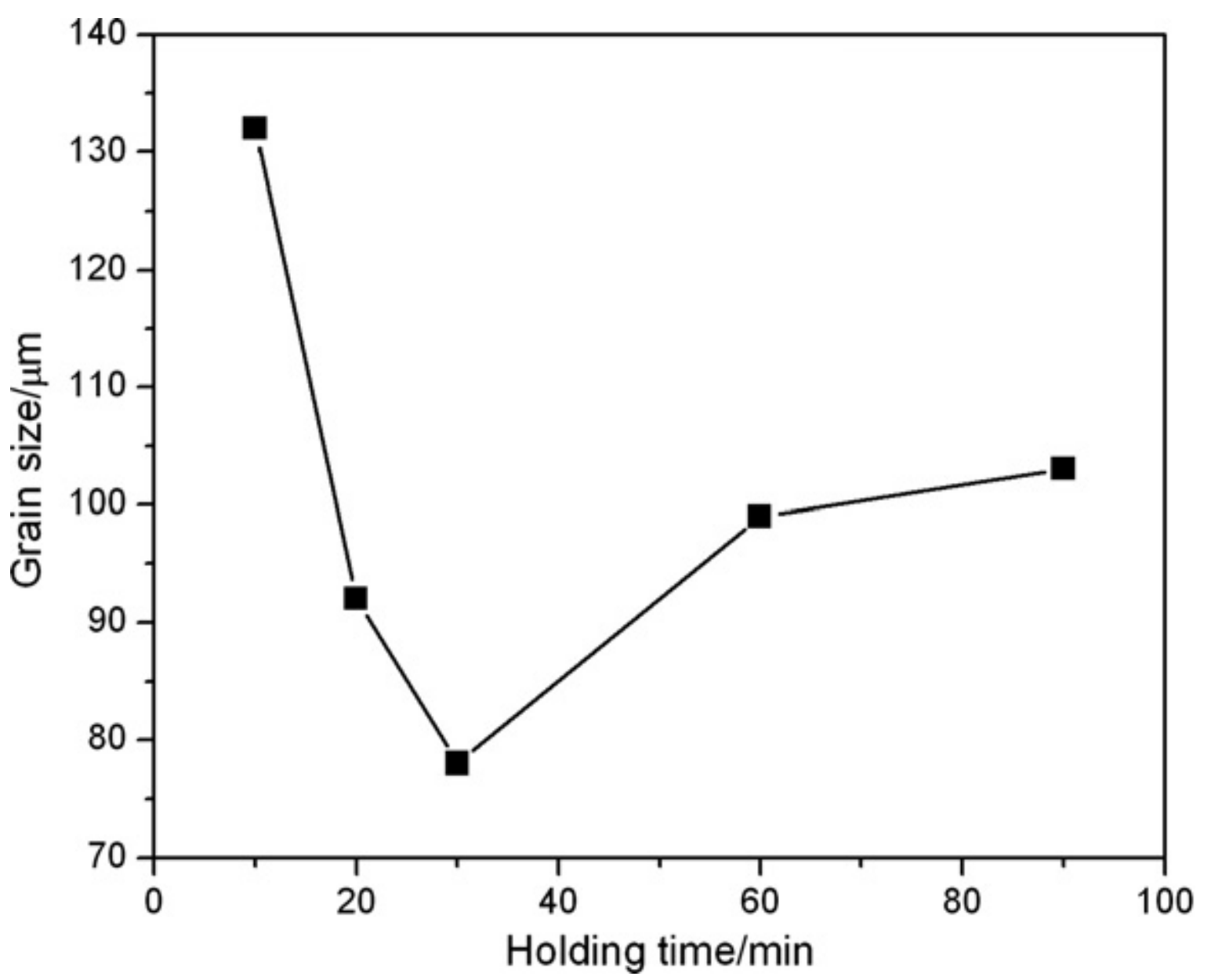

Fig. 2.7.15 Variation of grain size with holding time with Al-5Ti-1B addition to AZ91D [Chen et. al., 2012].

\subsection{Aluminum Nitride (AIN) Addition}

Aluminum nitride has a HCP crystal structure and the edge-to-edge matching model revealed that the inter-atomic spacing misfit and inter-planer spacing (d-value) mismatch between AlN and $\mathrm{Mg}$ at room temperature is $2.6 \%$ and is $2.67 \%$, respectively [ $\mathrm{Fu}$ et. al., 2009]. This crystallographic similarity has prompted researchers to investigate the effectiveness of AlN as grain refiner in Mg-Al alloys. Fu et. al., 2009 added $\mathrm{AlN}$ to $\mathrm{Mg}-3$ wt.\% $\mathrm{Al}$ and Mg-9 wt.\% $\mathrm{Al}$ in the form of a Mg-AlN master alloy in the ratio of 1:1.5 by weight. At an addition temperature of $765^{\circ} \mathrm{C}$ a 0.5 wt. $\%$ addition of $\mathrm{AlN}$ in $\mathrm{Mg}-3 \mathrm{wt} . \% \mathrm{Al}$ alloy reduced the alloy grain size from $450 \mu \mathrm{m}$ to $120 \mu \mathrm{m}$. Fig. 2.7.16 demonstrates the change in microstructure with addition of AlN in $\mathrm{Mg}-3$ wt.\% $\mathrm{Al}$ alloy [Fu et. al., 2009]. No further reduction in grain size was observed for addition levels beyond 0.5 wt.\%. At the same time, no change in grain size was observed for 
holding the melt up to $120 \mathrm{~min}$ at $765^{\circ} \mathrm{C}$ after adding $1 \mathrm{wt} \%$ AlN. The grain refinement mechanism of AlN to $\mathrm{Mg}-\mathrm{Al}$ alloys is not yet known.
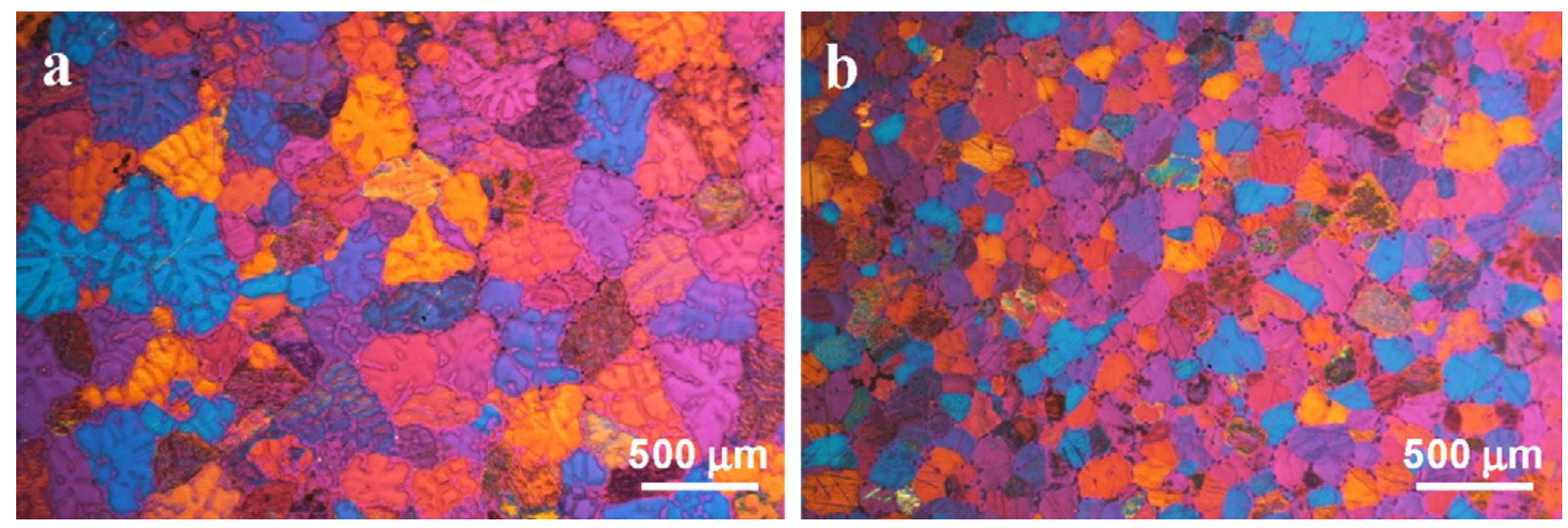

Fig. 2.7.16 Microstructure of Mg-3 wt.\% Al sample held at $765^{\circ} \mathrm{C}$ (a) without AIN (b) with AIN addition [Fu et. al., 2009].

\subsection{Calcium (Ca) Addition}

Calcium has a very high growth restriction factor of 11.94 in $\mathrm{Mg}$, only second to $\mathrm{Zr}$ (Table 2.5.1). Hence $\mathrm{Ca}$ is thought to be a potential grain refiner for $\mathrm{Mg}-\mathrm{Al}$ alloys. Calcium shows a significant grain refinement effect in pure $\mathrm{Mg}$ [Lee et. al. 2005]. However, the grain refinement efficiency of $\mathrm{Ca}$ in $\mathrm{Mg}-\mathrm{Al}$ alloys is found to be contradictory. Li et. al., 2004 investigated the influence of small additions of $\mathrm{Ca}$ on the grain size, microstructure, hot tearing susceptibility and tensile properties of AZ91D alloy. Along with some grain refinement effect with addition of 0.1 to $1 \mathrm{wt} . \% \mathrm{Ca}$ in AZ91D alloy, a substantial increase in hot tearing susceptibility coefficients (HSC) with rise in Ca content was also observed. Fig. 2.7.17 shows the effect of Ca content on the grain size and HSC for AZ91D alloy [Li et. al., 2004]. With an increase in $\mathrm{Ca}$ content there was an increase in $\mathrm{Al}_{2} \mathrm{Ca}$ phase formation in the alloy which suppressed the formation of $\beta-\mathrm{Mg}_{17} \mathrm{Al}_{12}$. The formation of $\mathrm{Al}_{2} \mathrm{Ca}$ phase is thought to be responsible for grain refinement (through grain growth restriction) as well as increase hot tearing susceptibility. The presence of $\mathrm{Al}_{2} \mathrm{Ca}$ on the grain boundaries was assumed to be responsible for worsening some of the mechanical properties like the ultimate tensile strength and the elongation of the alloy. 


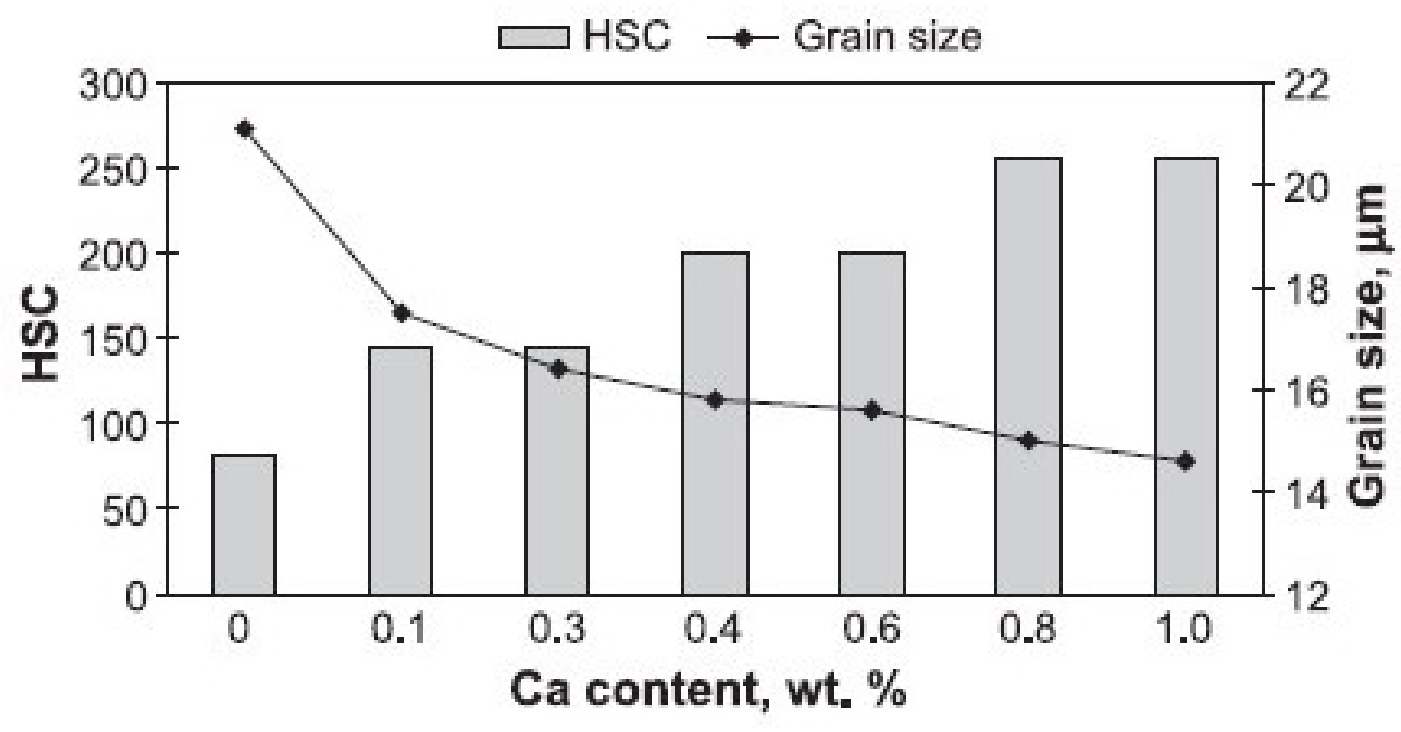

Fig. 2.7.17 Hot tearing susceptibility coefficient (HSC) and grain size of AZ91D alloy with various levels of Ca addition [Li et. al., 2004].

On the contrary, Elsayed et. al., 2009 observed that the addition Ca to AZ91D alloy resulted in grain coarsening of the alloy. With a change in the concentration of Ca from $0.5 \mathrm{wt} . \%$ to $1 \mathrm{wt} . \%$, the grain size increased from $284 \mu \mathrm{m}$ to $846 \mu \mathrm{m}$. Additional levels of $\mathrm{Ca}$ beyond $1 \mathrm{wt} . \%$ maintained the grain size between 600-800 $\mu$ m. Fig. 2.7.18 shows the grain size effect of $\mathrm{Ca}$ addition in the alloy for various addition levels [Elsayed et.al. 2009]. The authors did not provide any reasoning for grain coarsening with $\mathrm{Ca}$ addition in AZ91D alloy. Although their observation of the increase of hot tearing susceptibility of the alloy with rise of $\mathrm{Ca}$ content is similar to the observation made by Li et.al., 2004. However, these conflicting results along with its detrimental effect on mechanical properties have made Ca not a very attractive grain refiner for Mg-Al alloys. 


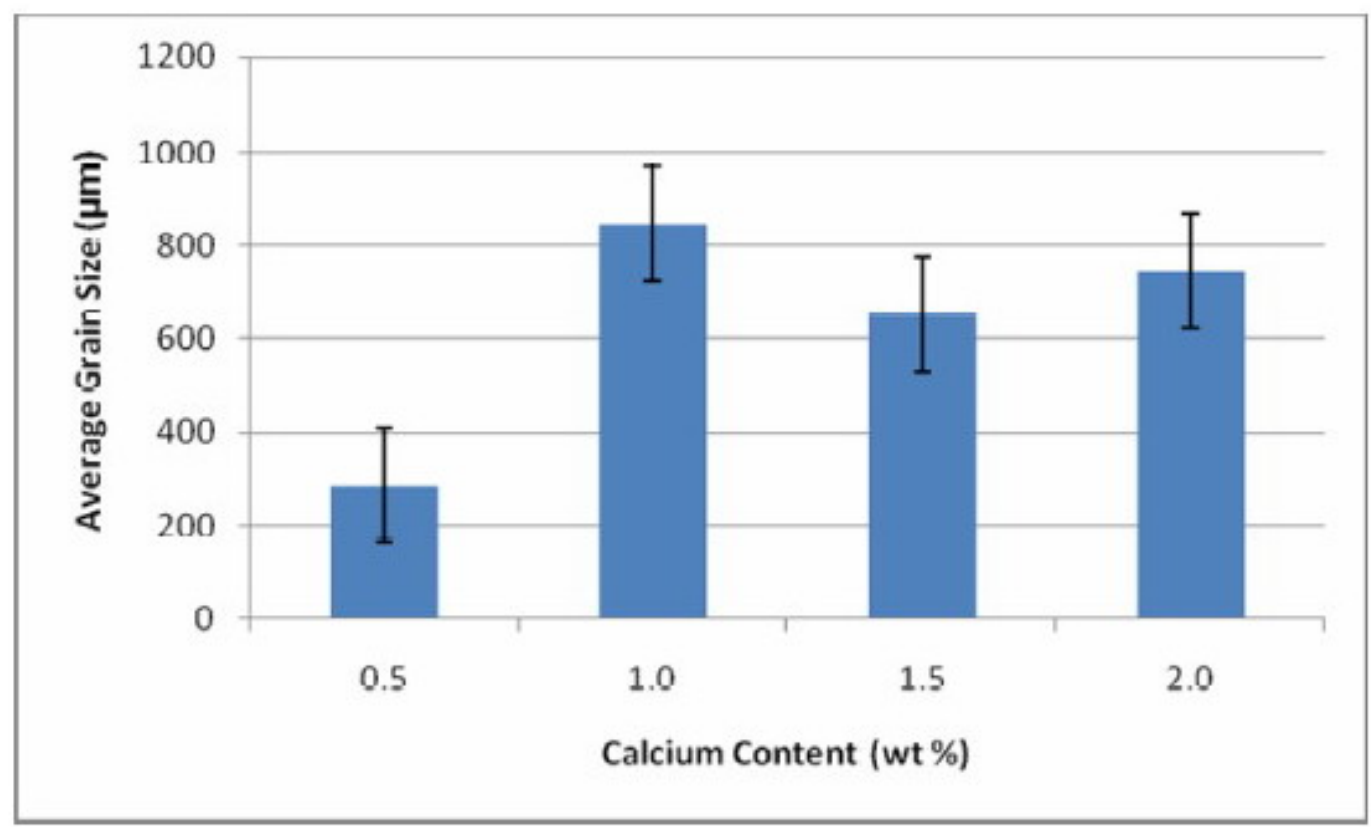

Fig. 2.7.18 Average grain size of AZ91D alloy with various levels of Ca addition [Elsayed et. al., 2009].

\subsection{Manganese (Mn) Addition}

Most commercial Mg-Al alloys contain Mn as it plays a critical role as an iron remover in the alloy as discussed in section 2.1. From the discussion in section 2.7.2 it is also known that the presence of $\mathrm{Mn}$ is essential for effective grain refinement of Mg-Al alloys through the superheating process. However, the refinement effect is suppressed by the presence of excessive $\mathrm{Mn}$. To clarify whether Mn can be used as a grain refiner for Mg-Al based alloys, a detailed study on the effect of $\mathrm{Mn}$ on grain size was conducted by Cao et. al., 2006. In this study four $\mathrm{Mg}$ alloys, binary Mg-3 wt.\% Al, Mg-6 wt.\% Al and Mg-9 wt.\% Al made of high purity Mg (99.98 wt.\%) and Al (99.999 wt.\%) and a commercial purity AZ31 alloy were employed. The alloy melt was prepared at $730^{\circ} \mathrm{C}$ under a protective cover gas $\left(1.0\right.$ vol.\% $\mathrm{SF}_{6}$ in 49 vol.\% dry air and 50 vol. $\% \mathrm{CO}_{2}$ ). The $\mathrm{Mn}$ was introduced in the alloys at different addition levels in the form of an Al-60 wt.\% Mn splatter. An initial rapid decrease in grain size was observed after adding Mn to all three high purity binary alloys and further addition of $\mathrm{Mn}$ resulted in little further reduction in grain size. A significant drop in grain size was observed with high purity $\mathrm{Mg}-3$ wt.\% $\mathrm{Al}$ with a small addition (around 0.1 wt.\%) of Mn. Obvious grain refinement was also achieved with commercial AZ31 alloy with addition of Al-60 wt.\% Mn 
splatter. The grain size dropped from 650 to $270 \mu \mathrm{m}$ after addition of $0.2 \mathrm{wt} . \% \mathrm{Mn}$. The results of the study are shown in Fig. 2.7.19 [Cao et.al. 2006]. It was proposed that the hexagonal close-packed $\varepsilon$-AlMn phase present in the Al-60 wt.\% Mn splatter acted as a nucleant for $\mathrm{Mg}$ grains. However, $\varepsilon$-AlMn intermetallics are stable only at temperatures above $840^{\circ} \mathrm{C}$, thus an obvious fading effect was observed for holding the melt for long time ( 2 hour) at the melt temperature of $730^{\circ} \mathrm{C}$.

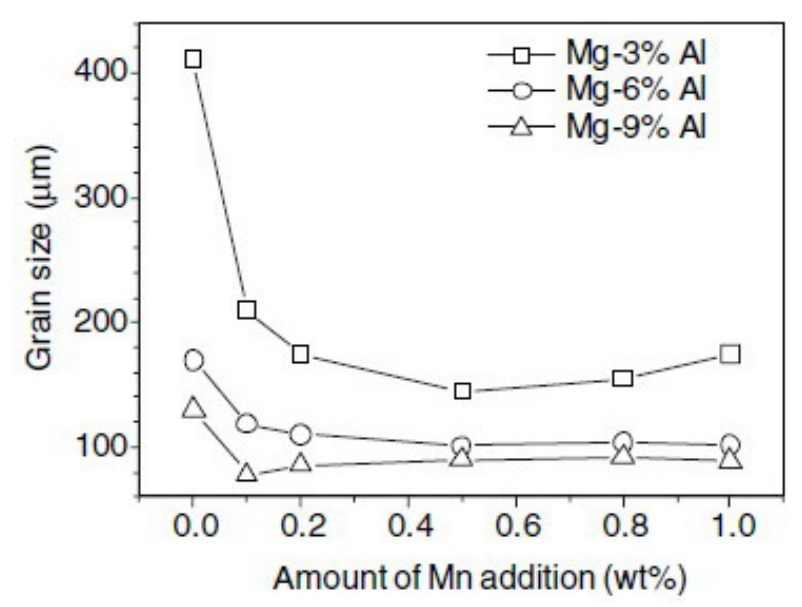

(a)

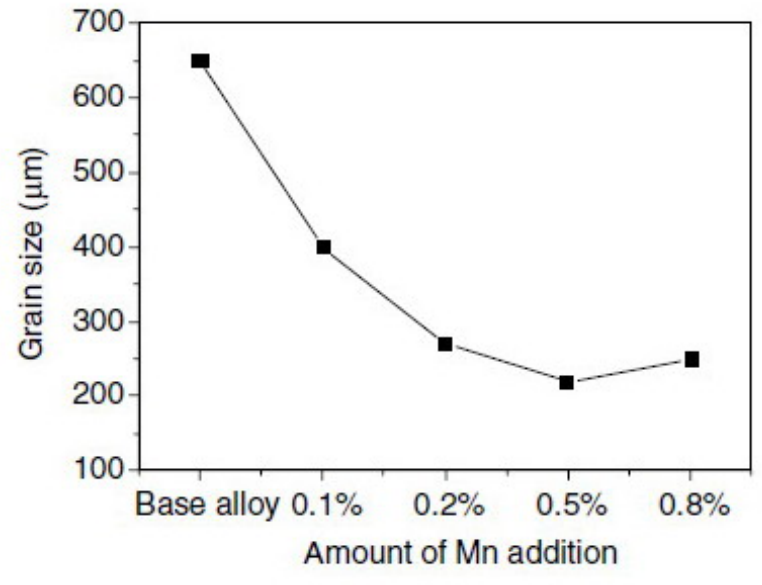

(b)

Fig. 2.7.19 Effect of Mn on average grain size of (a) high purity binary Mg-Al alloys and (b) AZ31 commercial alloy [Cao et. al., 2006].

In a separate study [Liu et. al., 2010], the role of Mn on the grain refining efficiency of AZ91D alloy after it was refined by $\mathrm{Al}_{4} \mathrm{C}_{3}$ was investigated. In this study a Mg-50 wt. $\% \mathrm{Al}_{4} \mathrm{C}_{3}$ master alloy and commercial purity Mn additive ZS-Mn75 (produced by Sichuan Lande Industry Co. Ltd.) were added to commercial purity AZ91D alloy at $750^{\circ} \mathrm{C}$. The addition of $0.6 \mathrm{wt} . \% \mathrm{Al}_{4} \mathrm{C}_{3}$ to commercial AZ91D alloys reduced the grain size of the alloy from $360 \mu \mathrm{m}$ (for untreated alloy) to $210 \mu \mathrm{m}$. However, the combined addition of $0.6 \mathrm{wt} . \% \mathrm{Al}_{4} \mathrm{C}_{3}$ and $0.27 \mathrm{wt} . \% \mathrm{Mn}$, 0.6 wt. $\% \mathrm{Al}_{4} \mathrm{C}_{3}$ and 0.47 wt. $\% \mathrm{Mn}$ and 0.6 wt. $\% \mathrm{Al}_{4} \mathrm{C}_{3}$ and 0.67 wt. $\%$ Mn further reduced the grain sizes of the alloy to $130 \mu \mathrm{m}, 132 \mu \mathrm{m}$ and $138 \mu \mathrm{m}$ respectively. Formation of Al-C-O-Mn-Fe-rich compounds with an Al-C-O-rich coating film were observed in grain centres. The particles formed through a reaction between $\mathrm{Al}_{4} \mathrm{C}_{3}$ and $\mathrm{Al}-\mathrm{Mn}-\mathrm{Fe}$ compounds were 
believed to be the potential nucleating substrates for primary Mg of the AZ91D alloy treated by the combination of $\mathrm{Al}_{4} \mathrm{C}_{3}$ and $\mathrm{Mn}$.

Elsayed et. al., 2009 studied the effect of Mn addition on the hot tearing susceptibility of AZ91D alloy. An increase in the hot tearing severity of the alloy was observed for the alloy when $\mathrm{Mn}$ content was above $0.5 \mathrm{wt} . \%$ in the alloy.

\subsection{Addition of Rare Earth Elements}

In recent years, grain refinement effect of rare earth elements (such as $\mathrm{Ce}, \mathrm{Y}$ ) on $\mathrm{Mg}-\mathrm{Al}$ alloys has been studied. Liu et. al., 2009 examined the grain refinement effect of Ce on AZ91 alloy. In the same study, the effect of Ce addition combined with either $\mathrm{Ca}$ or $\mathrm{Sr}$ was also investigated. Master alloys such as Al-10 wt.\% Ce, Al-30 wt.\% Ca and Al-10 wt.\% Sr were added to AZ91 $\mathrm{Mg}$ alloy (Mg-9 wt.\% Al-0.8 wt.\% $\mathrm{Zn}$ ) at $700{ }^{\circ} \mathrm{C}$. It was observed that the addition of $0.8 \mathrm{wt} . \%$ Ce to AZ91 alloy resulted in the reduction of the average grain size of the alloy from $107 \mu \mathrm{m}$ (base alloy) to $36 \mu \mathrm{m}$. Further reductions in average grain size were observed with AZ91-0.8 wt.\% Ce-0.2 wt.\% Ca and AZ91-0.8 wt.\% Ce-0.2 wt.\% Sr alloys. The dendritic structure of AZ91-0.8 wt.\% Ce became much finer and more uniform with further addition of either $\mathrm{Ca}$ or Sr. It was assumed that the grain refinement was mainly due to the impeding effect on grain growth of these elements on the primary $\alpha-\mathrm{Mg}$.

The grain refinement effect of $\mathrm{Y}$ on $\mathrm{Mg}$ alloys was studied by adding $\mathrm{Y}$ in the form of Mg-25.67 wt.\% Y master alloy in Mg-5 wt.\% Li-3 wt.\% Al-2 wt.\% Zn alloy [Cui et. al., 2011]. The addition of $\mathrm{Y}$ resulted in the formation of an $\mathrm{Al}_{2} \mathrm{Y}$ phase which resulted in grain refinement through hindering grain growth. The smallest grain size of the alloy was produced with the addition of $0.8 \mathrm{wt} . \% \mathrm{Y}$ to the alloy. At room temperature, the tensile properties of the alloy also improved with $\mathrm{Y}$ addition; tensile strength and ductility of the alloy reached peak value when Y addition were 0.8 wt.\% and 1.2 wt.\% respectively. Similar results of reduction in grain size and improvement in tensile properties were also reported when Y was added to AZ91D alloy in the form of Y-rich interalloy [Zhao et. al., 2009].

The addition of rare earth elements produce obvious grain refinement effect in $\mathrm{Mg}$-Al alloys but the high cost of these elements deters their use on a large scale. 


\subsection{ZnO-A Potential Grain Refiner}

In spite of success with previous refiners and refining processes discussed earlier in this chapter, there is no universally accepted refiner for $\mathrm{Mg}$-Al alloys that is environmentally friendly, reliable and easy to apply [StJohn et. al., 2005]. As such, there is a need to develop effective and environmentally friendly grain refiners for $\mathrm{Mg}-\mathrm{Al}$ alloys.

Fu et. al., 2008 examined $\mathrm{ZnO}$ as a potential grain refiner for pure $\mathrm{Mg}$ and $\mathrm{Mg}-3$ wt.\% Al. Using the edge-to-edge matching model (section 2.3.2), $\mathrm{ZnO}$ was found to have similar crystallographic parameters to pure magnesium. Various levels of $\mathrm{ZnO}$ powder were added to pure $\mathrm{Mg}$ (99.94 wt.\%) and $\mathrm{Mg}-3 \mathrm{wt} . \% \mathrm{Al}$ alloy at $720 \pm 5^{\circ} \mathrm{C}$ melt temperature. Significant grain size reductions from $1100 \mu \mathrm{m}$ to $410 \mu \mathrm{m}$ for pure $\mathrm{Mg}$ were observed with addition of 3 wt. $\% \mathrm{ZnO}$ to pure $\mathrm{Mg}$. The mean grain size of $\mathrm{Mg}-3 \mathrm{wt} . \% \mathrm{Al}$ was reduced from $420 \mu \mathrm{m}$ to $310 \mu \mathrm{m}$ with $1 \mathrm{wt} . \%$ addition of $\mathrm{ZnO}$ to the alloy. The as cast microstructure of $\mathrm{Mg}-3 \mathrm{wt} . \% \mathrm{Al}$ before and after addition of $1 \mathrm{wt. \%} \mathrm{ZnO}$ are shown in Fig. 2.7.20 [Fu et. al. 2008]. When $\mathrm{ZnO}$ was introduced to molten $\mathrm{Mg}$, part of $\mathrm{ZnO}$ was dissociated and which in turn, introduced $\mathrm{Zn}$ into the melt.

The grain refinement mechanism was attributed to the combined effects of grain growth restriction from $\mathrm{Zn}$ and heterogeneous nucleation of $\alpha-\mathrm{Mg}$ by undissociated $\mathrm{ZnO}$ particles [Fu et. al. 2008].
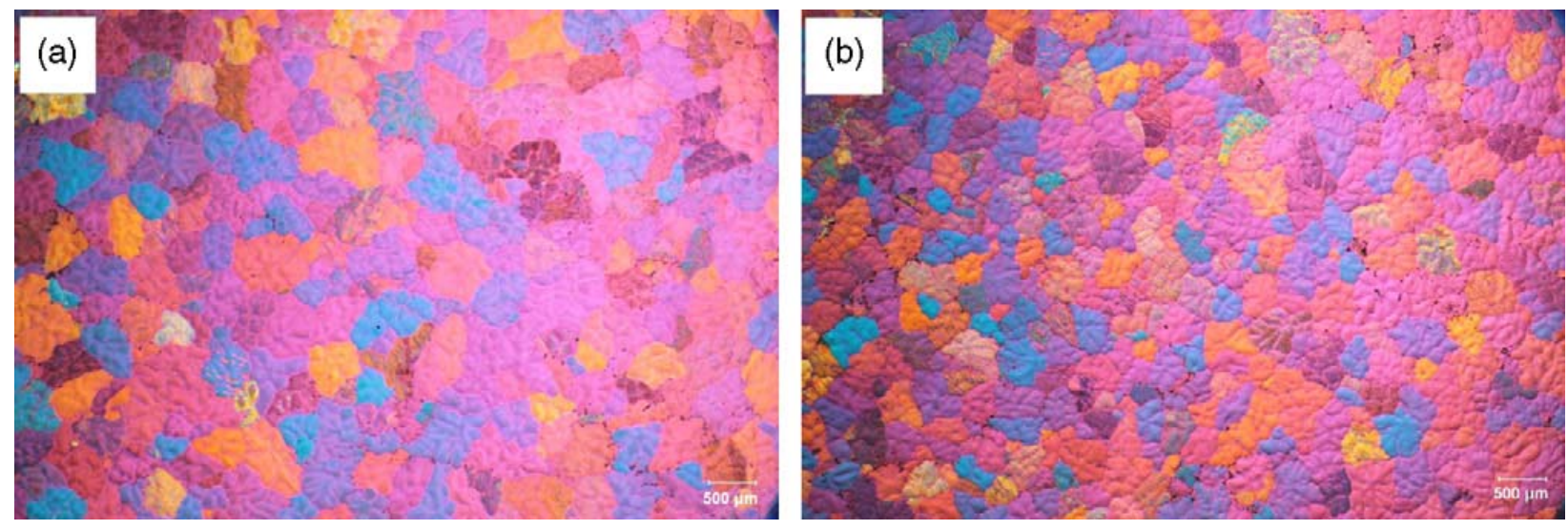

Fig. 2.7.20 Microstructure of Mg-3 wt.\% Al alloy (a) base alloy (b) after 1 wt.\% ZnO addition [Fu et. al., 2008]. 
Lee, 2011 carried out a preliminary study of ZnO in AZ91E alloy and found some encouraging results. With higher addition levels ( 2 wt.\%) of $\mathrm{ZnO}$ to AZ91E alloy, he found $75 \%$ grain size reduction compared to the base alloy. There is a need to carry out a detailed study of the effect of $\mathrm{ZnO}$ addition on grain refinement in AZ91E and Mg-9 wt.\% Al alloys.

In this research, an extensive study of the effect of $\mathrm{ZnO}$ in $\mathrm{Mg}$ alloys bearing $9 \mathrm{wt} . \% \mathrm{Al}$ (AZ91E commercial alloys and Mg-9 wt.\% Al binary alloy) has been carried out to specifically examine the effectiveness of $\mathrm{ZnO}$ as a potential grain refiner and to determine its refining mechanism. A separate study was conducted to investigate the effect of $\mathrm{ZnO}$ on permanent mold cast AZ91E alloys. The influence of $\mathrm{ZnO}$ on the grain size, microstructure, tensile properties and hardness at ambient temperature were studied to examine the grain refinement potential of $\mathrm{ZnO}$. 


\section{Chapter 3: Experimental Procedure}

This chapter begins with a flow chart describing the plan of study, followed by a discussion on the procedures carried out to perform the castings employed in this research. At the same time a detail description of materials used in this study, thermal analysis, microscopy, tensile testing, fractography, hardness and porosity testing is also presented.

\subsection{EXPERIMENTAL PLAN}

A schematic representation of the experimental plan is shown in Fig. 3.1.1.

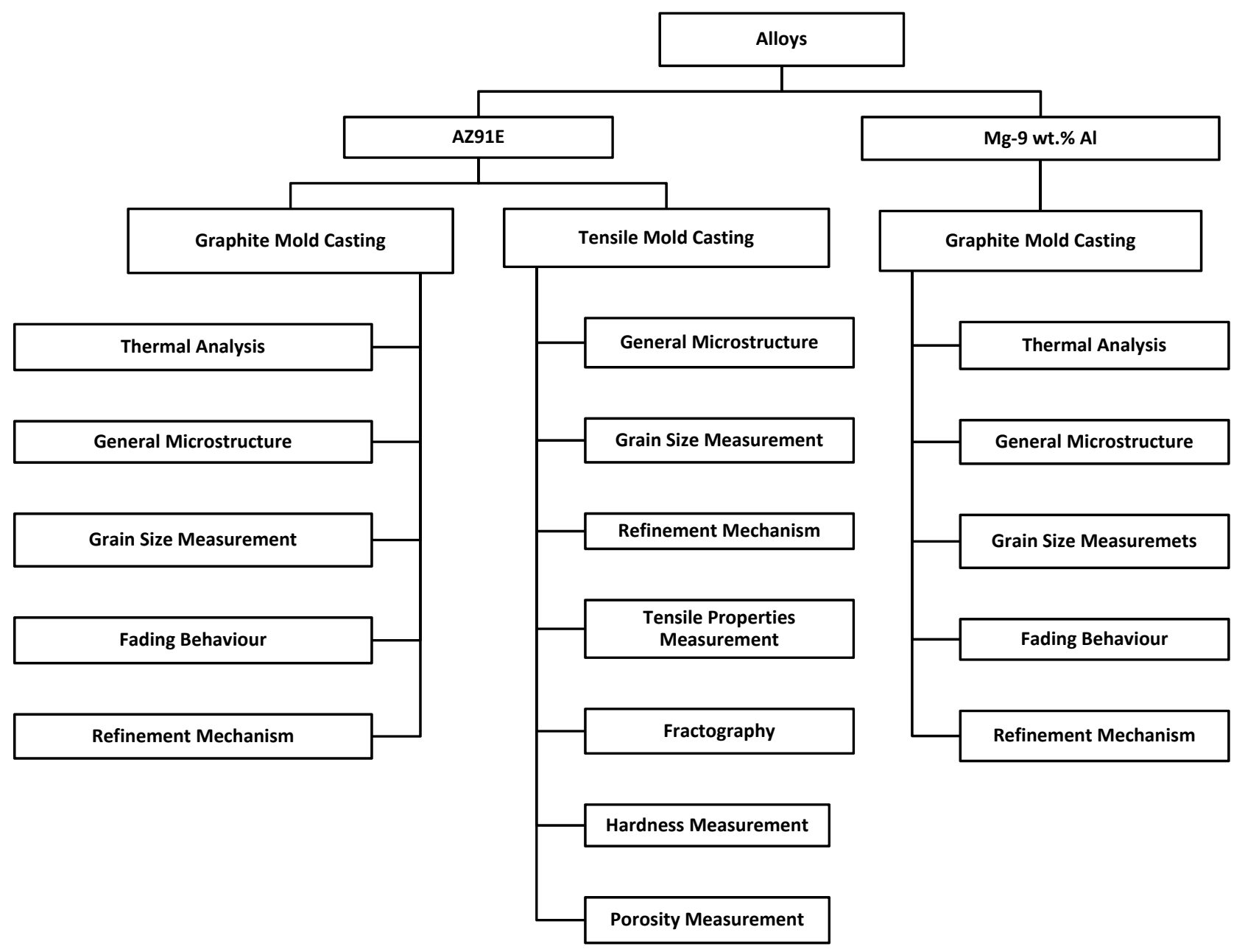

Fig. 3.1.1 Schematic representation of experimental plan. 


\subsection{MATERIAL}

\subsubsection{AZ91E ALLOY}

Virgin ingots of AZ91E Mg alloy were one of the base materials used in this study. The chemical composition analysis of the AZ91E alloy (batch analysis from the supplier) is given in Table 3.2.1.

Table 3.2.1 Composition of AZ91E Alloy (wt.\%)

\begin{tabular}{|c|c|c|c|c|c|c|c|c|}
\hline Al & Zn & Mn & Ce & Cu & Fe & Fe/Mn & Ni & Mg \\
\hline 9.3 & 0.65 & 0.24 & 0.01 & 0.005 & 0.002 & 0.008 & 0.0009 & Balance \\
\hline
\end{tabular}

\subsubsection{Mg-9 wt.\% Al BINARY ALLOY}

The Mg-9 wt.\% Al binary alloy was prepared using commercial purity $\mathrm{Mg}$ (99.8 wt.\%) and $\mathrm{Al}(99.7$ wt.\%). The predetermined proportions of these materials were put into carbon steel crucibles and melted in an electric resistance melting furnace, the detailed procedure of which is described in the following sections.

\subsubsection{ZnO GRAIN REFINER}

The $\mathrm{ZnO}$ grain refiner used in this experiment was received as powder with a purity of $99 \%$ (particle size: $<1 \mu \mathrm{m}$ ). A representative SEM image of these particles is as shown in Appendix-A2.

\subsection{GRAPHITE MOLD CASTING}

Graphite molds were used for most of the castings in this study. Graphite molds capable of producing circular bottom castings of $40 \mathrm{~mm} / 1.57$ inch diameter and $50 \mathrm{~mm} / 1.97$ inch height were made from machining $70 \mathrm{~mm} / 2.75$ inch diameter graphite shafts. Images of a graphite mold used in this experiment are shown in Fig. 3.3.1. 


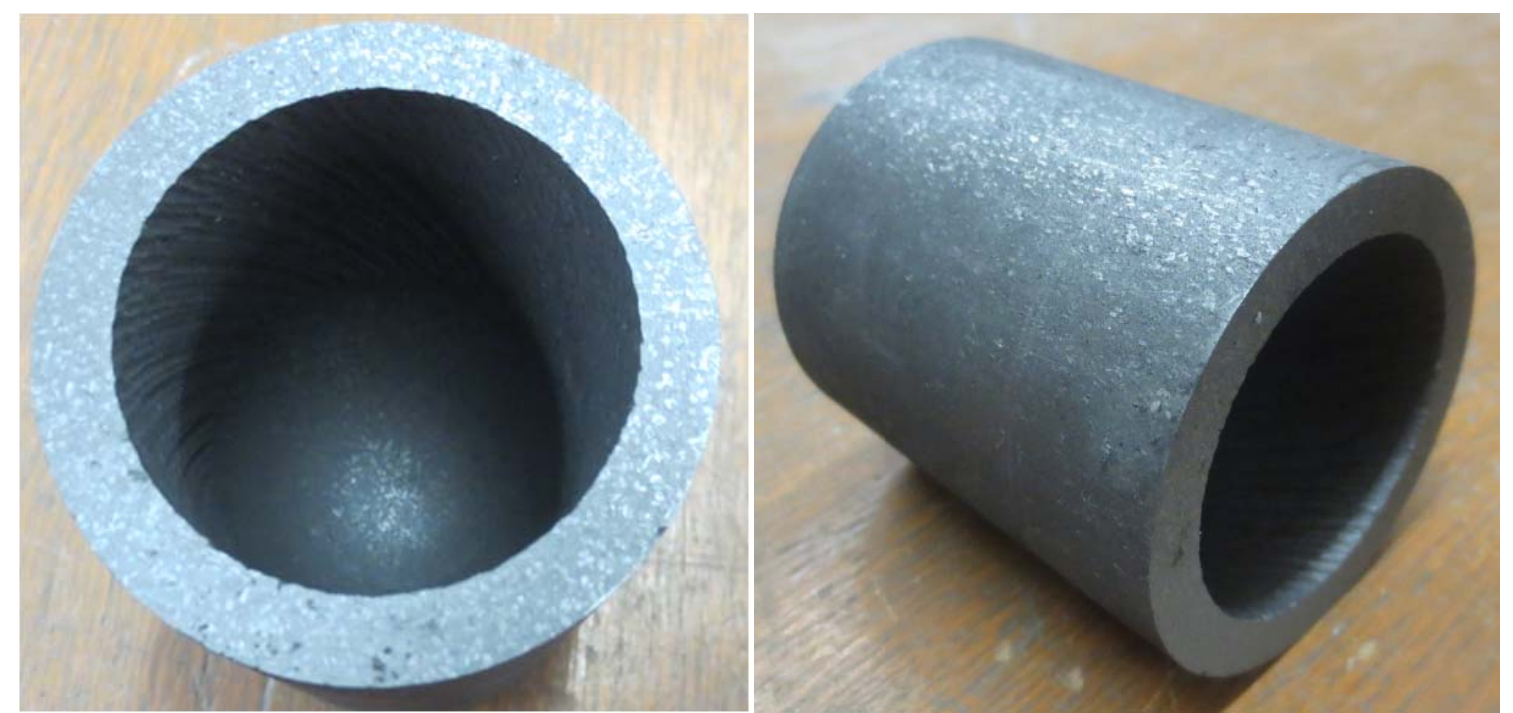

Fig. 3.3.1 Images of graphite molds from different angles.

Approximately $500 \mathrm{~g}$ of the base materials (both AZ91E and Mg-9 wt.\% Al separately) were melted at $750 \mathrm{C} / 1382 \mathrm{~F}$ set temperature in a steel crucible (diameter: $100 \mathrm{~mm} / 3.94$ inch and height: $150 \mathrm{~mm} / 5.91 \mathrm{inch}$ ) using an electrical resistance furnace with $\mathrm{CO}_{2}$ cover gas at the flow rate of 15 standard cubic feet per hour (SCFH) to protect melt from oxidation. The electric resistance furnace (PHS Kilns and Furnaces, Oakville, Ontario, Canada) used for this purpose was coupled with digital temperature controller.

$\mathrm{ZnO}$ was added as grain refiners to the alloys at different addition levels up to $3 \mathrm{wt} \% \mathrm{ZnO}$ of desired weight was wrapped into aluminum foils to prevent loose powders from scattering in the air during addition to the molten metal. $\mathrm{ZnO}$ was preheated at $250 \mathrm{C} / 482 \mathrm{~F}$ to remove moisture. Temperature of the melt was measured using a K-type thermocouple probe connected with temperature meter (Omega, model DP i8). $\mathrm{ZnO}$ was added to the melt at $750 \mathrm{C} / 1382 \mathrm{~F}$ and immediately stirred for 30 seconds with a coated (Foseco Dycote 36) propeller. After stirring, the material was held in the furnace for the duration of specific holding time (5 min or $60 \mathrm{~min}$ ). Any oxide that formed on the top of the melt was skimmed before pouring using a low carbon spoon.

Three graphite molds were preheated at $750 \mathrm{C} / 1382 \mathrm{~F}$ for 1 hour so that the molds are uniformly heated. The preheated molds were placed in the pouring platform immediately before pouring. Melt was then directly poured from the crucibles to the graphite molds at 
$720^{\circ} \mathrm{C} / 1328^{\circ} \mathrm{F}$. Immediately after pouring; the molds were covered with steel plate to avoid oxidation. Steel plate used for mold covering was $3 \mathrm{~mm} / \frac{1}{8}$ inch thick and had holes for thermocouple insertion. For rigidly holding the thermocouples, thermocouple holders were spot welded to the plates. Using set-screws and thermocouple holders, thermocouples were kept at fixed positions for all the castings during thermal data acquisitions. A schematic of the casting setup is shown in Fig. 3.3.2.

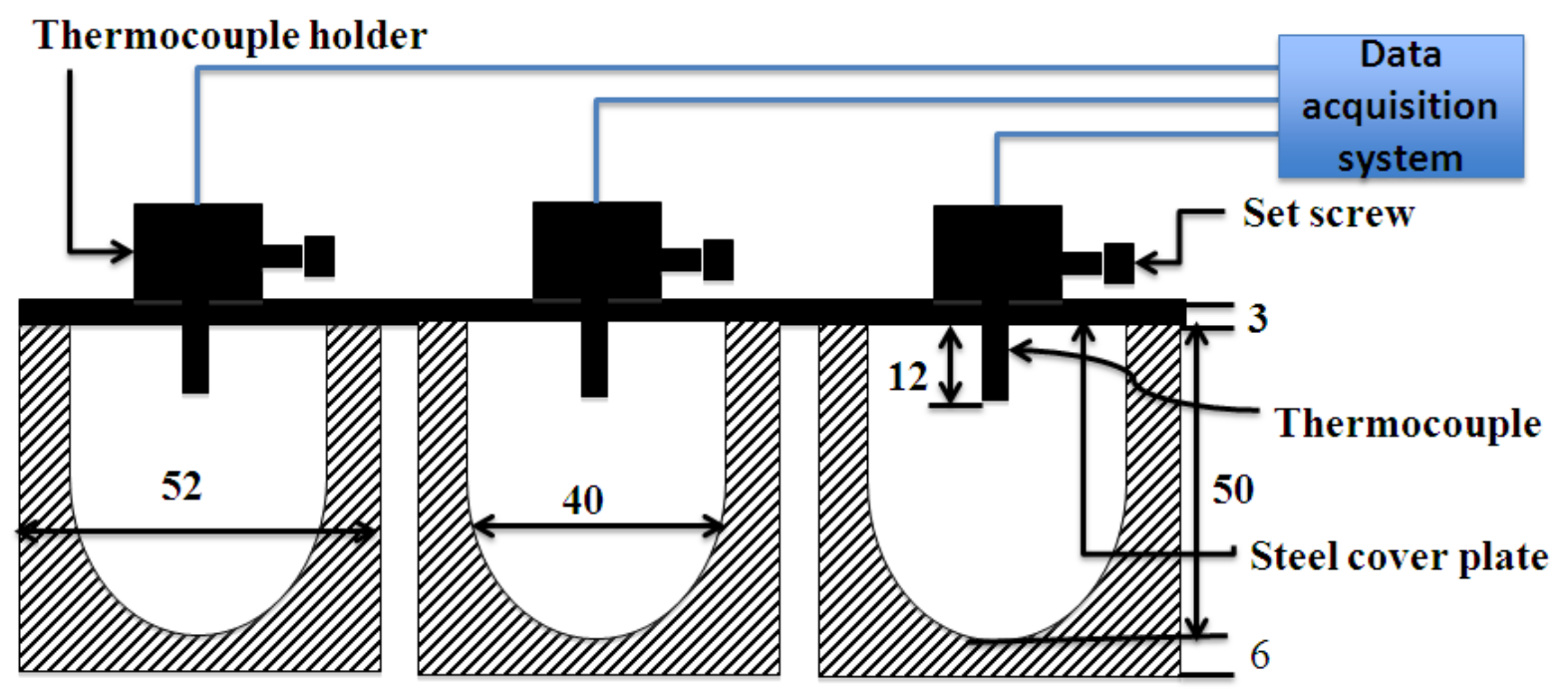

Fig. 3.2.2 Casting set-up in graphite mold (all dimensions are in $\mathrm{mm}$ ).

Thermocouples in the steel cover plate were positioned as illustrated in the figure. The thermocouples were connected to the data acquisition systems (Daytronic System 10, DataPAC) for measuring thermal data during metal solidification. The data acquisition system was started prior to pouring the molten material into the graphite mold to ensure that the entire cooling curve was obtained. Thermal data were collected from all the three graphite mold castings for data accuracy. The castings were repeated for each condition.

Graphite mold cast samples were used to evaluate the effectiveness of $\mathrm{ZnO}$ as grain refiner through grain size measurement, fading effect, and microstructure through optical microscopy and SEM, with a view to gain an understanding of the grain refinement mechanism. All the graphite mold casting parameters used in this study are summarized in Table 3.3.1. 
Pouring temperature was kept $720^{\circ} \mathrm{C} / 1328^{\circ} \mathrm{F}$ to match industry practice for $\mathrm{Mg}$ alloys. Addition levels were selected by observing trend of grain size reduction after using $\mathrm{ZnO}$. The high mold temperature was selected to maintain low cooling rate during metal solidification process. Holding time of 1 hour (60 minute) was selected to investigate the occurrence of any fading effect after considerable longer time.

\section{Table 3.3.1 Graphite Mold Casting Parameters}

\begin{tabular}{|c|c|}
\hline Parameter & Values \\
\hline Addition level (wt.\%) & AZ91E-0, 0.25, 0.5, 0.75, 1, 2, 3 \\
\cline { 2 - 2 } & Binary alloy-0, 0.5, 1, 2, 3 \\
\hline Addition temp. ( C / F) & $750 / 1382$ \\
\hline Holding time (min) & 5,60 \\
\hline Preheat temp. (C / F) & Graphite mold-750 / 1382 \\
\cline { 2 - 2 } & Grain refiner-250 / 482 \\
\hline Pouring temp. (C / F) & $720 / 1328$ \\
\hline
\end{tabular}

\subsection{TENSILE MOLD CASTING}

In this research, tensile mold castings were carried out to evaluate the tensile and other mechanical properties of AZ91E alloys with $\mathrm{ZnO}$ addition.

An ASTM B108-06 standard tensile mold made of H13 steel was used to prepare tensile specimens and is shown in Fig. 3.4.1. There were six thermocouple slots in the mold to measure the mold temperature. The mold was coated with Foseco Dycote 36 to ease casting ejection. Coating was done with compressed air spray gun at 30-40 $\mathrm{kPa}$ air pressure to ensure optimum application of coating.

Tensile mold was preheated in a gas fired furnace (Speedy-Melt, Mcenglevan, Danville, Illinois, USA). Temperature of the mold was measured by inserting K-type thermocouples in the mold slots and then connecting through thermal data acquisition system. Temperature at gauge point 
(middle thermocouple slot of the mold) was maintained at $510 \pm 5^{\circ} \mathrm{C} / 950 \pm 9^{\circ} \mathrm{F}$ during pouring the material.

The melting and casting procedure used for tensile mold casting is similar to that of the graphite mold casting (section 3.3). The quantity of the virgin AZ91E alloy melted for each experiment was approximately $1200 \mathrm{~g}$.

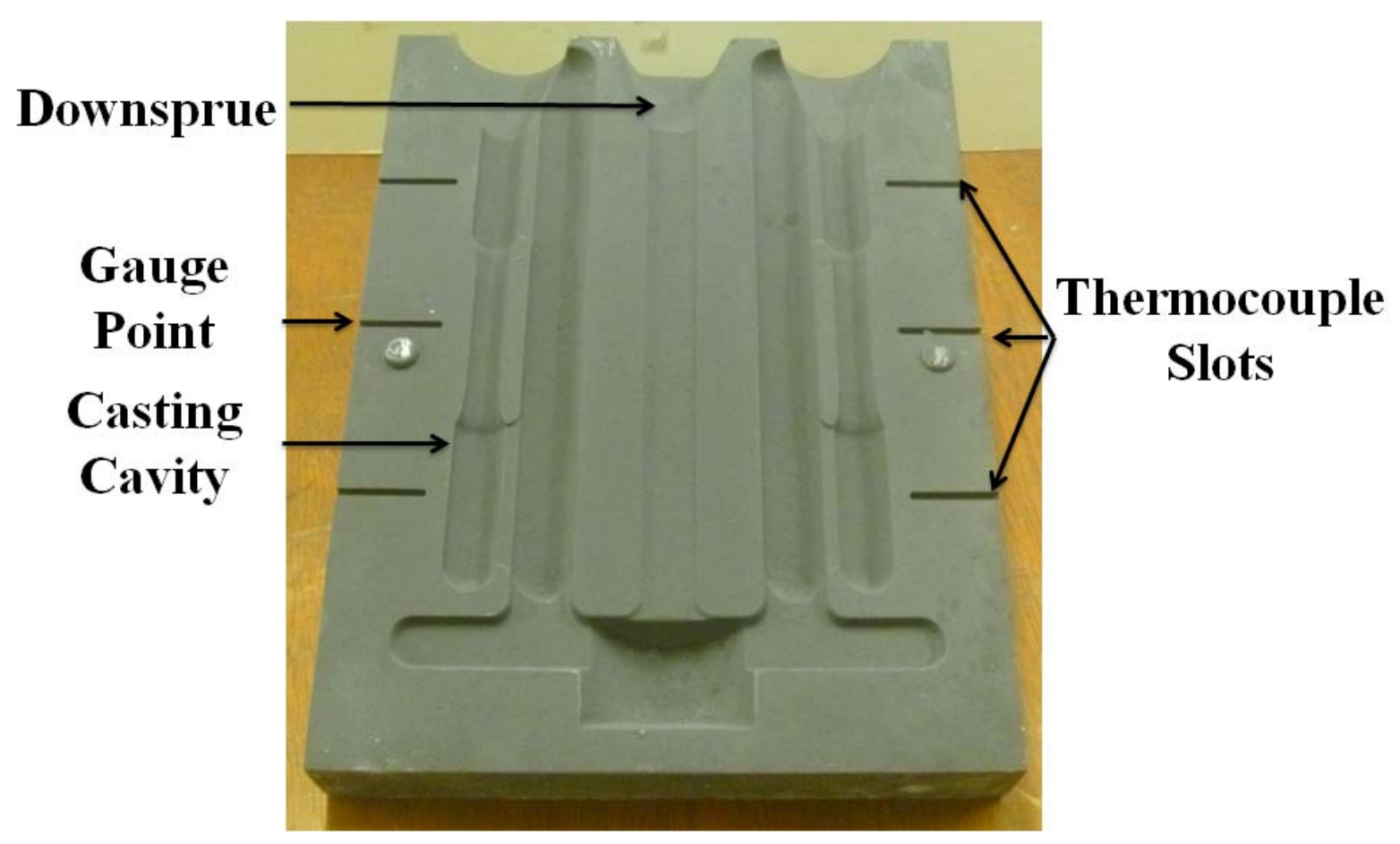

Fig. 3.4.1 ASTM B108-06 standard tensile mold.

Varying levels $(0,0.25,0.5,0.75,1$ and $3 \mathrm{wt} . \%)$ of $\mathrm{ZnO}$ were preheated to $250^{\circ} \mathrm{C} / 482^{\circ} \mathrm{F}$, added to the melt at $750^{\circ} \mathrm{C} / 1382^{\circ} \mathrm{F}$ and stirred with Foseco Dycote 36 coated steel propeller coupled with a hand drill for 30 seconds. After stirring, the melt was held in the furnace for 5 minutes. Similar to graphite mold casting (section 3.3) any oxide that formed on the top of the melt was skimmed before pouring.

The exact time for placing the preheated tensile mold in the pouring platform to maintain the temperature at gauge point at desired level $\left(510 \pm 5^{\circ} \mathrm{C} / 950 \pm 9^{\circ} \mathrm{F}\right)$ during pouring, was 
determined by trial and error. Molten material was directly poured from the crucible to the tensile mold at $720^{\circ} \mathrm{C} / 1328^{\circ} \mathrm{F}$.

The cast samples were cooled in still air and removed from the tensile mold ten minutes after the pouring. Two tensile bar specimens were prepared for each pour, and one repeat pour was made. Thus, a total of four tensile bars were available for each condition shown in Table 3.4.1.

Table 3.4.1 Tensile Mold Casting Parameters

\begin{tabular}{|c|c|}
\hline Parameter & Values \\
\hline Addition level (wt.\%) & $0,0.25,0.5,0.75,1,3$ \\
\hline Addition temp. ( $\mathrm{C} / \mathrm{F}$ ) & $750 / 1382$ \\
\hline Holding time (min) & 5 \\
\hline \multirow{2}{*}{ Preheat temp. ( $\mathrm{C} / \mathrm{F})$} & Tensile mold-510 $\pm 5 / 950 \pm 9$ \\
\hline & Grain refiner-250 / 482 \\
\hline Pouring temp. ( $\mathrm{C} / \mathrm{F}$ ) & $720 / 1328$ \\
\hline
\end{tabular}

Optimum grain refiner addition levels for tensile mold castings were determined from graphite mold casting experiments. Holding time was kept constant at 5 minute, as fading effect of $\mathrm{ZnO}$ in AZ91E was not observed in graphite mold casting for one hour (Section 4.2).

\subsection{THERMAL ANALYSIS}

Thermal analysis was carried out to record and quantify the solidification history of AZ91E and Mg-9 wt.\% Al binary alloy for graphite mold casting. Data were collected at 5 readings per second for 10 minutes. Data gathered through data acquisition system (Daytronic System 10) was transferred to a computer and analyzed using Microsoft EXCEL ${ }^{\circledR}$.

Cooling curves were generated from the temperature-time data and then analyzed to determine undercooling (UC), cooling rate (CR) and freezing range (FR) for each casting condition. The UC was measured as the decrease in temperature of the cooling curve near the beginning of solidification temperature, while CR was calculated as the rate of temperature drop from pouring 
temperature to just above liquidus temperature. The FR was measured as the difference between the liquidus and solidus temperatures determined from the cooling curves. These three parameters are shown in Fig. 3.5.1 for a typical cooling curve of base AZ91E alloy obtained from this research.

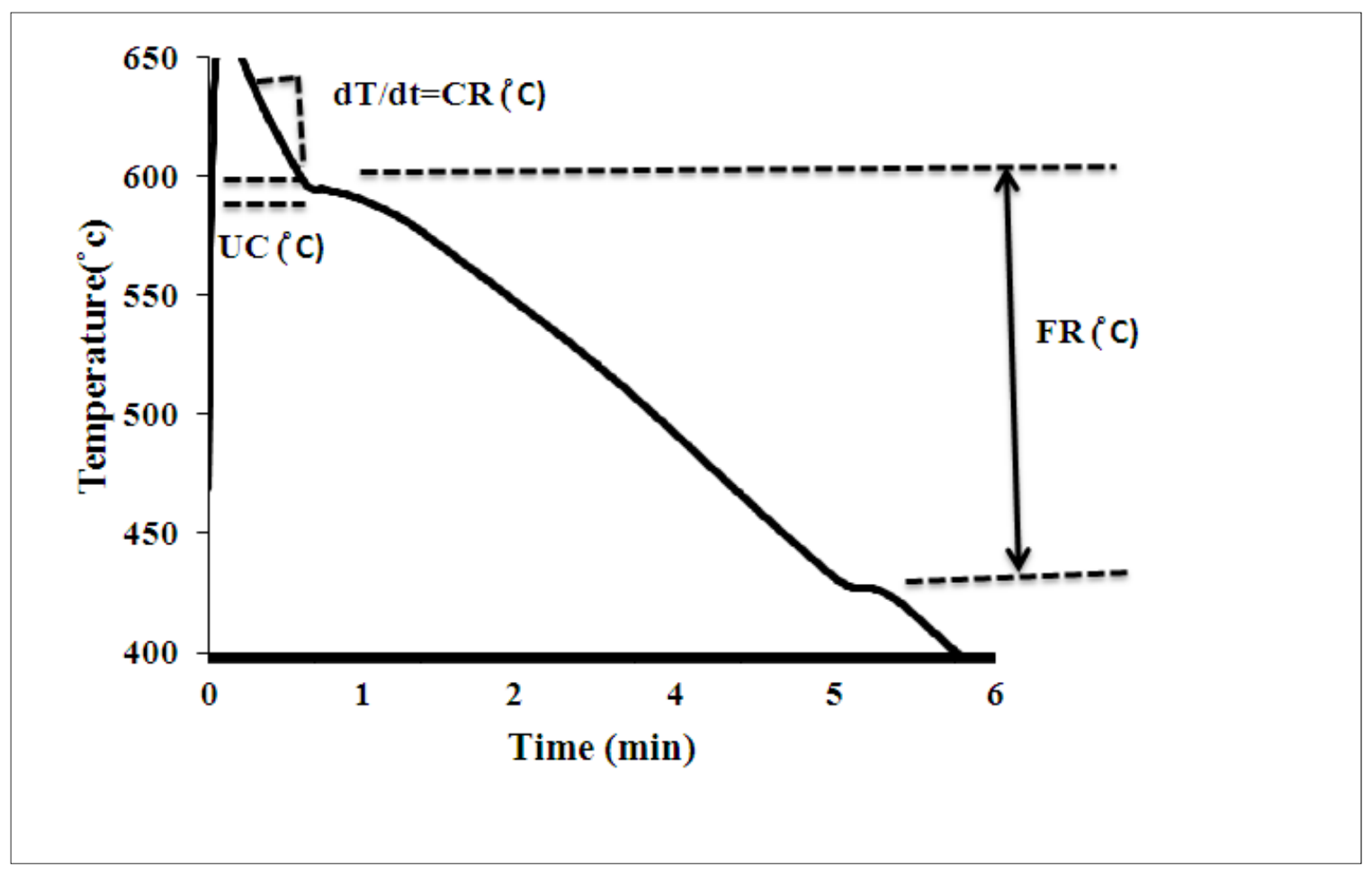

Fig. 3.5.1 Typical cooling curve of AZ91E alloy.

\subsection{MICROSTRUCTURE ANALYSIS}

For graphite mold castings (both AZ91E and Mg-9 wt.\% Al alloys), samples were extracted from castings for optical microscopy (OM) and scanning electron microscopy (SEM). A schematic showing the test surface is as shown in Fig. 3.6.1. Also, a schematic of the permanent tensile mold and sampling area (for metallography, hardness and porosity) are shown in Fig. 3.6.2.

Graphite and permanent tensile mold castings were sectioned to get test samples. All the analyses were done on the test surfaces as indicated in Fig. 3.6.1 and Fig. 3.6.2. The sectioned cast samples were subject to solution heat treatment at $420^{\circ} \mathrm{C} / 788^{\circ} \mathrm{F}$ for 24 hours and air quenched to dissolve eutectic $\mathrm{Mg}_{17} \mathrm{Al}_{12}$ located at the grain boundary and better facilitate grain size measurement. 


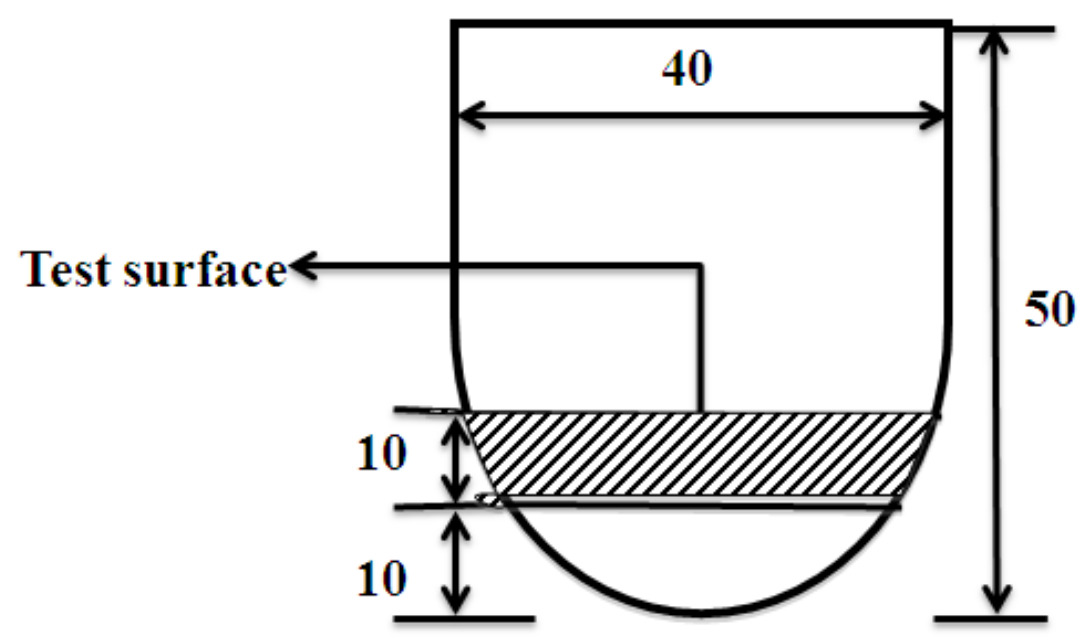

Fig. 3.6.1 Graphite mold castings indicating test surface (all dimensions are in $\mathbf{m m}$ ).

Solutionized samples were ground successively using 120,300, 600 and 1200 grit silicon carbide papers using water as lubricant in a grinding wheel of $150 \mathrm{rpm}$. Samples were held by hand and optimum pressure was applied. Samples were then polished by Lecloth in the same grinding wheel set up, successively using $5 \mu \mathrm{m} \mathrm{Al}_{2} \mathrm{O}_{3}$ for 3-4 minutes (in complimentary rotation), $3 \mu \mathrm{m}$ diamond suspension for 3 minutes (in complimentary rotation) and finally $1 \mu \mathrm{m}$ diamond suspension for 2 minutes (in contra rotation). After every polishing stage, the samples were cleaned by ethyl alcohol and dried with blast of compressed air.

Test surfaces of polished samples were analyzed using a JEOL JSM-6380LV scanning electron microscope (SEM) with backscattered electron detector (BSE) and the morphology of the alloys was observed. Energy dispersive X-ray (EDX) analysis was also performed to determine the chemical composition of the phases observed in the alloys. SEM fractography analysis was conducted on the tensile mold samples to analyze the fracture surfaces. The EDX point analysis was conducted in two areas on both matrix and $\beta$-phase and 10 point readings in each area were taken to find an average value. SEM operating conditions, i.e., voltage, magnification, working distance etc., are given in each SEM micrographs. 


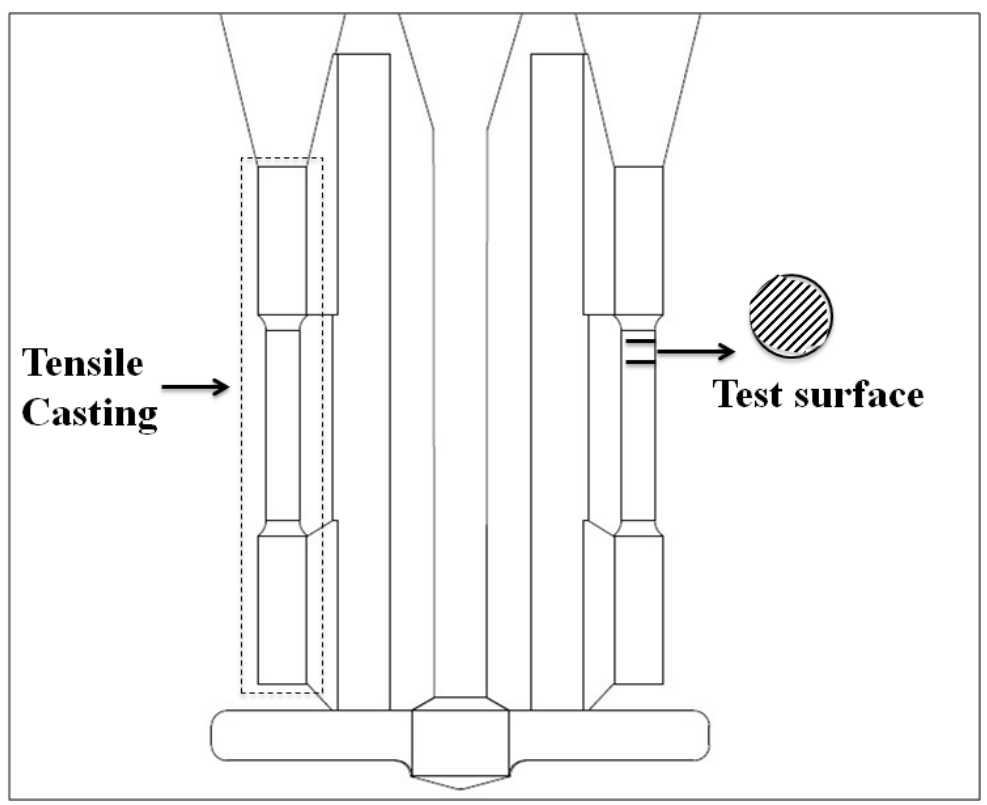

Fig. 3.6.2 Schematic showing the test surface of permanent tensile mold cast sample.

Optical microscopy $(\mathrm{OM})$ was performed on the test surface of graphite and permanent tensile mold castings by using Buehler optical lab microscope in conjunction with Buehler OMNIMET ${ }^{\circledR}$ image analysis software. OM was used to characterize the microstructure and measuring the grain size of the alloys.

For OM, polished samples were etched with an etchant solution. Chemical composition of the etchant used is provided in Table 3.6.1. The samples were gently agitated in the etchant solution for 30 seconds and then quickly rinsed with ethyl alcohol and dried with compressed air.

Table 3.6.1 Chemical Composition of Etchant Solution

\begin{tabular}{|c|c|}
\hline Chemicals & Quantity \\
\hline Distilled water & $10 \mathrm{ml}$ \\
\hline Acetic acid & $10 \mathrm{ml}$ \\
\hline Ethanol & $100 \mathrm{ml}$ \\
\hline Picric acid & $6 \mathrm{gm}$ \\
\hline
\end{tabular}


The linear intercept method was used to measure the grain sizes of the etched samples. A minimum of one hundred grain size readings were taken for grain size measurement of each sample.

\subsection{TENSILE TESTING}

Uniaxial tensile tests were conducted on the tensile bar samples at ambient temperature to determine the yield strength, ultimate tensile strength and elongation of the AZ91E alloys. A computer controlled universal material testing machine (United, Model- STM-50KN) was used at a nominal strain rate of $12 \mathrm{~mm} / \mathrm{min}$. An extensometer was attached to the gauge section to measure the tensile strain. Four samples of each alloy were tested to know the average final tensile properties $(0.2 \%$ yield stress-YS, ultimate tensile stress- UTS and elongation) of the alloys. Fracture surface morphologies and microstructures of the fracture surface were observed along the tensile loading direction using SEM. An image of a tensile bar specimen is shown in Fig. 3.7.1.

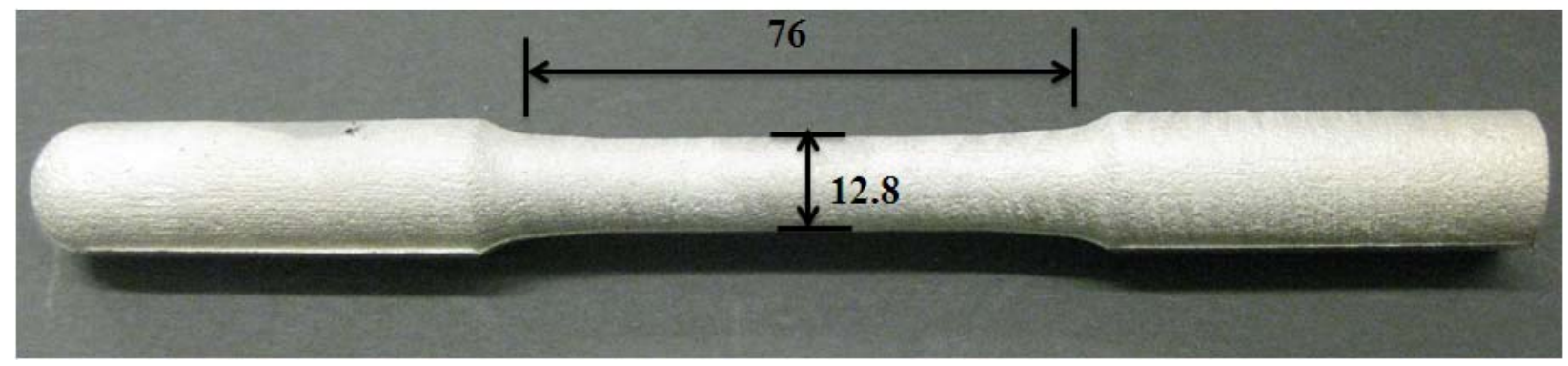

Fig. 3.7.1 Tensile bar specimen (all dimensions are in $\mathrm{mm}$ ).

\subsection{HARDNESS TESTING}

Hardness measurements of as cast non-solutionized tensile mold samples of refined and unrefined AZ91E alloys were taken on test surface as shown in Fig. 3.6.2. Rockwell Hardness E (HRE) and Vickers microhardness measurements of the alloy matrix (HV) were carried out on the test surfaces for all the alloys. For HRE values, a minimum of 25 readings were taken on test surface of each sample using a Rockwell hardness testing machine (Universal). A 1/8" steel ball indenter with $10 \mathrm{~kg}$ minor and $100 \mathrm{~kg}$ major load were used to create an indent on the surface. Vickers microhardness tester (Buehler) was used to collect HV values. HV values were obtained 
as an average of 10 indentations on each sample of the alloys with $100 \mathrm{~g}$ applied load and dwell time of 15 seconds.

\subsection{POROSITY MEASUREMENT}

The porosity of the permanent tensile mold casting was measured using the Archimedes principle on the test surface (Fig. 3.6.2). Density of an object can be determined by using this principle. To determine the density, the mass of the cast samples was measured on a scale in the air. Mass of a container with water was also measured. The sample was then submerged in the container at the mid level by suspending it with a fishing wire and the weight in this condition was recorded. The volume of the sample was then calculated by the weight difference of the samples in the air and in submerged condition. The porosity of the sample was calculated using Equation 3.9.1 with known theoretical density of the sample [Ho, 2009]:

$\%$ porosity $=\frac{100}{\rho_{s}}\left(\rho_{s}-\frac{M_{m} \rho_{w}}{M_{m+w}-M_{w}}\right)$

Equation 3.9.1.

where $\rho_{\mathrm{s}}$ is the theoretical density of the sample $\left(\mathrm{g} / \mathrm{cm}^{3}\right), M_{\mathrm{m}}$ is the mass of the sample $(\mathrm{g}), \rho_{\mathrm{w}}$ is the density of water at room temperature $(0.9982 \mathrm{~g} / \mathrm{cc})$ and $\mathrm{M}_{\mathrm{m}+\mathrm{w}}$ is the mass of water with sample. 


\section{Chapter 4: Results and Discussion}

This chapter closely follows the experimental procedures described in the previous chapter. In every section, an analysis follows the presentation of results. Graphite mold data for grain refinement, fading effects, refinement mechanism and thermal analysis are presented for the AZ91E alloy, followed by similar data for the Mg-9 wt.\% Al alloy (section 4.1-4.9). The tensile casting results are then presented (section 4.10-4.11). Finally, the tensile samples are analyzed for porosity (section 4.12).

\subsection{GRAIN REFINEMENT OF AZ91E ALLOY (GRAPHITE MOLD)}

Optical micrographs of as-cast and solutionized AZ91E alloy samples produced in graphite mold castings are shown in Fig. 4.1.1. The as-cast AZ91E, shown in Fig. 4.1.1-a consists of two distinct phases of $\alpha-\mathrm{Mg}$ and $\beta-\mathrm{Mg}_{17} \mathrm{Al}_{12}$. The grain structure is highly dendritic in nature. After solution heat treatment, the $\beta-\mathrm{Mg}_{17} \mathrm{Al}_{12}$ is dissolved and the grain boundaries are clearly visible as shown in Fig. 4.1.1-b. The average grain size of the base AZ91E alloy was $217 \mu \mathrm{m}$. With $0.5 \mathrm{wt} . \%$ and 0.75 wt. $\% \mathrm{ZnO}$ addition, the average grain sizes of the alloy were $126 \mu \mathrm{m}$ and $108 \mu \mathrm{m}$, respectively (Fig. 4.1.1-c and Fig. 4.1.1-d). The average grain sizes of the alloys with different levels of $\mathrm{ZnO}$ addition for 5 minutes holding time are summarized in Fig. 4.1.2 and Table 4.1.1. With increasing $\mathrm{ZnO}$ addition, the grain size of the alloys gradually decreased, up to

+ Most of the data presented in this chapter has been accepted or submitted for publication in peer reviewed journals.

1. Saha, S., Ravindran, C., "Grain Refinement of AZ91E and Mg-9 wt.\% Al Binary Alloys Using Zinc Oxide,” International Journal of Metalcasting, Accepted on May 13, 2014

2. Saha, S., Ravindran, C., "Effects of Zinc Oxide Addition on the Microstructure and Mechanical Properties of AZ91E Mg Alloy." International Journal of Metalcasting, Submitted on July 12, 2014 
an addition level of $0.75 \mathrm{wt} . \% \mathrm{ZnO}$. Beyond $0.75 \mathrm{wt} . \%$ addition of $\mathrm{ZnO}$ (up to $3 \mathrm{wt} . \%$ ) there was no significant change in grain size suggesting maximization of the potency of $\mathrm{ZnO}$ at $0.75 \mathrm{wt} \%$ $\mathrm{ZnO}$ in AZ91E alloy. The slight increase in grain size beyond 1 wt.\% $\mathrm{ZnO}$ is not significant if we consider the error bars. The possible reason for maximization of the potency of $\mathrm{ZnO}$ addition in $\mathrm{AZ91 \textrm {E }}$ at $0.75 \mathrm{wt} . \%$ addition is that with $\mathrm{ZnO}$ addition beyond $0.75 \mathrm{wt} . \%$ a balance is reached where increasing the number of nuclei is countered by increase in latent heat released and further reduction in grain size is not possible [Easton et. al., 2001], [Liu et. al., 2004].
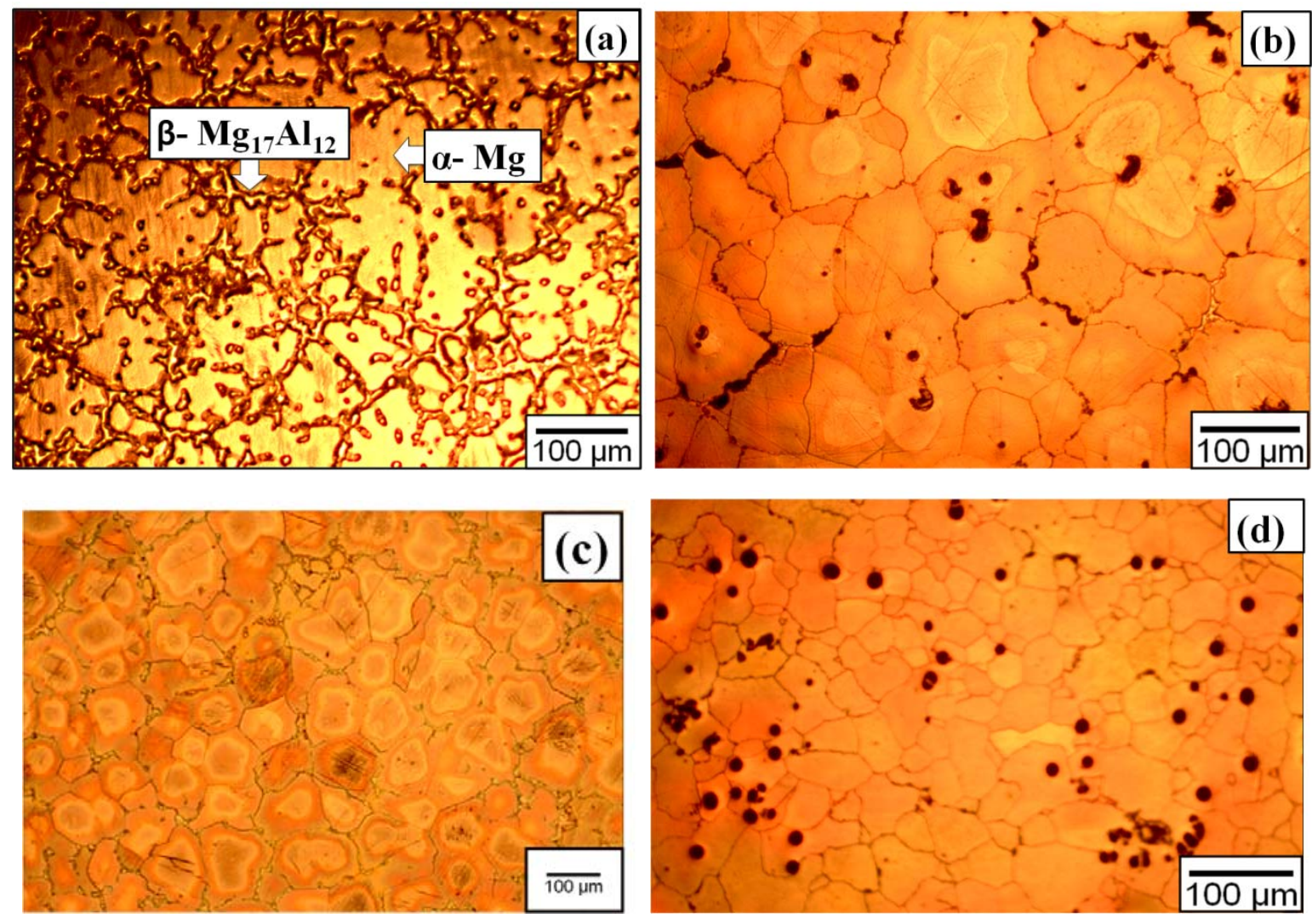

Fig. 4.1.1. Optical micrograph of (a) as cast base AZ91E alloy; after solutionized for 24 hours at $420^{\circ} \mathrm{C} / 788^{\circ} \mathrm{F}$ and etched (b) base alloy (average grain size $217 \mu \mathrm{m}$ )

(c) AZ91E+0.5 wt.\% ZnO (average grain size $126 \mu m$ ) (d) AZ91E+0.75 wt.\% ZnO (average grain size $108 \mu \mathrm{m}$ ). 


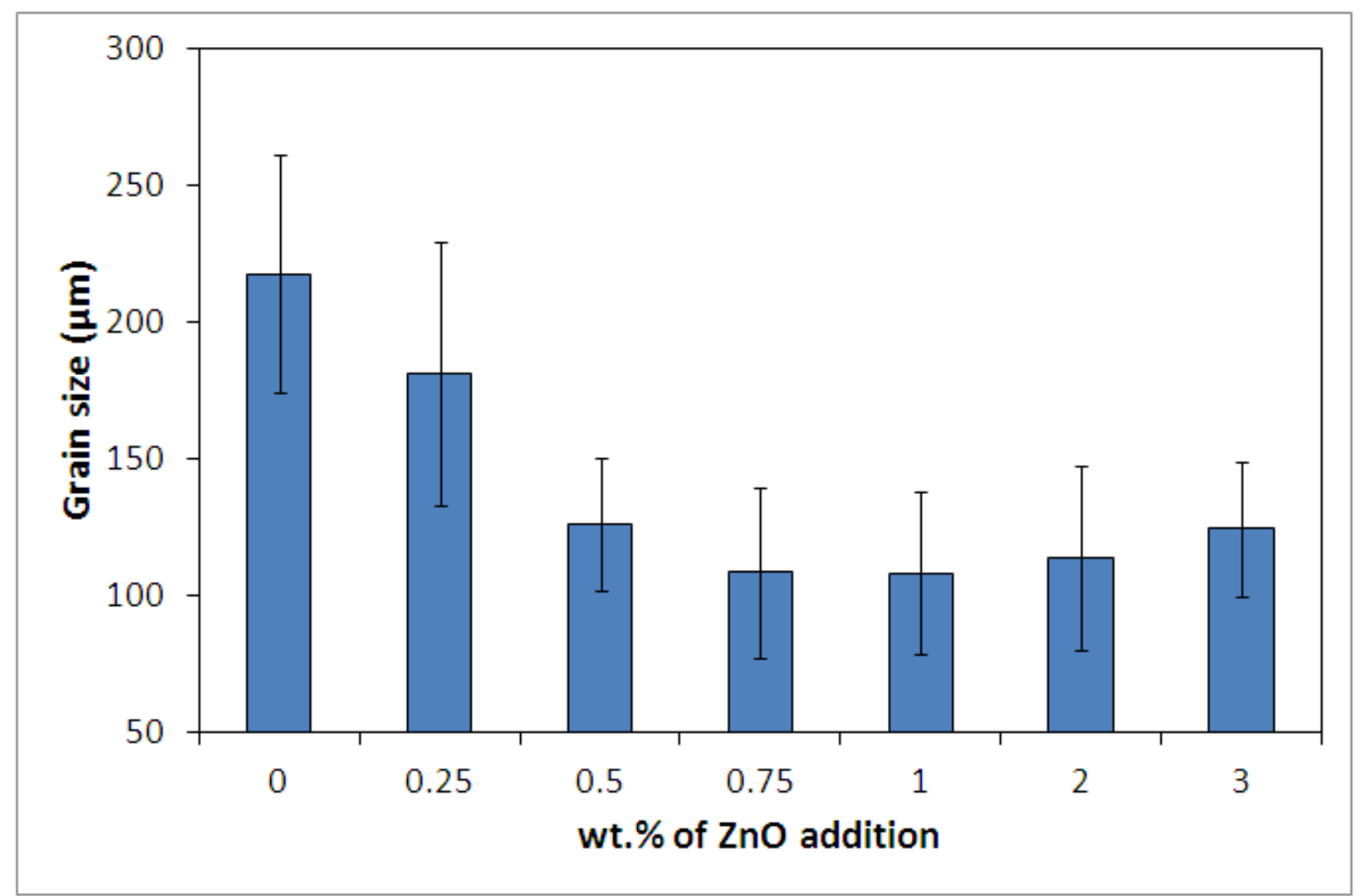

Fig. 4.1.2. Average grain size of AZ91E alloy with various ZnO addition levels.

Table 4.1.1. Grain Size of AZ91E Alloy at Different Addition Levels of ZnO (Graphite Mold)

\begin{tabular}{|c|c|c|c|}
\hline Addition Level (wt.\%) & Grain Size $(\boldsymbol{\mu m})$ & Std. Dev. (+/-) & Change (\%) \\
\hline 0 & 217 & 43.71 & - \\
\hline 0.25 & 181 & 48.20 & $16.58 \downarrow$ \\
\hline 0.5 & 126 & 24.06 & $41.93 \downarrow$ \\
\hline 0.75 & 108 & 31.32 & $50.23 \downarrow$ \\
\hline 1 & 108 & 29.40 & $50.23 \downarrow$ \\
\hline 2 & 114 & 33.72 & $47.46 \downarrow$ \\
\hline 3 & 124 & 24.53 & $42.85 \downarrow$ \\
\hline
\end{tabular}




\subsection{FADING IN AZ91E ALLOY (GRAPHITE MOLD)}

During grain refinement, holding the melt for a long time after the addition of the grain refiner before pouring, usually leads to develop coarse grain structure, instead of otherwise fine grain structure. This loss of refinement is termed as fading which is usually attributed to either dissolution or settling (or both) of nucleating particles during long holding [Chakraborty et. al., 2005]. A strong resistance to loss of grain refiner efficiency with holding of the melt at elevated temperature for extended periods of time is an important characteristic of a good grain refiner [Schumacher et. al., 1998]. The fading behaviour of ZnO in AZ91E alloy was examined by comparing 5 and 60 minutes after adding $0.5 \mathrm{wt} . \% \mathrm{ZnO}$ and same 5 and 60 minutes after adding $3 \mathrm{wt} . \% \mathrm{ZnO}$. The results are shown in Fig. 4.2.1. No significant fading was observed and this is consistent with the observations of $\mathrm{Fu}$ et. al.,2008 using pure $\mathrm{Mg}$ with $\mathrm{ZnO}$. The grain sizes at different conditions are shown in Table 4.2.1. The grain size remained constant at approximately $125 \mu \mathrm{m}$.

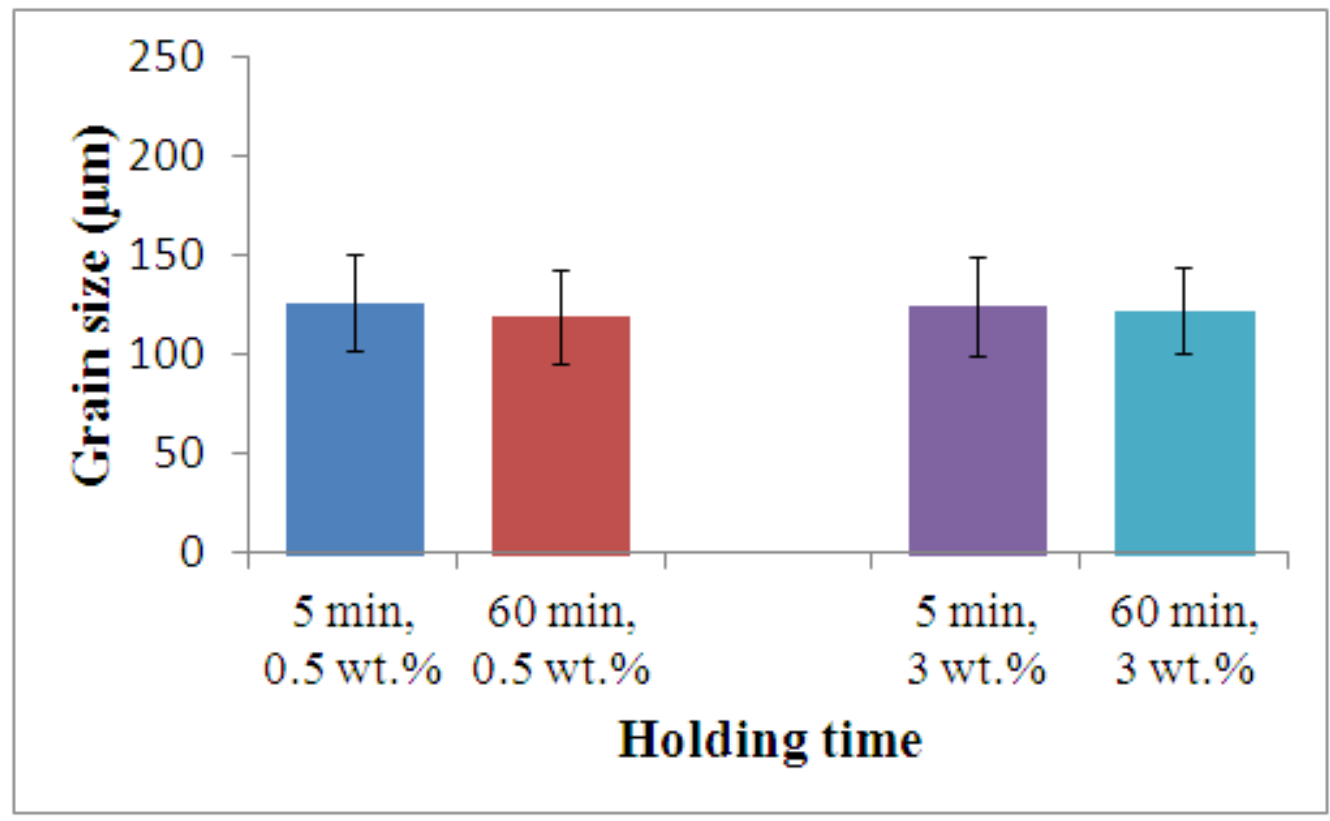

Fig. 4.2.1. Fading effect of ZnO in AZ91E at different holding times and addition levels. 
Table 4.2.1. Grain Size of AZ91E Alloy at Different Addition Levels of ZnO and Holding Time

\begin{tabular}{|c|c|c|c|c|}
\hline $\begin{array}{c}\text { Addition Level } \\
\text { (wt.\%) }\end{array}$ & $\begin{array}{c}\text { Holding Time } \\
\text { (Min.) }\end{array}$ & Grain Size $(\boldsymbol{\mu m})$ & Std. Dev. (+/-) & Change (\%) \\
\hline \multirow{2}{*}{0.5} & 5 & 126 & 24.06 & - \\
\cline { 2 - 5 } & 60 & 119 & 23.35 & $5.55 \downarrow$ \\
\hline \multirow{2}{*}{3} & 5 & 124 & 24.53 & - \\
\cline { 2 - 5 } & 60 & 122 & 22.00 & $1.61 \downarrow$ \\
\hline
\end{tabular}

\subsection{MECHANISM OF GRAIN REFINEMENT IN AZ91E ALLOY (GRAPHITE MOLD)}

SEM analysis of AZ91E enabled an understanding of refinement mechanism of $\mathrm{ZnO}$. It has been identified by other researchers [Zhang et. al., 2005], [Campbell, 1993] that a good lattice match between nucleating solid and grain refiner will promote heterogeneous nucleation. Both $\mathrm{Mg}$ and $\mathrm{ZnO}$ have excellent crystallographic similarity as discussed in subsection 2.3.2. With such crystallographic similarities it was expected that $\mathrm{ZnO}$ particles would act as heterogeneous nuclei for Mg.

SEM image of AZ91E alloy with 3 wt.\% $\mathrm{ZnO}$ is shown at low and higher magnification in Fig. 4.3.1-a and 4.3.1-b. Fig. 4.3.1-a shows a particle towards the center of the grain (indicated by arrow). The EDX in Fig. 4.3.1-c clearly indicated the $\mathrm{Zn}$ and $\mathrm{O}$ peaks. Thus it can be assumed that $\mathrm{ZnO}$ provided as heterogeneous nucleation site for $\alpha-\mathrm{Mg}$. 

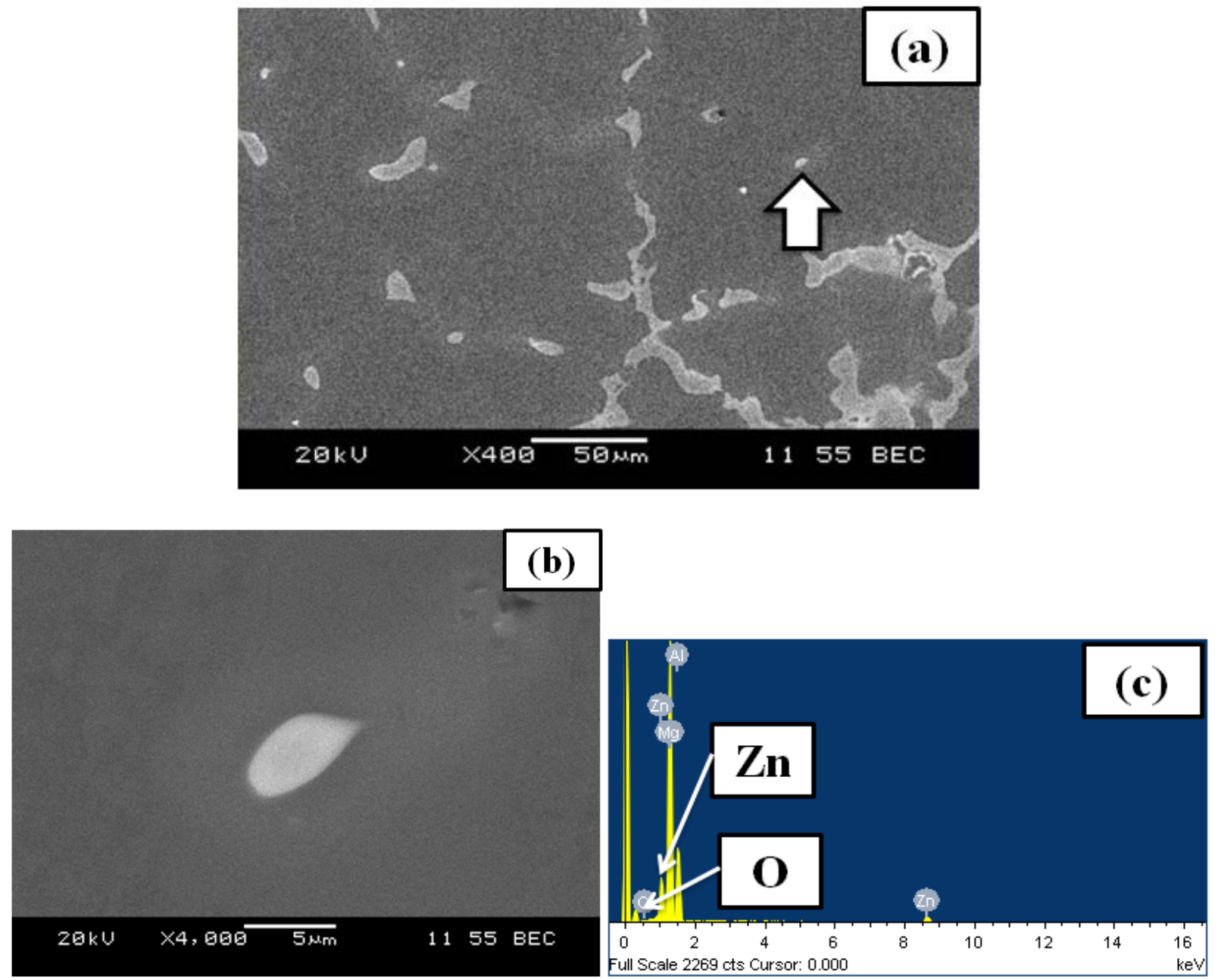

Fig. 4.3.1. SEM image of AZ91E with 3 wt.\% of ZnO (a) at low magnification and (b) at higher magnification and (c) corresponding EDX image of particle shown in (b).

\subsection{THERMAL ANALYSIS OF AZ91E ALLOY (GRAPHITE MOLD)}

The cooling curves for the base AZ91E alloy and AZ91E with 0.5 wt.\% ZnO are shown in Fig. 4.4.1. By analyzing the cooling curves, it was found that the base AZ91E alloy had an undercooling of $0.4^{\circ} \mathrm{C} / 0.7^{\circ} \mathrm{F}$ for primary phase nucleation. The undercooling was measured as the decrease in temperature of the cooling curve just after solidification beginning temperature $\left(\sim 595^{\circ} \mathrm{C} / 1103^{\circ} \mathrm{F}\right)$. With the addition of $\mathrm{ZnO}$, no undercooling was observed in the generated cooling curves further suggesting that the refinement mechanism was primarily heterogeneous nucleation by $\mathrm{ZnO}$. 


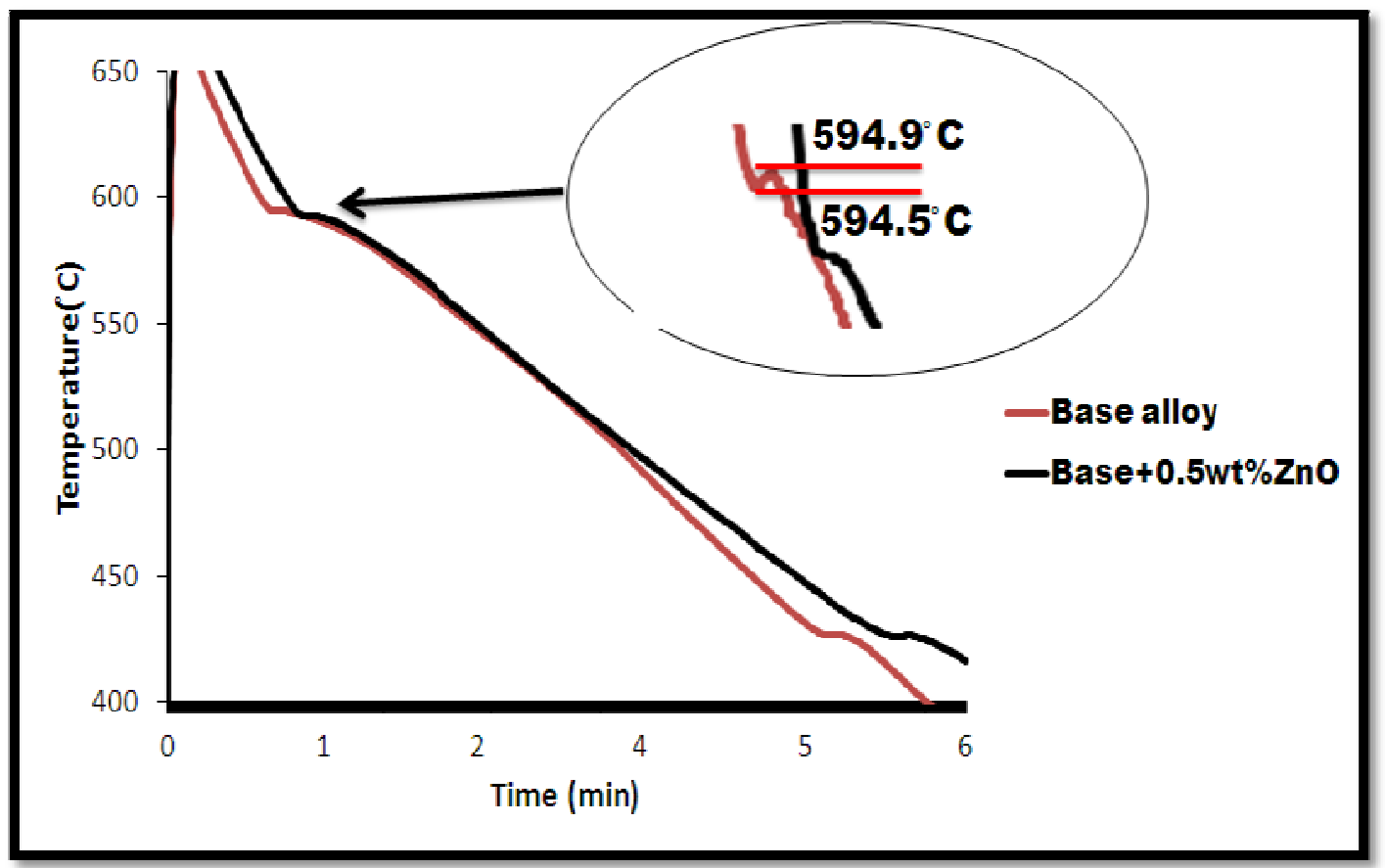

Fig. 4.4.1. Cooling curve of base AZ91E alloy and AZ91E with 0.5 wt.\% ZnO. Enlarged region as indicated is shown in the inset.

The freezing range (FR) of the alloys with different levels of $\mathrm{ZnO}$ is presented in Table 4.4.1. The FR was measured as the difference between the liquidus and solidus temperatures determined from the cooling curves. For base AZ91E alloy, FR was 166.8 C / 300.2 F, whereas after 3 wt.\% addition of $\mathrm{ZnO}$ FR was $169.5 \mathrm{C} / 305.1 \mathrm{~F}$. These increased FR with $\mathrm{ZnO}$ addition is an indication that the $\mathrm{ZnO}$ is changing the solidification behaviour of the alloy.

Along with an increase in $\mathrm{FR}$ with the increase of $\mathrm{ZnO}$ addition, the solidus temperature decreased as shown in Fig. 4.4.2. A similar trend was also observed by Wang et. al., 2002 while adding different addition levels of $\mathrm{Zn}$ in $\mathrm{Mg}$-Al alloys. As such, the trends may be attributed to increased solute level in the alloy with increasing addition of $\mathrm{ZnO}$ to the alloy. This trend of increased $\mathrm{Zn}$ solute with addition of $\mathrm{ZnO}$ to $\mathrm{AZ91E}$ prompted an investigation of the effect of $\mathrm{ZnO}$ on binary Mg-9 wt.\% Al. Since AZ91E already contains about 0.65 wt.\% Zn, the effect of solute $\mathrm{Zn}$ from $\mathrm{ZnO}$ in AZ91E during solidification process will be difficult to differentiate. By using Mg-9 wt.\% Al, the effect of solute $\mathrm{Zn}$ from $\mathrm{ZnO}$ can be very easily determined which will give an account of the effect of $\mathrm{ZnO}$ in AZ91E alloy. Cooling rate throughout the experiments 
was kept constant at $1.77 \pm 0.08^{\circ} \mathrm{C} / \mathrm{s}$. Cooling curves of AZ91E alloy at different addition levels of $\mathrm{ZnO}$ is provided in Appendix-A3.

Table 4.4.1. Freezing Range of AZ91E Alloy at Different Addition Levels of ZnO

\begin{tabular}{|c|c|c|}
\hline wt.\% of ZnO & ${\text { FR }\left({ }^{\circ} \mathbf{C} /{ }^{\circ} \mathbf{F}\right)}^{\text {Std. Dev.(+/-) }}$ \\
\hline 0 & $166.8 / 300.2$ & 2.14 \\
\hline 0.25 & $166.6 / 299.9$ & 1.29 \\
\hline 0.5 & $166.8 / 300.2$ & 0.23 \\
\hline 0.75 & $168.6 / 303.5$ & 0.91 \\
\hline 1 & $168.5 / 303.3$ & 1.41 \\
\hline 2 & $171.0 / 307.8$ & 0.83 \\
\hline 3 & $169.5 / 305.1$ & 1.27 \\
\hline
\end{tabular}

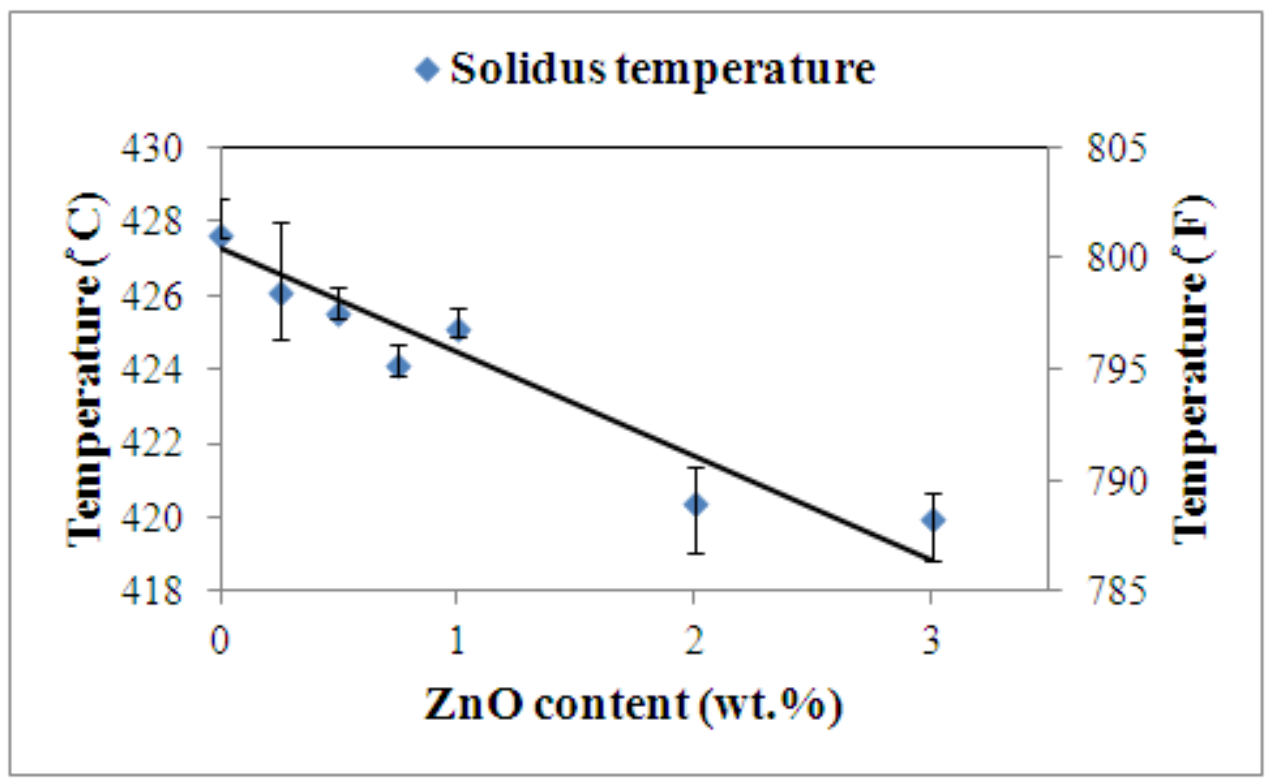

Fig. 4.4.2. Solidus temperature of AZ91E with ZnO content. 


\subsection{GRAIN REFINEMENT IN Mg-9 wt.\% AI ALLOY (GRAPHITE MOLD)}

The optical microscopy of solution treated base Mg-9 wt.\% Al alloy and with 1 wt.\% $\mathrm{ZnO}$ addition is shown in Fig. 4.5.1(a-b). All the casting parameters were kept the same as the conditions used for the AZ91E castings. Optical microscopy of the Mg-9 wt.\% Al alloys revealed that the average grain size of the base Mg-9 wt.\% Al binary alloy was $288 \mu \mathrm{m}$ which was approximately $24 \%$ larger than that of AZ91E alloy. This was likely due to the combined effect of $\mathrm{Zn}$ and $\mathrm{Mn}$ in the AZ91E alloy. Previous research has shown that both $\mathrm{Zn}$ [Fu et. al., 2008] and Mn [Elsayed et. al., 2009] have a grain refining effect on Mg-Al alloys.
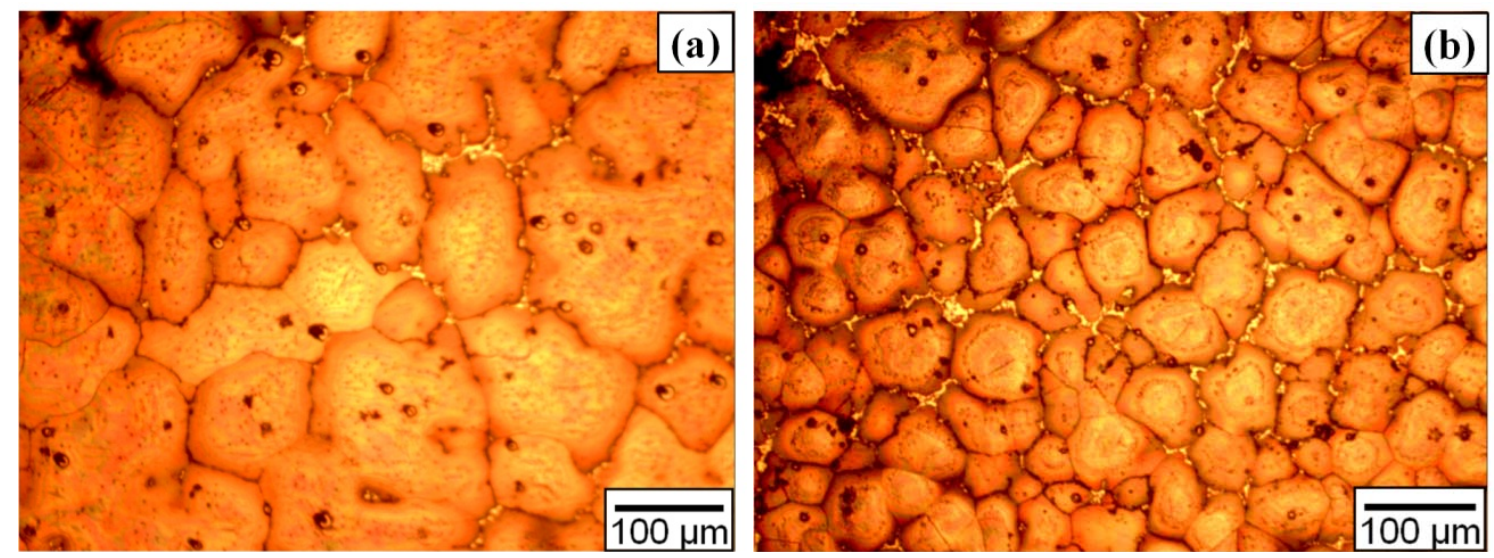

Fig. 4.5.1. Microstructure of Mg-9 wt.\% Al binary alloy after solution heat treatment (a) base alloy (average grain size-288 $\mu \mathrm{m}$ ) (b) with 1 wt.\% ZnO addition (average grain size-121 $\mu \mathrm{m}$ ).

Mg-9 wt.\% Al binary alloy castings with $0.5,1,2$ and 3 wt.\% of $\mathrm{ZnO}$ were produced. The average grain size of Mg-9 wt.\% $\mathrm{Al}$ with different addition levels of $\mathrm{ZnO}$ are shown in Fig. 4.5.2 and the results are summarized in Table 4.5.1. A similar grain refinement trend to that of AZ91E (Fig. 4.1.2) was observed for Mg-9 wt.\% Al alloy. Maximum grain size reduction was found at 3 wt. $\%$ addition of $\mathrm{ZnO}(93 \mu \mathrm{m})$, although beyond $0.5 \mathrm{wt} . \%$ addition of $\mathrm{ZnO}(121 \mu \mathrm{m})$ the grain size reduction was not very significant suggesting maximization of the potency of $\mathrm{ZnO}$ at 0.5 wt.\% $\mathrm{ZnO}$ in $\mathrm{Mg}-9$ wt.\% Al binary alloy. The possible reason for maximization of grain refinement potency of $\mathrm{ZnO}$ in $\mathrm{Mg}-9 \mathrm{wt} . \% \mathrm{Al}$ binary alloy at $0.5 \mathrm{wt} . \%$ addition is considered to be similar to that of the addition of $\mathrm{ZnO}$ in AZ91E alloy in graphite mold casting (Section 4.1). 


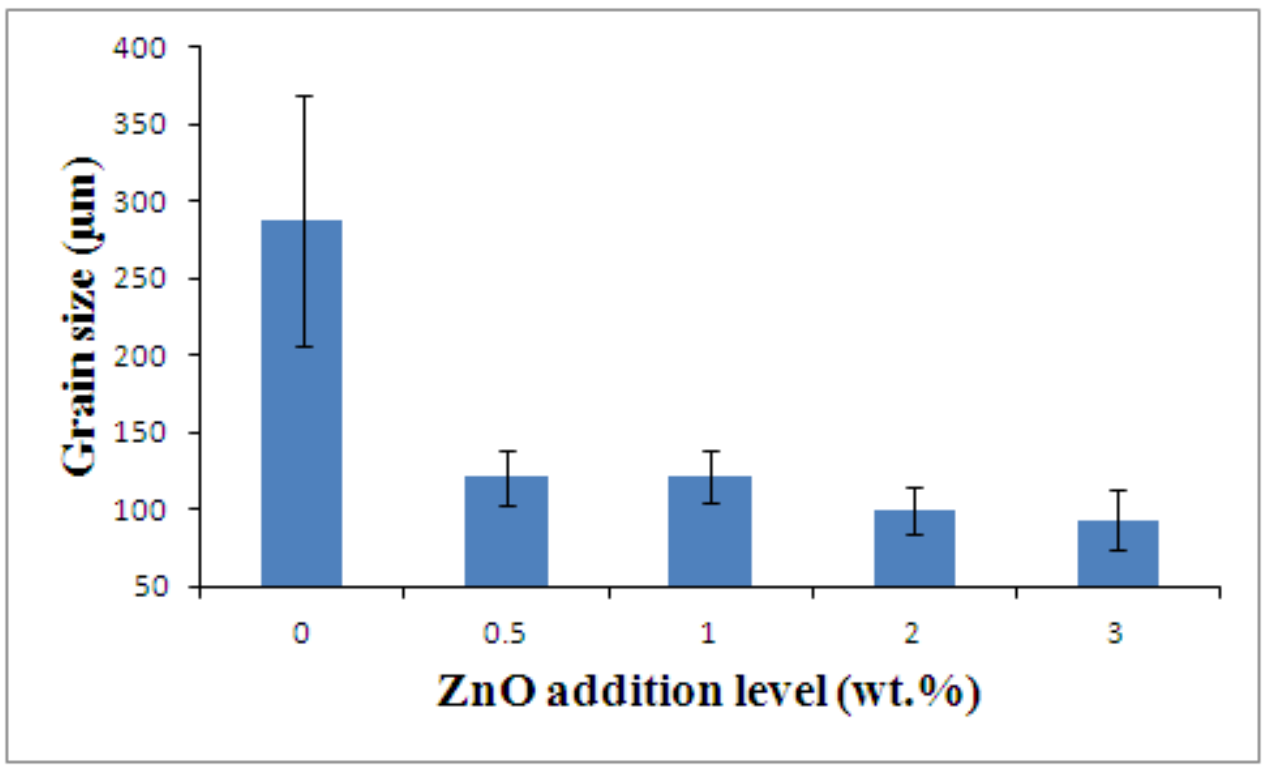

Fig. 4.5.2. Average grain size of Mg-9 wt.\% Al binary alloy with various levels of ZnO addition.

Table 4.5.1. Grain Size of Mg-9 wt.\% Al Alloy at Different Addition Levels of ZnO

\begin{tabular}{|c|c|c|c|}
\hline $\begin{array}{c}\text { Addition Level } \\
(\mathbf{w t} . \%)\end{array}$ & Grain Size $(\boldsymbol{\mu m})$ & Std. Dev. $(+/-)$ & Change (\%) \\
\hline 0 & 288 & 81.09 & - \\
\hline 0.5 & 121 & 17.38 & $57.99 \downarrow$ \\
\hline 1 & 121 & 16.66 & $57.99 \downarrow$ \\
\hline 2 & 100 & 15.38 & $65.28 \downarrow$ \\
\hline 3 & 93 & 19.32 & $67.70 \downarrow$ \\
\hline
\end{tabular}

For complete reduction of $\mathrm{ZnO}$ to $\mathrm{Zn}$, the $\mathrm{Zn}$ concentration with $0.5 \mathrm{wt} \%$ addition of $\mathrm{ZnO}$ to AZ91E (initially containing 0.65 wt.\% $\mathrm{Zn}$ ) would be higher than the same addition to binary Mg-9 wt.\% Al (equivalent to 0.4 wt.\% $\mathrm{Zn}$ ). In this experiment, the mean average grain sizes with 0.5 wt.\% $\mathrm{ZnO}$ addition to $\mathrm{AZ91E}$ and $\mathrm{Mg}-9 \mathrm{wt} \% \mathrm{Al}$ were similar at $126 \mu \mathrm{m}$ and $121 \mu \mathrm{m}$ respectively. This suggests that the grain refinement achieved by the $\mathrm{ZnO}$ particle addition is greater than that gained by an equivalent addition of Zn solute [StJohn et. al., 2013]. 


\subsection{FADING IN Mg-9 wt.\% Al ALLOY (GRAPHITE MOLD)}

The fading behaviour of $\mathrm{ZnO}$ in $\mathrm{Mg}-9 \mathrm{wt} \% \mathrm{Al}$ alloy was examined by comparing 5 and 60 minutes after adding $0.5 \mathrm{wt} . \% \mathrm{ZnO}$ and same 5 and 60 minutes after adding $3 \mathrm{wt} . \% \mathrm{ZnO}$. The results are summarized in Table 4.6.1 and graphically shown in Fig. 4.6.1. The average grain sizes at 0.5 wt.\% $\mathrm{ZnO}$ addition after 5 minutes and 60 minutes were $121 \mu \mathrm{m}$ and $126 \mu \mathrm{m}$ respectively. With 3 wt.\% $\mathrm{ZnO}$ addition average grain sizes after 5 minutes and 60 minutes were $93 \mu \mathrm{m}$ and $103 \mu \mathrm{m}$ respectively. No significant fading was observed which is consistent with the results of AZ91E alloy (Fig. 4.2.1).

Table 4.6.1. Grain Size of AZ91E Alloy at Different Addition Levels of ZnO and Holding Time

\begin{tabular}{|c|c|c|c|c|}
\hline $\begin{array}{c}\text { Addition Level } \\
\text { (wt.\%) }\end{array}$ & $\begin{array}{c}\text { Holding Time } \\
\text { (Min.) }\end{array}$ & Grain Size $(\boldsymbol{\mu m})$ & Std. Dev. (+/-) & Change (\%) \\
\hline \multirow{2}{*}{0.5} & 5 & 121 & 17.38 & - \\
\cline { 2 - 5 } & 60 & 126 & 21.10 & $4.13 \uparrow$ \\
\hline \multirow{2}{*}{3} & 5 & 93 & 19.32 & - \\
\cline { 2 - 5 } & 60 & 103 & 25.28 & $10.75 \uparrow$ \\
\hline
\end{tabular}

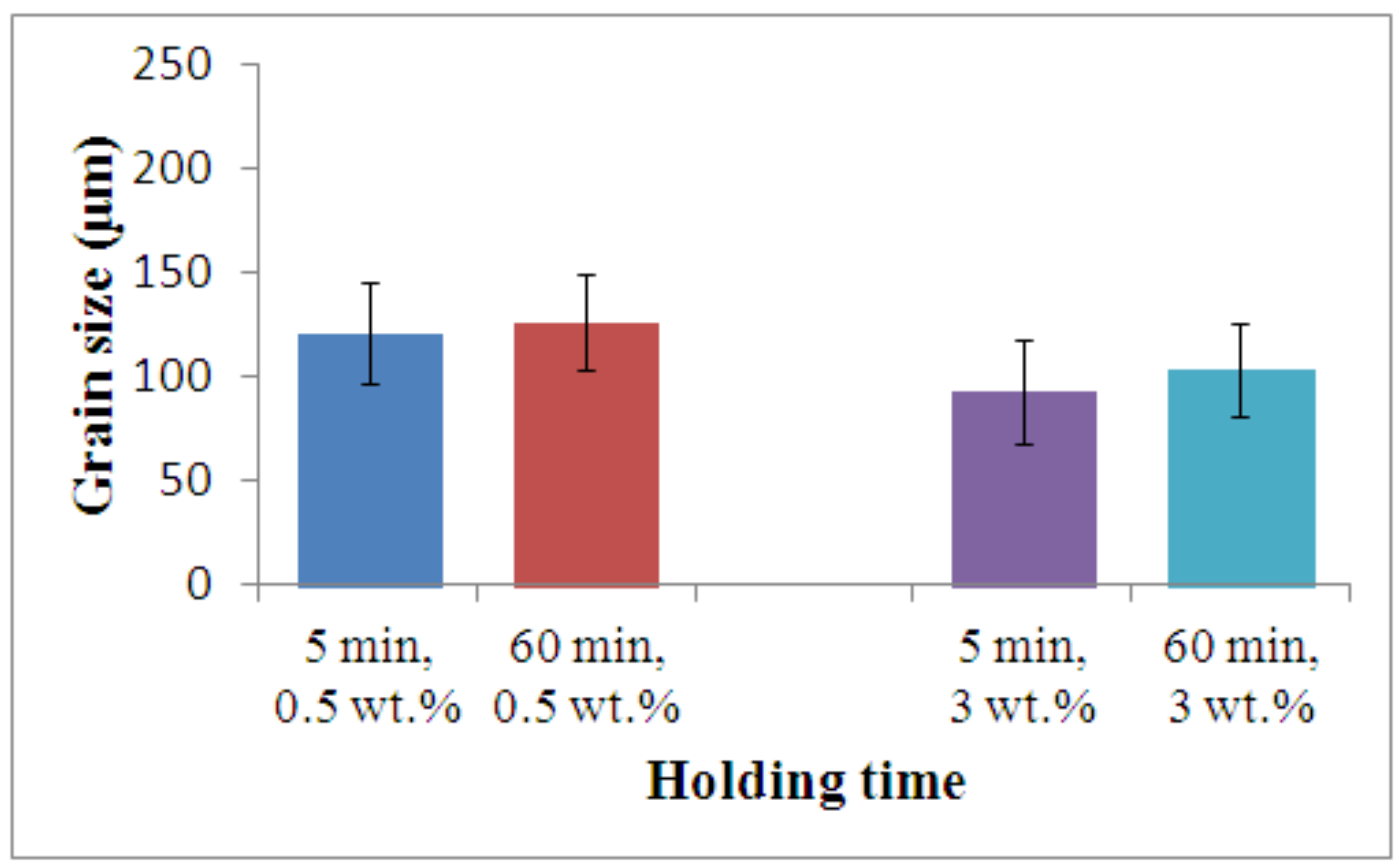

Fig. 4.6.1. Fading effect of ZnO in Mg-9 wt.\% Al binary alloy at different holding times and addition levels. 


\subsection{MECHANISM OF GRAIN REFINEMENT IN Mg-9 wt.\% AI ALLOY (GRAPHITE MOLD)}

The SEM and corresponding EDX results of base Mg-9 wt.\% $\mathrm{Al}$ are shown in Fig. 4.7.1. The sample consisted of $\alpha-\mathrm{Mg}$ matrix (Point A in Fig. 4.7.1) and $\beta-\mathrm{Mg}_{17} \mathrm{Al}_{12}$ (Point B in Fig. 4.7.1).
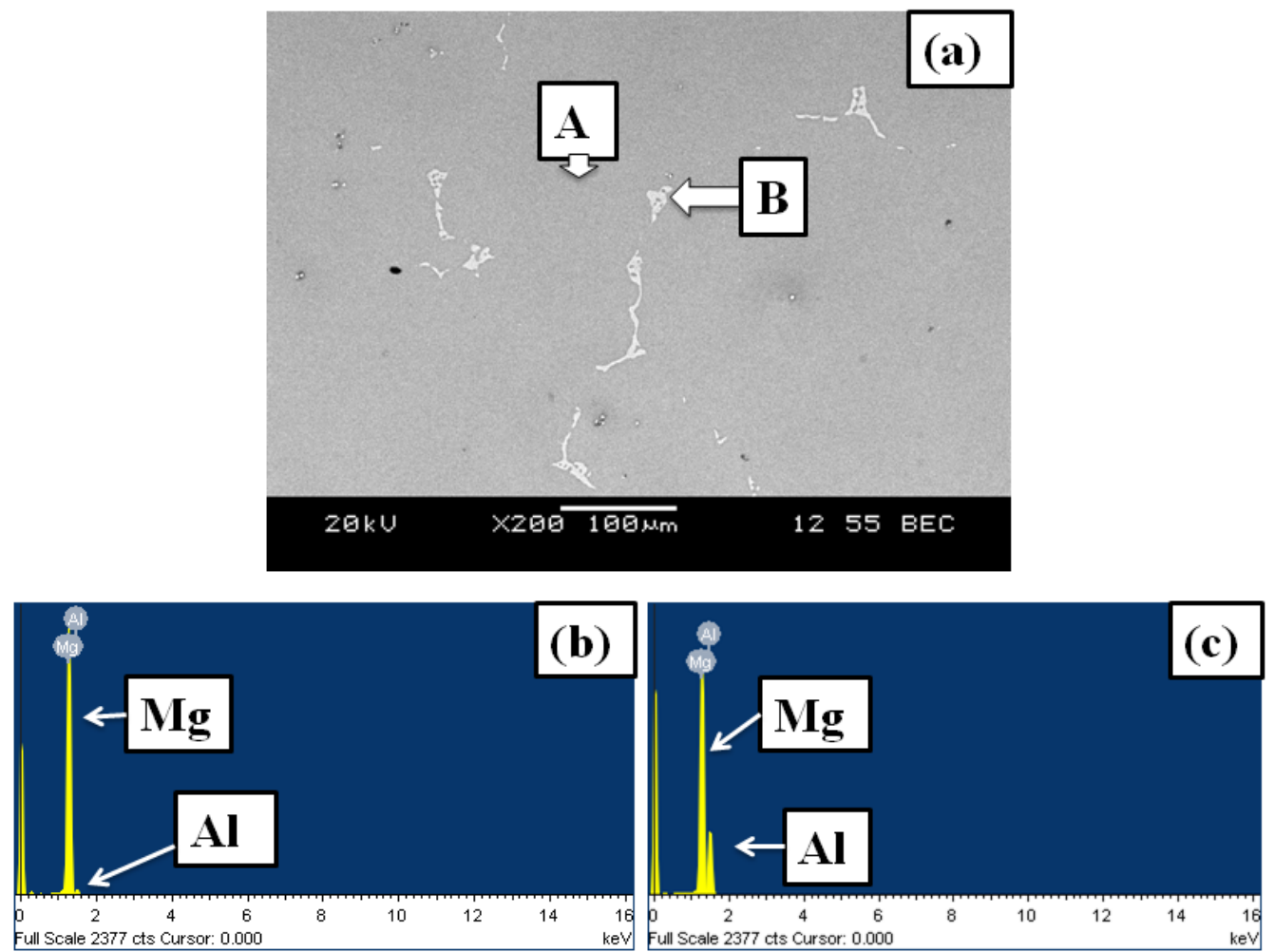

Fig. 4.7.1. (a) SEM image of base Mg-9 wt.\% Al showing $\alpha$-phase and $\beta$-phases (b-c) shows the EDX analysis of point-A and point-B respectively.

With increased $\mathrm{ZnO}$ addition, the $\beta$-phase was found to be increasingly enriched with $\mathrm{Zn}$ solute as shown in Fig. 4.7.2. This $\mathrm{Zn}$ solute is thought to have been liberated from $\mathrm{ZnO}$ because it reacted with $\mathrm{Mg}$ according to Equation 4.7.1 [Fu et. al., 2008]. Thermodynamic data of this chemical reaction is provided in Appendix-A4.

$\mathrm{ZnO}+\mathrm{Mg} \rightarrow \mathrm{MgO}+\mathrm{Zn}$

Equation 4.7.1

Therefore, since only a small amount of added $\mathrm{ZnO}$ particles act as nucleating sites, it is possible that some $\mathrm{ZnO}$ may have dissociated, which in turn, introduced $\mathrm{Zn}$ into the melt. 
Fig. 4.7.2 shows SEM image and corresponding Zn element maps of base Mg-9 wt.\% Al and with 1 wt.\%, 2 wt.\% and 3 wt.\% of $\mathrm{ZnO}$ addition, respectively. It is evident from the image that with an increased $\mathrm{ZnO}$ content in $\mathrm{Mg}-9$ wt.\% Al, increased $\mathrm{Zn}$ solute is observed ( in Fig. 14-b some background noises can be seen though $\mathrm{Zn}$ is absent). This supports results from thermal analysis suggesting increased FR and decreased solidus temperature with $\mathrm{ZnO}$ addition. Increased divorcing of intermetallic phases with additions of $\mathrm{ZnO}$ is also clearly visible, which is indicative of increased $\mathrm{Zn}$ solute presence and effective grain refining capability of $\mathrm{ZnO}$ [Dahle et. al., 2001]. 

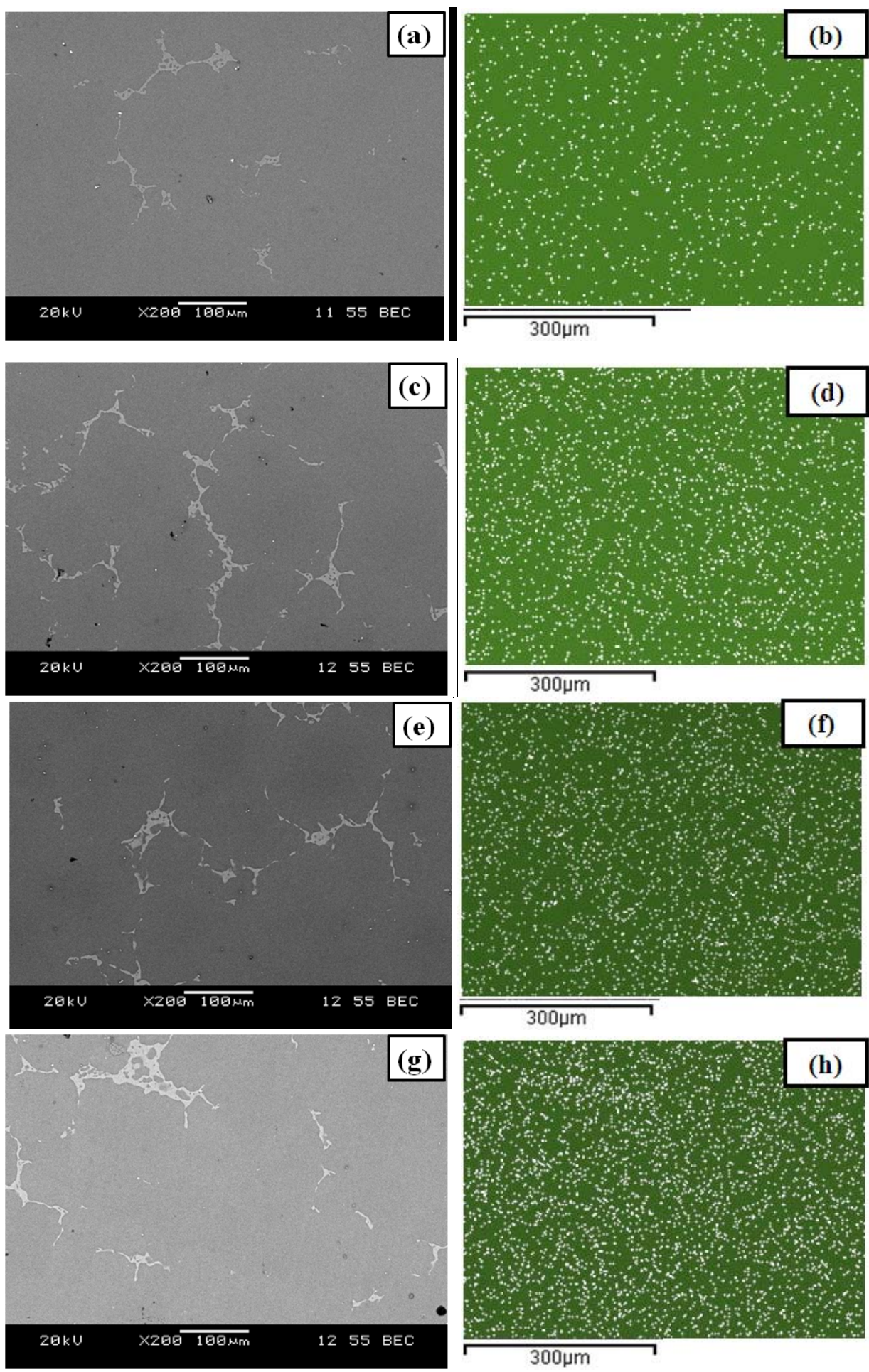

Fig. 4.7.2. SEM image and corresponding Zn element map of (x200) of Mg-9 wt.\% Al with (a-b) no addition of ZnO, (c-d) 1 wt.\% ZnO addition, (e-f) 2 wt.\% ZnO addition (g-h) 3 wt.\% ZnO addition. 
Fig. 4.7.3 shows the SEM and EDX results of Mg-9 wt.\% Al with 2 wt.\% addition of $\mathrm{ZnO}$. The bright white spots seen embedded within the $\mathrm{Mg}_{17} \mathrm{Al}_{12}$ indicate enriched $\mathrm{Zn}$. $\mathrm{Zn}$ has a relatively very high growth restriction factor of 5.31 in $\mathrm{Mg}$ (Table 2.5.1). This high growth restriction factor likely restricted the $\alpha-\mathrm{Mg}$ grain growth by generating constitutional undercooling in solidliquid interface, thus limiting the size of the grain [Lee et. al., 2000].
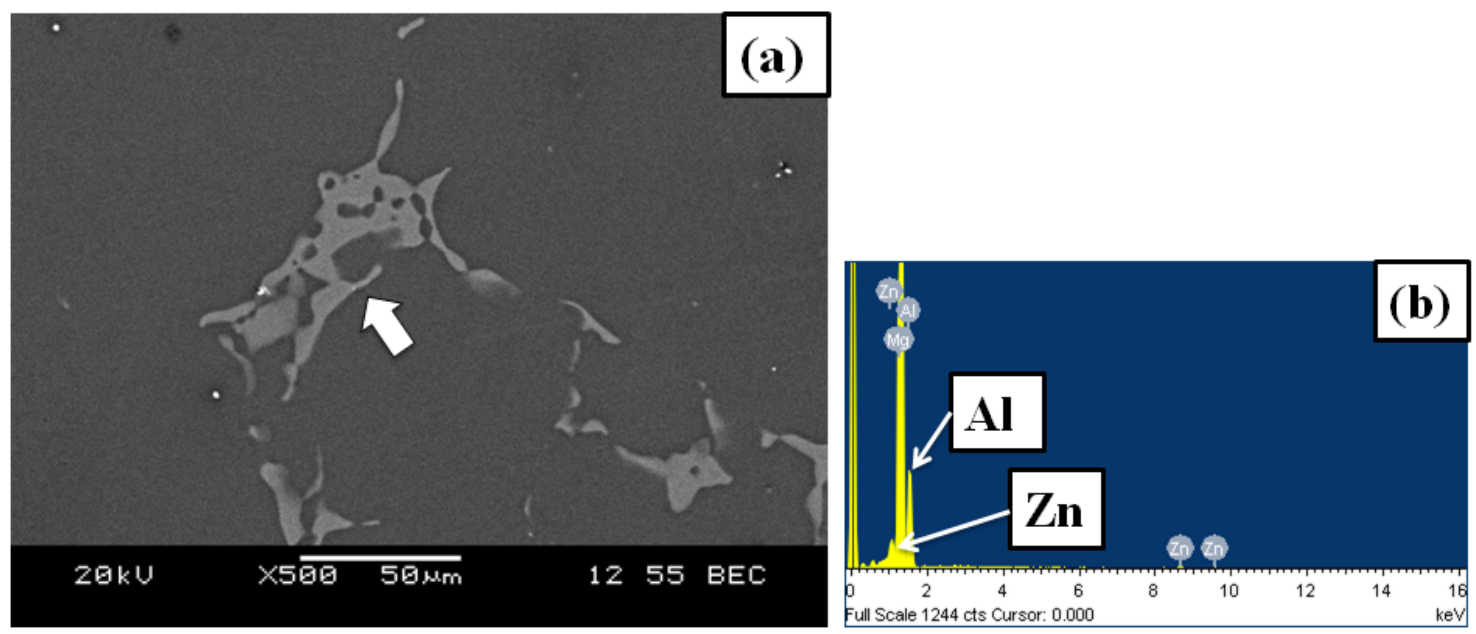

Fig. 4.7.3. Mg-9 wt.\% Al with 2 wt.\% ZnO (a) SEM image and (b) EDX results at location indicated by arrow.

\subsection{THERMAL ANALYSIS OF Mg-9 wt.\% AI ALLOY (GRAPHITE MOLD)}

Thermal analysis of Mg-9 wt.\% Al alloy with $\mathrm{ZnO}$ addition revealed the same characteristics to that of AZ91E alloy. By analyzing the generated cooling curves, no undercooling was observed with the addition of $\mathrm{ZnO}$ for all addition levels (cooling curves of $\mathrm{Mg}-9$ wt.\% Al alloy at different addition levels of $\mathrm{ZnO}$ are provided in Appendix-A5). The freezing range (FR) of the alloys with different levels of $\mathrm{ZnO}$ measured from the cooling curves is presented in Table 4.8.1. For base Mg-9 wt.\% Al alloy, FR was $160.0^{\circ} \mathrm{C}\left(288^{\circ} \mathrm{F}\right)$, whereas after 3 wt.\% addition of ZnO FR was $171.3^{\circ} \mathrm{C}\left(308.4^{\circ} \mathrm{F}\right)$. An increased $\mathrm{FR}$ with $\mathrm{ZnO}$ addition indicates the similar change in solidification behaviour to that of AZ91E alloy.

Along with an increase in FR with the increase of $\mathrm{ZnO}$ addition, the solidus temperature decreased as shown in Fig. 4.8.1. This decreased trend of solidus temperature is also similar to AZ91E alloy (Fig. 4.4.2). Similar thermal behaviours for AZ91E and Mg-9 wt.\% Al alloys of 
$\mathrm{ZnO}$ reinforces that the grain refining mechanism of $\mathrm{ZnO}$ for both the alloys appears to be via two routes:- 1) $\mathrm{ZnO}$ act as a nucleating site and 2) $\mathrm{ZnO}$ reacts with $\mathrm{Mg}$ according to Equation 4.7.1 increasing $\mathrm{Zn}$ solute in the melt providing growth restriction.

\section{Table 4.8.1. Freezing Range of Mg-9 wt.\% Al Alloy at Different Addition Levels of} ZnO

\begin{tabular}{|c|c|c|}
\hline wt. \% of $\mathbf{Z n O}$ & $\mathbf{F R}\left({ }^{\circ} \mathbf{C} /{ }^{\circ} \mathrm{F}\right)$ & Std. Dev.(+/-) \\
\hline 0 & $160.0 / 288.0$ & 2.9 \\
\hline 0.5 & $166.1 / 299.0$ & 1.9 \\
\hline 1 & $167.2 / 300.9$ & 1.78 \\
\hline 2 & $169.4 / 304.9$ & 1.45 \\
\hline 3 & $171.3 / 308.4$ & 1.27 \\
\hline
\end{tabular}

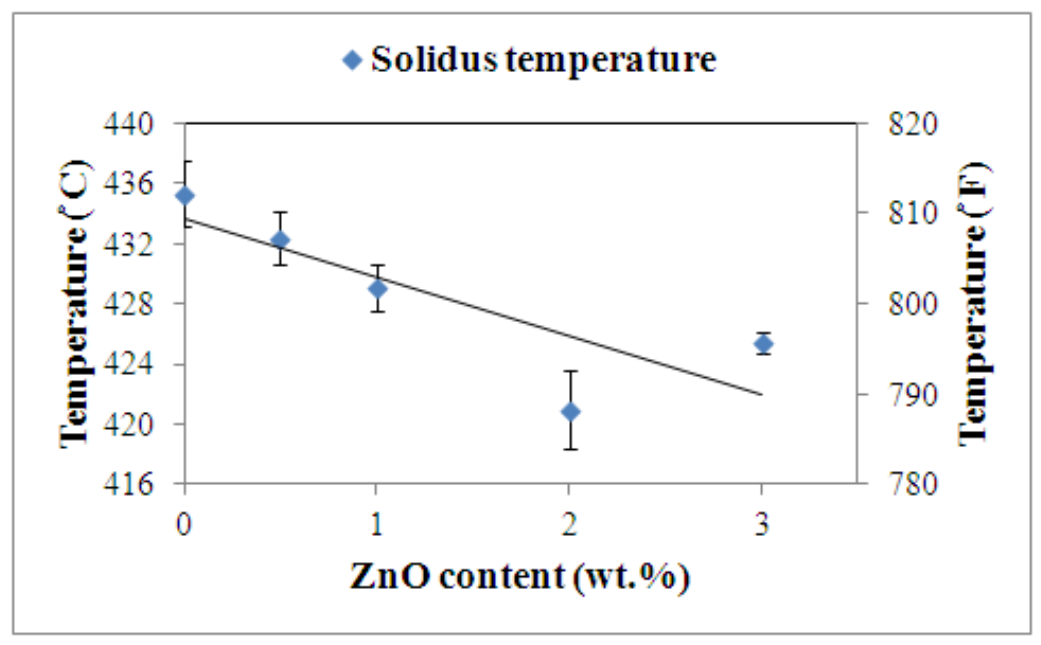

Fig. 4.8.1. Solidus temperature of Mg-9 wt.\% Al with ZnO content.

\subsection{GRAIN REFINEMENT OF AZ91E ALLOY (PERMANENT TENSILE MOLD)}

Optical micrographs of as-cast and solutionized AZ91E alloy samples are shown in Fig. 4.9.1. The as-cast AZ91E (Fig. 4.9.1-a), consists of two distinct phases of $\alpha-\mathrm{Mg}$ and $\beta-\mathrm{Mg}_{17} \mathrm{Al}_{12}$ as was in graphite mold (Fig. 4.1.1-a). The grain structure is highly dendritic in nature. After solution heat treatment, the $\beta-\mathrm{Mg}_{17} \mathrm{Al}_{12}$ is dissolved and the grain boundaries are clearly visible as shown in Fig. 4.9.1-b. The average grain size of the base was $133 \mu \mathrm{m}$. The etched surface of 
$\mathrm{AZ91E}+0.5$ wt.\% $\mathrm{ZnO}$ with grain size of $79 \mu \mathrm{m}$ is shown in Fig. 4.9.1-c. A significant reduction of grain size as compared to the base AZ91E alloy (Fig. 4.9.1-b) was observed. The average grain size at $0.75 \mathrm{wt} . \% \mathrm{ZnO}$ was $72 \mu \mathrm{m}$. The average grain sizes, measured using optical microscope, at different levels of $\mathrm{ZnO}$ addition are summarized in Fig. 4.9.2 and Table 4.9.1. The percentage decrease in grain sizes was comparable to those observed in graphite mold castings (Table 4.1.1). With increasing $\mathrm{ZnO}$ addition, the grain size gradually decreased, up to an addition level of $0.75 \mathrm{wt} \% \mathrm{ZnO}$. However, beyond $0.5 \mathrm{wt} . \%$ addition of $\mathrm{ZnO}$ (up to $3 \mathrm{wt} . \%$ ) no significant change in grain size was observed. The slight increase in grain size beyond 0.75 wt. $\% \mathrm{ZnO}$ is not significant considering the error bars. The possible reason for maximization of grain refinement potency of $\mathrm{ZnO}$ in AZ91E alloy was discussed in section 4.1.
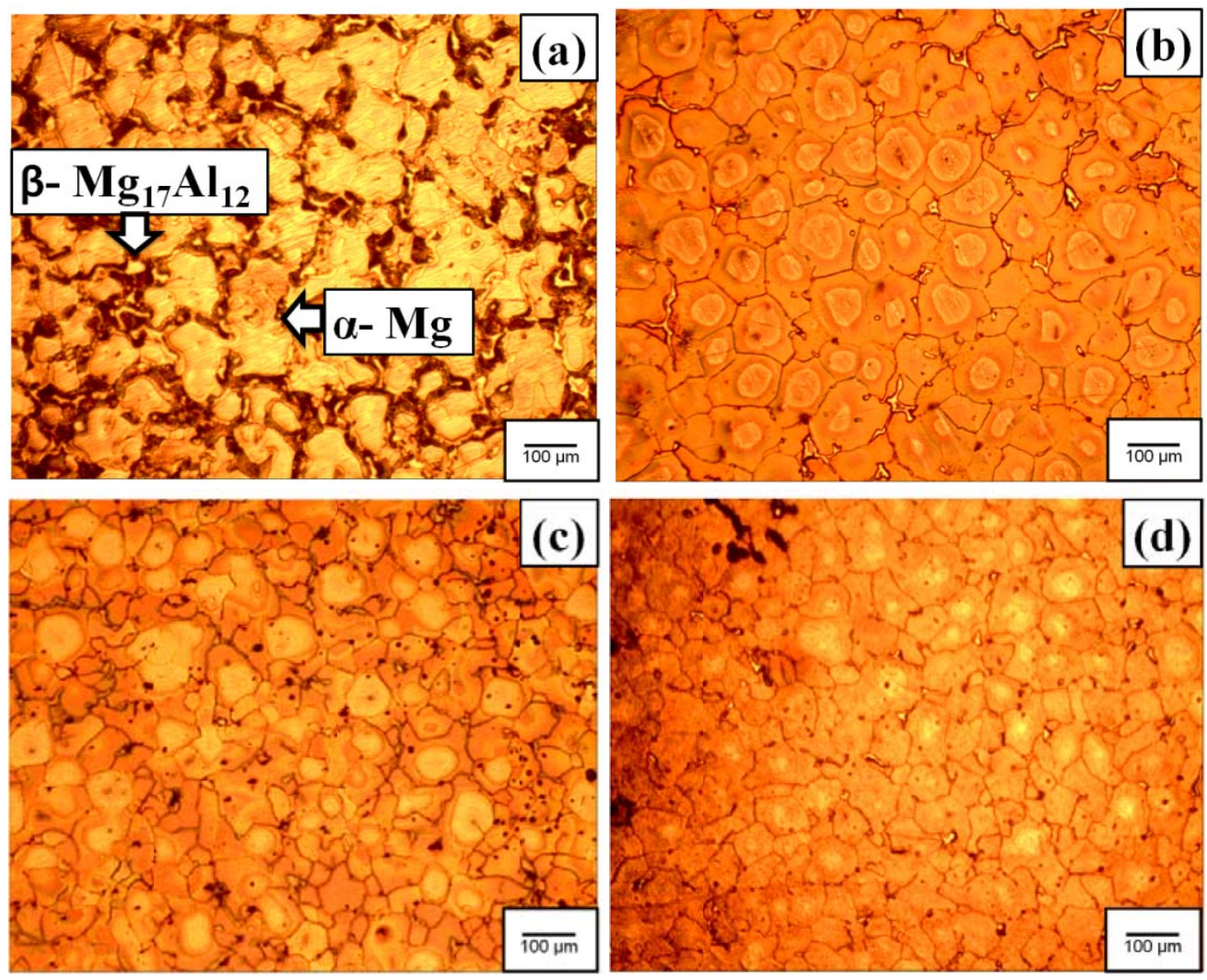

Fig. 4.9.1. Optical micrograph of (a) as cast base AZ91E alloy (b) base alloy after solution heat treatment at $420 \mathrm{C}$ for 24 hours and etching (average grain size $133 \mu \mathrm{m})$ (c) AZ91E+0.5 wt.\% ZnO (average grain size $79 \mu \mathrm{m})$ (d) AZ91E+0.75 wt.\% ZnO (average grain size $72 \mu \mathrm{m}$ ). 
Table 4.9.1. Grain Size of AZ91E Alloy at Different Addition Levels of ZnO (Permanent Tensile Mold)

\begin{tabular}{|c|c|c|c|}
\hline Addition Level (wt.\%) & Grain Size ( $\boldsymbol{\mu m})$ & Std. Dev. (+/-) & Change (\%) \\
\hline 0 & 133 & 23.69 & - \\
\hline 0.25 & 112 & 17.58 & $15.79 \downarrow$ \\
\hline 0.5 & 79 & 16.77 & $40.60 \downarrow$ \\
\hline 0.75 & 72 & 15.94 & $45.86 \downarrow$ \\
\hline 1 & 76 & 16.38 & $42.85 \downarrow$ \\
\hline 3 & 80 & 14.88 & $39.85 \downarrow$ \\
\hline
\end{tabular}

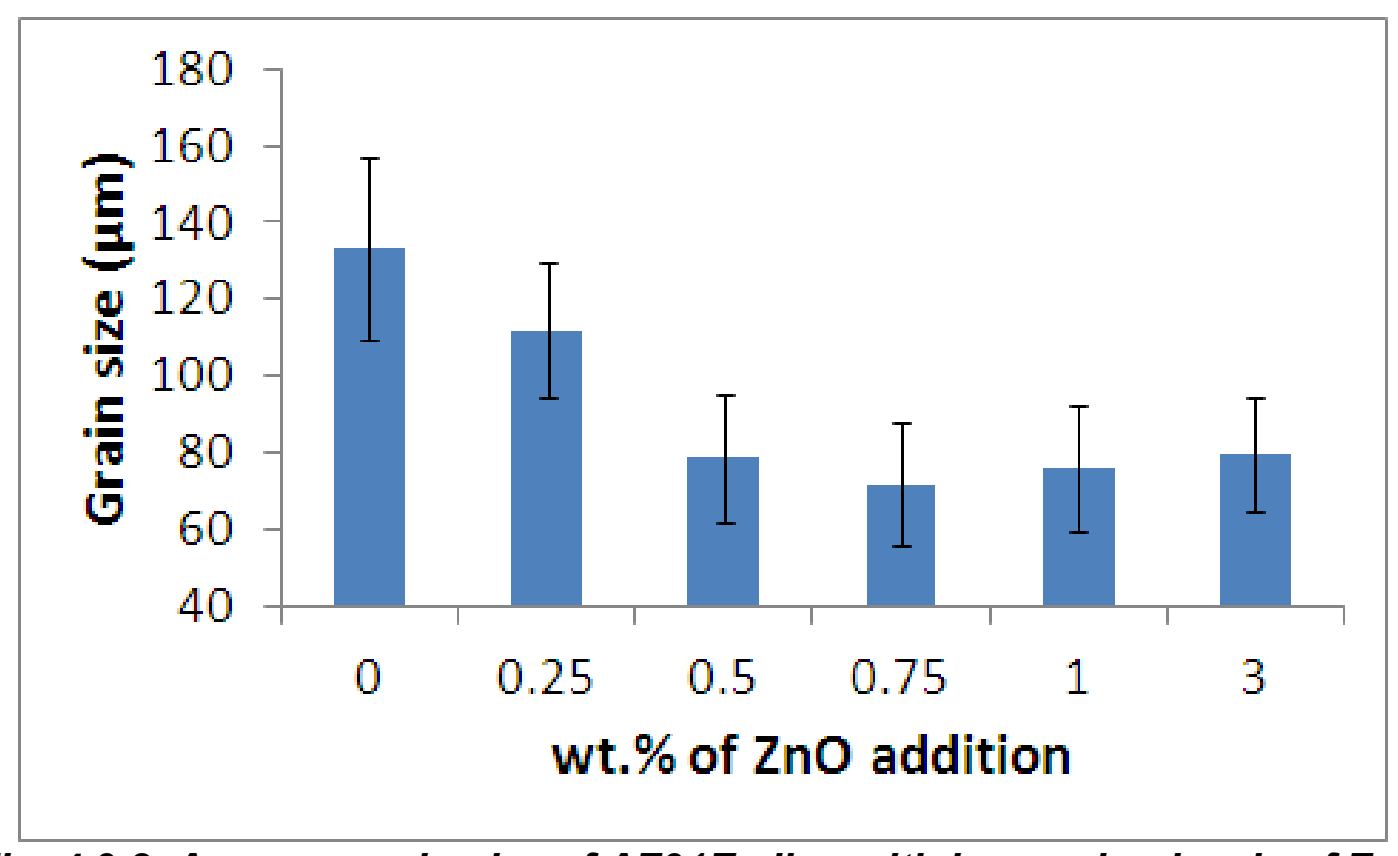

Fig. 4.9.2. Average grain size of AZ91E alloy with increasing levels of ZnO addition in permanent tensile mold casting.

\subsection{MECHANISM OF GRAIN REFINEMENT IN AZ91E ALLOY (PERMANENT TENSILE MOLD)}

The SEM and corresponding EDX results of base AZ91E alloy in permanent mold casting are shown in Fig. 4.10.1. The sample consisted of $\alpha-\mathrm{Mg}$ matrix (Point A in Fig. 4.10.1) and $\mathrm{Zn}$ enriched $\beta$ - intermetallics (Point B in Fig. 4.10.1). 

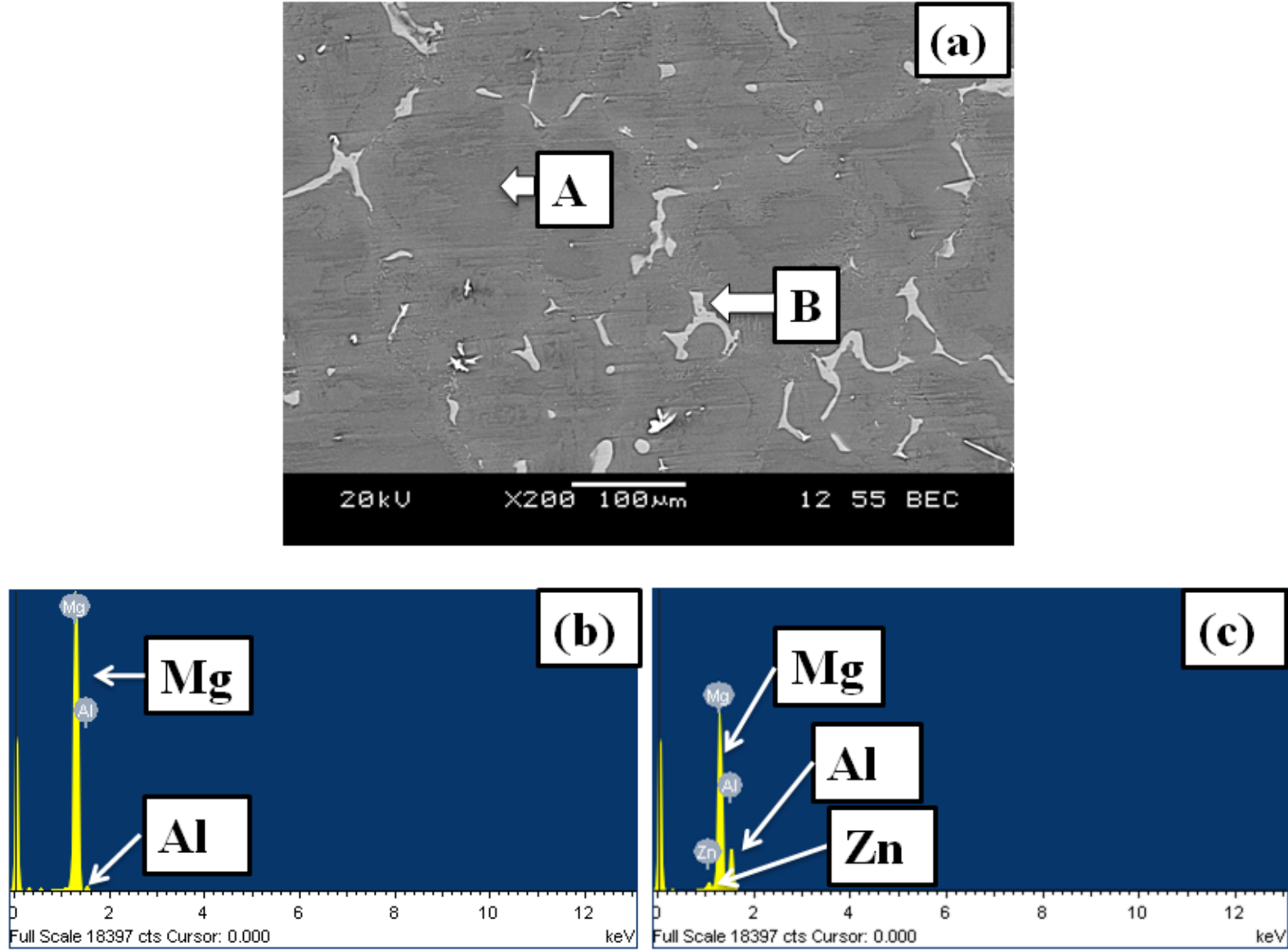

Fig. 4.10.1. (a) SEM image of base AZ91E alloy showing $\alpha$-phase and $\beta$-phase (b-c) shows the EDX analysis of point-A and point-B respectively.

An SEM image of AZ91E+3 wt.\% ZnO alloy with particles towards the center of a grain (indicated by arrow) is shown in Fig. 4.10.2. A magnified view of the particle indicated in Fig. 4.10.2-a is shown in Fig. 4.10.2-b. The corresponding EDX (Fig. 4.10.2-c) showed Zn and $\mathrm{O}$ peaks which can be assumed that $\mathrm{ZnO}$ acted as heterogeneous nucleation site for $\alpha-\mathrm{Mg}$. 

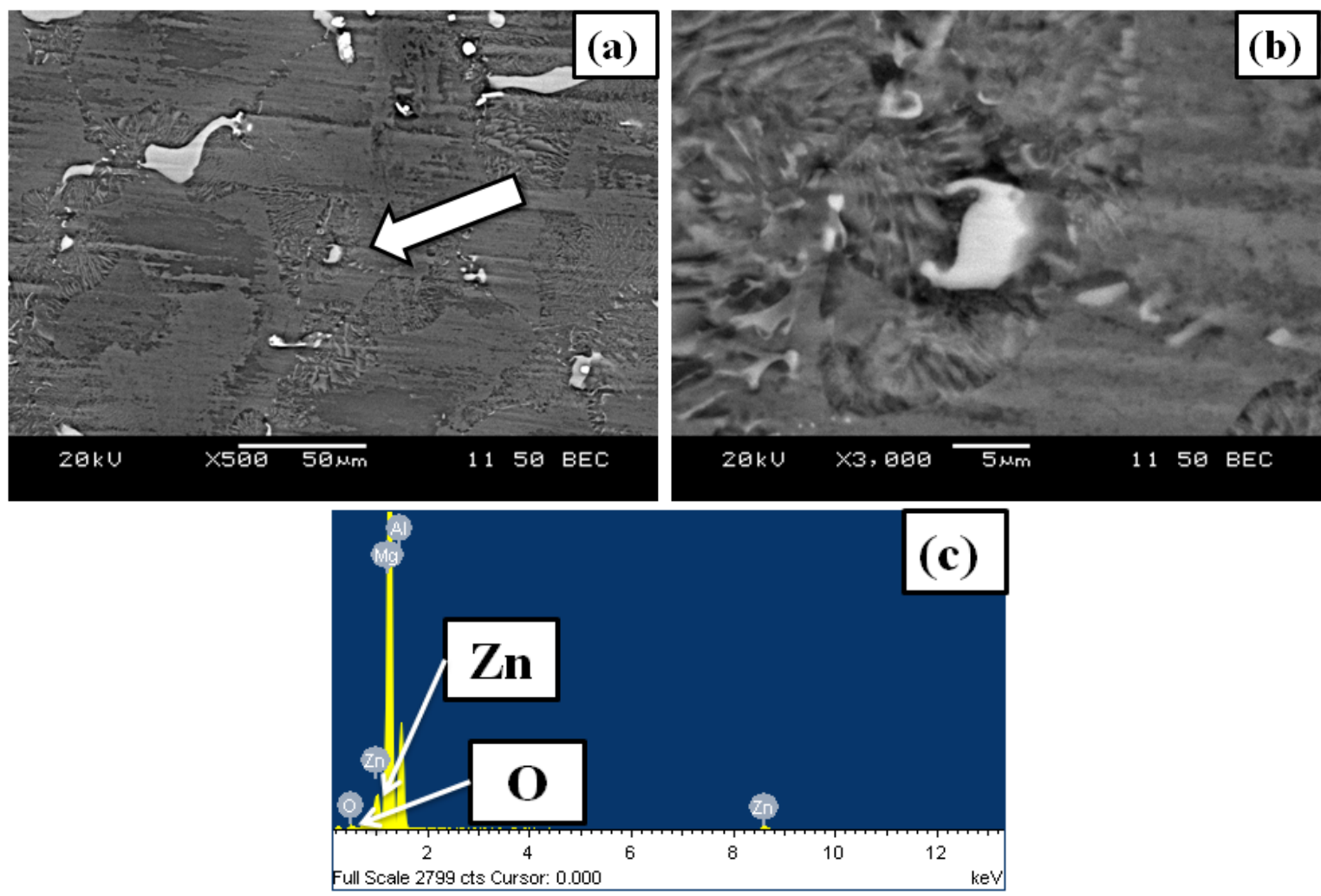

Fig. 4.10.2. SEM image of AZ91E alloy with 3 wt.\% ZnO (a) at low magnification (b) at higher magnification and (c) corresponding EDX image of particle shown in (b).

With increasing $\mathrm{ZnO}$ addition, the $\beta$-phase was found to be increasingly enriched with $\mathrm{Zn}$ solute as can be seen from Fig. 4.10.3 and Table 4.10.1. Fig. 4.10.3 shows SEM images and corresponding $\mathrm{Zn}$ element maps of base AZ91E alloy and AZ91E alloy with 3 wt.\% of ZnO addition, respectively. The $\mathrm{Zn}$ content in the alloys obtained through EDX point analysis is presented in Table 4.10.1. The overall $\mathrm{Zn}$ content in the alloys found through EDX area analysis is shown in Fig. 4.10.4. The overall $\mathrm{Zn}$ content in the base alloy and with addition of 3 wt. $\% \mathrm{ZnO}$ were $0.7 \mathrm{wt} . \%$ and $1.8 \mathrm{wt} . \%$ respectively. It is evident from the images that with $\mathrm{ZnO}$ addition in AZ91E alloy, increased $\mathrm{Zn}$ solute is observed in both matrix and $\beta$-phases. This $\mathrm{Zn}$ solute is thought to have been liberated from $\mathrm{ZnO}$ because it reacted with $\mathrm{Mg}$ according to Equation 4.7.1 similar to that in the case of graphite mold casting. Increased divorcing of intermetallic phases with additions of $\mathrm{ZnO}$ is also visible, which is indicative of increased $\mathrm{Zn}$ solute presence [Dahle et. al., 2001]. The high growth restriction factor of $\mathrm{Zn}$ in Mg (Table 2.5.1) 
effectively restricted the growth of $\alpha-\mathrm{Mg}$ grain. It is known that the resulting constitutional undercooling in solid-liquid interface limited the size of the grain [Lee et. al., 2000].
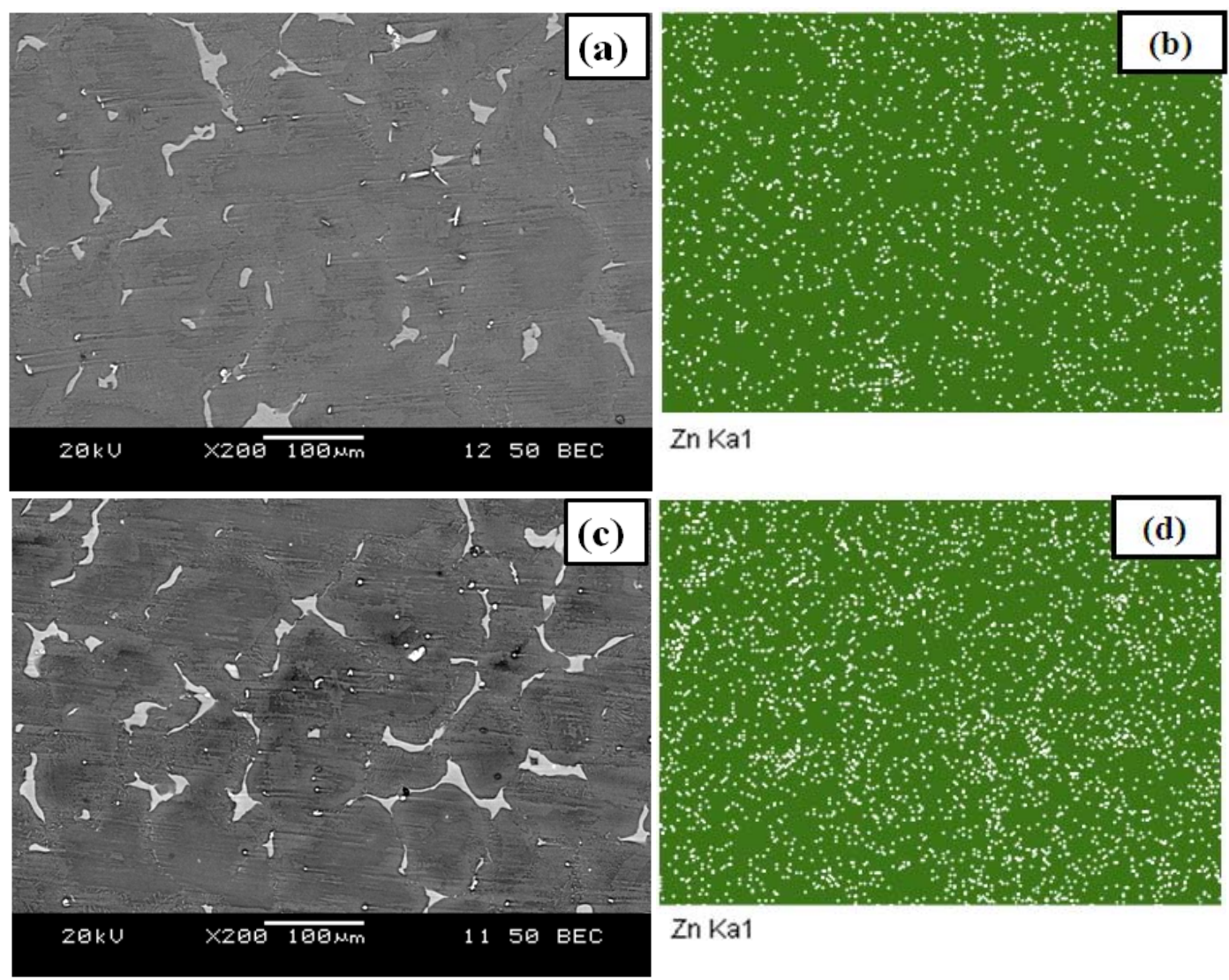

$\mathrm{Zn} \mathrm{Ka1}$

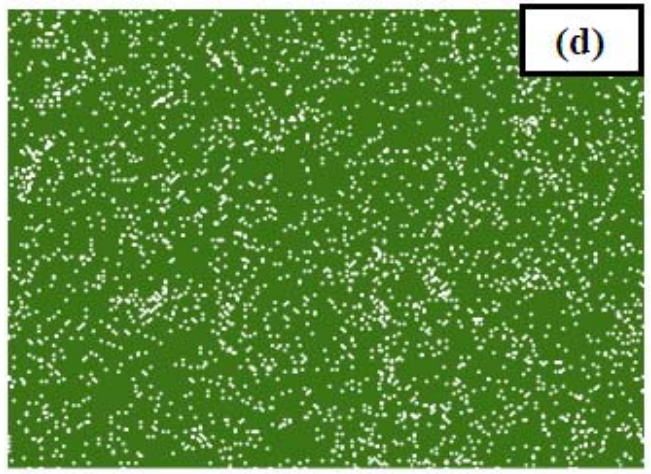

Zn Ka1

Fig. 4.10.3. SEM image and corresponding EDX map of AZ91E alloy with (a-b) no addition of $\mathrm{ZnO}$ and (c-d) $3 \mathrm{wt} . \% \mathrm{ZnO}$ addition.

Table 4.10.1. Average Zn Content (wt.\%) of AZ91E Alloy Castings Obtained Through EDX Point Analysis at Various ZnO Addition Levels

\begin{tabular}{|c|c|c|}
\hline \multirow{2}{*}{ Addition Level (wt.\%) } & \multicolumn{2}{|c|}{ Average Zn Content (wt.\%) } \\
\cline { 2 - 3 } & Matrix & $\boldsymbol{\beta}$-Phase \\
\hline 0 & $0.64 \pm 0.05$ & $2.5 \pm 0.16$ \\
\hline 3 & $1.62 \pm 0.18$ & $5.8 \pm 0.26$ \\
\hline
\end{tabular}



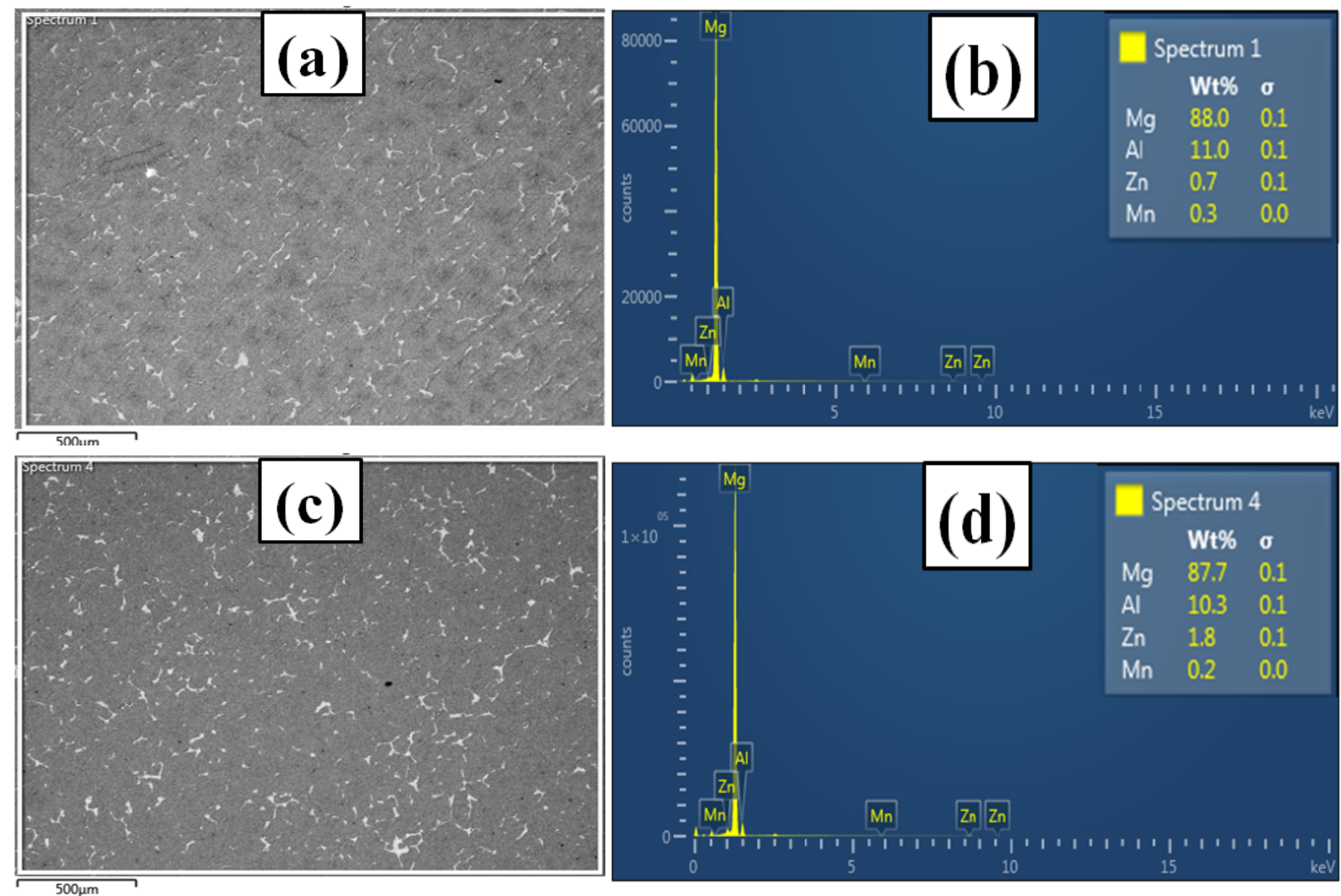

Fig. 4.10.4. SEM image and corresponding EDX analysis of AZ91E alloy with (a-b) no addition of $\mathrm{ZnO}$ and (c-d) 3 wt.\% $\mathrm{ZnO}$ addition.

A small amount of added $\mathrm{ZnO}$ particles acted as nucleating sites while the remaining $\mathrm{ZnO}$ may have dissociated, into $\mathrm{Zn}$ and $\mathrm{MgO}$ according to the chemical reaction shown in Equation 4.7.1. The presence of $\mathrm{MgO}$ in the alloys refined with $\mathrm{ZnO}$ is evident from the SEM image and corresponding EDX analysis as shown in Fig. 4.10.5. The melt appeared to oxidize to a greater extent with increasing $\mathrm{ZnO}$ addition. These analysis in permanent tensile mold casting further confirmed our assumptions of the grain refining mechanism of $\mathrm{ZnO}$ in $9 \mathrm{wt} . \% \mathrm{Al}$ containing $\mathrm{Mg}$ alloys ( as discussed in section 4.8), appears to be via two routes: - 1) $\mathrm{ZnO}$ act as a nucleating site and 2) $\mathrm{Zn}$ liberated during $\mathrm{ZnO}$ dissolution enabled grain growth restriction. 

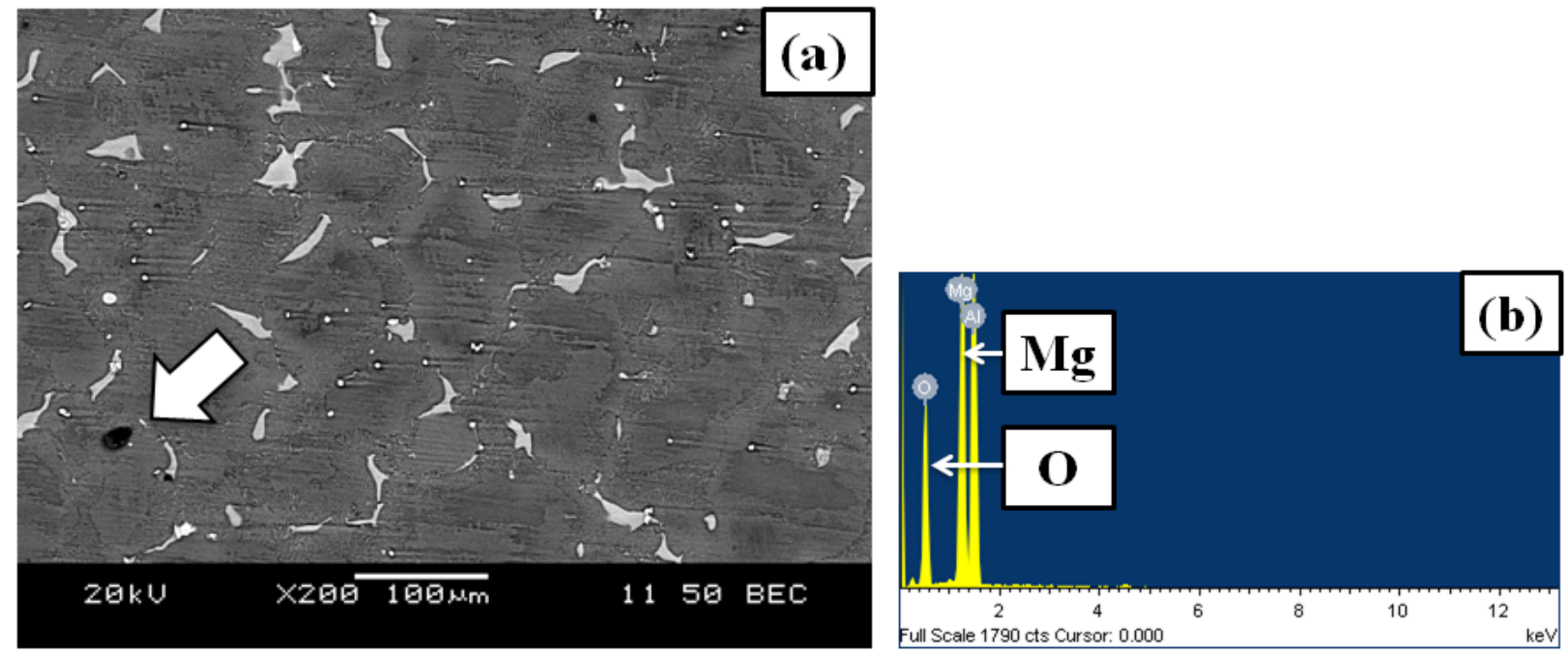

Fig. 4.10.5. SEM image and corresponding EDX analysis of AZ91E alloy with 3 wt.\% ZnO showing the presence of MgO.

\subsection{EFFECTS OF ZnO CONTENT ON MECHANICAL PROPERTIES OF AZ91E ALLOY (PERMANENT TENSILE MOLD)}

\subsubsection{TENSILE PROPERTIES}

The tensile properties $(0.2 \%$ offset yield strength, YS, ultimate tensile strength, UTS and elongation of the as-cast alloys tested at room temperature) are shown in Table 4.11.1 and Fig. 4.11.1. The YS, UTS and elongation of base AZ91E alloy was found to be $101 \mathrm{MPa}$, $154 \mathrm{MPa}$ and $3.05 \%$ respectively. With increasing $\mathrm{ZnO}$ addition, the $\mathrm{YS}$ of the alloys continuously increased. The YS with $3 \mathrm{wt} . \% \mathrm{ZnO}$ addition was $116 \mathrm{MPa}$ which was around $15 \%$ higher than the base alloy. From the base alloy to $0.5 \mathrm{wt} \% \mathrm{ZnO}$ addition, the UTS and elongation increased. The UTS and elongation of AZ91E with $0.5 \mathrm{wt} . \% \mathrm{ZnO}$ were $172 \mathrm{MPa}$ and $5.49 \%$ respectively. The maximum UTS value (177 $\mathrm{MPa}$ ) was found at $3 \mathrm{wt} . \% \mathrm{ZnO}$ addition ( $15 \%$ higher than that of the base alloy). The elongation beyond $0.5 \mathrm{wt} . \%$ addition continuously decreased. The elongation with $3 \mathrm{wt} . \% \mathrm{ZnO}$ addition was 4.3\%. Finer grain sizes associated with $\mathrm{ZnO}$ addition likely increased the strength of the alloys. In addition thinner and more divorced $\mathrm{Zn}$ enriched $\beta$-intermetallic phases were observed with increased $\mathrm{ZnO}$ addition. Finely distributed $\beta$-phase possibly improved alloy strengthening compared to the base alloy which has continuous brittle $\beta$-intermetallic phases. Solid solution strengthening of the alloys, due to increased $\mathrm{Zn}$ solute with increased $\mathrm{ZnO}$ addition, is considered to be responsible for reduction of 
the elongation beyond $0.5 \mathrm{wt} . \%$ of $\mathrm{ZnO}$ accompanied by an increase in tensile strength. In addition, the higher $\mathrm{ZnO}$ levels possibly introduced more oxides causing a reduction in elongation.

Table 4.11.1Tensile Properties of AZ91E Alloy with ZnO Addition

\begin{tabular}{|c|c|c|c|c|c|c|c|c|c|}
\hline \multirow{2}{*}{$\begin{array}{c}\text { Addition } \\
\text { Level } \\
\text { (wt.\%) }\end{array}$} & \multicolumn{3}{|c|}{$\mathbf{0 . 2 \%}$ YS } & \multicolumn{3}{c|}{ UTS } & \multicolumn{3}{c|}{ Elongation } \\
\cline { 2 - 10 } & $\mathbf{M P a}$ & $\begin{array}{c}\text { Std. } \\
\text { Dev. } \\
(+/-)\end{array}$ & $\begin{array}{c}\text { Change } \\
(\%)\end{array}$ & MPa & $\begin{array}{c}\text { Std. } \\
\text { Dev. } \\
(+/-)\end{array}$ & $\begin{array}{c}\text { Change } \\
(\%)\end{array}$ & $\begin{array}{c}\text { Std. } \\
\text { Dev. } \\
(+/-)\end{array}$ & $\begin{array}{c}\text { Change } \\
(\%)\end{array}$ \\
\hline 0 & 101 & 3.85 & - & 154 & 3.31 & - & 3.05 & 0.11 & - \\
\hline 0.25 & 107 & 5.17 & $5.9 \uparrow$ & 158 & 20.12 & $2.6 \uparrow$ & 4.94 & 0.47 & $61.9 \uparrow$ \\
\hline 0.5 & 110 & 3.09 & $8.9 \uparrow$ & 172 & 14.17 & $11.7 \uparrow$ & 5.49 & 0.57 & $80.0 \uparrow$ \\
\hline 0.75 & 111 & 1.34 & $9.9 \uparrow$ & 170 & 7.57 & $10.4 \uparrow$ & 4.79 & 0.40 & $57.0 \uparrow$ \\
\hline 1 & 113 & 1.25 & $11.9 \uparrow$ & 175 & 12.57 & $13.6 \uparrow$ & 4.59 & 0.59 & $50.5 \uparrow$ \\
\hline 3 & 116 & 8.35 & $14.9 \uparrow$ & 177 & 8.32 & $14.9 \uparrow$ & 4.30 & 0.36 & $40.9 \uparrow$ \\
\hline
\end{tabular}

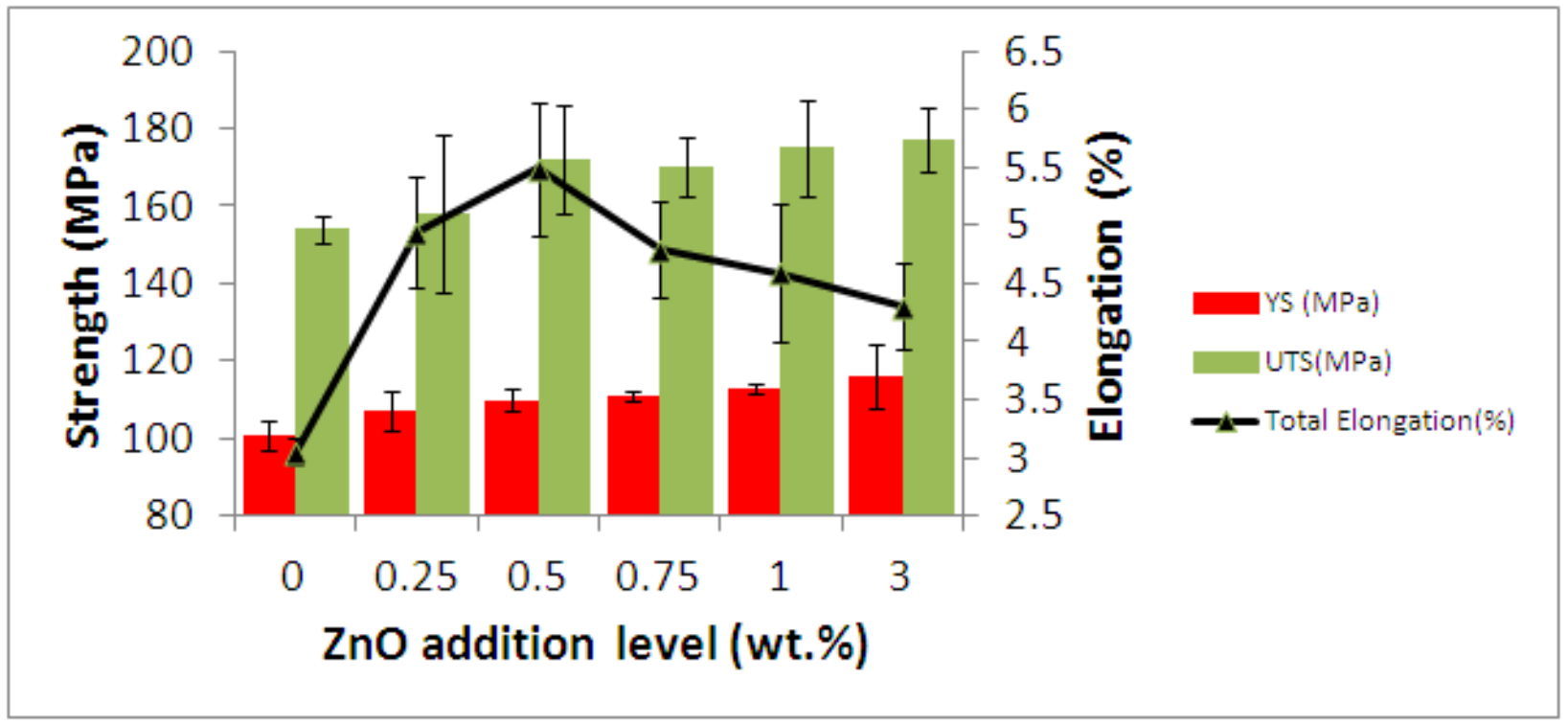

Fig. 4.11.1. Tensile properties of AZ91E alloy with various levels of ZnO addition. 
The variation of yield strength with grain size according to the Hall-Petch relation plotted in Fig. 4.11.2 according to equation 4.11.1. The yield strength and the corresponding grain sizes are presented in Table 4.11.2

$\mathrm{YS}=351.09 \mathrm{~d}^{-1 / 2}+72.05(\mathrm{MPa})$

Equation 4.11.1

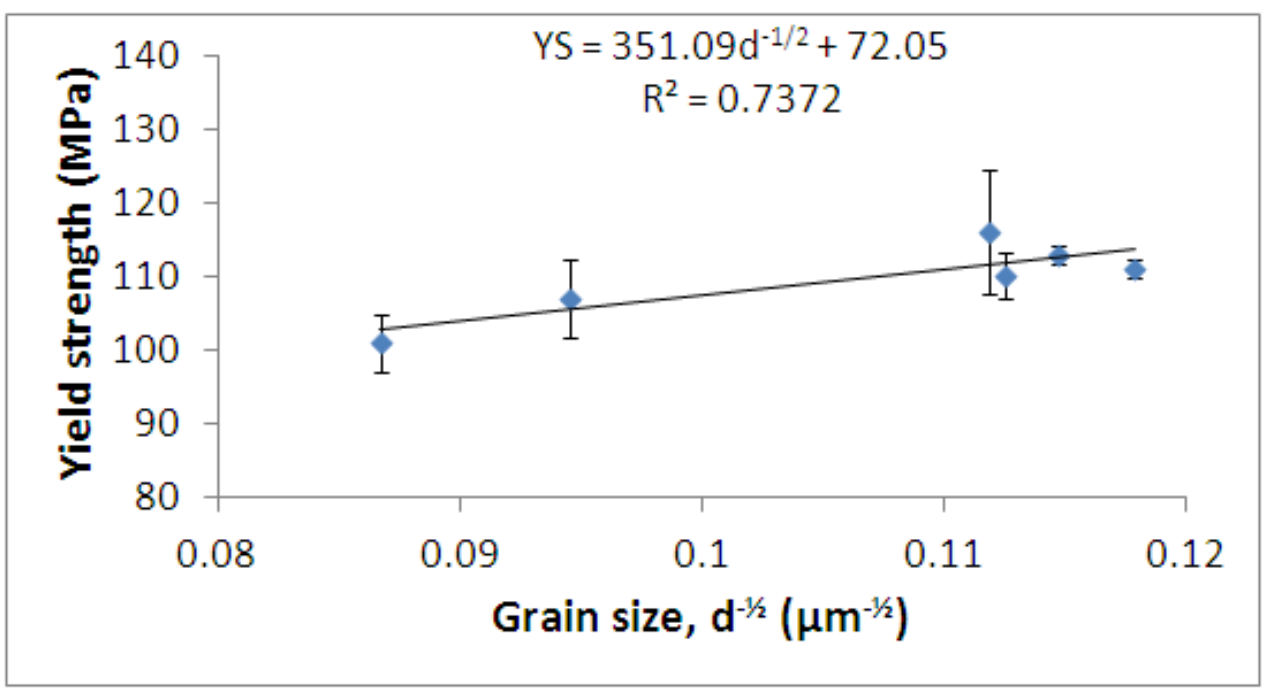

Fig. 4.11.2. Average YS of AZ91E alloy at different grain sizes.

Table 4.11.2. 0.2\% YS of AZ91E Alloy at Different Grain Sizes

\begin{tabular}{|c|c|c|}
\hline \multicolumn{2}{|c|}{ Grain Size $(\boldsymbol{\mu m})$} & \multirow{2}{*}{$\mathbf{0 . 2 \%}$ YS (MPa) } \\
\cline { 1 - 2 } $\mathbf{d}(\boldsymbol{\mu m})$ & $\mathrm{d}^{-1 / 2}(\boldsymbol{\mu m})^{-1 / 2}$ & 101 \\
\hline 133 & 0.087 & 107 \\
\hline 112 & 0.094 & 110 \\
\hline 79 & 0.113 & 111 \\
\hline 72 & 0.118 & 113 \\
\hline 76 & 0.115 & 116 \\
\hline 80 & 0.111 & \\
\hline
\end{tabular}




\subsubsection{FRACTOGRAPHY}

Samples for fracture analysis were prepared from the tested tensile specimens to gain a better understanding of the failure mode of the refined and unrefined AZ91E alloys. SEM images of the fractured tensile samples of (a) AZ91E, (b) AZ91E with 0.5 wt.\% addition and (c) AZ91E with 3 wt.\% addition of $\mathrm{ZnO}$ are shown in Fig. 4.11.3. Tensile fracture of $\mathrm{Mg}$ alloys at room temperature is usually brittle where cleavage is the principal fracture mode [Lu et. al., 2000]. Fig. 4.11.3-a reveals that the fracture surface of the base AZ91E alloy composed of large cleavage planes and cleavage steps (indicated by "1") and cleavage rivers with large crystal like morphology. Some secondary cracks (indicated by "2") can also be seen. From all these characteristics it can be assumed that the failure is cleavage fracture matching the low ductility (3.05\%) of the alloy (Fig. 4.11.1). On the other hand Fig. 4.11.3-b with AZ91E+0.5 wt.\% ZnO shows a finer microstructure with some secondary cracks and a few small cleavage planes. With further addition of $\mathrm{ZnO}$ the ductility of the alloy is decreased as can be seen from Fig. 4.11.3-c with 3 wt.\% addition of $\mathrm{ZnO}$. However, the fracture surface is dominant by many shallow dimples indicating more ductile (5.49\%) type fracture.
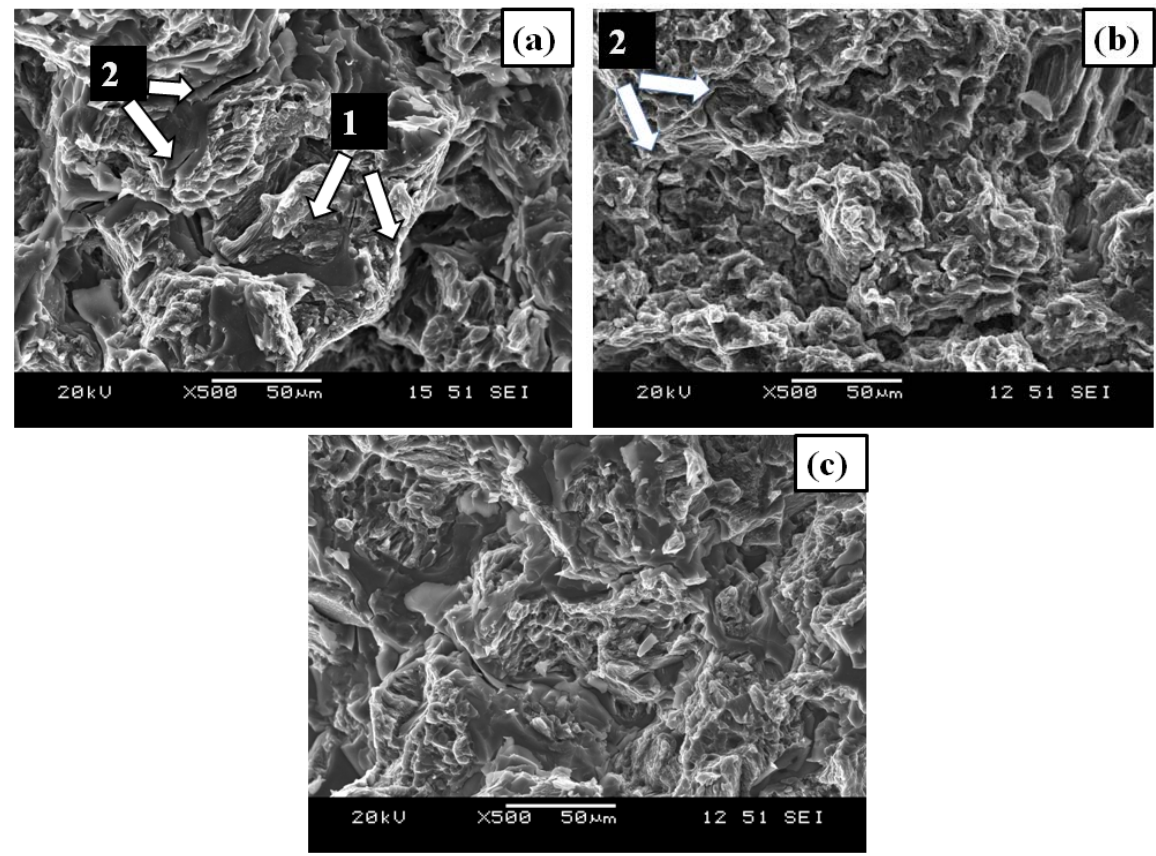

Fig. 4.11.3. SEM images of fracture surface of AZ91E alloy with (a) no addition of $\mathrm{ZnO}$ and (b) 0.5 wt. \% ZnO addition (c) 3 wt.\% ZnO addition. (1) Cleavage steps (2) Secondary crack. 
In the base AZ91E alloy, the $\alpha$-matrix is surrounded by hard and brittle $\beta$-phase along the grain boundaries which weaken the boundaries. It can be assumed that when load is applied, microcracks are readily initiated and propagated along the grain boundaries. This made the fracture surface more brittle in nature [Suresh et. al., 2011] (Fig. 4.11.3-a). The AZ91E alloy refined by $\mathrm{ZnO}$ has a finer microstructure and thinner, more divorced $\beta$-phase as compared to the base alloy. This may have helped in improving the strength of the grain boundaries. It is assumed that the cracks developed due to tensile loading, frequently pass through the matrix along with the grain boundaries resulting in a fracture surface showing more ductile character (Fig. 4.11.3-b).

\subsubsection{HARDNESS}

The effects of $\mathrm{ZnO}$ addition on the hardness of AZ91E alloy were studied in permanent tensile mold castings. The average Rockwell hardness values (HRE) and microhardness (HV) values of the matrix of AZ91E with different levels of $\mathrm{ZnO}$ addition are summarized in Table 4.11.3.

Table 4.11.3. Hardness of AZ91E Alloy with ZnO Addition

\begin{tabular}{|c|c|c|c|c|c|c|}
\hline \multirow{2}{*}{$\begin{array}{c}\text { Addition Level } \\
\text { (wt.\%) }\end{array}$} & \multicolumn{3}{|c|}{ Rockwell Hardness E Test } & \multicolumn{3}{c|}{ Vickers Hardness Test } \\
\cline { 2 - 7 } & $\begin{array}{c}\text { Hardness } \\
\text { (HRE) }\end{array}$ & $\begin{array}{c}\text { Std. Dev. } \\
(+/ /)\end{array}$ & $\begin{array}{c}\text { Change } \\
\text { (\%) }\end{array}$ & $\begin{array}{c}\text { Microhardness } \\
\text { (HV) }\end{array}$ & $\begin{array}{c}\text { Std. Dev. } \\
\text { (+/-) }\end{array}$ & $\begin{array}{c}\text { Change } \\
\text { (\%) }\end{array}$ \\
\hline 0 & 57 & 6.04 & - & 58 & 6.53 & - \\
\hline 0.25 & 57 & 3.97 & 0 & 61 & 8.14 & 5.2 \\
\hline 0.5 & 58 & 8.84 & 1.8 & 64 & 9.81 & 10.3 \\
\hline 0.75 & 60 & 7.70 & 5.3 & 65 & 5.22 & 12.1 \\
\hline 1 & 63 & 5.85 & 10.5 & 67 & 9.46 & 15.5 \\
\hline 3 & 65 & 3.70 & 14.0 & 72 & 5.82 & 24.1 \\
\hline
\end{tabular}

The average Rockwell hardness values (HRE) of AZ91E alloys with $\mathrm{ZnO}$ addition are shown in Fig. 4.11.4. With increasing $\mathrm{ZnO}$ addition, the HRE of the alloys also had an increasing trend. The hardness of the base AZ91E alloy was 57 HRE. Zinc oxide addition upto 0.5 wt.\% showed no significant change in HRE. Addition levels beyond 0.5 wt.\% showed an increase of $14 \%$ over that of the base alloy. 


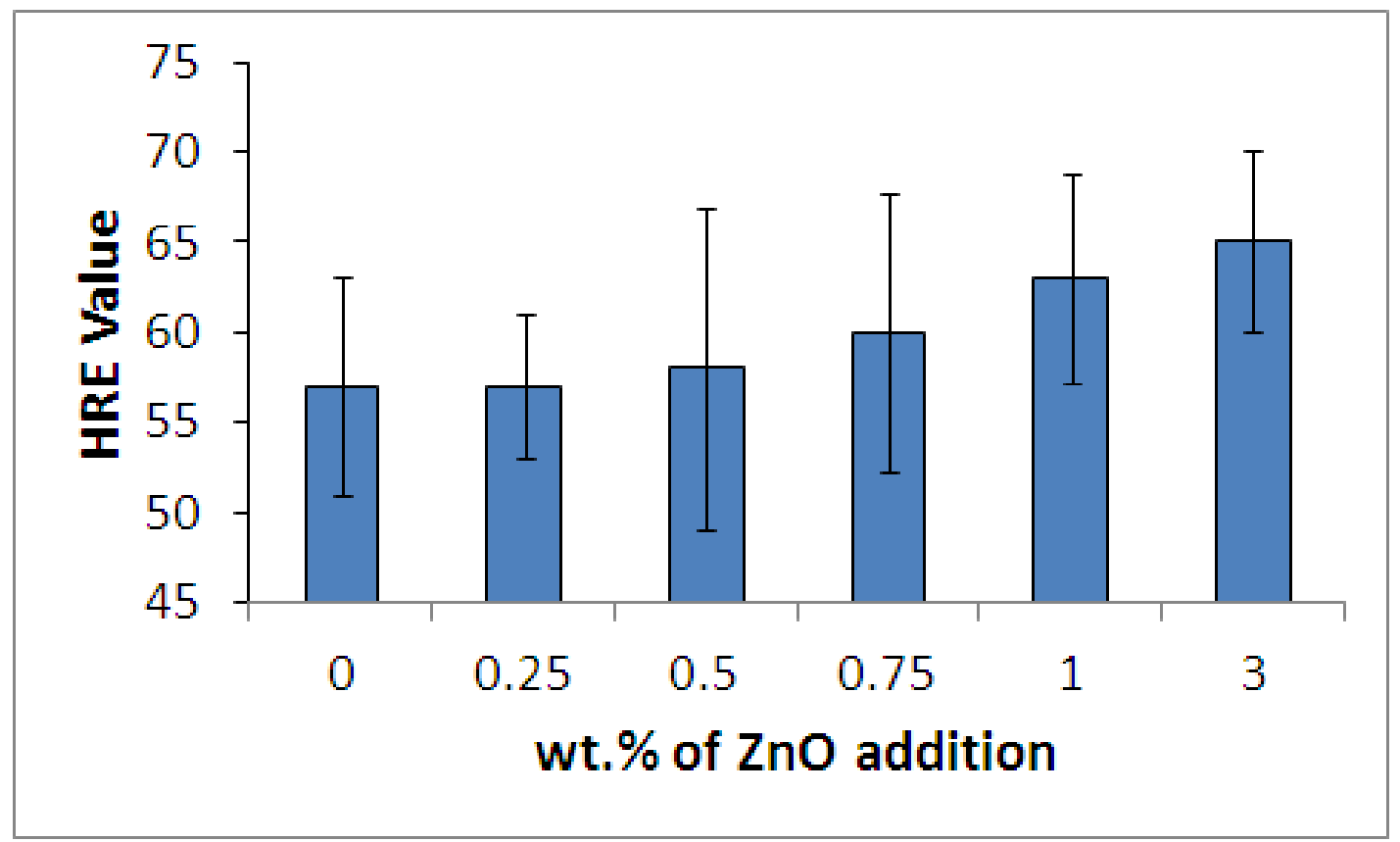

Fig. 4.11.4. Average HRE of AZ91E alloy with ZnO addition.

The microhardness (HV) values of the matrix of AZ91E with different levels of $\mathrm{ZnO}$ addition are shown in Fig. 4.11.5. The microhardness of the base alloy was $58 \mathrm{HV}$. With 0.25 and $0.5 \mathrm{wt} . \% \mathrm{ZnO}$ additions the microhardness values were $61 \mathrm{HV}$ and $64 \mathrm{HV}$ respectively. The average hardness of the alloy matrix at $3 \mathrm{wt} . \%$ addition of $\mathrm{ZnO}$ was $72 \mathrm{HV}(24 \%$ higher than the base alloy matrix).

Smaller grains result in larger grain boundary area. The larger grain boundary area can better impede dislocation motion compared to a coarse grain structure resulting in increased alloy strength [Cao et. al., 2006]. The increase in hardness and microhardness of the alloy with $\mathrm{ZnO}$ addition may also be related to solid solution strengthening of the matrix. 


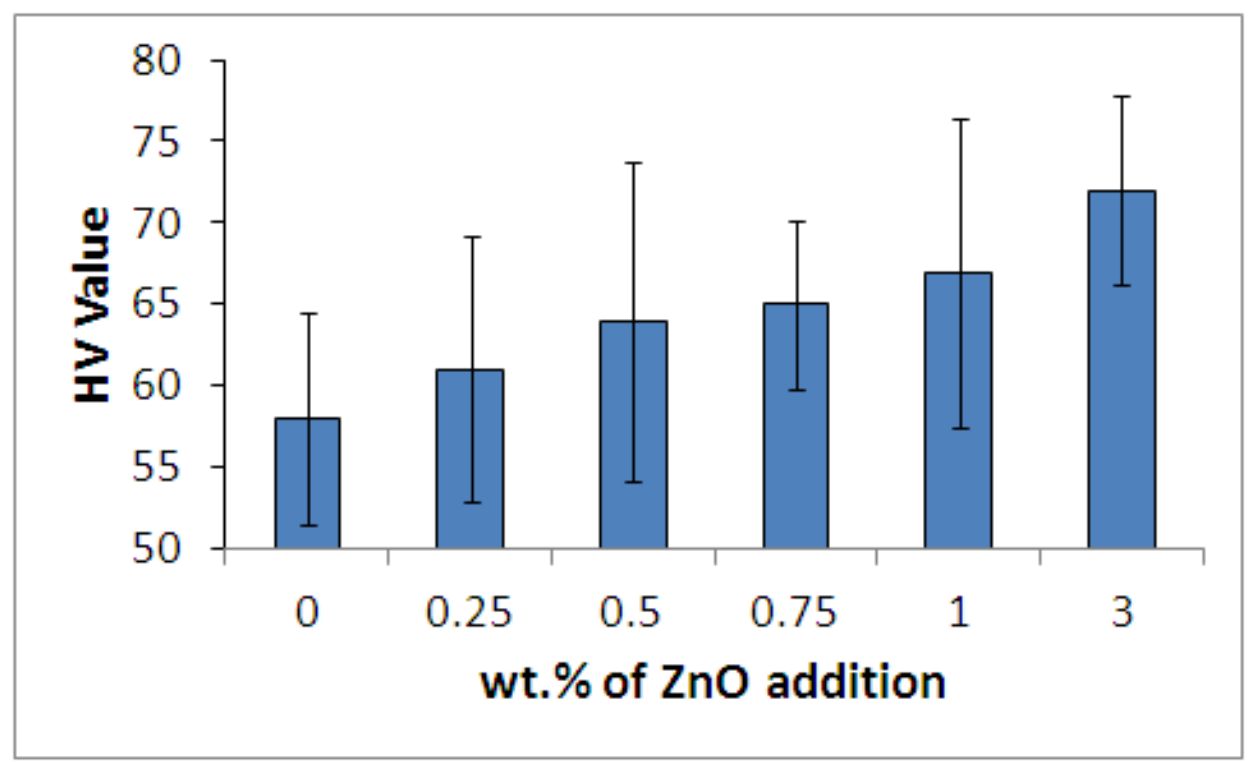

Fig. 4.11.5. Average microhardness of AZ91E alloy with ZnO addition.

\subsection{POROSITY}

The average porosity (\%) levels of all the castings used in this study were less than $2.5 \%$ as shown in Table 4.12.1 and Fig. 4.12.1. The low porosity levels indicate that the mechanical properties obtained in this study represented sound castings.

Table 4.12.1. Average Porosity (\%) Levels of AZ91E Alloy at Different Addition Levels of $\mathrm{ZnO}$

\begin{tabular}{|c|c|c|}
\hline Addition Level (wt.\%) & Porosity (\%) & Std. Dev. (+/-) \\
\hline 0 & 1.6 & 0.63 \\
\hline 0.25 & 2.15 & 0.32 \\
\hline 0.5 & 2.23 & 0.20 \\
\hline 0.75 & 1.6 & 0.35 \\
\hline 1 & 1.58 & 0.65 \\
\hline 3 & 1.01 & 0.22 \\
\hline
\end{tabular}




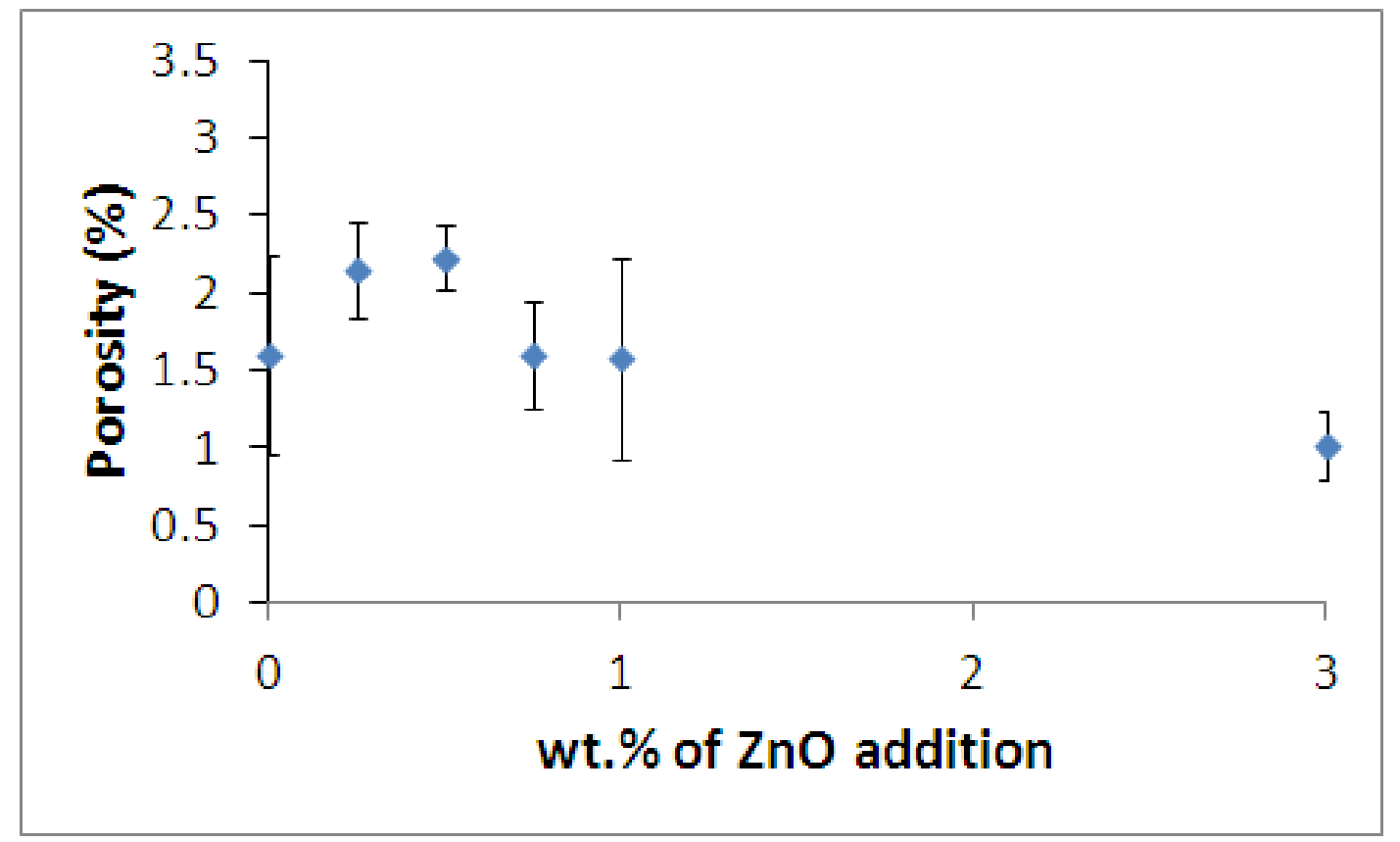

Fig. 4.12.1. Average porosity (\%) of AZ91E alloy with ZnO addition.

\subsection{CHAPTER SUMMARY}

The grain refinement effect of $\mathrm{ZnO}$ was significant in both AZ91E and binary Mg-9 wt.\% Al alloys. The effect persisted upto 1 hour of holding time. Addition of $\mathrm{ZnO}$ improved the mechanical properties of AZ91E alloy. 


\section{Chapter 5: Conclusions}

This study was conducted with a view to examine the effectiveness of $\mathrm{ZnO}$ as a potential grain refiner for AZ91E and Mg-9 wt.\% Al binary alloys as well as to determining its refining mechanism. The influence of $\mathrm{ZnO}$ on the grain size, hardness, and tensile properties at ambient temperature were studied. This study showed that $\mathrm{ZnO}$ is a reliable, effective and economical grain refiner for both $\mathrm{AZ}$ and binary alloys.

The conclusions drawn from this study are as follows:

\section{Graphite Mold Casting}

1. For AZ91E alloy, maximum grain size reduction (50\%) was found at $0.75 \mathrm{wt} . \%$ addition of $\mathrm{ZnO}(108 \mu \mathrm{m})$ and for $\mathrm{Mg}-9$ wt.\% Al binary alloy maximum reduction (68\%) was found at $3 \mathrm{wt} . \%$ addition of $\mathrm{ZnO}(93 \mu \mathrm{m})$.

2. No fading effect was observed for upto 1 hour of holding time for the $3 \mathrm{wt} . \% \mathrm{ZnO}$ in both $\mathrm{AZ}$ and binary alloys. Grain size was found to remain constant during this period.

3. Grain refinement was attributed heterogeneous nucleation due to $\mathrm{ZnO}$ and grain growth restriction of $\mathrm{Zn}$ (which was liberated during $\mathrm{ZnO}$ dissociation) on $\alpha-\mathrm{Mg}$ matrix.

\section{Tensile Mold Casting}

1. A grain size reduction of almost $44 \%$ was achieved with a small $(0.5$ wt. $\%)$ addition of $\mathrm{ZnO}$. The base alloy had a grain size of $133 \mu \mathrm{m}$. Optimum grain size reduction of the AZ91E alloy was achieved using $0.5 \mathrm{wt} . \% \mathrm{ZnO}$ addition resulting in grain size of $75 \mu \mathrm{m}$.

2. Grain refinement was attributed to heterarogeneous nucleation due to $\mathrm{ZnO}$. Further, $\mathrm{Zn}$ liberated during $\mathrm{ZnO}$ dissolution appears to have enabled grain growth restriction.

3. Addition of $\mathrm{ZnO}$ improved the tensile properties of the AZ91E alloy. For the base alloy, the YS, UTS and elongation were $101 \mathrm{MPa}, 154 \mathrm{MPa}$ and 3.05\% respectively. The highest YS and UTS of the alloy were found at 3 wt.\% addition of $\mathrm{ZnO}$ which were $116 \mathrm{MPa}$ and $177 \mathrm{MPa}$ respectively. These values were $15 \%$ higher than that of the base alloy. The maximum elongation was $5.49 \%$ observed using $0.5 \mathrm{wt} . \% \mathrm{ZnO}$ addition. 
4. SEM observations of tensile fracture surfaces revealed mainly cleavage type fracture for the base AZ91E alloy. With $0.5 \mathrm{wt} . \%$ addition of $\mathrm{ZnO}$, the fracture surfaces were dominated by shallow dimples along with small cleavage planes which were more quasi-cleavage in nature, indicating higher ductility in alloys refined with $\mathrm{ZnO}$.

5. With $\mathrm{ZnO}$ addition, the Rockwell hardness and Vickers microhardness of the alloys increased. With 3 wt.\% $\mathrm{ZnO}$ addition the HRE and $\mathrm{HV}$ of the alloys were higher than the base alloy by $14 \%$ and $24 \%$ respectively. 


\section{Chapter 6: Recommendations for Future Work}

The current study showed the potential of $\mathrm{ZnO}$ as a grain refiner for $\mathrm{Mg}$ alloys containing $9 \mathrm{wt} . \%$ Al. Further investigation is required to investigate some additional features in order to explore the total opportunity that can be gained from this grain refiner in an industrial set up.

1. Optimization of casting parameters (addition temperature, holding time, addition method) to reduce the reduction of $\mathrm{ZnO}$ in $\mathrm{Mg}$ alloys melt.

2. Study the post-recycle effect of $\mathrm{Mg}$ alloys refined by $\mathrm{ZnO}$ on grain size and mechanical properties.

3. Study the effects of $\mathrm{ZnO}$ particle size on the grain refinement and mechanical properties of Mg alloys.

4. Effect on mechanical properties with $\mathrm{ZnO}$ refined $\mathrm{Mg}$ alloys at service temperatures (e.g. $180-200^{\circ} \mathrm{C}$ ) for automotive engine block components. 


\section{Appendices}

\section{Appendix-A1: Mg-Al Phase Diagram}

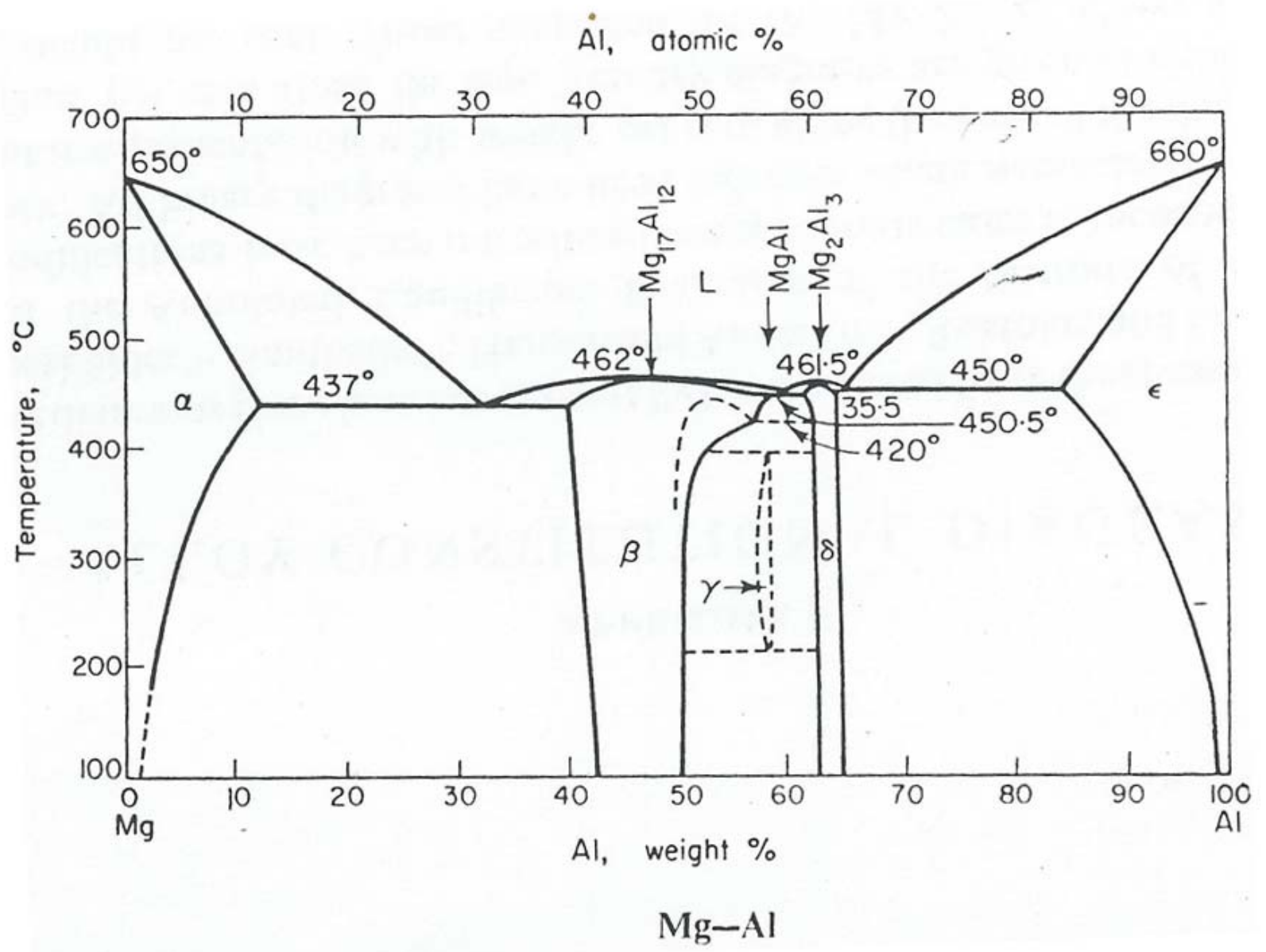

Fig. A.1 Mg-Al phase diagram [Emely, 1966]. 
Appendix-A2: SEM Image of ZnO
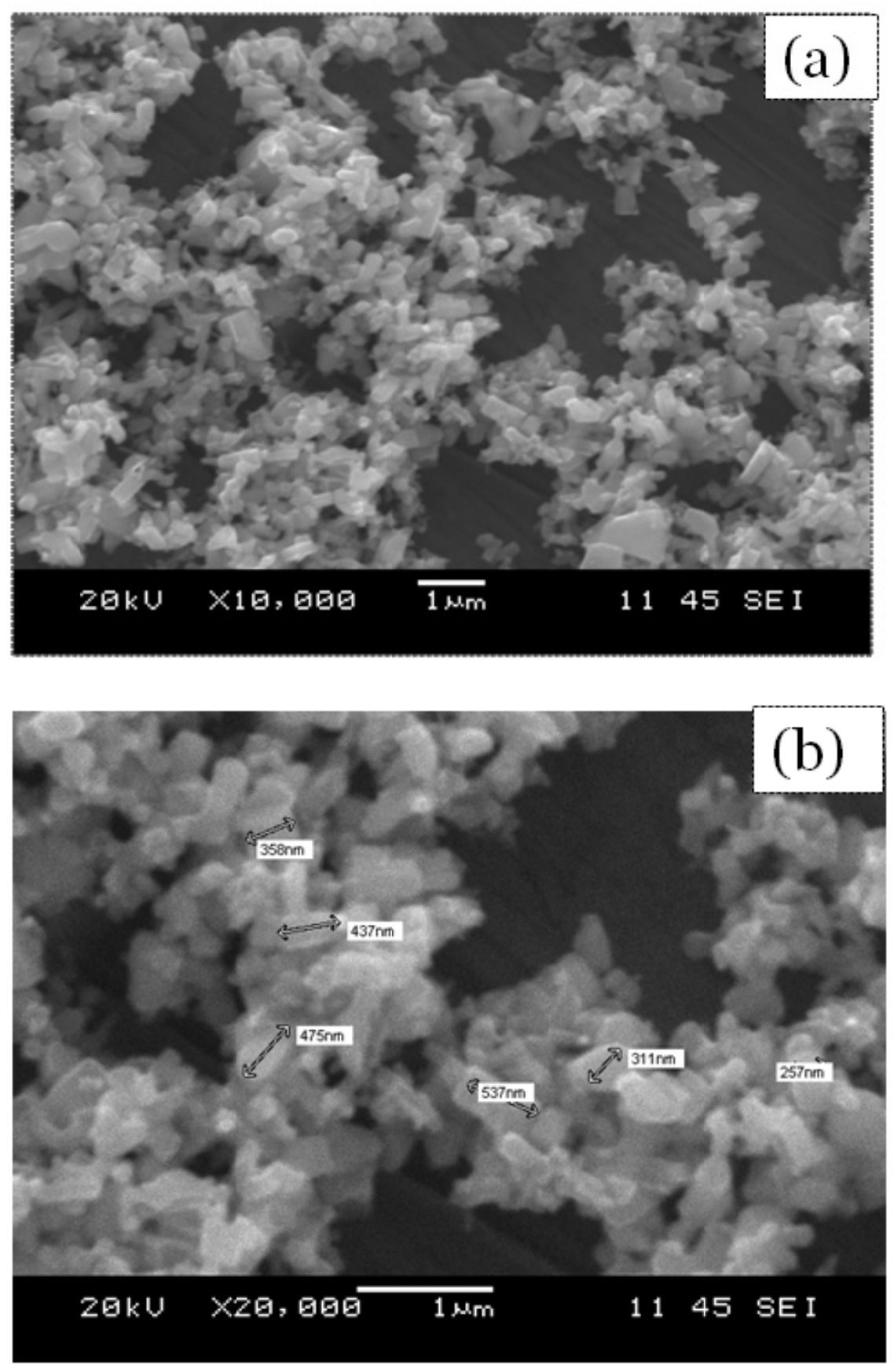

Fig. A.2 (a) Representative SEM image of ZnO (b) showing dimensions of individual ZnO particle. 
Appendix-A3: Cooling Curves of AZ91E+X wt. \% ZnO

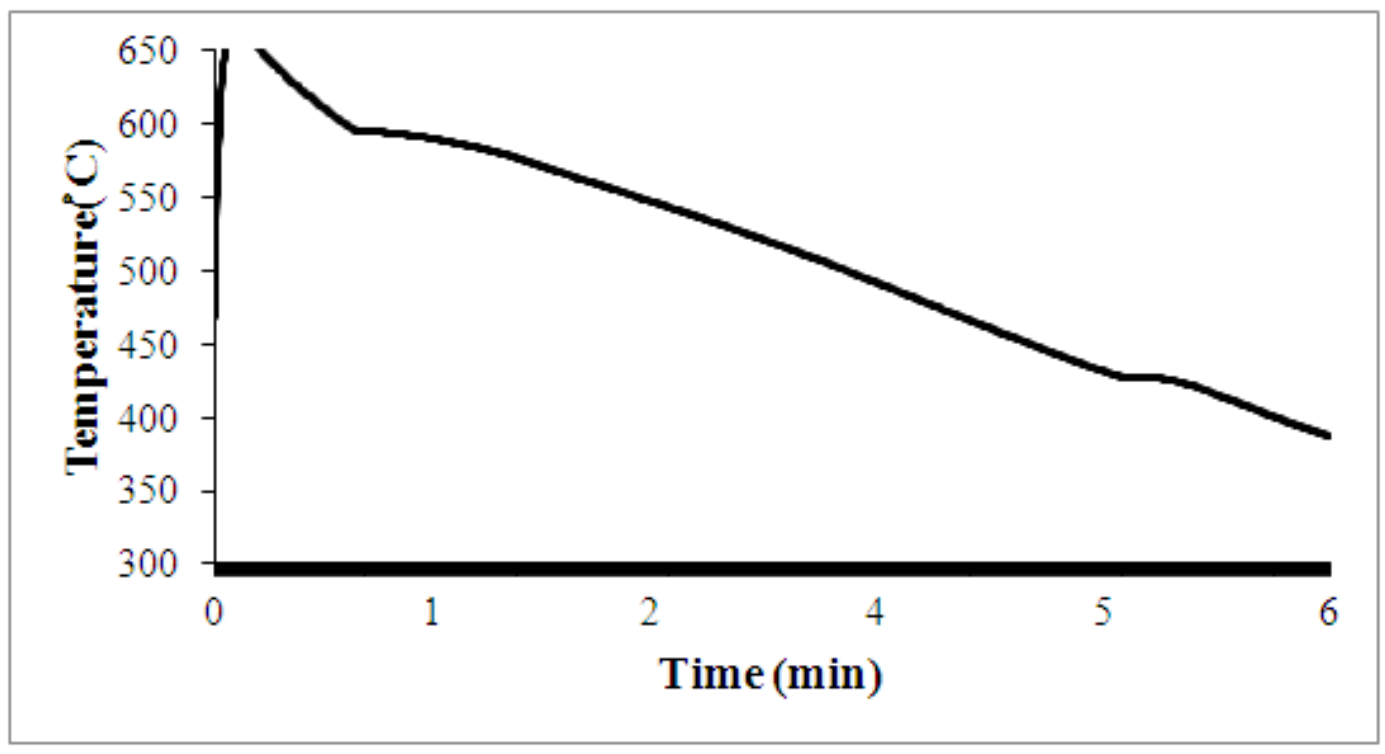

Fig. A.3.1. Cooling curve of base AZ91E alloy.

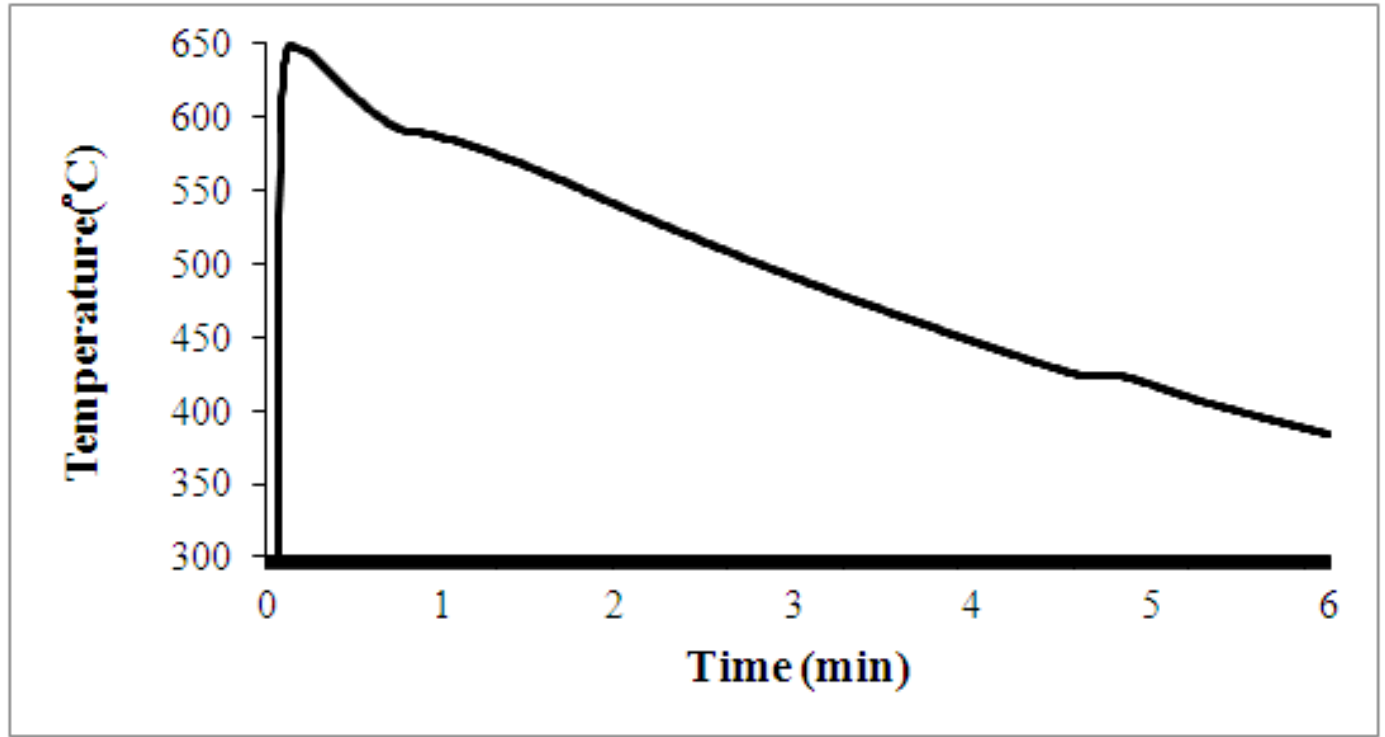

Fig. A.3.2. Cooling curve of base AZ91E + 0.25 wt.\% ZnO alloy. 


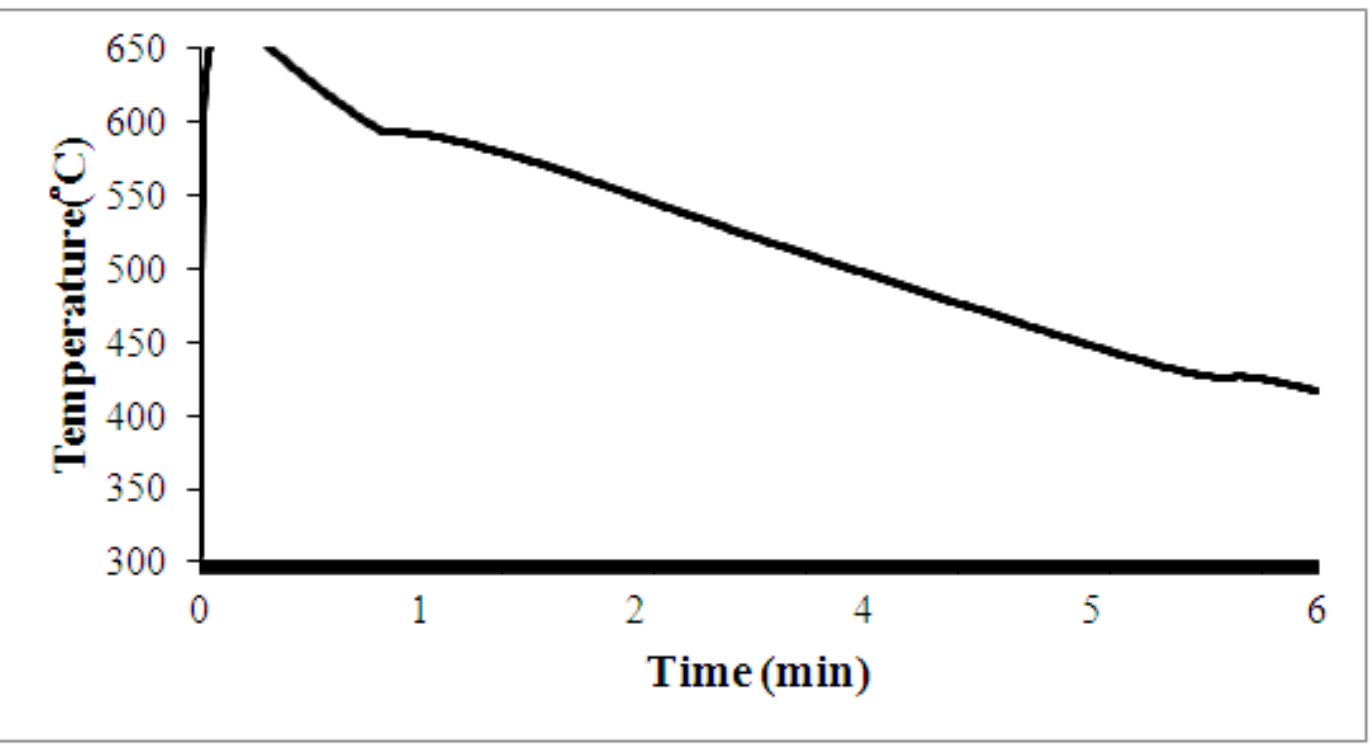

Fig. A.3.3. Cooling curve of base AZ91E + 0.5 wt. $\%$ ZnO.

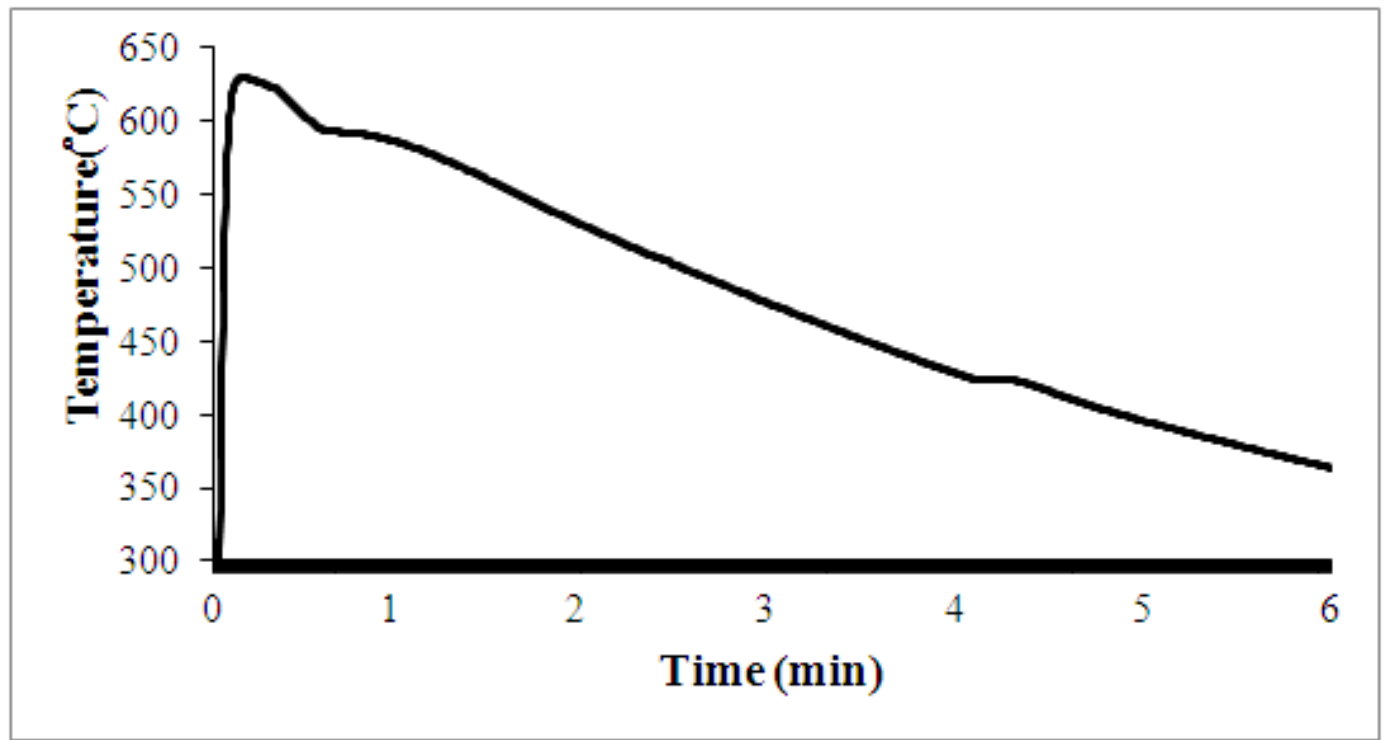

Fig. A.3.4. Cooling curve of base AZ91E + $0.75 w t . \%$ ZnO. 


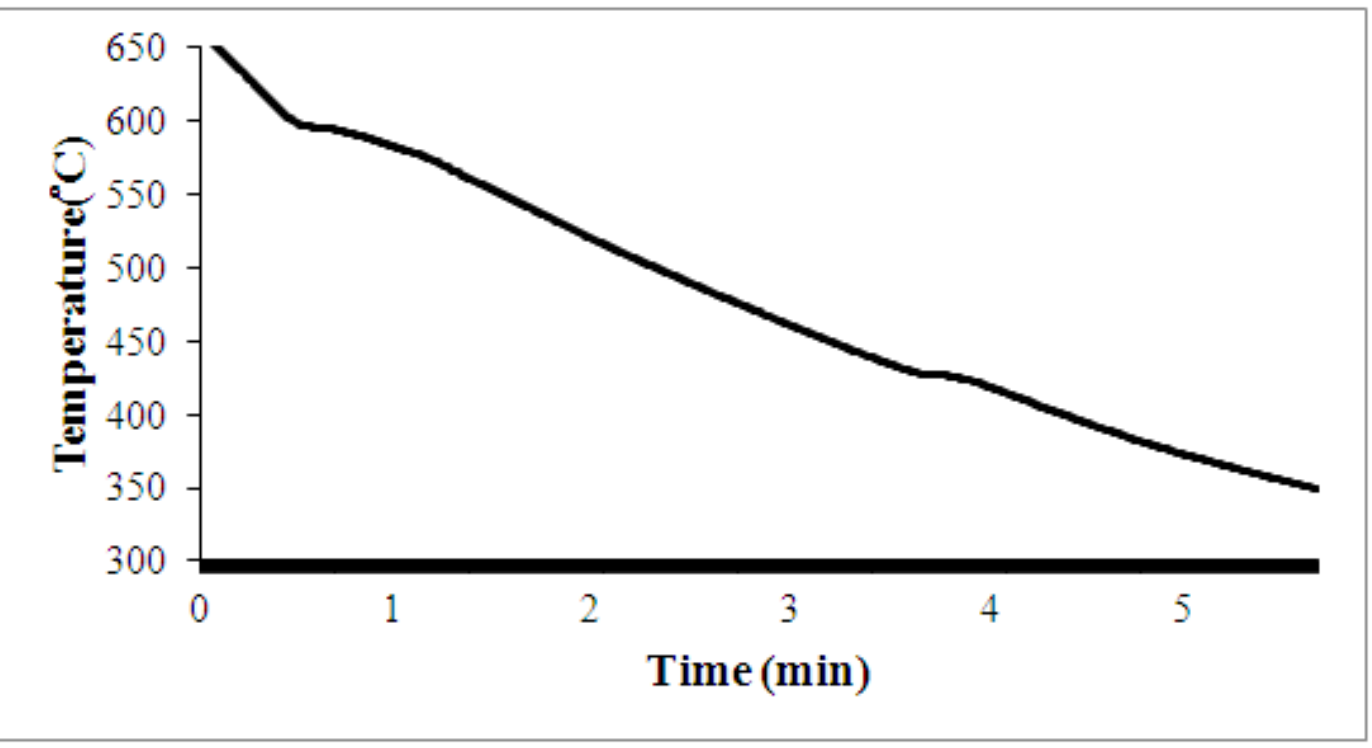

Fig. A.3.5. Cooling curve of base AZ91E + 1 wt.\% ZnO.

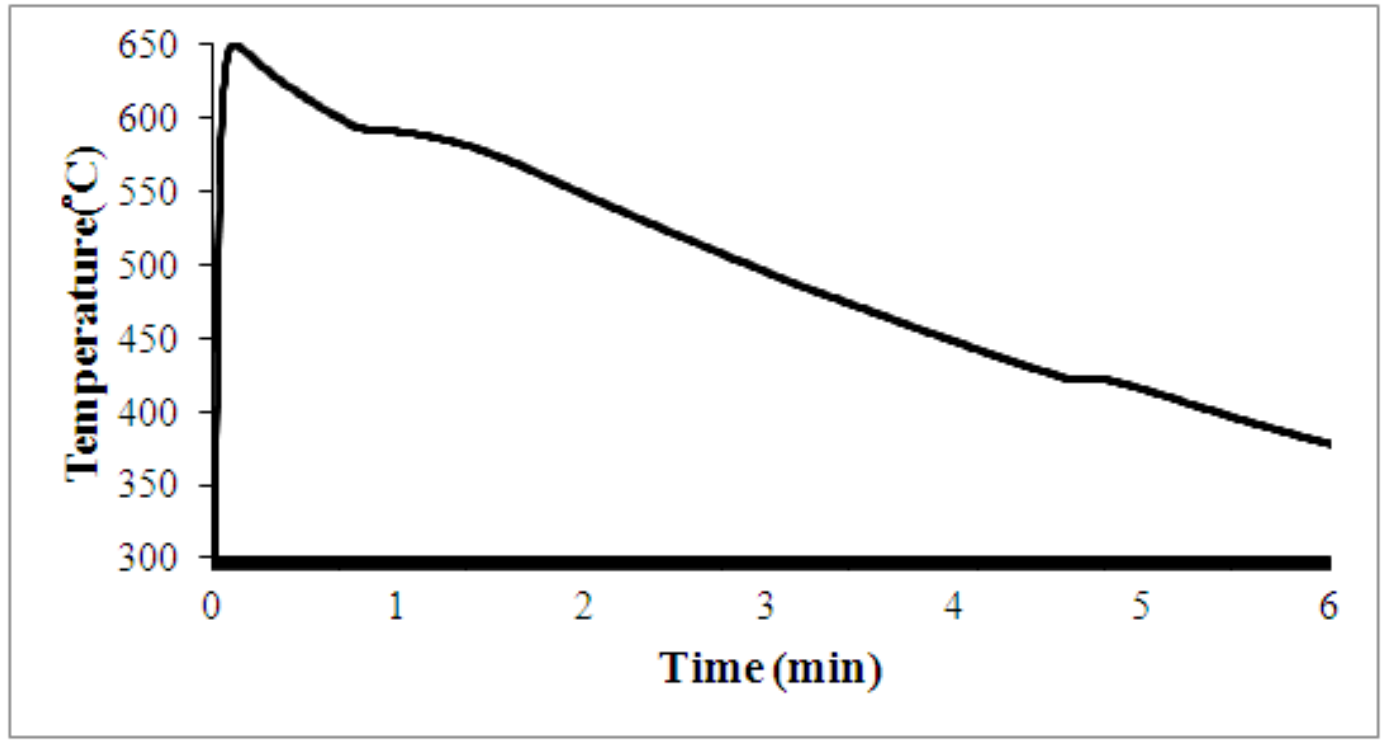

Fig. A.3.6. Cooling curve of base AZ91E + 2 wt.\% ZnO. 


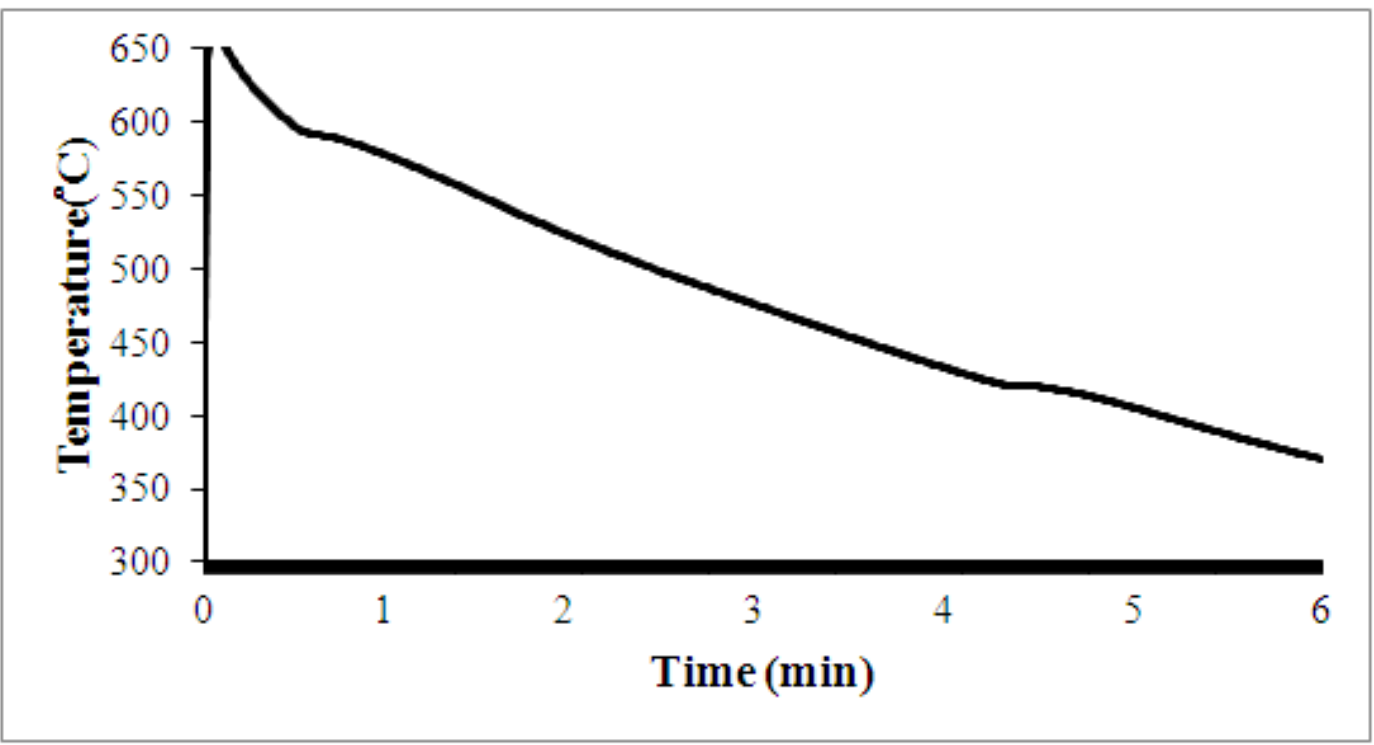

Fig. A.3.7. Cooling curve of base AZ91E + 3 wt.\% ZnO. 


\section{Appendix-A4: Free Energy Calculations}

The stability and equilibrium of a process or chemical reaction can be determined through thermo-chemical calculation. A negative value of the change in energy $(\Delta \mathrm{G})$ implies the process or chemical reaction is spontaneous and in forward direction. $\Delta \mathrm{G}$ (also known as "driving force") can be determined using Gibbs-Helmholtz equation [Kubaschewski, 1967]:

$\Delta \mathrm{G}^{\circ}=\Delta \mathrm{H}^{\circ}-\mathrm{T} \Delta \mathrm{S}^{\circ}$

Equation A4.1

where

$\Delta \mathrm{G}$ is the free energy of formation

$\Delta \mathrm{H}$ is the heat of formation

$\Delta \mathrm{S}$ is the entropy of reaction

Equation A4.1 was used to find the spontaneity and stability of the following reaction

$\mathrm{ZnO}+\mathrm{Mg} \rightarrow \mathrm{MgO}+\mathrm{Zn}$

Equation 4.7.1

A sample calculation for determining $\Delta \mathrm{G}$ is described below. All the thermodynamic data are collected from Kubaschewski, 1967.

Table A3.1. Heats of Formation, Standard Entropies of Different Substances

\begin{tabular}{|c|c|c|}
\hline Substance & $-\Delta \mathbf{H}_{\mathbf{2 9 8}}^{\circ}(\mathrm{Kcal} / \mathbf{m o l e})$ & $\mathbf{S}_{\mathbf{2 9 8}}$ (cal. $\mathbf{~ D e g}^{-1}$. $\mathbf{m o l e}^{-1}$ ) \\
\hline$<\mathrm{MgO}>$ & $143.7 \pm 0.2$ & $6.55 \pm 0.15$ \\
\hline$<\mathrm{Mg}>$ & 0 & $7.77 \pm 0.1$ \\
\hline$<\mathrm{Zn}>$ & 0 & $9.95 \pm 0.05$ \\
\hline$<\mathrm{ZnO}>$ & $83.2 \pm 0.3$ & $14.4 \pm 0.1$ \\
\hline
\end{tabular}

$<>\quad$ Solid

$\Delta \mathrm{G}^{\circ}=\left(\sum \Delta \mathrm{H}_{\text {products }}-\sum \Delta \mathrm{H}_{\text {reactents }}\right)-\left(\sum \mathrm{S}_{\text {products }}-\sum \mathrm{S}_{\text {reactants }}\right) \mathrm{T}$

$=(-) 60500-5.67 \mathrm{~T} \mathrm{cal} / \mathrm{mole}$

Hence, $\Delta \mathrm{G}$ at $\mathrm{ZnO}$ addition temperature $\left(750^{\circ} \mathrm{C} / 1023 \mathrm{~K}\right)$ is $-66.3 \mathrm{kcal} /$ mole. 
Appendix-A5: Cooling Curves of Mg-9 wt. $\% \mathrm{Al}+\mathrm{X}$ wt. $\% \mathrm{ZnO}$

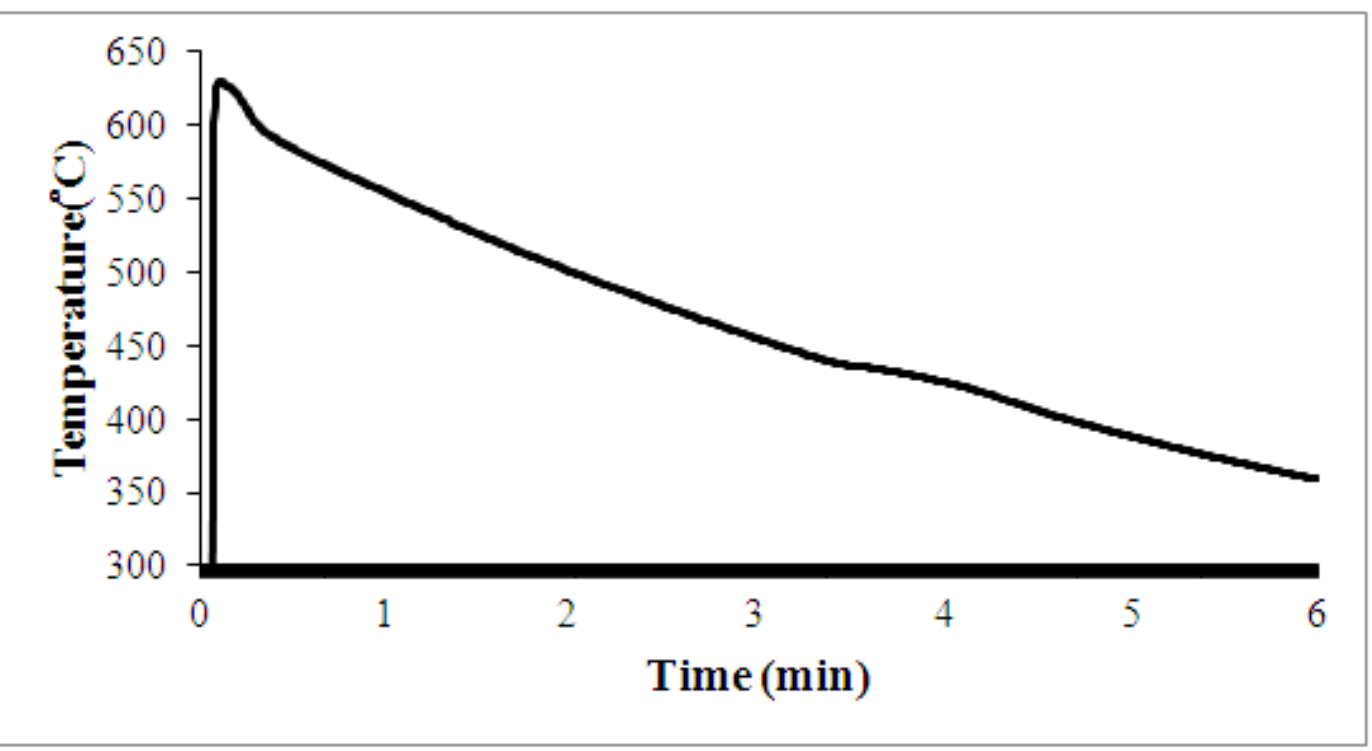

Fig. A.5.1. Cooling curve of base Mg-9 wt.\% Al.

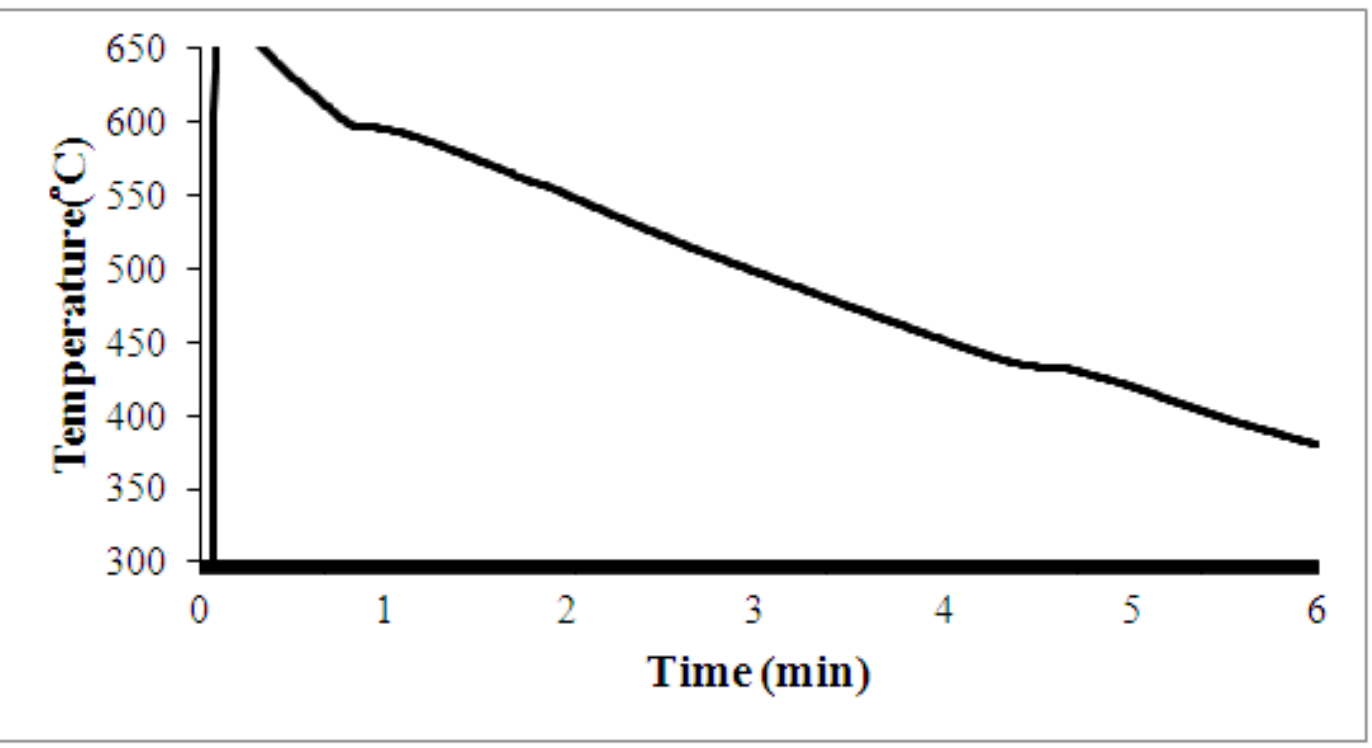

Fig. A.5.2. Cooling curve of base Mg-9 wt. $\%$ Al + $0.5 w t . \%$ ZnO. 


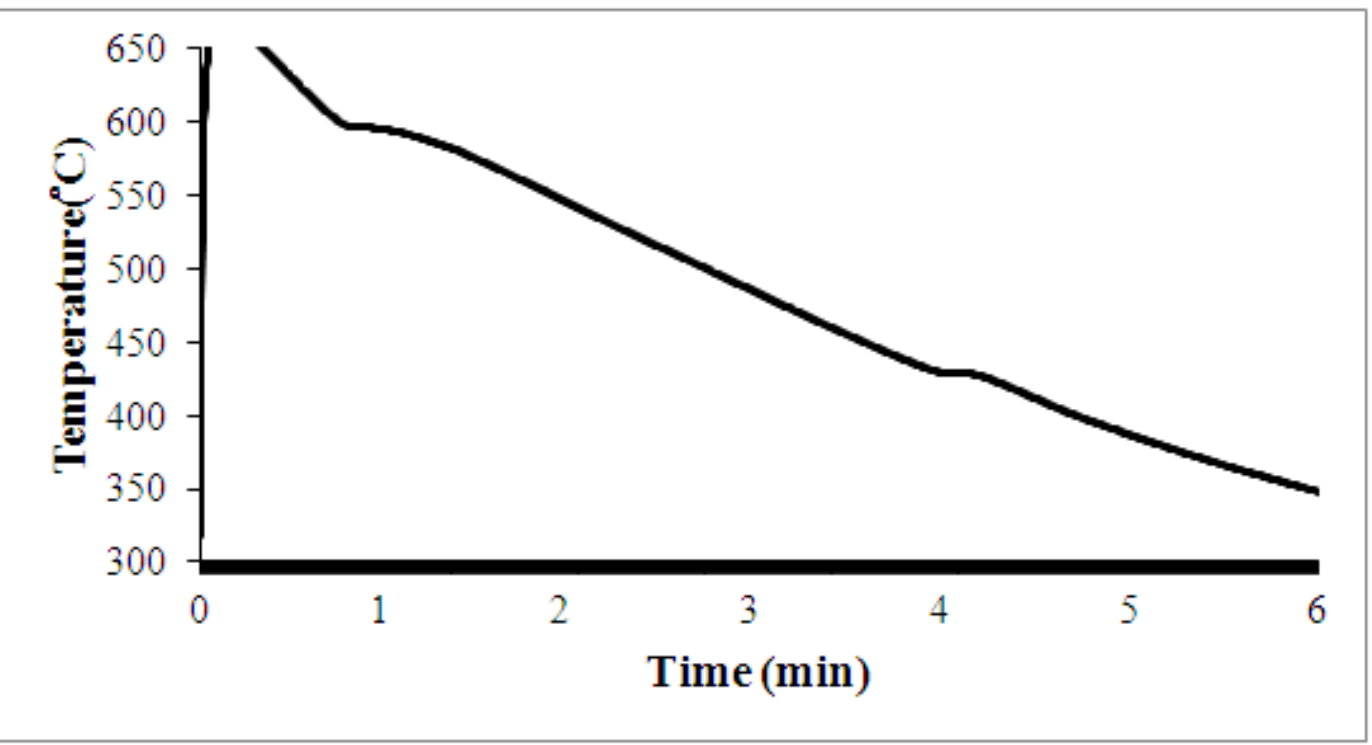

Fig. A.5.3. Cooling curve of base Mg-9 wt.\% Al + 1 wt.\% ZnO.

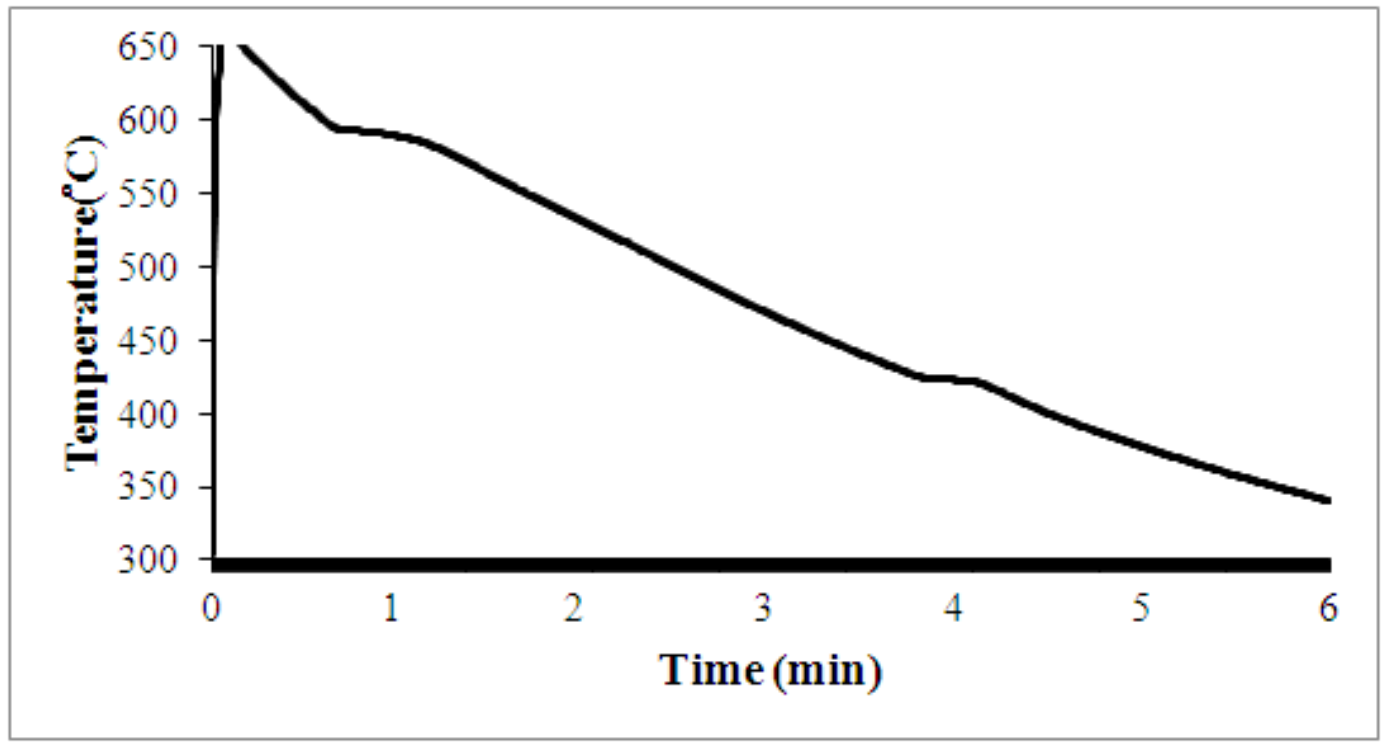

Fig. A.5.4. Cooling curve of base Mg-9 wt.\% Al + 2 wt.\% ZnO. 


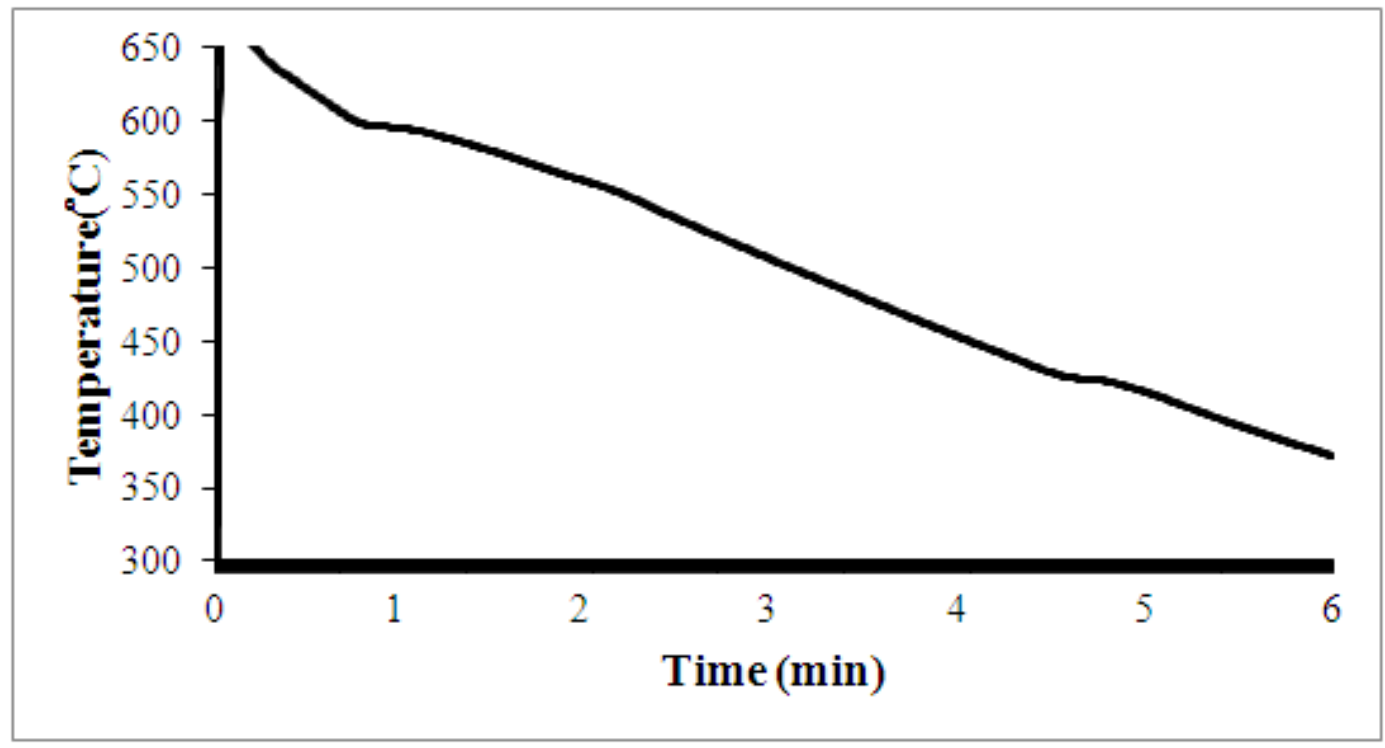

Fig. A.5.5. Cooling curve of base Mg-9 wt.\% Al + 3 wt.\% ZnO. 


\section{References}

1. Aghayani, M.K., Niroumand, B., "Effects of Ultrasonic Treatment on Microstructure and Tensile Strength of AZ91 Magnesium Alloys," Journal of Alloys and Compounds, Vol. 509, pp. 114-122 (2011).

2. Askeland, D.R., Fulay, P.P., Wright, W.J., "The Science and Engineering of Materials," Global Engineering, 2010.

3. ASM Handbook Committee, “ASM Metals Hand Book-Properties and Selection: Nonferrous Alloys and Special Purpose Materials,” ASM International, Vol. 2, 1992.

4. Avedesian, M.M., Baker, H., "Magnesium and Magnesium Alloys," ASM International, 1999.

5. Bamberger, M., "Structural Refinement of Cast Magnesium Alloys," Materials Science and Technology, Vol. 17, pp. 15-24 (2001).

6. Campbell, J., “Castings,” Butterworth-Heinimann, Woburn, M.A., 1993.

7. Cao, P., Qian, M., StJohn, D.H., "Effect of Iron on Grain Refinement of High-Purity Mg-Al Alloys," Scripta Materialia, Vol. 51, pp. 125-129 (2004).

8. Cao, P., Qian, M., StJohn, D.H., "Native Grain Refinement of Magnesium Alloys," Scripta Materialia, Vol. 53, pp. 841-844 (2005).

9. Cao, P., Qian, M., StJohn, D.H., "Effect of Manganese on Grain Refinement of Mg-Al Based Alloys," Scripta Materialia, Vol. 54, pp. 1853-1858 (2006).

10. Cao, P., Qian, M and StJohn, H., "Mechanism for Grain Refinement of Magnesium Alloys by Superheating," Scripta Materialia, Vol. 56, pp. 633-636 (2007).

11. Celotto, S., "TEM Study of Continuous Precipitation in Mg-9 wt.\% Al-1 wt.\% Zn Alloy," Acta Materialia, Vol. 48, pp. 1775-1787 (2000).

12. Chakraborty, M., Vinod Kumar, G.S., Murty, B.S., "Poisoning and Fading Phenomena in the Grain Refinement of Al and Its Alloys," Transactions of the Indian Institute of Metals, Vol. 58, No. 4, pp. 661-670 (2005).

13. Chen, T.J., Jiang, X.D. Ma, Y., Li, Y.D., Hao, Y., “Grain Refinement of AZ91D Magnesium Alloys by SiC," Journal of Alloys and Compounds, Vol. 496, pp. 218-225 (2010).

14. Chen, T.J., Ma, Y., Lv, W.B., Li, Y.D., “Grain Refinement of AM60B Magnesium Alloy by SiC Particles," Journal of Material Science, Vol. 45, pp. 6732-6738 (2010). 
15. Chen, T.J., Jiang, X.D., Ma, Y., Wang, R.Q., Hao, Y., "Grain Refinement of AZ91D Magnesium Alloy by $\mathrm{MgCO}_{3}$," Materials Research, Vol. 14(1), pp. 124-133 (2011).

16. Chen, T.J., Wang, R.Q., Ma, Y., Hao, Y., “Grain Refinement of AZ91D Magnesium Alloy by Al-Ti-B Master Alloy and Its Effect on Mechanical Properties," Materials and Design, Vol. 34, pp. 637-648 (2012).

17. Cui, C., Wu, L., Wu, R., Zhang, J., Zhang, M., "Influence of Yttrium on Microstructure and Mechanical Properties of As-Cast Mg-5Li-3Al-2Zn Alloy," Journal of Alloys and Compounds, Vo. 509, pp. 9045-9049 (2011).

18. Dahle, A.K., Lee, Y.C., Nave, M.D., Schaffer, P.L., StJohn, D.H., "Development of The AsCast Microstructure in Magnesium-Aluminum Alloys," Journal of Light Metals, Vol. 1, pp. 61-72 (2001).

19. D’Elia, F., “A Study on Grain Refinement and Hot Tearing in Permanent Mold Cast Aluminum Alloys,” Ryerson University, Toronto, M.A.Sc. Thesis, 2009.

20. Dieter, G.E., “Mechanical Metallurgy,” McGraw-Hill, Third ed., 1986.

21. Easton, M.A., StJohn, D.H., “A Model of Grain Refinement Incorporating Alloy Constitution and Potency of Heterogeneous Nucleation Particles," Acta Materialia, Vol. 49, pp. 1867-1878 (2001)

22. Easton, M.A., Schiffl, A., Yao, J.Y., Kaufmann, H., “Grain Refinement of Mg-Al (-Mn) Alloys by SiC Additions," Scripta Materialia, Vol. 55, pp. 379-382 (2006).

23. Elsayed, A., Lee, K., Ravindran, C., "Effect of Ca and Mn Additions on the Castability and Mechanical Properties of AZ91D Mg Alloy Permanent Mold Castings," AFS Transactions, Vol. 117, pp. 659-672 (2009).

24. Elsayed, A., "Novel Grain Refinement of AZ91E Magnesium Alloy and the Effect on Hot Tearing During Solidification,” Ryerson University, Toronto, M.A.Sc. Thesis, 2010.

25. Elsayed, A., Lun Sin, S., Ravindran, C.R., "Finding and Removing Inclusions in Magnesium Alloys," Advanced Materials and Process, , pp. 15-19 (2014).

26. Emley, E.F., "Principles of Magnesium Technology,” Pergamon Press, London, 1966.

27. Flemings, M.C., “Solidification Processing,” McGraw-Hill, USA, 1974.

28. Fu, H.M., Qiu, D., Zhang, M.X., Wang, H., Kelly, P.M., Taylor, J.A., “The Developments of a New Grain Refiner for Magnesium Alloys Using Edge-to-Edge Model,” Journal of Alloys and Compounds, Vol. 456, pp. 390-394 (2008). 
29. Fu, H.M., Zhang, M.X., Qiu, D., Kelly, P.M., Taylor, J.A., “Grain Refinement by AlN Particles in Mg-Al Based Alloys," Journal of Alloys and Compounds, Vol. 478, pp. 809-812 (2009).

30. Gao, S.Y., Cui, J.Z., Li, Q.C., Zhang, Z.Q., "The Research on The Effect of $\mathrm{MgCO}_{3}$ on Grain Refinement in AZ31 Magnesium Alloys," Mat.-wiss.u. Werkstofftech, Vol. 41, Issue 8, pp. 652-656 (2010).

31. Gruzleski, J.E., "Microstructure Development during Metal Casting," American Foundrymen's Society Inc, Illinois, 2000.

32. Ho, S.S.C., "Lost Foam Castings of Periodic Cellular Materials with Aluminum and Magnesium Alloys," University of Toronto, M.A.Sc. Thesis, 2009.

33. Huang, Y., Kainer, K. U., Hort, N., "Mechanism of Grain Refinement of Mg-Al Alloys by SiC Inoculation,” Scripta Materialia, Vol. 64, pp. 793-796 (2011).

34. Jin, Q., Eom, J.P., Lim, S.G., Park, W.W., You, B.S., "Grain Refining Mechanism of a Carbon Addition Method in a Mg-Al Magnesium Alloy," Scripta Materialia, Vol. 49, pp. 1129-1132 (2003).

35. Kelly, P.M., Zhang, M.X., "Edge-to-Edge Matching- the Fundamentals," Metallurgical and Materials Transactions, Vol. 37A, pp. 833-839 (2006).

36. Kubaschewski, O., Evans, E.LL., Alcock, C.B., "Metallurgical Thermochemistry” Pergamon Press Ltd., London, 1967.

37. Lee, Y.C., Dahle, A.K., St.John, D.H., "The Role of Solute in Grain Refinement of Magnesium,” Metallurgical and Materials Transactions A, Vol. 31A, pp. 2895-2906 (2000).

38. Lee, K., "A Study on Grain Refinement of AZ91E Magnesium Alloy with Al-5TiB 2 , Al$\mathrm{Al}_{4} \mathrm{C}_{3}$ and $\mathrm{ZnO}$ Additions," Ryerson University-Toronto, M.A.Sc. Thesis, (2011).

39. Li, P., Tang, B., Kandalova, E.G., "Microstructure and Properties of AZ91D Alloy with Ca Additions," Materials Letters, Vol. 59, pp. 671-675 (2005).

40. Li, M.J., Tamura, T., Miwa, K., "Microstructure Formation and Grain Refinement of MgBased Alloys by Electromagnetic Vibration Technique," Transaction of Nonferrous Metals Society of China, Vol. 20, pp. 1192-1198 (2010).

41. Liu, Y., Liu, X., Xiufang, B., "Grain Refinement of Mg-Al Alloys with $\mathrm{Al}_{4} \mathrm{C}_{3}-\mathrm{SiC} / \mathrm{Al}$ Master Alloy," Materials Letters, Vol. 58, pp. 1282-1287 (2004). 
42. Liu, X., Osawa, Y., Takamori, S., Mukai, T., "Microstructure and Mechanical Properties of AZ91 Alloy Produced with Ultrasonic Vibration," Materials Science and Engineering A, Vol. 487, pp. 120-123 (2008).

43. Liu, S.F., Liu, L.Y., Kang, L.G., "Refinement Role of Electromagnetic Stirring and Strontium in AZ91 Magnesium Alloys," Journal of Alloys and Compounds, Vol. 450, pp. 546-550 (2008).

44. Liu, S.F., Li, B., Wang, X.H., Su, W., Han, H., "Refinement Effect of Cerium, Calcium and Strontium in AZ91 Magnesium Alloy," Journal of Material Processing Technology, Vol. 209, pp. 3999-4004 (2009).

45. Liu, S., Zhang, Y., Han, H., Li, B., "Effect of Mg-TiB 2 Master Alloy on the Grain Refinement of AZ91D Magnesium Alloy," Journal of Alloys and Compounds, Vol. 487, pp. 202-205 (2009).

46. Liu, S., Zhang, Y., Han, H., "Role of Manganese on the Grain Refining Efficiency of AZ91D Magnesium Alloys Refined by $\mathrm{Al}_{4} \mathrm{C}_{3}$," Journal of Alloys and Compounds, Vol. 491, pp. 325329 (2010).

47. Lu, Y.Z., Wang, Q.D., Ding, W.J., Zeng, X.Q., Zhu, Y.P. "Fracture Behavior of AZ91 Magnesium Alloy,” Material Letters, Vol. 44, pp. 265-268 (2000).

48. Lu, L., Dahle, A.K., StJohn, D.H., "Grain Refinement Efficiency and Mechanism of Aluminum Carbide in Mg-Al Alloys," Scripta Materialia, Vol. 53, pp. 517-522 (2005).

49. Mordike, B.L., Ebert, T., “Magnesium Properties-Applications-Potential,” Materials Science and Engineering A, Vol. 302, pp. 37-45 (2001).

50. Motegi, T., "Grain-Refining Mechanisms of Superheat-Treatment of and Carbon Addition to Mg-Al-Zn Alloys,” Materials Science and Engineering A, Vol. 413-414, pp. 408-411 (2005).

51. Murty, B.S., Kori, S.A., Chakrabory, M., "Grain Refinement of Aluminum and Its Alloys by Heterogeneous Nucleation and Alloying," International Materials Reviews, Vol. 47, No. 1, pp. 3-28 (2002).

52. Nimityongskul, S., Jones, M., Choi, H., Lakes, R., Kou, S., Li, X., "Grain Refinement Mechanisms in Mg-Al Alloys with $\mathrm{Al}_{4} \mathrm{C}_{3}$ Microparticles," Materials Science and Engineering A, Vol. 527, pp. 2104-2111 (2010).

53. Pearson, W.B., "A Handbook of Lattice Spacings and Structures of Metals and Alloys," Pergamon press, Oxford, United Kingdom, 1964. 
54. Qian, M., Cao, P., "Discussion on Grain Refinement of Magnesium Alloys by Carbon Inoculation,” Scripta Materrialia, Vol. 52, pp. 415-419 (2005).

55. Qiu, D., Zhang, M.X., "Effect of Active Heterogeneous Nucleation Particles on the Grain Refining Efficiency in An Mg-10 wt\% Y Cast Alloys," Journal of Alloys and Compounds, Vol. 488, pp. 260-264 (2009).

56. Ramirez, A., Qian, M., Davis, B., Wilks, T., "High-intensity Ultrasonic Grain Refinement of Magnesium Alloys: Role of Solute,” International Journal of Cast Metals Research, Vol. 22, No. 1-4, pp. 260-263 (2009).

57. Robert, T., Noguez, M.E., Salas, G., Montejano, S., "Influence of Grain Refinement on Some Mechanical Properties of Non Ferrous Cast Alloys," Acta Metall. Mater, Vol. 40, No. 4, pp. 771-777 (1992).

58. Schumacher, P., Greer, A.L., Worth, J., Evans, P.V., Kearns, M.A., Fisher, P., Green, A.H., "New Studies of Nucleation Mechanisms in Aluminum Alloys: Implications for Grain Refinement Practice,” Material Science and Technology, Vol. 14, pp. 394-404 (1998).

59. Srinivasan, A., Pillai, U.T.S., Swaminathan, J., Das, S.K., Pai, B.C., "Observations of Microstructural Refinement in Mg-Al-Si Alloys Containing Strontium,” Journal of Materials Science, Vol. 41, pp. 6087-6089 (2006).

60. StJohn, D.H., Qian, M., Easton, M.A., Cao, P., Hildebrand, Z. "Grain Refinement of Magnesium Alloys,” Metallurgical and Materials Transactions A, Vol. 36A, pp. 1669-1679 (2005).

61. StJohn, D.H., Cao, P., Qian, M., Easton, M.A., “A New Analytical Approach to Reveal the Mechanism of Grain Refinement," Advanced Engineering Materials, Vol. 9, No. 9, pp. 739746 (2007).

62. StJohn, D.H., Easton, M.A., Qian, M., Taylor, J.A., "Grain Refinement of Magnesium Alloys: A Review of Recent Research, Theoretical Developments, and Their Application," Metallurgical and Materials Transactions A, Vol. 44A, pp. 2935-2949 (2013).

63. Suresh, M., Srinivasan, A., Ravi, K.R., Pillai, U.T.S., Pai, B.C., "Influence of Boron Addition on the Grain Refinement and Mechanical Properties of AZ91 Mg Alloy," Materials Science and Engineering A, Vol. 525, pp. 207-210 (2009). 
64. Suresh, M., Srinivasan, A., Pillai, U.T.S., Pai, B.C., "The Effect of Charcoal Addition on the Grain Refinement and Ageing Response of Magnesium Alloy AZ91,"Material Science and Engineering A, Vol. 528, pp. 8573-8578 (2011).

65. Tammura, Y., Haitani, T., Yano, E., Motegi, T., Kono, N., Sato, E., "Grain Refinement of High-Purity Mg-Al Alloy Ingots and Influences of Minor Amounts of Iron and Manganese on Cast Grain Size," Materials Transactions, Vol. 43, N0. 11, 2784-2788 (2002).

66. Vinotha, D., Raghukandan, K., Pillai, U.T.S., Pai, B.C., "Grain Refining Mechanisms in Magnesium Alloys-An Overview," Transactions of the Indian Institute of Metals, Vol. 62, Issue 6, pp. 521-532 (2009).

67. Wang, Y., Wang, Q., Wu, G., Zhu, Y., Ding, W., "Hot Tearing Susceptibility of Mg-9Al-xZn Alloy," Material Letters, Vol. 57, pp. 929-934 (2002).

68. Xu-liang, M., Xiang, W., Xin-lin, L., Lei, Y., "Effect of A15Ti1B Master Alloy on Microstructures and Properties of AZ61 Alloys," Trans. Nonferrous Met. Soc., Vol. 20, pp. 397-401 (2010).

69. Yang, M., Pan, F., Cheng, R., Tang, A., "Comparation about Efficiency of Al-10Sr and Mg10Sr Master Alloys to Grain Refinement of AZ31 Magnesium Alloys," Journal of Materials Science, Vol. 42, pp. 10074-10079 (2007).

70. Yano, E., Tamura, Y., Motegi, T., Sato, E., "Effect of Carbon Powder on Grain Refinement of an AZ91 Magnesium Alloy," Materials Transactions, Vol. 44, No. 1, pp. 107-110 (2003).

71. Zeng, X., Wang, Y. Ding, W., Luo, A.A., Sachdev, A.K., "Effect of Strontium on the Microstructure, Mechanical Properties and Fracture Behavior of AZ31 Magnesium Alloys," Metallurgical and Materials Transactions A, Vol. 37A, pp. 1333-1341 (2006).

72. Zhang, M.X., Kelly, P.M., Qian, M., Taylor, J.A., "Crystallography of Grain Refinement in Mg-Al Based Alloys," Acta Materialia, Vol. 53, pp. 3261-3270 (2005).

73. Zhao, Z., Chen, Q., Wang, Y., Shu, D., "Microstructure and Mechanical Properties of AZ91D Alloy with Y Addition,” Material Science and Engineering A, Vol. 515, pp. 152-161 (2009). 